\title{
Structural changes in chronic hibernating myocardium: aspects of dedifferentiation
}

Citation for published version (APA):

Ausma, J. (1997). Structural changes in chronic hibernating myocardium: aspects of dedifferentiation. [Doctoral Thesis, Maastricht University]. Universiteit Maastricht. https://doi.org/10.26481/dis.19970425ja

Document status and date:

Published: 01/01/1997

DOI:

10.26481/dis.19970425ja

Document Version:

Publisher's PDF, also known as Version of record

\section{Please check the document version of this publication:}

- A submitted manuscript is the version of the article upon submission and before peer-review. There can be important differences between the submitted version and the official published version of record.

People interested in the research are advised to contact the author for the final version of the publication, or visit the DOI to the publisher's website.

- The final author version and the galley proof are versions of the publication after peer review.

- The final published version features the final layout of the paper including the volume, issue and page numbers.

Link to publication

\footnotetext{
General rights rights.

- You may freely distribute the URL identifying the publication in the public portal. please follow below link for the End User Agreement:

www.umlib.nl/taverne-license

Take down policy

If you believe that this document breaches copyright please contact us at:

repository@maastrichtuniversity.nl

providing details and we will investigate your claim.
}

Copyright and moral rights for the publications made accessible in the public portal are retained by the authors and/or other copyright owners and it is a condition of accessing publications that users recognise and abide by the legal requirements associated with these

- Users may download and print one copy of any publication from the public portal for the purpose of private study or research.

- You may not further distribute the material or use it for any profit-making activity or commercial gain

If the publication is distributed under the terms of Article $25 \mathrm{fa}$ of the Dutch Copyright Act, indicated by the "Taverne" license above, 
Structural changes in chronic hibernating myocardium: aspects of dedifferentiation 


\section{ISBN $90-9010480-1$}

Ausma, Jantje

Oud-Turnhout : JAP advertising, B-2360

Bockverzorging: Bob Joossen-Meyvis, FotoGrafiek, J.R.F., B-2340 Beerse, Belgium Illustratie omslag: Anne Crols, bobj.

Maquette: bobj. 


\section{Structural changes in chronic hibernating myocardium: aspects of dedifferentiation}

Proefschrift

ter verkrijging van de graad van doctor aan de Universiteit Maastricht, op gezag van de Rector Magnificus, Prof. mr. M.J. Cohen, volgens het besluit van het College van Decanen, in het openbaar te verdedigen op vrijdag 25 april 1997 om 16.00 uur

door

Jantje Ausma

geboren op 2 maart 1969 te Groningen. 


\section{Promotores:}

Prof. dr. M. Borgers

Prof. dr. F.C.S. Ramaekers

\section{Beoordelingscommissie:}

Prof. dr. R.S. Reneman (voorzitter)

Dr. M.J.A.P. Daemen

Prof. dr. H.J. Jongsma (Universiteit Utrecht)

Prof. dr. J. Schaper (Max Planck Institute, Bad Nauheim, Germany)

Prof. dr. H. Wellens

The investigations described in this thesis were carried out at the Department of Molecular Cell Biology \& Genetics, Cardiovascular Research Institute Maastricht, Maastricht University, Maastricht, The Netherlands.

This study was supported by the Janssen Research Foundation. 


\section{Contents}

Chapter 1: Introduction

The structural basis for functional abnormalities of chronic hibernating myocardium

Chapter 2

Chronic ischemic viable myocardium in man: aspects of dedifferentiation

Chapter 3

Molecular changes of titin in left ventricular dysfunction as a result of chronic hibernation

Chapter 4

Nuclear lamin expression in chronic hibernating myocardium in man

Chapter 5

Chronic hibernating myocardium: interstitial changes

Chapter 6

Structural changes of atrial myocardium due to sustained atrial fibrillation in the goat

Chapter 7

Dedifferentiation of atrial cardiomyocytes as a result of chronic atrial fibrillation

Chapter 8

General Discussion

Summary

Samenvatting

Dankwoord

Curriculum vitae 


\section{Chapter 1: Introduction The structural basis for functional abnormalities of chronic hibernating myocardium}

Based on: Ausma J, Ramaekers F, Shivalkar B, Thoné F, Flameng W, Borgers M. Cellular adaptation in hibernating myocardium in man

In: Hori M, Maruyama Y, Reneman RS (eds), Cardiac adaptation and failure, Springer-Verlag Tokyo, 1994, pp85-99 


\section{Clinical aspects of chronic hibernating myocardium}

\section{Definition and criteria for identification of hibernating myocardium}

The concept of "hibernating myocardium" was introduced in 1985 by Rahimtoola for patients with coronary artery disease showing left ventricular dysfunction without signs of an infarction on the electrocardiogram. The author proposed that "Ischemia is not always transient. There is a prolonged subacute or chronic stage of myocardial ischemia that is frequently not accompanied by pain and in which myocardial contractility and metabolism and ventricular function are reduced to match the reduced blood supply. As a result, a new state of equilibrium is reached whereby myocardial necrosis is prevented, and the myocardium is capable of returning to normal or near-normal function on restoration of an adequate blood supply". It is thought that the hibernating response is an act of self-preservation by myocardium endangered by an oxygen supply too low to deliver normal work; in other words, it has adapted its functional capacity to the limited oxygen supply, and hence to the lowered energy availability. Although it was initially thought that recovery of the myocardium after revascularization was instantaneous, it is now believed that hibernating myocardium can be classified according to the outcome as either acute hibernation with almost immediate recovery, subacute hibernation with delayed recovery of days to weeks, or chronic hibernation in which recovery takes weeks to months (Rahimtoola, 1995).

One aspect of considerable debate is related to the question whether the hibernating state is caused by sustained underperfusion, by repeated brief periods of underperfusion, or by a combination of both (Vanoverschelde et al., 1993; Rahimtoola 1995; Gerber et al., 1996). In patients with coronary artery disease, coronary flow reserve decreases as the degree of stenosis increases. Oxygen supply can be insufficient in these patients to compensate for increased cardiac workload, hence leading to myocardial ischemia. In this case, intermittent episodes of ischemia and consequently post-ischemic contractile dysfunction (stunning) are considered to be an integral part of chronic left ventricular dysfunction.

It is currently believed that the following clinical features are fundamental to hibernating myocardium: 1) myocardial blood flow is reduced to such an extent that it is responsible for persistant segmental wall motion abnormality; 2) there is no evidence of myocardial infarction but tissue remodelling takes place; 3) there is recovery of regional myocardial function after restoration of blood flow.

An assumption of crucial importance in the context of hibernation and its reversibility is the presence of viable cells in such a dysfunctional myocardial segment. Another important question concerns whether or not such viable cells in the myocardium are structurally normal and whether possible abnormalities in structure contribute to the delay of functional recovery of the myocardium after restoration of blood flow. The most convincing observation hitherto made in support of the notion that hibernating tissue is viable, is the existence of a mismatch between blood-flow and metabolic activity in dysfunctioning myocardial segments, 
as measured with the Positron Emission Tomography (PET) technique (Schelbert 1991; Takeishi et al., 1991; Brunken et al., 1986; Tillisch J, 1986).

\section{Diagnosis of chronic hibernating myocardium}

To identify viable but poorly functioning myocardium, PET is considered to be the technique that may give the most reliable diagnosis. Among the other techniques available, thallium imaging and low dose dobutamine echocardiography are currently the most frequently used in the clinical setting. All allow reversible dysfunction to be predicted with a high degree of sensitivity (greater than $80 \%$ ). They seem to vary, however, in terms of specificity, thallium imaging showing the lowest $(50-55 \%)$ and dobutamine echocardiography the highest $(80-85 \%)$ specificity ${ }^{18}$ Fluorodeoxyglucose- or ${ }^{99 m}$ Tc Sestamibi-single photon emission computed tomography (SPECT) imaging, contrast echocardiography and integrated backscatter imaging new modalities which better look promising in their ability to identify jeopardized but vialbe myocardium (Vanoverschelde et al.,1996).

With PET, myocardial viability can be identified on the basis of intact metabolic activity in regions of underperfused and dysfunctional myocardium. The most extensive experience thus far has been achieved with ${ }^{13} \mathrm{~N}$-ammonia $\left(\mathrm{NH}_{3}\right)$ to measure myocardial perfusion and ${ }^{18}$ F-fluorodeoxyglucose (FDG) as a marker of regional uptake of exogenous glucose. Viable myocardium can be identified by the normal-to-enhanced FDG uptake in regions with reduced perfusion $\left(\mathrm{NH}_{3}\right.$ labelling), the so called flow-metabolic "mismatch" pattern. This technique has been evaluated in several clinical studies (Schelbert 1991; von Dahl et al., 1994; Eitzmann et al., 1992; Vanoverschelde et al., 1993; Maes et al., 1994; 1995; Shivalkar et al., 1996; Gerber et al., 1996; Camici et al., in press) and appeared to identify hibernating myocardium that will manifest improvement of contractile function after revascularization.

It is imperative that the criteria for patients to be included in a chronic hibernation group be clearly delineated in order to exclude any possibility that patients suffering from myocardial stunning and/or infarction might slip in. Therefore, the term "chronic hibernating myocardium" in this study designates tissue obtained from patients which strictly fulfilled the following criteria: I) severe stenosis of one or more coronary arteries; 2 ) decreased wall motion and regional ejection fraction;

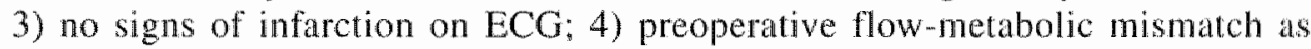
documented by PET; 5) recovery of function, wall motion and/or ejection fraction 3-6 months after revascularization.

\section{Morpological aspects of chronic hibernating myocardium}

The purpose of studying whether hibernating myocardium exhibits a relation between function, metabolism and subcellular organisation is to identify a possible structural basis for the degree of contractile dysfunction and the variability of functional recovery after revascularization. Proof for a possible relationship 
between regional wall motion abnormalities of hibernating segments and their underlying histology is not easy to obtain. The reasons for this are found in the limited spatial resolution of the kinetic measurement on the one hand, and the small sample size of the biopsy used for histology on the other. Such a biopsy, weighing approximately $15 \mathrm{mg}$, might not be representative of the whole dysfunctional segment. However, the biopsy technique offers the only possiblitity to correlate myocardial structure and function in vivo.

Before Rahimtoola introduced the term "hibernating myocardium", Flameng and coworkers had shown, in fact, that there were patients presenting with significant coronary artery stenosis and impaired wall motion in the absence of myocardial infarction (Flameng et al., 1981; 1984). It was proposed in these studies that structural changes, varying in severity from patient to patient, might be causely related to the chronicity of the functional deficit on one hand, and to the variability of functional recovery after revascularization on the other. Degenerative features, including myocardial fibrosis were, however, observed in only part of the patients: myocardial fibrosis was absent in a considerable number. The cardiomyocytes from the latter patients had an altered morphology: the volume fraction of myofibrils was reduced, glycogen was present in large quantities, numerous mini-mitochondria were present, the amount of sarcoplasmic reticulum was reduced and $\mathrm{T}$-tubular invaginations were seldomly seen. These changes, observed in a considerable number of cardiomyocytes, were at the time assigned as degenerative in nature.

In a more recently performed analysis of the histology of chronic ischemic myocardium (Borgers et al., 1993) the initial idea that the cellular changes observed were degenerative in nature was rejected. In lieu, for reasons given below, it was proposed that the cellular changes represent a switch from an active contractile state to a more or less stable surviving (dormant) state, hence perfectly matching the term hibernation from a morphological point of view.

\section{Ultastructure of chronic hibernating myocardium}

The key observation characterizing cardiomyocytes of hibernating myocardium wats the progressive loss of contractile material (sarcomeres) without loss of cell volume. This is clearly distinct from atrophic degeneration. The depletion of sarcomeres is seen initially at the cell center (perinuclear region) and may extend towards the periphery, involving the whole cytoplasm. In most cases, the space left by the dissolution of the sarcomeres became occupied by glycogen (Fig 1,2). Another characteristic feature is the presence of numerous small mini-mitochondria (Fig 2a) within or adjacent to the glycogen-rich perinuclear areas. As for the nuclei, many have lost their normal smoothly stretched contour, and instead have a tortuous appearance projecting numerous extensions into the surrounding cytosol. The chromatin is evenly distributed over the nucleoplasm (Fig 2b). Another intracellular change involves the loss of sarcoplasmic reticulum (SR). Organized SR is virtually absent; in this place, there is a network of disorganized profiles of 

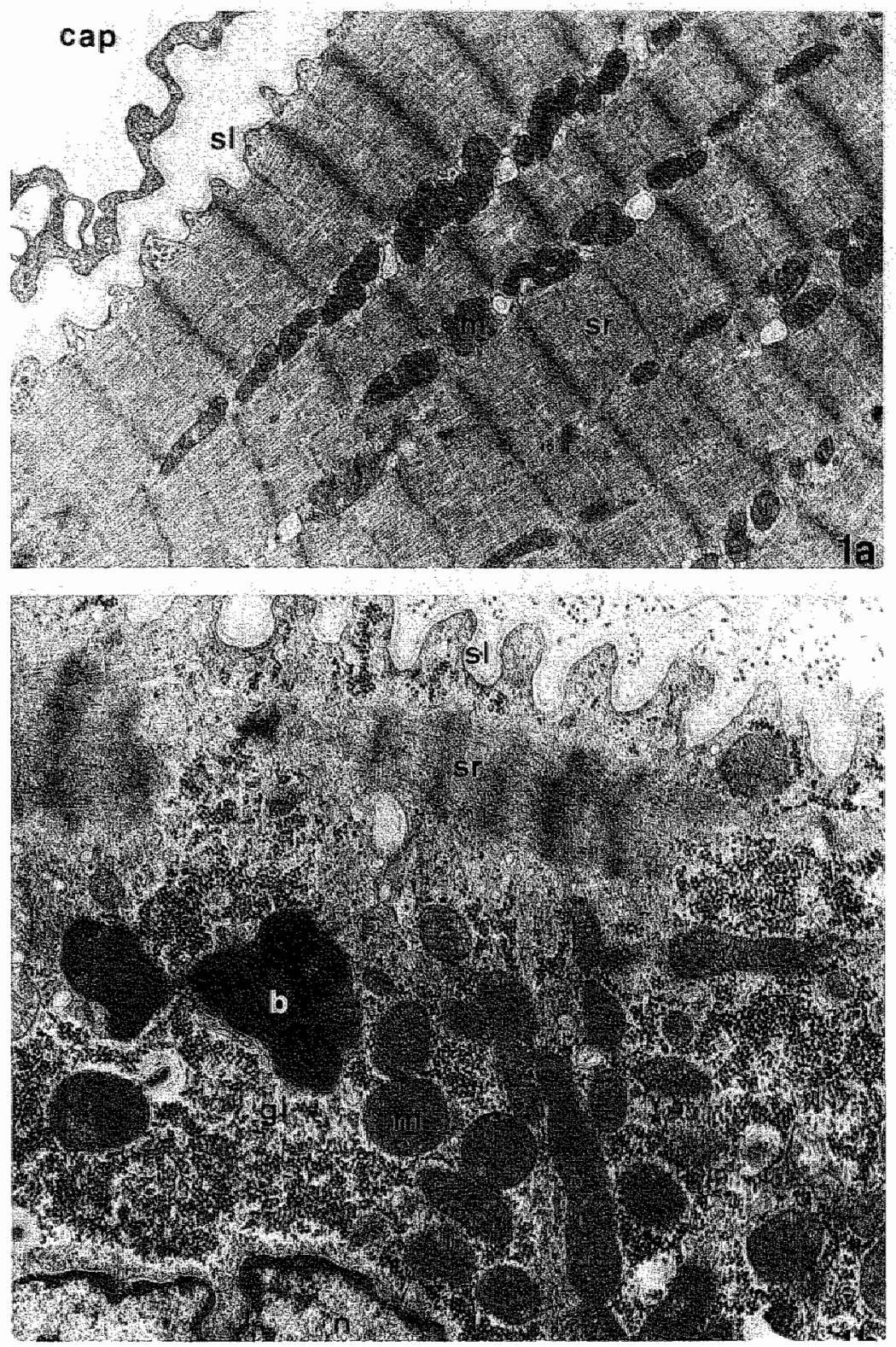

Fig 1. Electron microscopy a) normal human myocandum. Note the regularly structured sarcomeres $(\mathrm{sr})$ surrounded by rows of milochondria $(\mathrm{m})$. sl, sarcolemma. cap blood capht lary $(x 1000)$ and b) a cardiomyocyte from a hibemating myocardial area. Samomeres (sr) are only seen at the cell periphery. The cyloplasm is occupied by glycogen (gl), mitochondria $(m)$, and residual bodies (b). n. nucleas. Note the intact sarcolemma (st) $(x 13800)$. 

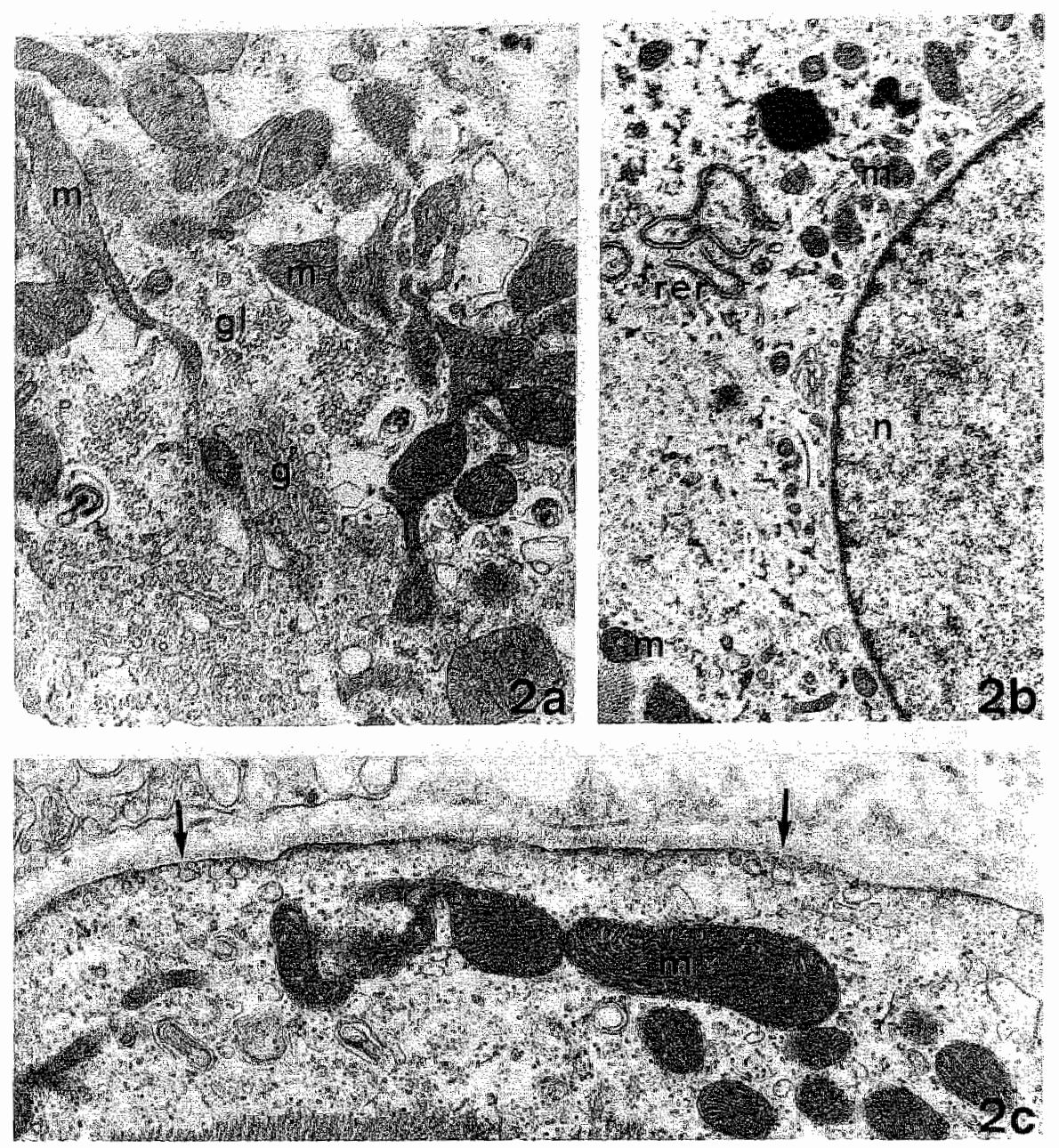

Fig 2 a-c. Electron microscopy showing characteristic changes in hibenating cells.

a. The cell center shows mumerous abmormally shaped but structurally intact mitochondra

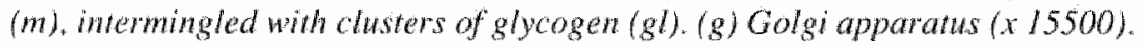

b. The round muclews (n) has dispersed chromatin. Rough endoplaswic reticulum (rev) and many min-mitochondria (m) are found in its wicinity (x I1600).

c. The cell periphery showing numerous pinocyrotic vesicles (arrows) associated with the sarcolemwa. Note the absence of savomeres at the periphery. Mitochondria $(m)(x 25000)$.

reticular membranes in the myolytic areas. In many cells, SR was even completely absent. In these cells, fragments of rough endoplasmic reticulum were frequently encountered and the sarcolemma presented numerous pinocytotic vesicles (Fig $2 \mathrm{c}$ ), thereby resembling those of endothelial and smooth muscle cells (Borgers et al. $1993 a)$. 
Remarkably, typical degenerative changes such as cytoplasmic vacuolization, cytosolic edema, mitochondrial swelling, membrane disruption, accumulation of secondary lysosomes, membrane whorls, and lipid droplets are virtually absent in hibernating myocardium. The general impression is that the substructures present in the cells of such affected segments are perfectly healthy. As far as the intercellular space is concerned, apart from an increased volume, no striking abnormalities are noticed. Microvascular endothelium, pericytes, and interstitial mesenchymal cells display well-preserved substructures. Some patients show a substantial increase in interstitial tissue, apparently correlating with the extent of myocardial cell change (see table 1). Obviously, the extent of myolytic and extracellular compartment changes may be an important factor in determining the degree and speed of functional recovery after revascularization (Borgers et al. 1993a).

Morphologic features distinguishing hibernating cells from those in orher pathophysiologic conditions

The subcellular changes described above are entirely at variance with those seen in stunned myocardium, in acute severe ischemia leading to infarction, and in endstage cardiomyopathies. The structural alterations of cardiomyocytes in stunned myocardium have not been documented in man, but morphologic features (Fig 3) resembling the subtle changes seen in stunned myocardium of animals are frequently encountered in human biopsies after repeated short ischemic periods when the intermittent aorta cross-clamping procedure is used for coronary artery bypass grafting (CABG) (Flameng et al.,1981; Vandeplassche et al.,1991). In animals, stunning resulted in a characteristic changes: the loss of intramatricial granules in mitochondria and the occurrence of clumped mitochondrial cristae, a picture never seen in normal or hibernating myocardium. Clumping of cristae was the earliest sign of deterioration noticed and was shown to be accompanied by activation of proton-translocating ATPase and the intramitochondrial formation of harmful oxygen species (Vandeplassche et al., 1991).

Changes in ultrastructure that occur during and after an acute ischemic insult have been extensively reported for the heart (Schaper et al., 1979). Based on morphologic criteria, alterations can be divided into categories ranging from minor reversible changes to damage beyond repair. The severity of the changes largely depends on the degree and duration of ischemia. The detailed morphology of postischemic myocardium has been amply described previously (Schaper et al. 1979; Jennings et al 1978; Borgers et al.. 1981; 1987) and will be only briefly commented upon in this chapter. A picture demonstrating a necrotic cell in the acute phase of infarction is seen in fig. 4 . The extent of injury after acute ischemia can be deduced from damage to the subcellular organelles, listed below in increasing order of severity: 1) Mitochondria: swelling with loss of intramatricial granules; clarification of the matrix; disorientation and disruption of cristae; blebbing and 

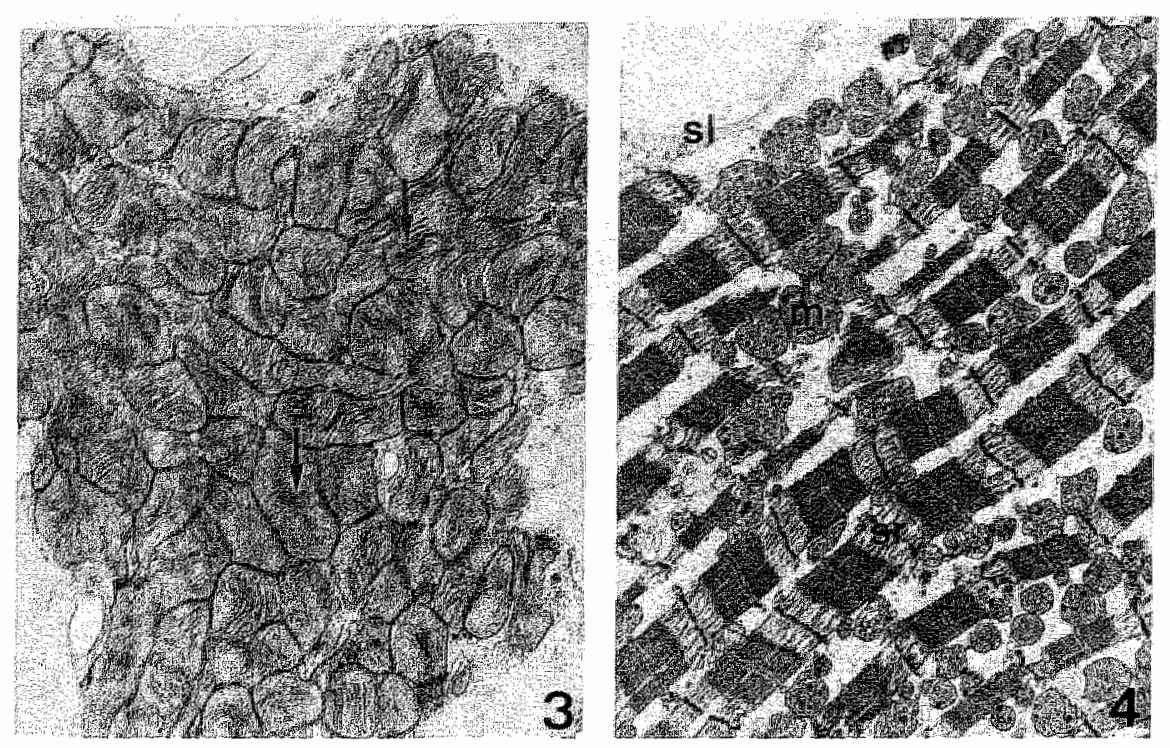

Fig 3. Electron microscopy of stunned myocardium. Mitochondria, although nowmally shaped, are dewoid of intramatrix granules and possess chumped cristae (arrows). These are the only changes which are at variance with nomal myocardial cells (x 11600).

Fig 4. Electron microscopy of an acuty infarcted area. Note the irreversibly degenerated structures such as mitochondria (m), sarcomeres (sr) in an edematows cytosol. The sarcolemma (st) is barely recognizable $(x 5600)$.

disruption of the outer membrane, presence of flocculent densities (Jennings granules). 2) Cytosol: depletion of glycogen stores; cellular edema, reflected by increased cell volume. 3) Nucleus: margination of chromatin; pyknosis. 4) Sarcoplasmic reticulum: swelling. 5) Sarcolemma: fuzzy appearance of the sarcolemma-glycocalyx complex; blebbing and discontinuities of sarcolemma; swelling of T-tubular invaginations; loss of cytoskeletal-sarcolemma connections. 6) Sarcomeres: irregularities and depletion of Z-lines; contraction bands; overt myolysis (Borgers and Flameng, 1993). All the above-mentioned subcellular changes are absent in cardiomyocytes in chronic hibernating myocardium. This observation, together with a number of other arguments, favor the hypothesis that hibemating cells are healthy and actively metabolizing. The additional arguments include 1) Cytochrome oxidase activity can be demonstrated in their mitochondria, despite the fact that the cardiomyocytes are morphologically altered (Fig 5). There are no signs of uncoupling of mitochondria because proton translocating ATPase is absent, as is the case for acute ischemia (Borgers, unpublished data). 2) The integrity of cellular calcium homeostasis is suggested by the absence of cytochemically demonstrable calcium overload (Fig 6). The phospholipid-bound 

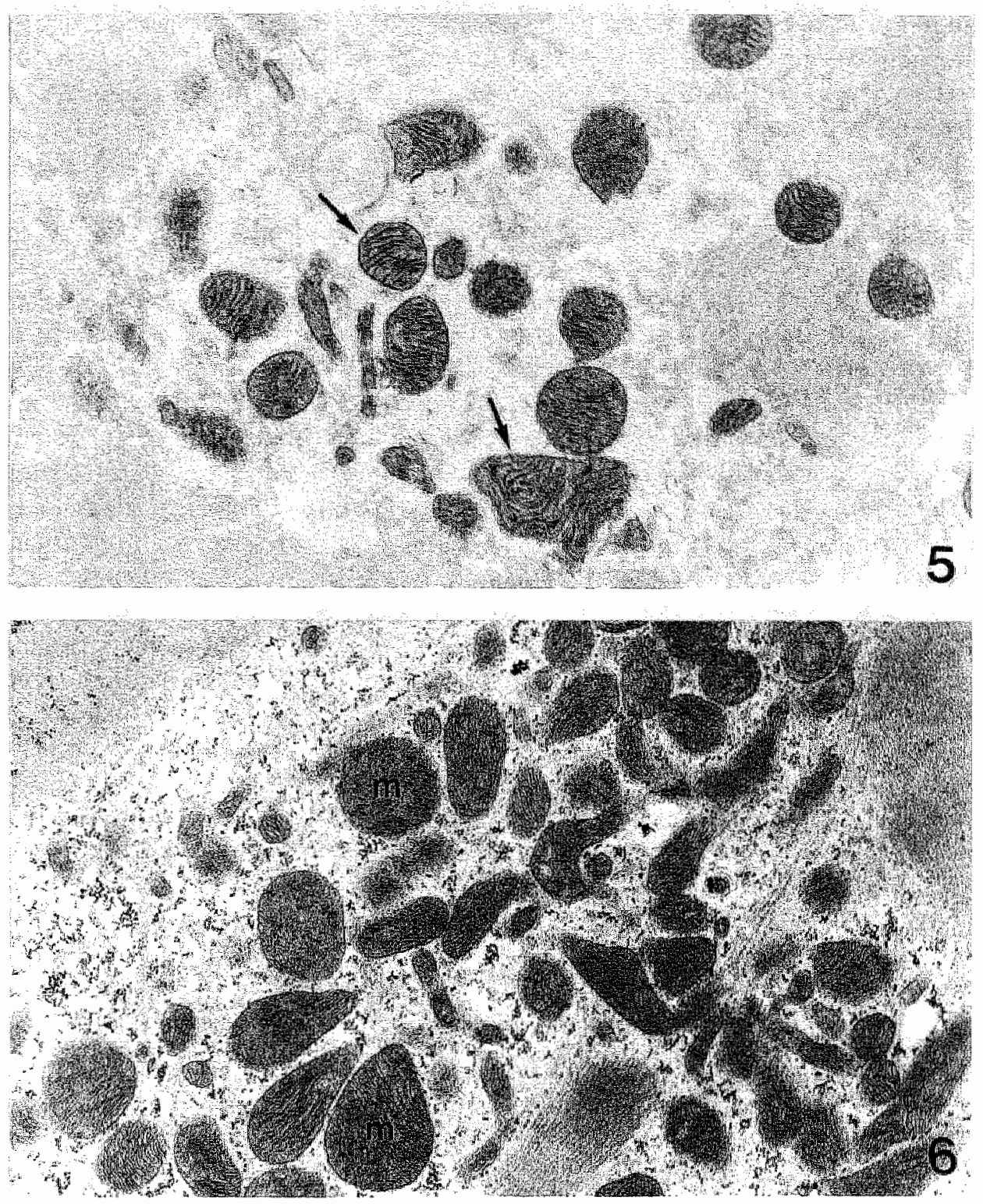

Fig 5. Enzyme cytochemical derection of cytochrome c oxidase activity present in the abnormally shaped mitochondra of hibemating cells. The activity is seen as a dark precipitate confined to the mitochondrial cristac (arrows) (A 16950).

Fig 6. Calcium localization in mitochondria $(m)$ of a hibernating cell. Unlike the mitochondria of nomally structured cells (not shown). the mitochondria of this cell are virmally devoid of calcium precipitate $(x 17400)$. 
fraction of calcium is preserved at the plasma membrane of hibernating cells, and mitochondria are virtually devoid of a calcium precipitate (Borgers et al., 1993b). 3) Hibernating cells suffer less from acute ischemia than their neighboring normally structured cells (Borgers and Flameng, 1993). Examination of biopsies from hibernating myocardium taken at the end of CABG reveal that "hibernating" cells are much less susceptible to acute ischemia than the adjacent cells that have a normal ultrastructure. After $\mathrm{CABG}$, the mitochondria of hibernating cells are not or only slighty swollen, whereas in adjacent normally structured cells, mitochondria show a more marked clarification of the matrix. In addition, the latter mitochondria possess considerably more calcium deposits than those of the hibernating cells (Borgers and Flameng, 1993). Moreover, no difference between pre- and post-CABG biopsies is seen in the substructure of the sarcolemmaglycocalyx complex of hibernating cells. The intimate association of the external lamina of the glycocalyx with the sarcolemma is preserved and no discontinuities in the lipid bilayer are noticed. In contrast, distinct abnormalities of the sarcolemma-glycocalyx complex are present in cells possessing normal substructures. The nuclei of hibernating cells do not show chromatin condensation as nuclei of normal cells in the post-CABG biopsies do. 4) Apoptotic changes are not or only rarely observed in the altered cardiomyocytes from patients fulfilling the criteria of chronic hibernating myocardium but are found in cardiomyocytes bordering infarcted zones. In the areas at the border of a fibrotic scar, interestingly, there are often cells resembling those of the "hibernating" type (Sharov et al., 1996; Borgers et al., in press).

A more complex picture of structural changes is seen in cardiomyopathic myocardium (Schaper et al., 1991). In a significant number of the biopsies obtained from cardiomyopathic patients, "hibernating" cells are found intermingled with cells that clearly show signs of degeneration as described above (Fig 7). In the latter cells, the most common morphologic changes include myolysis, tortuous nuclei, mega-mitochondria (of the size of nuclei) with lipid-like inclusions and intramatricial glycogen clumps, and whorl-like myelin structures (a common sign of membrane degeneration).

\section{Quantitative aspects of strwctural changes in chronic hibernating myocardium} Since glycogen accumulation is the hallmark of the changes in the cardiomyocytes, the degree of change was quantitatively evaluated by light microscopy in the endoand epicardial parts of the myocardium. As reported previously (Borgers et al., 1993a; Vanoverschelde et al., 1993; Maes et al., 1994; Depré et al., 1995) cardiomyocytes were labelled as affected when more than $10 \%$ of the volume fraction of sarcomeres was lost. Because the degree of myolysis correlates in almost all instances with accumulation of glycogen, the number of affected cells were scored by light microscopic examination of sections stained with periodic acid Schiff (PAS) (Fig 8a-d). The area occupied by PAS-positive material (glycogen) 


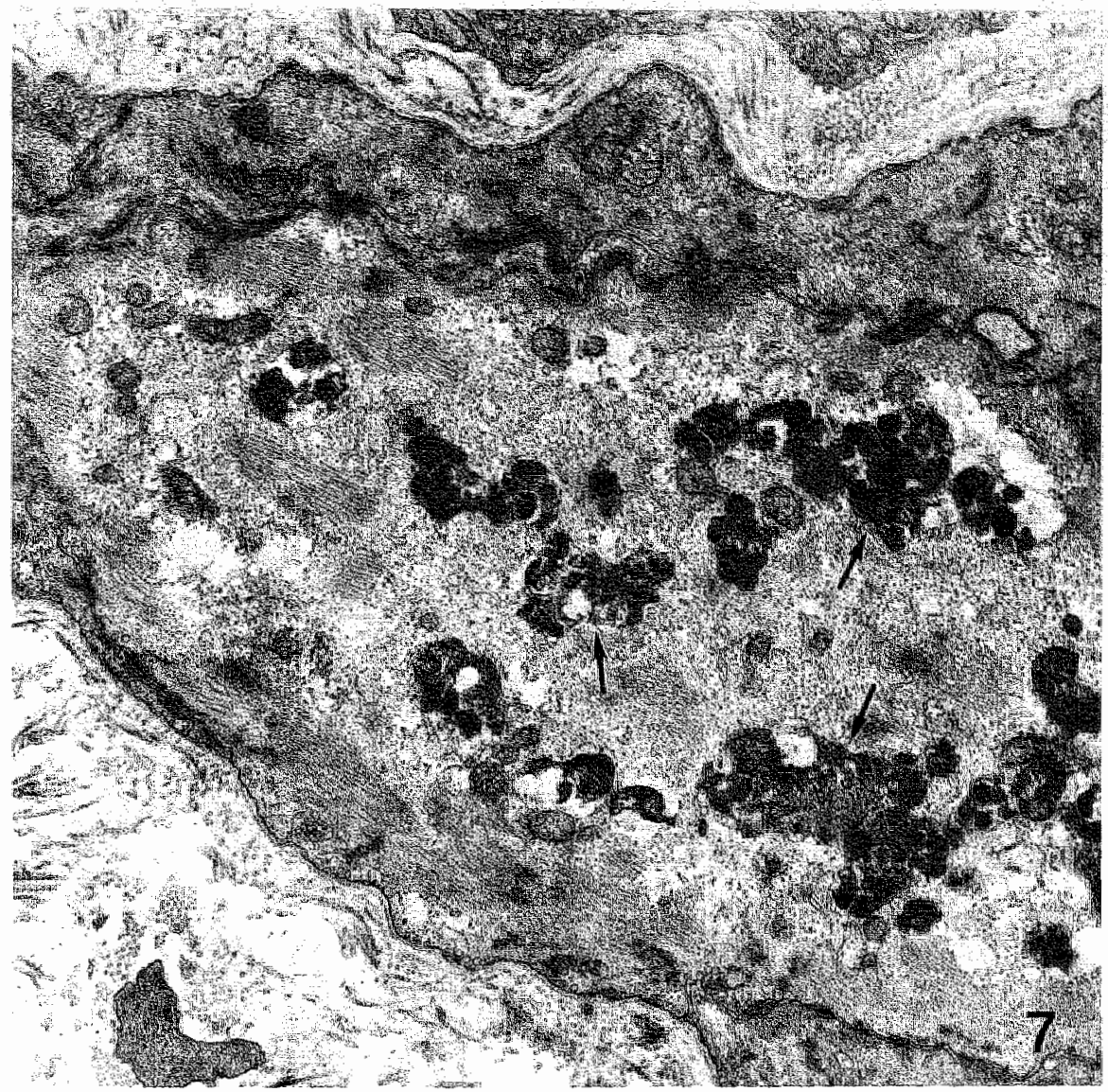

Fig 7. Electron microscopy of cardiomyocyte degeneration. The center of this myolytic cell is, in contrast to hibernating cells, filled with necrotic remnants (arrows) $(x 14300)$.

was taken as a direct measure of the loss of contractile material. In order to quantify the extent of the cellular changes in the different layers of the myocardium, at least 200 myocardial cells per segment were scored. The glycogen content varied from a slight depostion to huge accumulation in severely affected cells, in which only a few sarcomeres remained at the periphery of the cell. In segments filled with these structurally altered cells, an increase in the amount of connective tisue was observed. The relative volume of the extracellular matrix was assessed by standard morphometric methods (Borgers et al., 1993a).

An initial study dealing with the quantification of myolytic changes in epi- and endocardial biopsies from the anterior wall in a group of patients $(n=83)$ with severe coronary artery stenosis without infarctions (Borgers et al., 1993a) revealed 

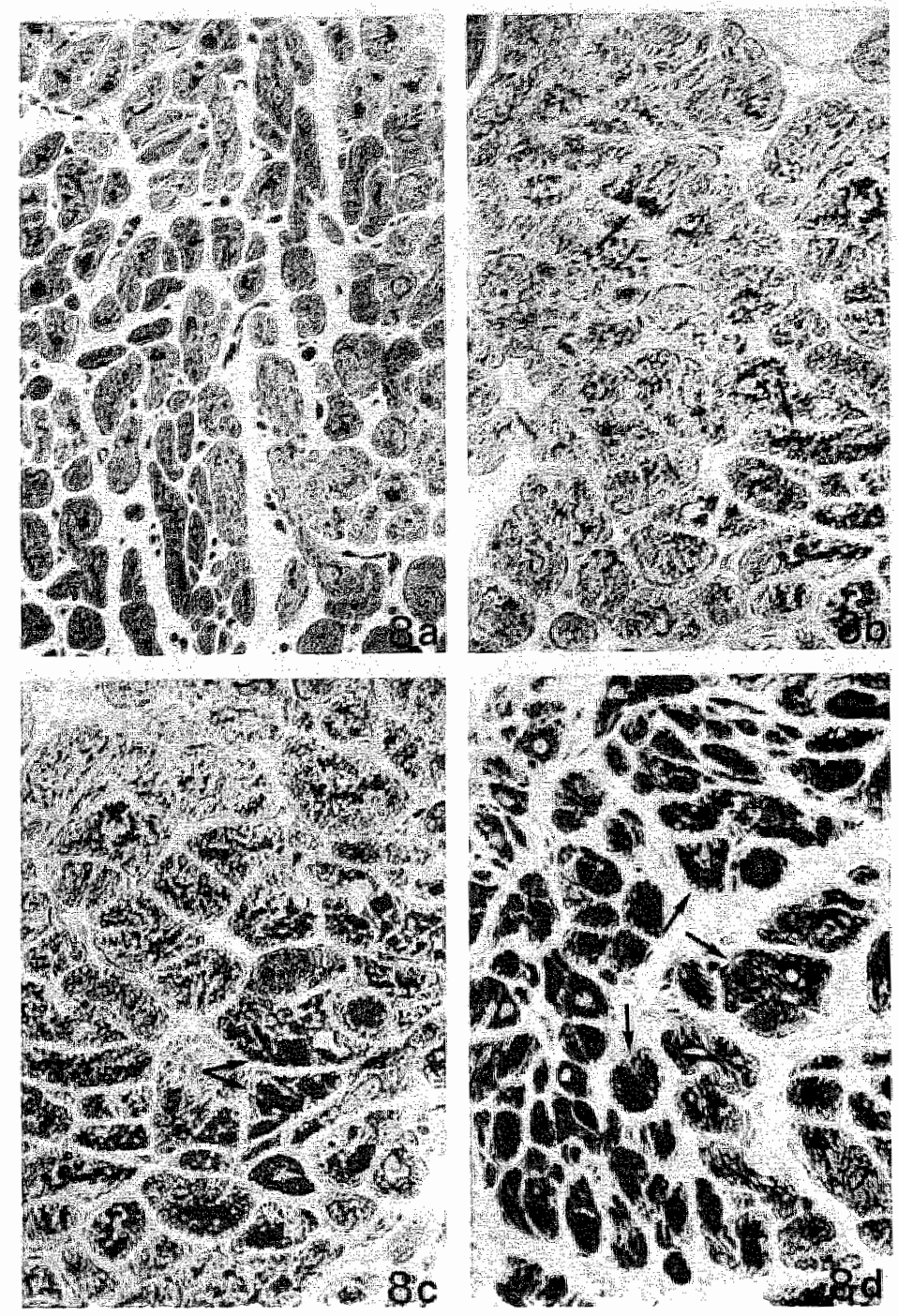

Fig Saud. Light microscopy of different degrees of cellular changes in chronic ischemic moocandium. The sections are stained with periodic acid Schiff (PAS), a stain for glycogen (dark areas).

a. Section thongh a non-affected area. showing absence of PAS stain (x 210 ).

b. A minority of cells are PAS positive (arrows) (x210).

c. A significan number of otherwise normally shaped cells stamed for glycogen (arrows) (x 210).

d. The majority of cells are darkely staned, due to the accumulation of huge amounts of glycogew (arrows) ( 210$)$. 
Table 1: Quantitative data of biospy samples from patients with chronic hibernating myocardium fiom previous siudies.

\begin{tabular}{|c|c|c|c|}
\hline Reference & $\begin{array}{c}\text { Number of } \\
\text { patients }\end{array}$ & $\begin{array}{l}\text { Myolytic cells } \\
\text { (mean } \pm \text { SEM) }\end{array}$ & $\begin{array}{l}\text { Connective tissue } \\
\text { (mean } 5 \text { SBM }\end{array}$ \\
\hline Maes er al. 1995 & 15 & $\begin{array}{l}23 \pm 6 \% \text { (epi) } \\
28 \pm 12 \% \text { (endo) }\end{array}$ & $\begin{array}{rrr}10 \pm 6 \% & (\mathrm{epi}) \\
11 \pm 9 \% & \text { (endo) }\end{array}$ \\
\hline Shivalkaret.at... 1996 & 18 & $24 \pm 10 \%$ & $13 \pm 10 \%$ \\
\hline Depré et al. 1995 & 16 & $35 \pm 14 \%$ & $24 \pm 13 \%$ \\
\hline
\end{tabular}

that an important number of cardiomyocytes were affected by myolysis; in some biopsy samples the quantity reached $>90 \%$ of the total cell population. The endocardial part was more affected by myolysis than the epicardial part. The connective tissue content had increased from $2 \%$ in the normal situation to $17 \%$ in the epicardial part and $19 \%$ in the endocardial part (Borgers et al., 1993a).

The myocardial biopsies used for the studies described in this thesis were quantitatively evaluated for the parameters desribed above. The results have been described before (Maes et al., 1995; Shivalkar et al., 1996; Depré et al., 1995) and are summarized in table 1.

\section{Hypothesis}

\section{Chronic hibernating myocardium- A phenotype change akin to dedifferentiation rather than degeneration}

Patients with chronic hibernating myocardium exhibit a delay in recovery of contractile function after restoration of the blood flow. Structural adaptation of the myocardium to chronic ischemia might be responsible for this delay. Most of the adaptive changes that hibernating cells undergo during chronic ischemia are changes that are reminiscent of dedifferentiation rather than degeneration. Hence the question can be asked of whether hibernating cells are of an embryonic/fetal phenotype. The morphological changes seen in hibernating myocardium corresponding to structural features of embryonic/neonatall myocardial cells are: 1) paucity of contractile filaments; 2) accumulation of glycogen; 3) presence of altered nuclei with peculiar distribution of chromatin; 4) low amount of sarcoplasmic reticulum; 5) presence of rough endoplasmic reticulum; 6) virtual absence of Ttubules and 7) sarcolemma studded with pinocytotic vesicles.

In the developing heart, and also seen in normal adult cardiomyocytes after prolonged stay in culture, sarcomeres are much less abundant than in adult cells. In embryonic cells, glycogen also accumulates around the nucleus, and glucose is 
preferred over fatty acids as energy source (Manasek, 1968; Harary, 1979) However, the amount of glycogen in hibernating cells sometimes greatly exceeds the amount observed in embryonic cells. Nuclei of embryonic cells are characterized by an even distribution of heterochromatin, in contrast to adult cells where the heterochromatin is clustered towards the nuclear membrane. Hibernating cardiomyocytes have this embryonic-like heterochromatin distribution. Moreover, a structural feature typical for embryonic/fetal heart cells is the presence of rough endoplasmic reticulum, which may be considered as a sign of active protein synthesis. The smooth sarcoplasmic reticulum is not extensively developed and lacks organization in both embryonic and hibernating cells.

It is of great importance to know whether cardiomyocytes are in a state of dedifferentiation as opposed to degeneration, because this status might determine the final outcome, i.e. recovery of function after revascularisation. The hallmark question is therefore: are dedifferentiated cells able to redifferentiate to the adult contractile phenotype. In addition to this, it is imperative to delineate the relative contribution of extracellular matrix changes to the functional deficiency and to the extent of functional recovery. The relative contribution of the extracellular matrix remodelling to wall motion abnormalities in chronic hibernating myocardium is not known, although it is conceivable that the extent of remodelling is one of the major limitations in functional recovery because of impaired compliance and loss of coherent contractile ability.

The importance of the above described changes will remain a controversial issue until a reproducible animal model becomes available in which the various aspects of the chronic hibernating state in man can be reproduced. Untill recently, only low flow ischemic models for acute hibernation have been described (Marban 1991; Chen et al.,1994; 1995). In a pig model with progressive coronary artery occlusion (Shen and Vatner, 1995) it was demonstrated that the myocardium distal to the occlusion has clinical features of hibernating myocardium, i.e. depressed wall motion, but no clear structural adaptation. But structural examination was not performed. As long as no reliable and reproducible model system exists, questions related to the possible reversibillity of the changes can not be answered.

\section{Aim of this thesis}

As described above, the structural changes in chronic hibernating myocardium involve typical cellular remodelling phenomena. These morphological changes are non-degenerative in nature and point in the direction of a dedifferentiation process. This dedifferentiation hypothesis was tested by studies on the molecular basis of the structural changes. As a tool, the expression and supramolecular organisation of markers for normal differentiation were examined immunocytochemically. These constituents are synthesized during development in a programmed fashion resulting in an altered phenotype of the cardiomyocytes. If the dedifferentiation hypothesis were to hold for hibernating myocardium, the expression of these structural 
proteins would be expected to be down-regulated sequentially, while the synthesis of proteins typical of embryonic/neonatal myocardium would be up-regulated. Degenerative myocardium, by contrast, would show a more random loss of structural proteins.

The second goal was to produce an animal model for chronic hibernating myocardium based on the structural aspects seen in biopsy samples from patients with chronic hibernating myocardium.

\section{References}

Borgers $M, 1981$. The role of calcium in the toxicity of the myocardium. Histochem J 13: 839-848.

Borgers M, Guo Shu L, Xhonneux R, Thoné F, Van Overloop P, 1987. Changes in ulltrastructure and $\mathrm{Ca} 2+$ distribution in the isolated working rabbit heart after ischemia. A time-related study. Am J Pathol 126; 92-102.

Borgers M, Thoné F, Wouters L, Ausma J, Shivalkar B, Flameng W, 1993a. Structural correlates of regional myocardial dysfunction in patients with critically coronary artery stenosis: chronic hibernation? Cardiovasc Pathol 2: 237-245.

Borgers M, De Nollin S, Thone F, Wouters L, Van Vaeck L, Flameng W, 1993b. Distribution of calcium in a subset of chronic hibernating myocardium in man. Histochem J 25: 312-318.

Borgers M and Flameng W, 1993. Morphology of the acute and ischemic myocardium in man. In: Ischemia-reperfusion in cardiac surgery. Piper HM and Preusse $\mathrm{CJ}$ (eds). Kluwer Acadamic publishers, pp. 353-375.

Borgers M. Pathological findings in chronic hibernating myocardium. In: Hendrickx GR, Wijns WC, Vatner SF, Elsevier, Amsterdam, 1997, in press.

Brunken R, Tillisch J, Schwaiger M, Child JS, Marshall R, Mandelkern M, Phelps M, Schelbert HR, 1986. Regional perfusion glucose metabolism and wall motion in chronic electrocardiographic Q-wave infarctions. Evidence for persistence of viable tissue in some infarct regions by positron emission tomography. Circulation 73: 951-963.

Camici PG, Wijns WC, Borgers M, De Silva R, Ferrari R, Heusch G, Heyndrickx G, Knuuti J, Lammerstsma AA, Liedtke JA, Melin J, Opie LH, Paternostro G, Rahimtoola SH, Schelbert SH, Schelbert HR, Schwaiger M, Taegtmeyer H, Vanoverschelde JL, Vatner SF. Pathophysiological mechanisms of chronic reversible left ventricular dysfunction due to coronary artery disease (hibernating myocardium). Circulation, in press.

Chen C, Gillam L, Chen L, Knibb D, Knight D, Waters D, 1995. Temporal hierarchy in functional and ultrastructural recoveries between short-term and chronic hibernating myocardium after reperfusion. Circulation 92: $1-552$.

Chen C, Li L, Chen LL, Prada JV, Chen MH, Fallon Jt, Weyman AE, Waters D, Gillam L, 1994. Incremental dosis of dobutamine induce a biphasic respons in dysfunctional left ventricular regions subtending coronary stenosis. Circulation 90, 756-766. 
Depre $\mathrm{C}$, Vanowerschelde JLJ, Melin JA, Borgers M, Bol A. Ausma J, Dion R, Wijns W. 1995 Structural and metabolic correlates of the reversibility of chronic left ventricular ischemic dysfunction in humans. Am J Physiol 268: H1265-1275.

Eitzman Di, al-Aour ZR, Kanter HL, Von Dahl J, Kirsh M, Deeb GM, Schwaiger M, 1992. Clinical outcome of patients with advanced coronary artery disease afer viability studies with positron emission tomography. I Am Coll Cardiol 20: 559-565.

Flameng W, Suy R, Schwarz F, Borgers M, Piessens J, Thoné F, Van Ermen H, De Geest H, 1981. Ultrastructural correlates of left ventricular contraction abnormalities in patients witl chronic ischemic heart disease: determinats of reversible segmental asynergy postrevasculariation surgery. Am Heart J 102: 1.46-1.57.

Flameng W, Wouters L, Sergeant $\mathbb{P}$, Lewi P, Borgers $M$, Thoné F, Suy $R, 1984$. Multwariate analysis of angiographic histologic and electrocardiographic data in patients with coronary heart disease. Circulation 70: 7-17.

Harary J, 1979. Biochemistry of cardiac development: in vivo and in vitro studies. In: Handbook of Physiology section 2: The cardiovascular system. Berne RM et al (eds) American Physiological Society, Bethesda, Maryland, vol I, pp43-60.

Jennings RB, Hawkins IK, Lowe JE, Mill ML, Klotman S, Reimer SA, 1978. Relation between high energy phosphate and lethal injury in myocardial ischemia in the dog. Am I Pathol 92: 187-214.

Maes A, Flameng W, Nuyts J, Borgers M, Shivalkar B, Ausma J, Bormans G, Schiepers C, De Roo M, Mortelmans L, 1994. Histological alterations in chronically hypoperfused myocardium. Correlation with PET findings. Circulation 90: 735-745.

Maes A, Flameng W, Borgers M, Nuyts J, Ausma J, Bormans $G$, Van de Werf F, De Roo M Mottelmans L, 1995. Regional myocardial blood flow, glucose utilizaton and contractile function before and after revascularization and ultrastructural findings in patients with chronic coronary artery disease. Eur J Nucl Med 22: 1299-1305.

Manasek FJ , 1968. Mitosis in developing cardiac muscle. J Cell Biol 37: 191-196

Marban E, 1991. Myocardial stunning and hibernation. The physiology behind the colloquialism. Circulation 83:681-688

Rahimtoola SH, 1985. A perspective on the three large multicenter randomized clinical trials of coronary bypass surgery for chronic stable angina. Circulation (Suppl V) 72 : $123-135$.

Rahimtoola $\mathrm{SH}$ 1995. From coronary artery disease to heart failure: Role of the hibernating myocardium. Am J Cardiol 75: 16E-22E.

Schaper J, 1979. Ultrastructure of the myocardium in acute ischemia. In: The pathophysiology of myocardial perfusion. Schaper W et al. (eds) Elsevier, NorthHolland, $581-673$.

Schaper J, Froede TA, Hein St, Buck H, Hashizume H, Speiser B. Friedl A, Bleese N, 1991. Impairement of the myocardial ultrastructure and changes of the cytoskeleton in dilated cardiomyopathy. Circulation 83: 504-514.

Schelbert HR, 1991. Positron emission tomography for the assessment of myocardial viability, Circulation (Suppl I) 84: [-122-131. 
Sharow VG, Sabbah HN, Shimoyama H, Goussev AV, Lesch M, Goldstein S, 1996. Evidence of cardiocyte apoptosis in myocardium of dogs with chronic heart failure. Am J Pathol 148: 141-149.

Shen Y-T, Vatner SF. 1995. Mechanism of impared myocardial function during progressive coronary stenosis in conscious pigs. Hibernation versus stunning? Circulation 76: 479-488.

Shivalkar B, Maes A, Borgers M, Ausma J, Scheys I, Nuyts J, Mortelmans L, Flameng W, 1996. Only hibernating myocardium invariably shows early recovery after coronary revascularization. Circulation 94, 308-315.

Takeishi Y, Tono-oka I, Kubota I, Ikeda K, Masakane I, Chiba J, Abe S, Tsuiki K, Komatani A, Yamaguchi I, Washio M, 1991. Functional recovery of hibernating myocardium after coronary bypass surgery: Does it coincide with improvement in perfusion. Am Heart J 122: 665-670.

Tillisch J, Brunken R, Marshall R, Schwaiger M, Mandelkern M, Phelps M, Schelbert HR, 1986. Prediction of cardiac wall motion abnormalities predicted by using positron emission tomography. N Engll J Med 36: 1995-1999.

Vandeplassche G, Hermans C. Thone F, Borgers M. 1991. Stunned myocardium has increased mitochondrial NADH oxidase and ATPase activities. Cardioscience 2, 47-53.

Vanoverschelde JLJ, Wijns W, Depré C, Essamri B, Heyndricks S, Borgers M, Bol A, Melin J, 1993. Mechanisms of chronic regional postischemic dysfunction in humans: New insights form the study on non-infarcted collateral dependent myocardium. Circulation 87: 1513-1523.

Vanoverschelde JLJ, Gerber BL, D'Hondt A-M, De Kock M, Dion R, Wijns W, Melin $J, 1995$. Preoperative selection of patients with severely impaired left ventricular function for coronary revascularization. Role of low-dose dobutamine echocardiography and exercise-redistribution-reinjection thallium SPECT. Circulation 92: II 37-44.

Vanoverschelde J-LJ, Gerber G, Pasquet A, Melin JA, 1996. Nuclear and echocardiographic imaging for prediction of reversible left ventricular ischemic dysfunction after coronary revascularization: current status and future directions. J Cardiovasc Pharmacol, 28 (Suppl I): S27-S36.

Von Dahl J, Eitzman Dt, al-Aour ZR, Kanter HL, Hicks RJ, Deeb GM, Kirsh MM, Schwaiger M, 1994. Relation of regional function, perfusion, and metabolism in patients with advanced coronary artery disease undergoing surgical revascularization. Circulation 90: 2356-2366. 


\title{
Chapter 2 \\ Chronic ischemic viable myocardium in man: aspects of dedifferentiation
}

Jannie Ausma, Gert Schaart, Fred Thoné, Bharati Shivalkar, Willem Flameng, Christophe Depré, Jean-Louis Vanoverschelde, Frans Ramaekers and Marcel Borgers

Cardiovasc. Pathol 4: 29-37 (1995)

\begin{abstract}
Histologic analysis of biopsies derived from patients with chronic dysfunctional but viable (hibernating) myocardium showed characteristic cell alterations. These changes consisted of a partial to complete loss of sarcomeres, accumulation of glycogen, and disorganisation and loss of sarcoplasmic reticulum. Most of the adaptive changes that these affected cells undergo are suggestive of dedifferentiation. In the present study the expression and organizationall pattern of contractile and cytoskeletal proteins such as titin, cardiotin and $\alpha$-smooth muscle actin were assessed in hibernating and normal myocardium because the expression and organization of these constituents have been related to certain stage of cardiomyocyte differentiation. In normal cells titin shows a cross-striated staining pattern, whereas cardiotin displays a fibrillar array, parallel to the sarcomeres. $\alpha$-Smooth muscle actin is not expressed in adult cardiomyocytes. The expression of titin in a punctated pattern and the marked decrease to virtual absence of cardiotin in hibernating cardiomyocytes speak in favor of an embryonic phenotype of these cells. The reexpression of $\alpha$-smooth muscle actin in hibernating cells strongly supports this hypothesis. The observations on three different structural proteins of heart muscle suggest that hibernating myocardium acquired aspects of muscle cell dedifferentia* tion.
\end{abstract}




\section{Introduction}

The term hibernating myocardium was coined by Rahimtoola (1) to describe a state of left ventricle dysfunction which occurs during chronic myocardial ischemia. In this condition, the reduced ventricle function can be partially or completely restored to normal if the myocardial oxygen supply/demand ratio is favorably altered by improving blood flow and/or reducing demand. The hibernating response of the heart, namely a diminished function to cope with a reduced myocardial blood flow, could be considered as an act of self-preservation (little blood, little work) (2). Another characteristic of hibernation is that after blood flow is restored, the recovery of function is either rapid (acute hibernation) or slow to very slow (chronic hibernation) (2-4).

We have recently described the morphologic changes in cardiac biopsies obtained from several groups of patients with chronic myocardial ischemia(5-8). Typical structural changes were noted in the cardiomyocytes of a substantial number of patients. The affected cardiomyocytes showed loss of sarcomeres, sarcoplasmic reticulum and T-tubules and presented abundant plaques of glycogen, strands of rough endoplasmic reticulum, numerous small mitochondria, and nuclei with uniformly dispersed chromatin (6). It was proposed that segments in which these structural changes prevail are charactereristic of chronic hibernating myocardium and most probably are those that do not recover immediately after revascularization. Instead, they might show a delayed recovery of function because structural remodeling requires time in order to regain sufficient contractile material $(2,4,7,8)$.

Because cells of such dysfunctional myocardium show virtually no signs of necrosis, the question arose as to what type of subcellular changes could underlie the hibernating phenomenon. The key observation - the replacement of contractile material (sarcomeres) by glycogen, together with some of the above-mentioned cytological changes - suggest that these cardiomyocytes acquired dedifferentiation rather than necrotic properties (5-8).

The aim of the present study was to substantiate the hypothesis of dedifferentiation, and we therefore investigated the expression, assembly and (re)organisation of markers of cardiac cell development. For this purpose we used monoclonal and polyclonal antibodies against contractile and cytoskeletal proteins to study the expression and organisation of these muscle constituents in biopsies of patients with chronic dysfunctional but viable myocardium.

During cardiogenesis different structural proteins appear at different phases of myofibril formation, and the organisation of most of these muscle-specific proteins changes with differentiation (9-13). The expression and organisation of musclespecific proteins is related to the degree of cardiac muscle development. Firstly, titin is an important high-molecular-weight $(3000 \mathrm{kDa})$ elastic protein that spans the sarcomeres from $\mathrm{M}$ - to $\mathrm{Z}$-lines. The I-band part of titin is flexible and contributes to muscle elastic recoil. The $\mathrm{A}$ band part is anchored to myosin. Titin might regulate 
thick filament length and maintain the alignment of thick filaments (14). Titin undergoes structural changes during differentiation (9-13). Second, a recently described structural component of the myocardium, the high-molecular-weight protein cardiotin ( $300 \mathrm{kDa}$ ), has been located between the myofibrils (15). Cardiotin cannot be detected in embryonic hearts of mice, rabbits and human and seems to be expressed only after birth (15). Up to now the structure and function of cardiotin have been unknown. Third, if chronic hibernating myocardium possesses aspects of dedifferentiation, the question arises whether a re-expression of proteins which are found exclusively in the embryonic heart, such as $\alpha$-smooth muscle actin, can be observed (16-18). With the localization of these three protein constituents, we intend to verify the link between myocardial hibernation and muscle cell dedifferentiation.

\section{Materials and methods}

\section{Patients}

The human cardiac material used in this study consisted of transmural biopsies from 20 patients obtained during coronary bypass surgery. All patients gave their informed consent. The study was approved by the local ethical committees for research. The detailed individual patient characteristics are described in previous papers $(7,8)$. In brief, the 20 patients ( 16 men, 4 woman; age range $45-78$ years) had known coronary artery disease (single or two vessel disease); left anterior descending artery (LAD) stenosis $70 \%(n=3), 80 \%(n=7), 90 \%(n=5), 100 \%(n=5)$ and had marked anterior wall motion abnormalities as evaluated by cineangiography and two-dimensional echocardiography. Global and regional ejection fractions were determined. with radionucleotide angiography before and 3 to 6 months after coronary artery bypass grafting (CABG). The viability of the myocardium was verified by positron emision tomography. All patients included in this study demonstrated a flow/metabolic mismatch. Based on the above criteria, they were considered to fulfill the criteria of chronic hibernation $(7,8)$. Functional improvement after bypass surgery was seen 3 to 6 months after surgery. The functional measurements included global ejection fractions $(51 \% \pm 11 \%$ before, $60 \% \pm 10 \%$ after surgery, $\mathrm{p}<0.05)$ and regional ejection fraction $(42 \pm 11 \%$ before, $54 \% \pm 13 \%$ after surgery, $\mathrm{p}<0.05)(8)$ or left ventricular $(\mathrm{LV})$ end-diastolic volume (decrease) and resting anterior wall motion score (improvement by at least one full grade after revascularization; Depré, unpublished data, 1994).

A first biopsy was fixed for a minimum of 2 hours in $3 \%$ glutaraldehyde buffered to $\mathrm{pH} 7.4$ with $90 \mathrm{mM} \mathrm{KH}_{2} \mathrm{PO}_{4}$, washed in the buffer, postfixed for $1 \mathrm{hr}$ in $2 \% \mathrm{OsO}_{4}$ buffered with $50 \mathrm{mM}$ veronal acetate, dehydrated in a graded series of ethanol and embedded in epoxy resin (Epon) (19). A second biopsy was used for immunohistochemical studies. For that purpose, biopsies of 13 patients were directly frozen in isopentane precooled with liquid nitrogen, and used to test for the expression of titin and cardiotin. Expression of $\alpha$-smooth muscle actin was studied 
in 7 other biopsies, which were fixed according to the periodate-lysineparaformaldehyde method: biopsies were immersed for 6 hours in a solution containing $0.01 \mathrm{M}$ periodate, $0.075 \mathrm{M} \mathrm{L}$-lysine and $2 \%$ paraformaldehyde in $0.037 \mathrm{M}$ $\mathrm{Na}_{2} \mathrm{HPO}_{4}$ buffer ( $\mathrm{pH} 6.0$ ), further fixed in $4 \%$ paraformaldehyde in the same buffer ( $\mathrm{pH} \mathrm{7.4)}$ for 16 hours and finally stored in the buffer solution. Before frozen sections were made, the biopsies were washed successively with 10,15 and $20 \%$ sucrose in phosphate buffered saline (PBS) for 4 hours in each solution before they were frozen in isopentane precooled in liquid nitrogen.

Left ventricle biopsies derived from 7 donor hearts, which were either used for orthotopic transplantation or homograft prelevation, also used in a previously published study (6), were treated as above and served as nonischemic controls.

\section{Light microscopic evaluation}

Light microscopic morphometry of morphologic changes was performed on $2-\mu \mathrm{m}-$ thick sections of Epon-embedded biopsies, which were stained with periodic acid Schiff (PAS) and $0.1 \%$ toluidine blue to quantify the loss of myofibrils and glycogen content. The nature of the PAS-positive material has been verified by electron microscopic examination, and glycogen could be unambigously identified. The degree of cellular change was evaluated only in cells in which the nucleus was present in the plane of the section. Cells were planimetrically scored for glycogen content (6).

\section{Immunohistochemical studies}

The following primary antibodies were used in this study:

1) A mouse monoclonal antibody 9D10 to titin. This antibody recognizes an epitope in the I-band at the A-I junction in striated muscle (20-22) obtained from the Developmental Studies Hybridoma Bank, maintained by the Department of Molecular Sciences, Johns Hopkins University of Medicine, Baltimore MD, USA and the department of Biology, University of Iowa, Iowa City IA, USA, under contract N01-HD-6-2915.

2) A mouse monoclonal antibody $R 2 G$ to cardiotin, a structural component of the cardiomyocytes (15).

3) A mouse monoclonal antibody, sm-1, reacting specifically with the $\alpha$-smooth muscle isoform of actin $(16,23)$ (Sigma, St. Louis, Missouri).

4) A mouse monoclonal antibody, $s \mathrm{r}-1$, which recognizes striated muscle $\alpha$-actin $(16,23)$ (DAKO A/S, Glostrup, Denmark) .

5) A mouse monoclonal antibody DE-R-11 to desmin which labels the desmin of skeletal, cardiac and smooth muscle cells (25) (DAKO A/S, Glostrup, Denmark).

6) A mouse monoclonal antibody RD301 to desmin, which recognizes the tail part of desmin $(26,27)$.

7) A mouse monoclonal antibody to striated muscle myosin (MF-20), obtained from Developmental Studies Hybridoma Bank, maintained by the Department of 
Molecular Sciences, Johns Hopkins University of Medicine, Baltimore MD, USA and the Department of Biology, University of lowa, lowa City IA, USA, under contract N01-HD-6-2915 from NICHD. The antibody reacts with all sarcomeric myosins (embryonic and adult) (28).

8) A mouse monoclonal antibody, MF-30, obtained from Developmental Studies Hybridoma Bank, maintained by the Department of Molecular Sciences, Johns Hopkins University of Medicine, Baltimore MD, USA and the Department of Biology, University of lowa, Iowa City IA, USA, under contract N01-HD-6-2915 from NICHD. The antibody reacts with the S2 fragment of the neonatal and adult myosin heavy chain of various neonatal and adult species (28).

9) A mouse monoclonal antibody (TM311) which reacts with tropomyosin (Sigma Immunochemicals, St. Louis, Missouri).

Furthermore, Rhodamine-labelled phalloidin was used to stain F-actin (dilution 1:80 in PBS Molecular Probes Inc., Eugene, Oregon).

Indirect immunofluorescence assays were performed on 5- $\mu \mathrm{m}$-thick frozen sections. They were air dried before use, and treated with $0.5 \%$ Triton X-100 (BDH Chemicals Ltd., Poole, UK) in PBS for 5 minutes at room temperature, followed by a wash in PBS. The sections were incubated with the primary antibodies for 45 minutes and washed with PBS (three steps of 10 minutes each). The sections were then incubated for 45 minutes with the secondary, huorescein isothiocyanate (FITC)-conjugated Goat-anti-mouse Ig (Southern Biotechnology Associates (SBA) Inc., Birmingham, Alabama). The sections were washed in PBS (three steps of 10 minutes each), placed in distilled water for $5 \mathrm{~min}$, followed by a postfixation step in methanol for 5 minutes (except for cardiotin). The sections were air-dried and mounted in Mowiol (Hoechst, Frankfurt a.M./Germany). Nuclei were routinely stained with DAPI (4'-6-diamidine 2-o-phenylindole Sigma Chemicals, St. Louis, Missouri diluted 1:10000). As a control, application of the first antibody was omitted.

Immunoperoxidase labeling was used for glutaraldehyde and/or periodate-lysineparaformaldehyde (PLP) fixed biopsies. The fixed biopsies were frozen in isopentane precooled liquid nitrogen. Five-micron-thick sections were air dried before use, and treated with $0.5 \%$ Triton $\mathrm{X}-100$ for $15 \mathrm{~min}$ at room temperature, followed by 10 minutes wash in PBS. The sections were then treated with $1 \mathrm{mg}^{-\mathrm{ml}^{-1}}$ $\mathrm{NaBH}_{4}$ in PBS for 15 minutes, washed with PBS and preincubated with $5 \%$ normal goat serum in $0.1 \%$ bovine serum albumin (BSA Sigma, St.Louis, Missouri) in PBS. After a wash in PBS supplemented with $0.1 \%$ BSA, the sections were incubated overnight with the primary antibody at room temperature. The sections were then washed for 30 minutes in PBS and incubated for 1 hour with peroxidaseconjugated rabbit-anti-mouse Ig (DAKO A/S, Glostrup, Denmark). After washing with PBS (three steps of 10 minutes each) peroxidase activity was detected with 3amino-9-ethylcarbazole (AEC, Sigma, St. Louis, Missouri). Therefore $40 \mathrm{mg}$ of 
AEC was dissolved in $10 \mathrm{ml} N, \mathrm{~N}$ dimethylformamide (Merck, Darmstadt, Germany) and added to $190 \mathrm{ml}$ of $0.05 \mathrm{M}$ sodium acetate buffer ( $\mathrm{pH} 4.95$ ). Hydrogen peroxide was added to a final concentration of $0.01 \%(v / v)$. After incubation for 10 minutes the sections were rinsed with tap water, counterstained with haematoxylin ((Sigma Diagnostics, St. Louis, Missouri) diluted 1:4 with distilled water) and mounted with Kaiser's glycerol gelatin (Merck, Darmstadt, Germany).

All slides were examined with a Zeiss Axiophot microscope. Photographs of the immunofluorescense studies were taken with a Kodak Tri-X-pan film with a 400 ISO setting and the photographs of the immunoperoxidase-labelled sections were taken with a Kodak EPY 64 T film with a 64 ISO setting.

\section{Results}

\section{Light microscopic changes}

The most important change in cellular substructure seen in a considerable number of myocardial cells from chronic hibernating myocardial segments was the depletion of contractile material without loss of cell volume. Loss of contractile material was in many cells limited to the vicinity of the nucleus, but in others it comprised the bulk of the cytoplasm, leaving only a few or no sarcomeres at the periphery of the cell. The myolytic areas, being the spaces in which myofilaments had dissolved, became occupied by glycogen and many small mitochondria (Fig. 1). Cells were considered as affected when more than $10 \%$ of the cell volume is occupied by glycogen (6). The mean percentage of affected cells was $28 \%$ for the group of 20 patients. Signs of a purely degenerative nature, such as acute necrosis of the myocytes, abnormal storage of lipids and phospholipids in the form of droplets or multilamellar bodies, gross intracellular edema, and the presence of inflammatory cells -as described for acute myocardial infarction, idiopathic congestive heart failure and various forms of cardiomyopathies- were rarely seen. An increase in connective tissue was consistently observed in areas in which structurally affected myocardial cells prevailed.

\section{Immunofluorescence studies}

Affected cells which displayed myolysis in the perinuclear area showed no contractile and cytoskeletal proteins in the sarcomere-free zones when assayed with monoclonal and polyclonal antibodies directed against actin, myosin, tropomyosin, desmin, titin and cardiotin (Table 1). At the cell periphery, where sarcomeres persisted, the organization of myosin, actin, tropomyosin and desmin remained apparently intact. The intermediate filament protein desmin showed cross-striations in the Z-line of remaining sarcomeres. Even in cells with huge zones of myolysis, desmin striations were normally arranged in the peripheral sarcomeres. The organisation of the sarcomeric proteins actin, myosin and tropomyosin was comparable between the sarcomeres of chronic hibernating and control hearts. 

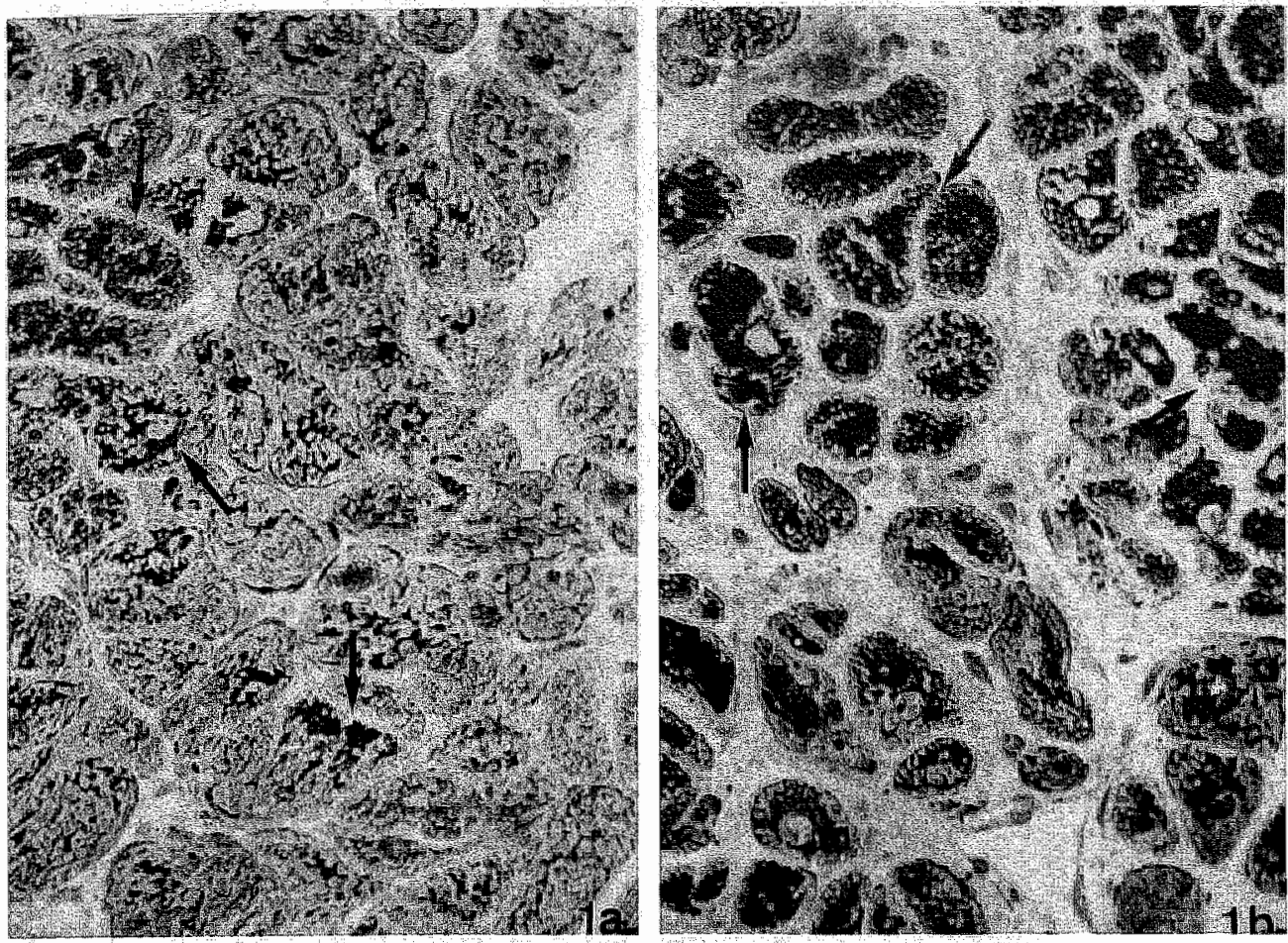

Figure I. Light microscopy of morphological changes in chronic ischemic myocardium. (a) Section of a slighty affected area, showing PAS staining in a few cells only (arrows). (b) Area of severely affected myocardium with a high number of cells staining for PAS dwe to the accumulation of glycogen (arrows). (Magnification X 300).

Table 1. Comparison of Immunohistochemical Results for a-Smooth Muscle Actin, Cardionin, and Titin in Normal Adult. Embryonic, and Hibernating Myocardium

\begin{tabular}{lccccc}
\hline Antibody & Antigen recognizec & Adult heart & $\begin{array}{c}\text { Appearance during } \\
\text { embryongenesis }\end{array}$ & $\begin{array}{c}\text { Hibernating } \\
\text { Heart }\end{array}$ & References \\
\hline SM-1 & $\begin{array}{c}\alpha-\text { Smooth } \\
\text { muscle actin }\end{array}$ & Absent & Diffuse & Diffuse & 16,17 \\
R2G & $\begin{array}{c}\text { Cardiotin } \\
\text { Titin }\end{array}$ & Filamentous & Diffuse & Diffuse & 15 \\
9010 & Cross-striated & Punctated & Punctated & 10,12, \\
& & & & & 13,14 \\
\hline
\end{tabular}



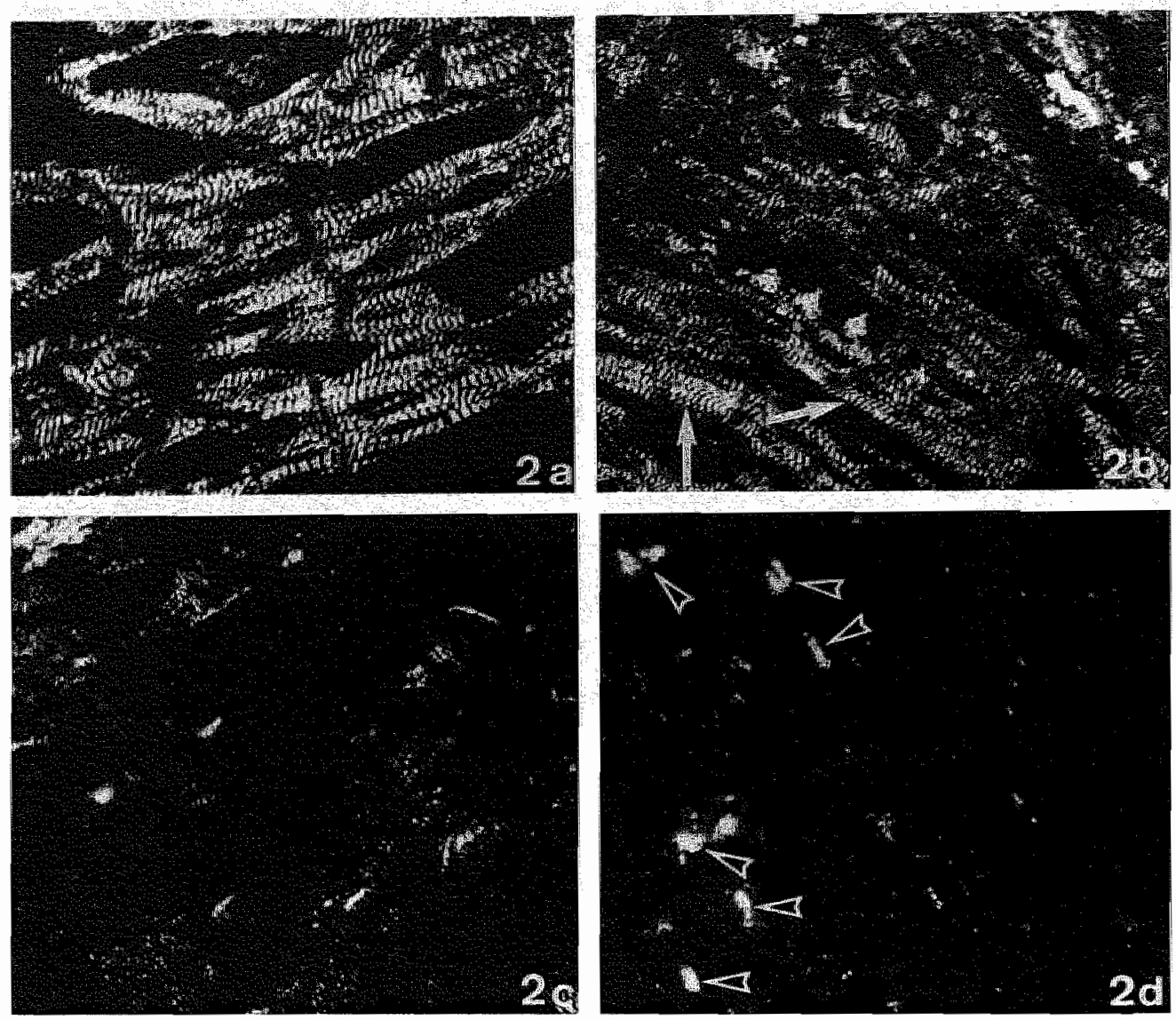

Figure 2. Immunofluorescence micrographs of sections from hibernating myocardium, showing increasing levels of titin disorgamisation. (a) Titin, showing typical double banded strations, is present in an area without myolysis (b) Double banded striations are less abundant in this affected area. Arrows indicate a normal zone with double titin bands and asterisks indicate areas where titm striarions are diminished. (c) Marked change of titin staining pattens in chronic hibenating myocardium. Only a few short vith striations and titin dots are seen. (d) This area of chronic hibernating myocardimm is whally negative for the titin antibody 9010 staining. The large dots of fluorescent clusters are lipofuscin deposits (arowheads). (Magnification X430). 


\section{Titin}

The monoclonal antibody to titin (9D10 used in $7.2 \mu \mathrm{g} / \mathrm{ml}$ concentration) showed typical double banded cross-striations in normal myocardial cells of the control hearts. Smooth muscle, epithelial and mesenchymal cells were negative. In contrast to the sarcomeric proteins listed earlier, most of the patients with chronic hibernating myocardium presented marked changes in the organisation and expression of titin. The most distinct mark, the double-banded cross-striations, disappeared first. Titin became visible as single bands in parts of the sarcomeres (Fig. 2b). The distance between the cross-striations varied, and the fluorescence intensity was lowered. However, in a limited number of the affected cells titin was arranged normally, the typical double banded cross striated pattern being preserved (Fig. 2a) where sarcomeres remained intact. In areas where severely affected cells prevailed, only shorter striations of titin remained (Fig. 2c). The most pronounced down-regulation of titin expression appeared in the most severely affected cells, where titin appeared sparsely and only in a punctated fashion (Fig. 2d).

\section{Cardiotin}

In normal cardiac muscle cells the monoclonal antibody to cardiotin (R2G, used in $25 \mu \mathrm{g} / \mathrm{ml}$ concentration) displayed a longitudinal filamentous localisation between the myofibrils, perpendicular to the desmin striations. The cardiotin filaments were regularly interspaced and spanned several sarcomeres (Fig. 3a). The cardiotin expression was restricted to the cardiomyocytes.

The cardiotin distribution was affected in most of the biopsies from patients with chronic hibernating myocardium. In the least affected cells the cardiotin filaments became shorter (Fig. 3b), whereas in more severely affected ones the cardiotin filaments were sparse (Fig. 3c) and ultimately its structure disappeared entirely (Fig. 3d).

\section{$\alpha$-Smooth muscle actin}

$\alpha-S$ mooth muscle actin was not found in cardiomyocytes of the normal myocardium when assessed with the monoclonal antibody sm-1 (used in $1.3 \mu \mathrm{g} / \mathrm{ml}$ concentration; Fig. 4a). In chronic hibernating myocardium $\alpha$-smooth muscle actin could be detected in a number of hibernating cells. Occasional areas of hibernating myocardium uniformly presented a moderate expression of $\alpha$-smooth muscle actin in all cells (Fig . 4b). The same figure shows also that the smooth muscle cells of the coronary blood vessels reacted strongly with $\alpha$-smooth muscle actin antiserum. In other areas strongly reactive cells were found intermingled with completely negative ones (Figs, $4 \mathrm{c}$ and $4 \mathrm{~d}$ ). In cells with severe myolysis, most of the $\alpha$ smooth muscle actin was located around the zone affected by myolysis, at spots where sarcomeres were still present (Fig. 4c). 

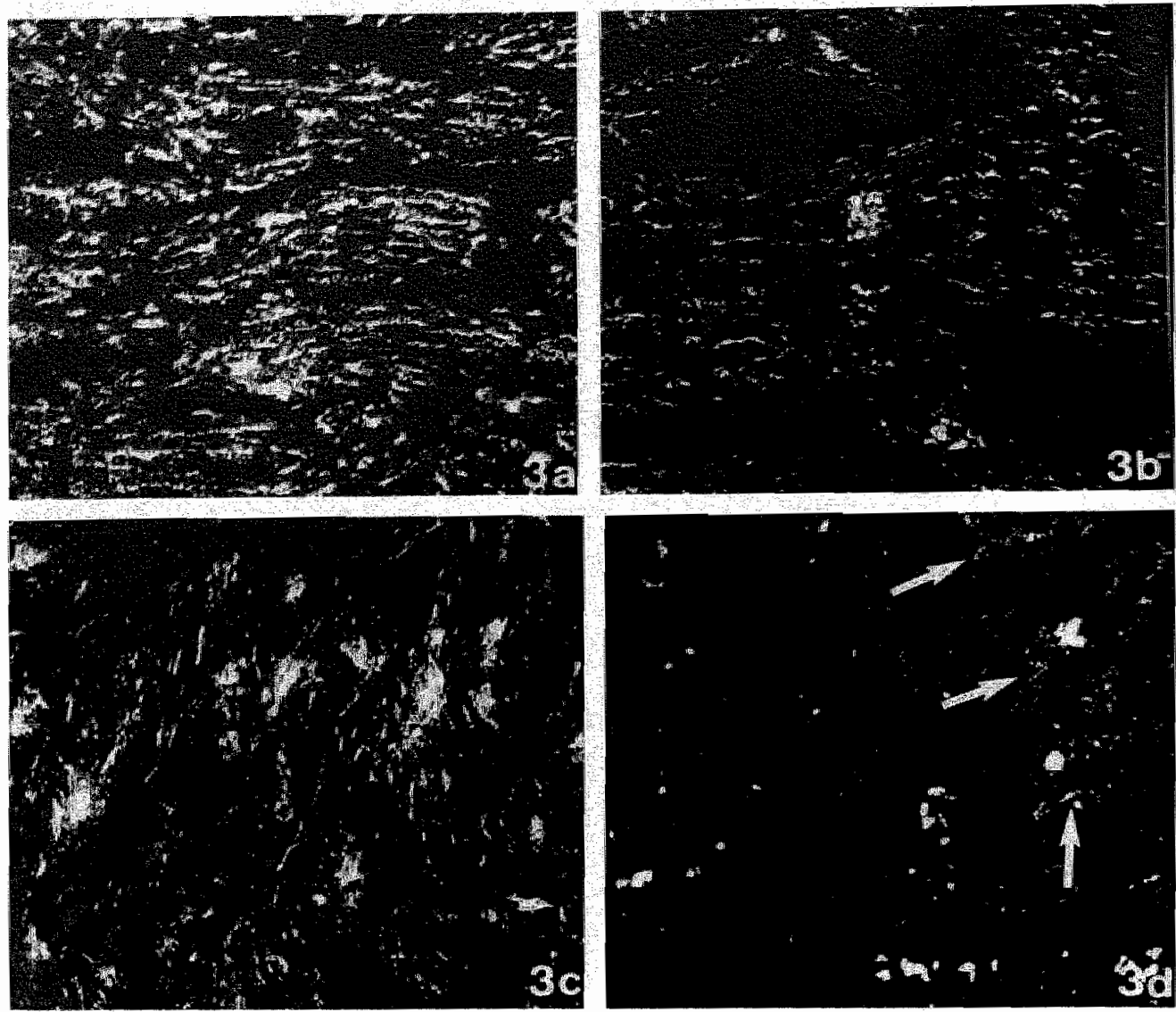

Figure 3. Immunoftuorescence micrographs of cardiotin localisation. (a) Cardiotin, with characteristic longiudinal orientated filaments, running parallel at regular disiance betwean the sarcomeres, in morphologically nowmal myocardiam. (b) The cardiotin filaments are shorter and less abundant in hibernating heart muscle cells. (c) A more pronounced distuption of the cardiotin structure is seen in this severely affected area in a chronic hibermating myocandial segment. (d) Area as in c: only a few spots of cardiotin are present (arrous) (Magnification $X 430$ ). 

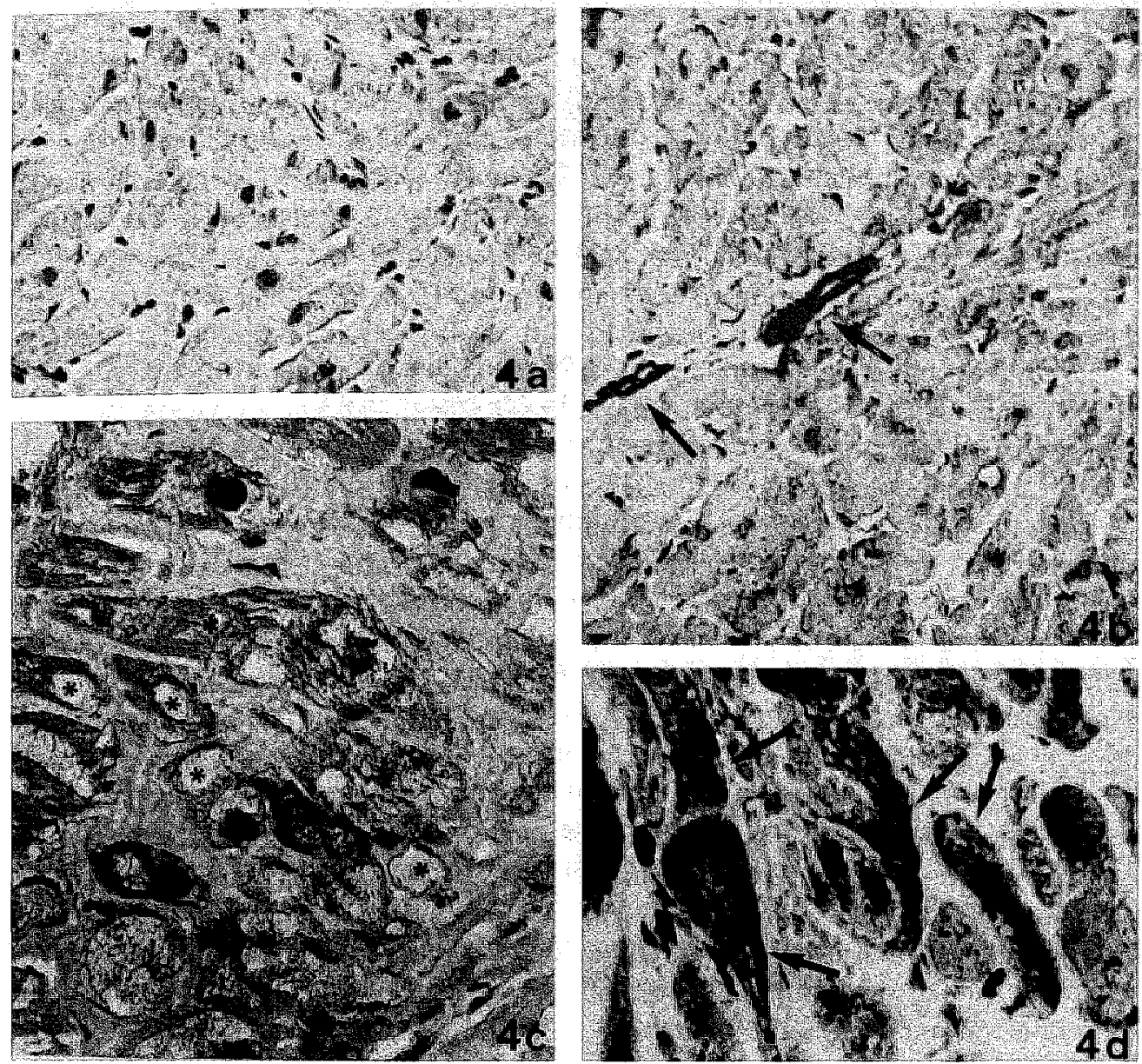

Figure 4. Immumoperoxidase labeling of $\alpha$-smooth muscle actin. (a) $\alpha$-Smooth muscle actin in control myocardium. Staming is absent from the cardiomyocytes. (b) a-Smooth muscle actin is seen in moderate amounts in mavy cells of hibernating myocardium whereas it is strongly expressed in vascular smooth muscle cells (arrows). (c) A segmen in which some cardiomyocytes are strongly positive for a-smooth muscle actin, mainly at the periphery of the cells. Other cells with severe myolysis are negative for o-smooth muscle actin (asterisks). (d) A chronic hibernating myocardial segment in which the majority of candiomyocytes display high levels of a-smooth muscle actin (arrows). (Magnification a,b: X185 $c, d: X 430)$. 


\section{Discussion}

\section{Morphological changes}

Cells of chronic hibernating myocardium are characterized by structural changes that could be interpreted as cellular dedifferentiation. These are (1) depletion of contractile material, (2) accumulation of glycogen, (3) presence of altered nuclei with evenly distribution of chromatin, (4) strong decrease of sarcoplasmic reticulum, (5) presence of rough endoplasmic reticulum, (6) virtual absence of Ttubuli and $(7)$ vesiculization of the sarcolemma $(6-8,29)$. The replacement of sarcomeres by glycogen can be regarded as the hallmark change in the structure of cardiomyocytes in patients with chronic hibernating myocardium(6-8).

In previous work $(5,29,30)$ it has been shown that these cells are actively metabolizing and possess a number of characteristics indicative of health: (1) cytochrome oxidase activity can be demonstrated in their mitochondria, despite the fact that they have a markedly altered morphology; there are no signs of uncoupling of mitochondria given that proton translocating ATPase cannot be shown (29); (2) the integrity of cellular calcium homeostasis is suggested by the absence of cytochemically demonstrable calcium overload; the phospholipid-bound fraction of calcium is preserved at the plasma membrane of hibernating cells, and mitochondria are virtually devoid of calcium precipitate (30); (3) hibernating cells are less susceptible to acute ischemia than their neighbouring cells with a normal structure (5). Briefly, biopsies were also taken from patients at the end of CABG (not used in this study). The ischemic damage (especially to mitochondria) was much more pronounced in structurally normal (non-myolytic) cells than in hibernating (myolytic) cells.

It is conceivable that if the structural changes in the affected cardiomyocytes were reversible (redifferentiation), it would take the cells a prolonged period of time to rebuild a normal contractile machinery. This might, at least in part, explain the delay in recovery of ventricle function after revascularization that is seen in a number of patients with chronic hibernating myocardium $(2,3,7,8)$. That cells so affected can redifferentiate again, has been indirectly suggested by Borisov (31), who described that cardiac muscle cells at early, intermediate and terminal stages of differentiation are capable of adaptive remodeling of their contractile system both in vivo and in vitro. Moreover, Sharp et al. (32) established that in verapamilarrested cultured neonatal rat heart cells, in which initially a steep reduction in the amount of actin was detected, the process could be entirely reversed upon omission of the drug. During chronic hibernation the hypo/akinesia (contractile unloading) may lead to a similar reduction in the amount of actin and other sarcomeric proteins. Dedifferentiation of cardiomyocytes has also been noticed in papillary muscle of the cat after mechanical unloading but with normal blood flow and the reversibility of the changes has been demonstrated (33). At variance with hibernating cells, the papillary muscle cells did not contain high amounts fo glycogen. 
Also, some of the observed structural features of hibernating cells strongly resemble those seen in embryonic and neonatal cardiomyocytes (34). These changes were mainly the abundant presence of glycogen and the paucity of myofilaments. In this study we presented immunohistochemical data in support of the assumption that hibernating cells may have an embryonic or neonatal phenotype by assessing the expression, organisation and assembly of some markers which are known to undergo changes during cardiac development.

\section{Titin}

The immunohistochemical staining pattern of titin as detected by antibody $9 \mathrm{D} 10$ was the earliest to redistribute and ultimately disappear in the sarcomeres of hibernating myocardial cells, whereas the organisation and expression of the other sarcomeric proteins studied still remained intact. Actin, myosin, tropomyosin and desmin were seen in a normal striated state in sarcomeres remaining at the periphery of the cell. Morano et al. (35) found that the amount of titin and the titinmyosin heavy chain ratio were lower in embryonic and failing human hearts (not further specified) than in normal adult heart fibers. The disappearance of titin staining as seen in our study was gradual and started as a fragmentation of the titin striations, followed by a pattern with a dot-like appearance. The staining patterns of titin in the hibernating cells is the reverse sequence of that during embryogenesis. For example, the punctated expression pattern of titin seen in hibernating cells is also the hallmark of the earliest stages of embryonic myocardiogenesis. Studies on cardiac myofibrilllogenenis in early chick embryos, $(10,11,36)$, mouse embryos (12) and rabbit embryos (13) all confirm the presence of titin spots during the early stages of differentiation of heart muscle cells. Further development of myocardial cells induces a rearrangement of the titin aggregates to periodically aligned titin structures in the newly arising myofibrils, with subsequent display of titin doublets. Titin punctation precedes short striated stretches of titin, as observed in differentiating skeletal muscle cells in culture $(37,38)$. Thus, in hibernating cardiomyocytes, titin is detected in an embryonic-like expression pattern.

\section{Cardiotin}

The disappearance of cardiotin provides another argument for the change to an embryonic or neonatal phenotype of the chronic hibernating myocardium. The expression of cardiotin in the heart is thought to be initiated after birth (15). In the hearts of Rhesus monkeys aged 5 and 13 months, a relatively weak, occasionally diffuse staining pattern was detected for cardiotin. In adult (20-years-old) monkey hearts a normal staining pattern for cardiotin was observed that was comparable to that seen in the adult human heart. In rabbit embryos of different stages of development, no cardiotin was detected between days 8 and 28 of pregnancy. In a 16-week-old human embryonic heart no cardiotin was found, either. However, the adult human heart was found to be strongly positive for cardiotin (15). 
Redistributions in cardiotin staining comparable to that in developing heart cells are observed in the human hibernating myocardium. Again, the order of disruption of the cardiotin structure during hibernation is a reverse sequence of events that takes place during the development of the heart.

\section{$\alpha-$ Smooth muscle actin}

With a monoclonal antibody specific for the $\alpha$-smooth muscle isoform of actin (23), this protein could be detected in some of the hibernating cells. So, chronic hibernation leads to a coexpression of the embryonic form of $\alpha$-smooth muscle actin in cardiomyocytes next to the striated $\alpha$-cardiac actin isoform. The coexpression of $\alpha$-sarcomeric (skeletal or cardiac) actin and $\alpha$-smooth muscle actin is seen during the onset of muscle-fiber formation of both skeletal and cardiac muscle in various species. The smooth muscle actin form is gradually lost from the striated muscle cells during development (16-18). Conversely, adult cardiomyocytes in long-term culture go through distinct dedifferentiation steps and resemble embryonic heart cells in that they re-express the $\alpha$-smooth muscle actin isoform (39-41).

In some cases, when severe myolysis took place, $\alpha$-smooth muscle actin was more abundant at the periphery of the cell. Some cells with severe myolysis, however, showed no $\alpha$-smooth muscle actin expression. These cells are possibly in a stage of dedifferentiation in which this protein is not yet expressed. Moreover, it is not known if myocytes expressing $\alpha$-smooth muscle actin lack cardiotin and titin, because immunohistochemical studies had to be performed on different biopsies: for $\alpha$-smooth muscle actin expression fixed biopsies were used, and for titin and cardiotin unfixed biopsies were used.

\section{Acknowledgement}

Part of this work is upported by the Dutch Heart Foundation MW-NHS 92.316 (G.S)

\section{Conclusions}

Chronic hibernating cardiomyocytes exhibit protein expression and distribution patterns resembling those of the embryonic phenotype. The punctated expression of titin and the diffuse appearance to complete absence of cardiotin argue in favor of this hypothesis. The re-expression of $\alpha$-smooth muscle actin in the hibernating cardiomyocytes fully substantiates the notion that these cells have adopted an embryonic phenotype. It is therefore suggested that cardiomyocytes in chronic hibernating myocardium have acquired cellular aspects of dedifferentiation. There were no myocytes in which cardiotin was virtually absent and in which titin remained intact, but no sequence of events of the changes affecting the cytoskeletal and contractile proteins during hibernation could be defined. 


\section{References}

1. Rahimtoola SH: A perspective on the three large multicenter randomized clinical trials of coronary bypass surgery for chronic stable angina. Circulation 1985; 72: V-123-135.

2. Rahimtoola SH: The hibernating myocardium. Am Heart J 1989;117:211-221.

3. Ross J: Myocardial perfusion-contraction matching. Implications for coronary heart disease and hibernation. Circulation 1991; 83:1076-1083.

4. Schelbert HR: Positron emission tomography for the assessment of myocardial viability. Circulation 1991; 84:1-122-131.

5. Borgers $M$ and Flameng $W$ : Morphology of the acute and chronic ischemic myocardium in man. Ischemia-reperfusion in candiac surgery. Edited by Piper HM and Preusse CJ. Boston Kluwer Academic Publishers 1993; pp353-375.

6. Borgers M, Thoné F, Wouters L, Ausma I, Shivalkar B, Fllameng W: Structural correlates of regional myocardial dysfunction in patients with critically coronary artery stenosis: chronic hibernation? J Cardiovasc Pathol 1993; 2:237-245.

7. Vanoverschelde J-LJ, Wijns W, Depré C, Essamri B, Heyndricks GR, Borgers M, Bol A, Melin $\mathrm{J}$ : Mechanisms of chronic regional postischemic dysfunction in humans: new insights from the study of non-infarcted collateral dependent myocardium. Circulation $1993 ; 87: 1513-1523$.

8. Maes A, Shivalkar B, Flameng W, Nuyts J, Borgers M, Ausma J, Bormans G, Schiepers C, De Roo M, Mortelmans L: Histological alterations in chronically hypoperfused myocardium: correlation with PET findings. Circulation 1994; in press.

9. Danto BI, Fischman DA: Immunocytochemical analysis of intermediate filaments in embryonic heart cells with monoclonals to desmin. J Cell Biol 1984; 98:2179-2191.

10. Tokuyasu $\mathbb{K T}$, Maher PA: Immunocytochemical studies of cardiac myofibrillogenesis in early chick embryos. I. Presence of immunofluorescent titin spots in premyofibril stages. J Cell Biol 1987; 105:2781-2793.

11. Tokuyasu KT, Maher PA: Immunocytochemical studies of cardiac myofibrillogenesis in early chick embryos. II Generation of a-actinin dots within titin spots at the time of the first myofibril formation. J Cell Biol 1987; 105:2795-2801.

12. Schart $\mathrm{G}$, Viebahn $\mathrm{C}$, Langmann $\mathrm{W}$, Ramaekers FCS: Desmin and titin expression in early postimplantation mouse embryos. Development 1989; 107:585-596.

13. Van der Loop FTL, Schaart G, Langmann W, Ramaekers FCS, Viebahn Ch.: Expression and organisation of muscle specific proteins during early development stages of the rabbit heart. Anat Embryol 1992; 185:439-450.

14. Hortwits $\mathrm{R}$, Podolsky $\mathrm{RJ}$. The positional stability of which filaments in activated skeletal muscle depends on sarcomere length: evidence for the role of titin filaments. J Cell Biol 1987; 105: 2217-2223.

15. Schart G, Van der Ven PFM, Ramaekers FCS: Characterization of cardiotin, a structural component in the myocard. Eur J Cell Biol 1993; 62:34-48.

16. Woodcock-Mitchell J, Mitchell JJ, Low RB, Kieny M, Sengel P, Rubbia L, Skalli O, Jackson B, Gabbiani $\mathrm{G}$ : $\alpha$-Smooth muscle actin is transiently expressed in embryonic rat cardiac and skeletal muscles. Differentiation 1988; 39:161-166. 
17. Babai $F$, Musir-Aghdam J, Schurch W, Royal A, Gabbiani G: Coexpression of $\alpha$ sarcomeric, a-smooth muscle actin and desmin during myogenesis in rat and mouse embryos I. Skeletal muscle. Differentiation 1990;44:132-142.

18. Bochaton-Piallat M-L, Ropraz P, Gabbiani G, Santeusanio G. Palmieri G, Schiaroli S, Spagnoli LG: Actin isoform and intermediate filament protein expression in human developing skeletal muscle. BAM 1992; 2:83-87.

19. Flameng W, Wouters $L_{\text {, Sergeant }}$, Lewi P, Borgets M, Thone F, Suy R: Mullivariate analysis of angiographic histologic and electrocardiographic data in patients with coronary heart disease. Circulation 1984; 70*7-17.

20. Wang S-M, Greaser ML: Immunocytochemical studies using a monoclonal anitbody to bovine cardiac titin on intact and extracted myofibrils. J Muscle Res Cell Motil 1985; $6: 293-312$

21. Greaser ML, Handel SE, Wang S-M, Schultz E, Bulinski JC, Lessard JL: Assembly of titin, myosin, actin and tropomyosin into myofibrils in cultured chick cardiomyocytes. Cellular and molecular biology of muscle development. Edited by Stockdale F, Kedes L. UCLA Symposium on molecular and cellular biology. New York, New Series 1989; $93: 246-257$.

22. Handel SE, Wang S-M, Greaser ML, Schultz E, Bullinski JC, Lessard JL: Skeletal muscle myofibrillogenesis as revealed with monoclonal antibody to titin in combination with detection of the alpha and gamma isoforms of actin. Dev. Biol 1989; 132:35-44 .

23. Skalli O, Ropraz P, Trzeciak A, Benzonana G, Gillesen D, Gabbiani G: A monoclonal antibody against $\alpha$-smooth muscle actin: a new probe for smooth muscle differentiation. J Cell Biol 1986;103:2787-2796.

24. Skalli O, Gabbiani G, Babaï F, Seemayer TA, Pizzolato G, Schürch W: Intermediate filament proteins and actin isoforms as markers for soft tissue tumor differentiation and orgin. II Rhabdomyosarcomas. Am J Path 1988; 130: 515-531.

25. Debus E, Weber K, Osborn M: Monoclonal antibodies to desmin, the muscle specific intermediate flament. EMBO J 1983; 2:2305-2312.

26. Pieper FR, Schaart G, Krimpenfort PJ, Hendrik JB, Moshage HJ, van de Kemp A, Ramaekers FCS, Berns A, Bloemendal H: Transgenic expression of the muscle specific intermediate filament protein desmin in non-muslce cells. J Cell Biol 1989; 108:1009. 1024.

27. Raats FR, Henderik JB, Verdijk M, van Oort FLG, Gerards WLM, Ramaekers FCS, Bloemendal H: Assembly of the carboxy-terminally deleted desmin in vimentin free cells. Eur J Cell Biol 1991; 56:84-103.

28. Bader D, Masaki T, Fischman DA: Immunochemical analysis of myosin heavy chain during avian myogenesis in vivo and in vitro. J Cell Biol 1982; 95:763-770.

29. Ausma I, Ramaekers F, Flameng W, Borgers M: Cellular adaptation in hibernating myocardium in man. Cardiac adaptation and failure. Edited by Hori M, Maruyama Y, Reneman RS. Tokyo, Springer-Verlag 1994; in press. 
30. Borgers $M$, De Nollin S, Thone F, Wouters L, Van Vaeck L, Flameng W: Distribution of calcium in a subset of chronic hibemating myocardium in man. Histochem J 1993; 25:31:2-318.

31. Borisov AB: Myobrilogenesis and reversible disassembly of myofibrils as adaptive reactions of cardiac muscle cells. Acta Physiol Scand 1991: S599:71-80.

32. Sharp WW, Terracio $\mathbb{L}$, Borg TK, Samarel AM: Contractile activity modulates actin synthesis and turnover in cultured neonatal rat heart cells. Circ Res $1993 ; 73: 172-183$.

33. Thompson EW, Marino TA, Uboh CE, Kent RL, Cooper G: Atrophy reversal and cardiocyte redifferentiation in reloaded cat myocardium. Circ Res 1984; 367-377.

34. Manasch FJ: Mitosis in developing cardiac muscle. J Cell Biol 1968; 37:91-196.

35. Morano I, Hadiche K, Koch A, Schwinger $R$, Böhm M, Bartel S, Erdman E, Krause G: Titin, myosin light chains and C-protein in the developing and failing human heart. I Mol Cell Cardiol 1993; 25:S131.

36. Wang S-M, Greaser ML, Schultz E, Bulinski JC, Lin JJC, Lessard JL: Studies on cardiac myofibrilogenesis with antibodies to titin, actin, tropomyosin and myosin. I Cell Biol 1988; 107:1075-1083.

37. Van der Ven PMF, Schaart G, Jap PHK, Sengers RCA, Stadhouders AM, Ramaekers FCS: Differentiation of human skeletal muscle cells in culture: maturation as indicated by titin and desmin striation. Cell Tissue Res 1992; 270:189-198.

38. Van der Ven PMF, Schaart G, Croes HJE, Jap PHK, Ginsel LA, Ramaekers FCS: Titin aggregates associated with intermediate filaments align along stress fiber-like structures during human skeletal muscle cell differentiation. J Cell Sci 1993; 106:749-759.

39. Eppenberger ME, Hauser I, Baechi T, Schaub MC, Brunner UT, Dechesne CA, Eppenberger HM: Immunocytochemical analysis of the regeneration of myofibrils in long-term cultures of adult cardiomyocytes of the rat. Dev Biol 1988; 130:1-15.

40. Eppenberger-Eberhardt ME, Flamme I, Kurer V, Eppenberger HM: Reexpression of $\alpha$ smooth muscle actin isoform in cultured adult rat cardiomyocytes. Dev Biol 1990; 139:269-278.

41. Messerli JM, Eppenberger-Eberhardt ME, Rutishauser BM, Swarb P, von Arx P, KochScheidemann S, Eppenberger HM, Perriard J-C: Remodelling of cardiomyocyte cytoarchitecture visualized by three-dimensional (3D) confocall microscopy. Histochem $1993 ; 100: 193-202$. 


\title{
Chapter 3 \\ Molecular changes of titin in left ventricular dysfunction as a result of chronic hibernation
}

\author{
Jannie Ausma, Dieter Fürst, Fred Thoné. Bharati Shivalkar, Willem Flameng,
} Klaus Weber, Frans Ramaekers and Marcel Borgers

J. Mol. Cell. Cardiol. 27: 1203-1212 (1995)

\begin{abstract}
Cardiomyocytes of chronic hibernating myocardium are affected by partial to complete loss of sarcomeres, accumulation of glycogen, adaptations in size and shape of mitochondria, reorganisation of nuclear chromatin and depletion of sarcoplasmic reticulum. The nature of these changes, which from a purely morphologic viewpoint are akin to dedifferentiation, needed further clarification at the molecular level. For this purpose we have studied the expression and reorganization of titin, one of the earliest markers of cardiomyocyte differentiation. By use of monoclonal antibodies, recognizing different epitopes distributed over the whole length of the titin molecule, we were able to detect changes in its molecular organization as a result of chronic hibemation. The epitopes of the titin molecule attached to the Z-disc and those present close to the M-line remained detectable at all stages of hibernation, while epitopes at the A-I junction and parts of the myosin anchoring region of the molecule became masked or were lost. A fragmented or punctated appearance of the titin staining pattern with antibodies to A-I junction related epitopes is found in cells which we consider to represent a more advanced stage of dedifferentiation. Changes in the distribution of the titin molecule or its molecular environment in hibernating myocardium resemble at least in part changes occurring during muscle cell differentiation, although in reversed order.
\end{abstract}




\section{Introduction}

The term "hibernating myocardium" was coined by Rahimtoola (1985) to describe a state of left ventriclular dysfunction in patients with coronary artery disease in the absence of myocardial infarction. This process is, at least partially, reversible upon restoration of blood flow to the affected segment. The hibernating response of the heart has been considered as an act of self preservation to cope with a reduced myocardial blood flow (Rahimtoola, 1989). The recovery of function is described to be either rather quick (acute hilternation) or slow to very slow (chronic hibernation) (Rahimtoola, 1989; Ross, 1991; Schelbert, 1991).

Recently Borgers et al. (1993 a,b) described the morphologic changes of cardiac biopsies obtained from 98 patients with left ventricular ischemic dysfunction. The typical structural changes, noted in cardiomyocytes of almost all patients, included loss of sarcomeres, the presence of abundant plaques of glycogen, loss of sarcoplasmic reticulum, occurrence of rough endoplasmic reticulum, shape changes of mitochondria and redistribution of nuclear chromatin. It was proposed that segments in which these structural changes prevail are characteristic of chronic hibernating myocardium and most probably are those that do not recover immediately after revascularization. Instead they might showed a delayed recovery of function (weeks to months), because structural remodeling requires time in order to regain sufficient contractile material (Rahimtoola, 1989; Schelbert, 1991; Vanoverschelde et al., 1993). The characteristic change of hibernating cells concerns the replacement of contractile material (sarcomeres) by glycogen, a phenomenon that always starts in the perinuclear area of the cell and gradually extends towards the periphery in most altered cells. Since the lack of contractile filaments, the presence of accumulated glycogen (Manasek, 1986) and the preference of glucose over fatty acids as energy source (Harary, 1979) are characteristic features of embryonic cells, these criteria are considered as hallmarks suggesting that hibernating cells going through a proces of dedifferentiation:

In biopsies derived from patients with chronic hibernating myocardium the expression, organisation and assembly of markers of cardiac cell development were studied to support the dedifferentiation hypothesis of hibernating cells. Titin was chosen as a dedifferentiation marker. Titin is a giant elastic protein of half sarcomere length, spanning the distance from the Z- to M-line (Fuirst et al., 1988; 1989a). Protein sequences derived from cDNA cloning show that the carboxyterminal end of titin is at the M-band (Labeit et al., 1992). It is one of the earliest markers of cardiomyocyte differentiation (Tokuyasu and Maher, 1987; Wang et al., 1988a; Schaart et al., 1989; Schultheiss et al., 1990; Van der Loop et al. 1992). In this study the sequence of organisational and redistributional changes of titin in hibernating myocardial cells, were monitored with antibodies to different epitopes of the titin molecule. 


\section{Materials and methods}

Parients

The human cardiac tissue material used in this study consisted of transmural biopsies obtained from 17 patients at the time of coronary bypass surgery. All patients gave their informed consent. The study was approved by the local ethical committees for research. The detailed individual patient characteristics are described in previous papers (Vanoverschelde et al., 1993; Maes et al.,1994). In brief, all patients had severe LAD stenosis and marked anterior wall abnormalities as evaluated by angiography and $2 \mathrm{D}$ echocardiography. The viability of the myocardium was verified by Positron Emission Tomography (PET) and by the assessment of function 3-6 months after coronary bypass surgery. All patient material dealt with in this paper fulfilled the criteria of chronic hibernation as defined previously (Vanoverschelde et al., 1993; Maes et al.,1994).

\section{Morphologic evaluation}

Of all patients a first biopsy was fixed for a minimum of $2 \mathrm{hr}$ in $3 \%$ glutaraldehyde buffered with $90 \mathrm{mM} \mathrm{KH}_{2} \mathrm{PO}_{4}$, washed in the buffer and postfixed for $1 \mathrm{hr}$ in $2 \%$ $\mathrm{OsO}_{4}$ buffered with $50 \mathrm{mM}$ veronal acetate, dehydrated in a graded series of ethanol and embedded in epoxy resin (Epon) (Flameng et al., 1984). Light microscopic evaluation of morphologic changes was performed on $2 \mu \mathrm{m}$ thick sections of Eponembedded biopsies, which were stained with periodic acid Schiff (PAS) and $0.1 \%$ toluidine blue to quantify the glycogen content and the loss of myofibrils. The degree of cellular change was evaluated in cells where the nucleus was visible in the plane of the section. The number of cells affected by myolysis was obtained by evaluating at least 200 cells per biopsy.

Left ventricle biopsies derived from 7 donor hearts, which were either used for orthotopic transplantation or homograft prelevation, also used in a previously published study (Borgers et al. 1993), were treated as above and served as nonischemic controls.

\section{Indirect immunofluorescence assays}

A second biopsy of the hibernating myocardium was quickly frozen in isopentane pre-cooled with liquid nitrogen. Five micron thick sections were air-dried before use, and treated with $0.5 \%$ Triton X-100 (BDH Chemicals Lid., Poole, UK) in phosphate-buffered saline (PBS) for $5 \mathrm{~min}$ at room temperature, followed by washing in PBS. The sections were incubated with the primary antibodies for 45 min at room temperature and washed with PBS (three steps of 10 min each). They were subsequently incubated with the secondary, fluorescein isothiocyanate (FITC) conjugated goat-anti-mouse Ig-subclass specific antibody (Southern Biotechnology Associates (SBA) Inc, Birmingham, USA), or goat-anti-rabbit antibody (SBA) for polyclonal antisera for $45 \mathrm{~min}$ and then washed in PBS (three steps of $10 \mathrm{~min}$ each). 
In the double-labelling procedure the immunostaining steps were repeated with second primary antibody of another Ig-subclass, the sections were washed in PB: and then incubated for $45 \mathrm{~min}$ with the secondary, Texas Red conjugated Ig subclass specific antibody (SBA, Birmingham, AL, USA).

After these immunohistochemical procedures the sections were placed in distille water for $5 \mathrm{~min}$, followed by postfixation in methanol for $5 \mathrm{~min}$. The sections wen air-dried and mounted in Mowiol (Hoechst, Frankfurt a.M., Germany) (Osborn an Weber, 1982). Nuclei were routinely stained with $4^{2}-6$-diamidine 2-a-phenylindol (DAPI: Sigma Chemicals, St. Louis, USA) in a dilution of 1:10000 with PBS. As : control, application of the first antibody was omitted.

\section{Confocal scaning laser microscopy}

Double label immunostained myocardium sections were observed with a Bio-Rac MRC-600 confocal scanning laser microscope (Bio-Rad Laboratories, Richmond CA, USA) equipped with a Krypton/Argon mixed gas laser (Ion Laser Technology Salt Lake City, UT, USA) with two separate wavelenghts for the excitation of fluorescein isothiocyanate $(488 \mathrm{~nm})$ and Texas Red $(568 \mathrm{~nm})$ and mounted on a Zeiss Axiophot microscope (Carl Zeiss, Oberkochen, Germany).

\section{Antibodies}

The following antibodies were used in this study: The epitopes of the titin antibodies have been schematically presented in Fig 1 .

1) pTitin, a rabbit polyclonal antibody against titin which reacts the $A$ band and the A-I junction but not with the I band or the $Z$ disc (Gassner, 1986). 2) A mouse monoclonal antibody $9 D 10$ to titin. This antibody recognizes an epitope in the Iband at the A-I junction in skeletal and cardiac muscle (Wang and Greaser, 1985; Wang et al., 1988a; Greaser et al., 1989; Handel et al., 1989). The 9D 10 monoclonal antibody was developed by $M$. Greaser and obtained from the Developmental Studies Hybridoma Bank maintained by the department of Pharmacology and Molecular Sciences, Johns Hopkins University School of Medicine, Baltimore MD 21205, USA and the department of Biology, University of Iowa, Iowa City IA, USA, under contract N01-HD-2-3114 from the NICHD. 3) T30, a mouse monoclonal titin antibody which reacts with repetitive sequences of the A-band. T30 detects 5 of the $7 \mathrm{C}$-stripes, that coincide with binding places for myosin associated proteins, i.e. the C-protein and H-protein (Fürst et al., 1989a). 4) T31, at mouse monoclonal titin antibody which reacts with repetitive sequences of the A-band. T31 detects both P-stripes that coincide with binding places of the $\mathrm{H}$ protein (Fürst et al., 1989a). 5) T12, a mouse monoclonal titin antibody which reacts with an epitope in the I-band just before the Z-disc (Fürst et al., 1988). 6) SR-1, a mouse monoclonal antibody recognizing striated muscle $\alpha$-actin (Skalli et al. 1988) (DAKO A/S, Glostrup, Denmark). 7) The mouse monoclonal desmin antibodies DE-R-11 (Debus et al., 1983) (DAKO A/S, Glostrup, Denmark) and 
RD301 (Schaart ef al., 1989; Raats et al, 1991). 8) MF 20, a mouse monoclonal antibody recognizing all forms of myofibrillar myosin heavy chain (Bader $e$ al., 1982). The MF 20 monoclonal antibody was developed by D. Fischman and obtained from the Developmental Studies Hybridoma Bank maintained by the department of Pharmacology and Molecular Sciences, Johns Hopkins University School of Medicine, Baltimore MD 21205, USA and the department of Biology, University of Iowa, Iowa City IA, USA, under contract NOL-HD-2-3114 from the NICHD. 9) MF 30 , a mouse monoclonal antibody, it recognizes the $S 2$ fragment of the myosin heavy chain of various neonatal and adult species (Bader et al, 1982). The MF 30 monoclonal antibody was developed by $D$. Fischman and obtained from the Developmental Studies Hybridoma Bank maintained by the department of Pharmacology and Molecular Sciences, Johns Hopkins University School of Medicine, Baltimore MD 21205, USA and the department of Biology, University of Iowa, Iowa City IA, USA, under contract N01-HD-2-31 14 from the NICHD. 10) The mouse monoclonal antibody TM311 which reacts with tropomyosin (Sigma Immunochemicals, St.Louis, USA) . 11) The mouse monoclonal vimentin antibody RV203 (Schaart et al., 1991). In addition rhodamine labelled phalloidin was used to stain F-actin (dilution 1:80 in PBS) (Molecular Probes Inc. Eugene, OR, USA).

\section{Results}

\section{Morphological changes}

The most important change in cellular substructure seen in a considerable number of myocardial cells from chronic hibernating myocardial segments was the depletion of contractile material without loss of cell volume. Loss of contractile material was in many cells limited to the vicinity of the nucleus, but in others it comprised the bulk of the cytoplasm, leaving only a few or no sarcomeres at the periphery of the cell (Fig. 2a). The myolytic areas, being the spaces in which myofilaments were dissolved, became occupied by glycogen and many small mitochondria (Fig. 2b). Cells were considered as atfected by the process of myolysis when more than $10 \%$ of the cell volume was occupied by glycogen (Borgers et al 1993b). Within a group of 17 patients $25 \pm 15 \%$ of all cells were affected. An increase in connective tissue was consistently observed in areas in which structurally affected myocardial cells prevailed (Fig. 2a).

\section{Immunofluorescence assays}

In parts of the myocardium which contained only normally structured cells the antibodies pTitin, T30 and 9D10, which label three different epitopes in the A-I junction part of titin (Fig. 1), showed a similar double-banded cross-striated pattern (Fig. 3a). Hibernating cells with perinuclear myolysis showed the same distribution pattern. However, in those cells the cross-striated staining pattern was limited to the peripherally located sarcomere strands (Fig. 3b). In most hibernating cells with a severe degree of myolysis, the double-banded staining-pattern was absent for the 


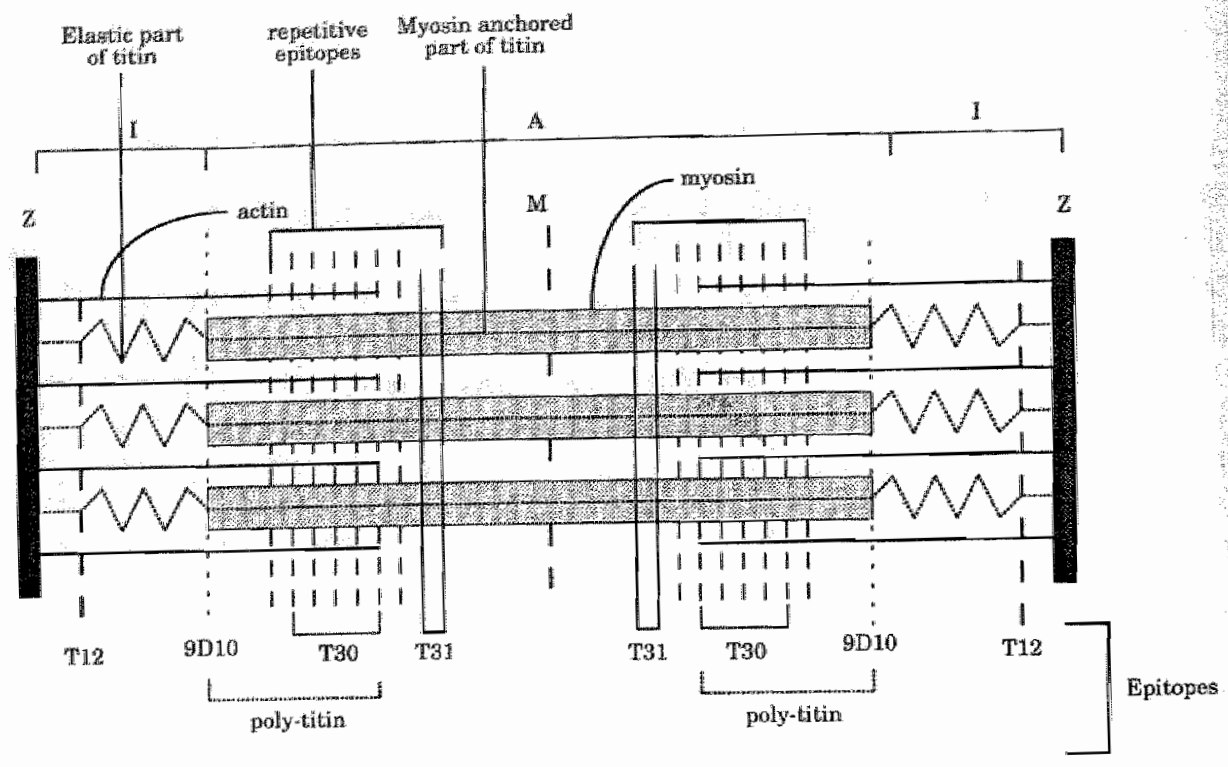

Figure 1. Schematic representation of the topography of the epitopes recognized by the different anti-titin antibodies. $Z: Z$ line, $M$ : center of the $M$ band. $A$ and I mark the anisotropic and isotropic bands respecrively.

three antibodies. This disappearance of a titin cross-striated staining pattern for the antibodies 9D10, T30 and pTitin seems to be a stepwise process, the earliest observed change was the loss of double-banded titin staining and the occurrence of the titin staining pattern as single bands (Fig. 3c). In addition, the staining intensity was markedly lower as compared to normal cells. In more severely affected cells the striation patterns of titin normally crossing the whole cardiomyocyte, was limited to certain parts of the cell. The titin striations were lost, only locally some short titin striations remained (Fig. 3c). In the most severely affected areas, 9D10, T30 and pTitin showed an even more distinct decrease of the titin cross-striations. Many cells lost their cross-striated staining pattern or showed a punctate (dot-like) staining reaction (Fig. 3d).

In contrast to pTitin, 9D10 and T30 the cross-striated staining pattern of T12, which recognizes an epitope at the 1 -band just before the Z-line, and T31 recognizing two repetitive epitopes close to the centre of the A-band, were retained throughout the various stages of myolysis (Figs 4a-d). With these two antibodies titin striations were seen at a regular distance in the sarcomeres of the hibernating cells. There were no differences in the staining patterns with these anti-titin antibodies in different zones of the chronic hibernating myocardium (Fig. 4a,c). From double- 

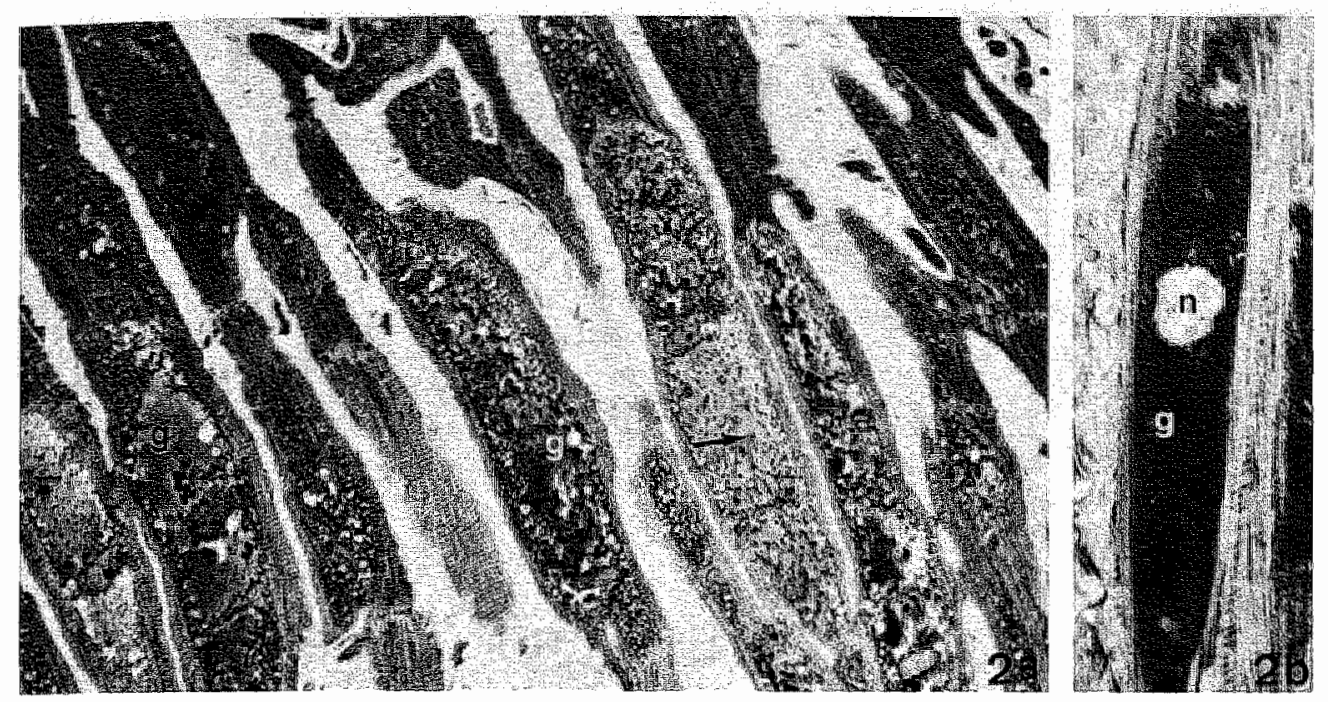

Figure 2, Light microscopy of morphologic changes in chronic hibernating myocardium. (a) Two micron thick section of an affected area, stained with tolwidine blue showing that the centers of most cells are myolytic. The myolytic areas are filled with amorphous material (glycogen, g) intermingled with small dots (mitochondria, arrow). Increased amounts of connective tissue material suround the cardiomytes. Magnification: X440. (b) Severely hibernating cells with large amounts of glycogen $(\mathrm{g})$ seen as dark zones surounding the nucleus (n) subsequent to PAS staining. Magnification: X575

labelling immunofluorescence studies it was obvious that the organisation of titin nearby the Z-line (T12) and close to the centre of the A-band (T31) was still intact while in the same cells the cross-striated titin staining patterns for epitopes at the first part of the A-band and A-I junction were completely lost (Figs $4 a$, b and 4c.d).

In contrast to the titin disorganisation, other sarcomeric proteins remained well organized in the sarcomeres. Even in zones with severe changes in 9D10, T30 and p Titin staining, actin, myosin, tropomyosin and desmin still showed clear crossstriations, similar to those as seen in the sarcomeres of normal myocardium. As an example, the staining pattern of desmin in relation to the titin 9010 epitope is shown in the figures $5 \mathrm{a}$ and $5 \mathrm{~b}$. In figures $5 \mathrm{c}$ and $5 \mathrm{~d}$ confocal laser scanning microscopic pictures of myosin and titin are showm. The sarcomeres in this figure have a clear cross-striated myosin pattern, while the titin epitope recognized by 9D 1.0 is scarely visible. a-Smooth muscle actin became re-expressed in chronic hibenating myocardium cells, but vimentin expression was not detected in the dedifferentiating cardiomyocytes.

In order to investigate the localization in relation to the $Z$ - and $M$-line and distance of different titin epitopes during stages of dedifferentiation of chronic hibernating 

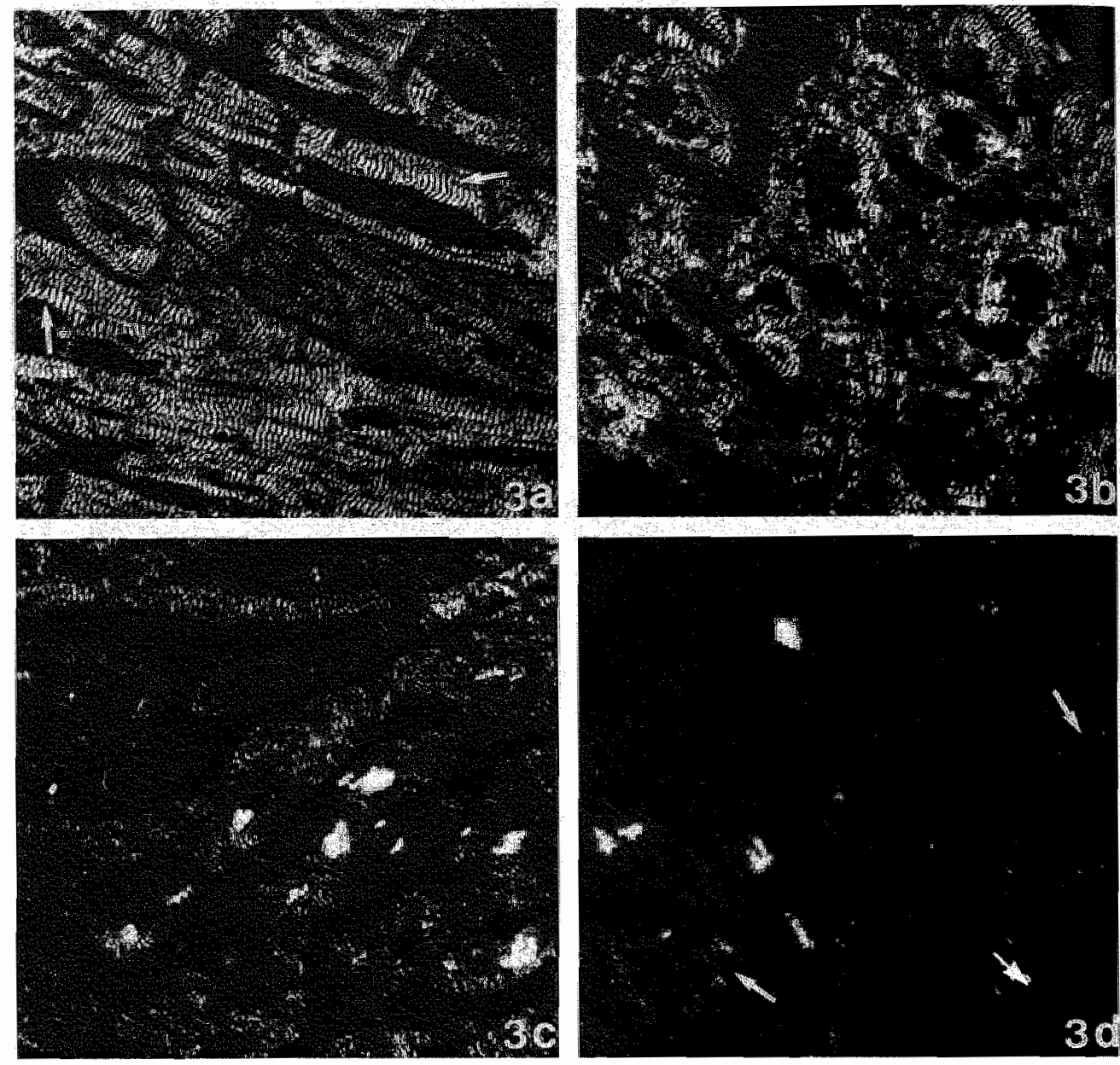

Figure 3. Immunofhorescence micrographs of frozen sections of myocardium of patients with chonic hibernation, incubated with antibodies against the A-I junction part of titin. As an example the 9010 staining is shown. (a) Tith staining in a nearly normal pattern. Double-banded coss-striations are indicated by arrows. (b) Cells in which sarcomeres are located only at the periphery of the cell. Most of these cells showed typical double-banded striations at weiv periphery. (c) Marked dectease of titin staining in chronic hibernating myocardium: only shor titin striations and titin punctations. (d) Only a residual staining is present (arrows). The large dots which are visible around the nucle represent lipofuchsin anofliworescence. Magnification: X430. 

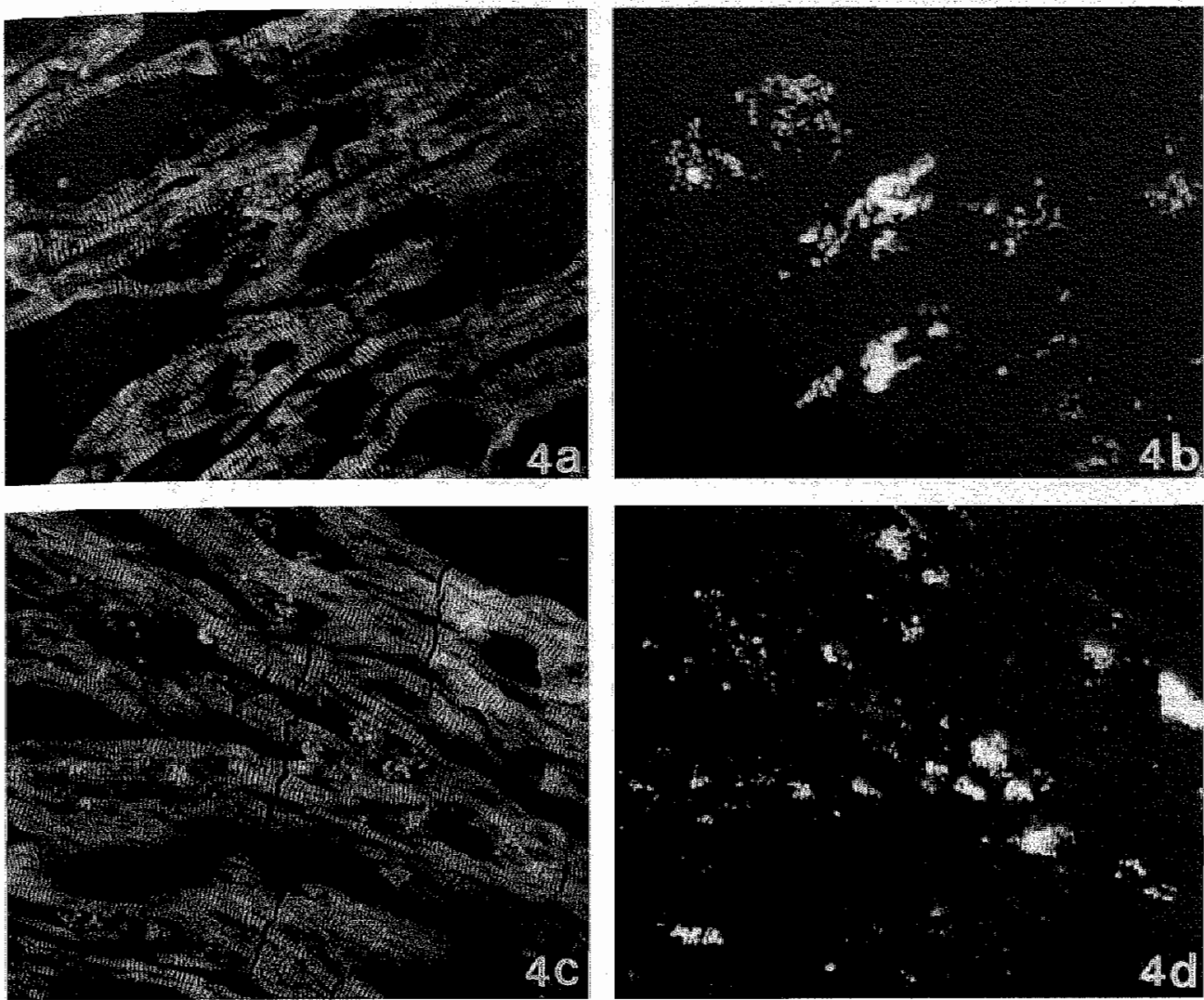

Figure 4. (a,b) Double-labelling of a section of chronic hibernating myocardium with two anti-titin antibodies, one which recognizes the I-band part of titin nearby the Z-line (TI2) and the other recognizes the A-I junction part (9DIO). Note that T12 sraining remained intact in severely affected cardiomyocytes (a), while 9Dlo staining was almost completely lost (b). (c,d) Double-labelling of a section of chronic hibernating myocardium with two anti-titin antibodies, one which recognizes the A-I junction part (9D/O) and the other which recognizes the A-band part of titin nearby the M-line (T31). T31 staining remand intact in the severely affected cardiomyocytes $(c)$, while 9010 staining was totally absent (d). Magnification. $X 430$.

myocardium confocal scanning laser microscopy analysis was performed. The litin epitopes recognized by T31 never coincide with the Z-disc (desmin positive), indicating that the titin epitopes at the centre of the A-band have not dramatically changed their position within the remaining sarcomeric structure. 

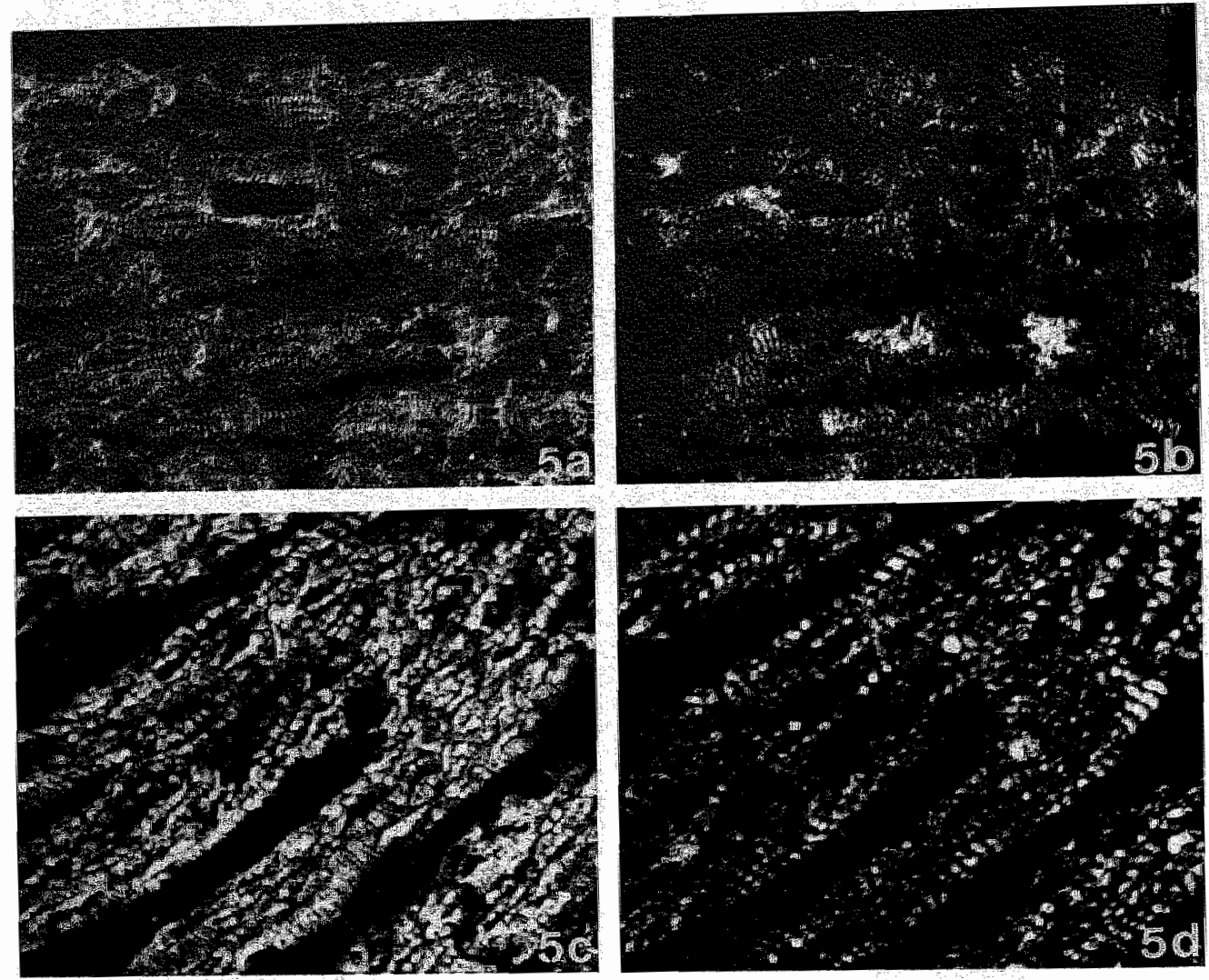

Figure 5. (a,b) Double-labelling of a section of chronic hibernating myacardium with desmin and titin (9D10). (a) Desmin staining still remains intact in these cells while (b) titin, on the other hand is only seen as spots and short striations. (c,d) Confocal laser scanning microscopy of a chrowic hibernating segment with myosin staining (MF-20) display in a clear cross striated pattem (c), whereas only some tivin $(9010)$ is seen (d).

Magmificarion: $a, b \times 420 ; c, d \times 1150$.

\section{Discussion}

Cardiomyocytes of chronic hibemating myocardium undergo typical ultrastructural changes of which the replacement of sarcomeres by glycogen is the hallmark (Borgers et al., 1993b: Ausma et al., 1994). These observations have been considered as morphologic indicators of cardiomyocyte dedifferentiation. In addition, recent studies (Ausma et al., 1995) showed that $\alpha$-smooth muscle actin, a protein that gradually disappears from cardiomyocytes during development, became re-expressed in hibernating cardiomyocytes. Also titin, which is one of the earliest sarcomeric proteins during embryogenesis, appeared to change its immunocytochemical detectability in hibernating cardiomyocytes. Other 
sarcomeric and cytoskeletal proteins such as actin, myosin, tropomyosin and desmin remained intact in sarcomeres at the periphery of the hibernating cardiomyocytes.

\section{Effects of hibernation on the titin molecular srructure}

Studying the organisation of titin with monoclonall antibodies against different epitopes situated along this large molecule provides new insights into structural changes of this protein during hibernation. The use of antibodies directed to the epitopes of the titin molecule present at the A-band and the A-I junction of the sarcomere revealed that this part of the molecule is masked or lost in hibernating cells. On the other hand, the epitope of $\mathrm{T} 12$, localized in close proximity to the Zline and the T31 epitope, known to be situated at the centre of the A-band, remained detectable during the process of heart muscle cell adaptation. These results strongly indicate a change in the structure of the titin molecules, in particular, in its normally rigid middlle part. In the $\mathrm{N}$-terminus ( $\mathrm{Z}$-line part) and the C-terminus (M-line part) of titin seems to remain intact during hibernation. Changes at the molecular level, either occurring in the titin molecule itself or in its molecular assembly with other sarcomeric proteins, apparently start at part of titin anchored to myosin (recognized by pTitin and T30) as well as the junction between the elastic and rigid part of the molecule (recognized by 9D10). The absence of titin staining at this part of the molecule can be the result of proteolytic degradation, but it is also possible that it results from a change in the molecular environment of the titin molecules. When analysed in more detail, T30 and T31 monoclonal antibodies were shown to recognize repetitive epitopes in the titin molecules, that coincide with the binding places of specific myosin associated proteins, i.e. the C-protein and $\mathrm{H}$-protein. The T31 epitope coincides with the two P-stripes, which contain only the H-protein. The T30 epitope coincides with five of the seven C-stripes, places on which both C-protein and the H-protein are attached to myosin. It has been suggested that C-protein interacts with titin (Furst et al.1992, Koretz et al. 1993). Differences in titin epitope detectability during (de)differentiation might well be related to changes in the molecular environment of titin, resulting from a change in the interaction between $\mathrm{C}$-protein and titin.

The A-band region of titin has been shown to become extensible when it is detached from myosin (Wang et al.1988b, Higuchi et al.1992). Higuchi et al.(1992) also showed that during partial depolymerization of thick filaments, the anti-titin antibodies recognizing a specific position in the A-band showed immunoreactivity at a constant distance from the M-line. As the thick filament almost completely was depolymerized, these titin antibodies were found to localize at the Z-line, suggesting detachment of the titin molecule from the M-line anchoring. In chronic hibernating myocardium on the other hand, the thick filaments are still present and as a result T31 immunostaining is still normal, indicating that titin is not detached from the M-line of the thick filaments. 
Changes in titin during chronic hibernation: differentiation in reverse?

Borisov (1991) has described that cardiac muscle cells at early, intermediate and terminal stages of differentiation are capable of adaptive remodeling of their contractile system both in vivo and in vitro. This implies that dedifferentiated cardiomyocytes can redifferentiate again. Moreover, Sharp et al (1993) established that in verapamil-arrested cultured neonatal rat heart cells, in which initially a steep reduction in the amount of actin was observed, the process could be entirely reversed upon omission of the drug. During chronic hibernation hypo/akinesia may lead to a similar reduction in the amount of contractile material, hence indicating a process of dedifferentiation to a state comparable with neonatal cardiomyocytes.

The loss of the titin epitope stained by antibody 9D10 in chronic hibernating myocardial cells started with the fragmentation of titin striations, ultimately leading to dot-like staining. A similar punctate pattern was also seen with 9D10 during cardiac and skeletal myofibrillogenesis at the onset of the formation of myofibrils (Tokuyasu and Mayer, 1987; Wang et al., 1988a,b; Schaart et al., 1989; Schultheiss et al, 1990; Van der Loop et al., 1992), and during skeletal muscle cell differentiation in culture (Van der Ven et al, 1992;1993).

The persistence of a "normal" T31 epitope staining pattern in affected cardiomyocytes seems in conflict with the idea that titin organization starts at the Zline and progresses towards the $M$ band (Fürst et al., 1989b) as deduced from comparing changing titin organization during in vivo or in vitro differentiation processes with that of apparently dedifferentiating hibernating cells. During myofibril formation in mouse skeletal muscle the T30 and T31 epitopes of titin are revealed simultanously (Fürst, unpublished observation). However, during dedifferentiation in hibernating myocardium, the T31 epitope is still detectable, whereas the T30 epitope is not. It is assumed that the adaptive dedifferentiation process during hibernation take considerably more time than embryonic differentiation. Therefore, it is possible that such subtle differences in the organization of distinct A-band titin epitopes cannot be detected during skeletal muscle development of the mouse, because of the relatively high speed of differentiation. Likewise, the localization of titin A-band epitopes has not yet been documented in developing human cardiac muscle. Therefore, it cannot be excluded that species differences as well as variations in the organization of the sarcomeres of skeletal and cardiac muscle cause this apparent discrepancy. Also, dedifferentiation of chronic hibernating myocardium is not complete, as indicated by the lack of vimentin expression. The most plausible explanation for the observed differences in titin organization during hibernation and myofibrillogenesis, respectively, may be that in the dedifferentiation process is not completely revert at all the steps of sarcomere assembly. 


\section{Acknowledgements}

We are grateful to Dr D. Gassner for the gift of polyclonal anti-titin antibodies. We thank Dr G. van Eys and Dr G.Schaart for critically reading the manuscript.

\section{References}

Ausma J, Ramaekers F, Shivalkar B, Thoné F, Flameng W, Borgers M, 1994. Cellular adaptation in hibernating myocardium in man. In: Hori $M$, Maruyama $Y$, Reneman RS (eds.) Cardiac adaptation and failure. Springer-Verlag, Tokyo 85-99.

Ausma I, Schaart G, Thoné F, Shivalkar B, Flameng W, Depré C, Vanoverschelde J-L, Ramaekers $F$, Borgers $M$, 1995. Chronic ischemic viable myocardium in man: aspects of dedifferentiation. Cardiovasc Pathol 4: $29-37$.

Bader D, Masaki T, Fischman DA, 1982. Immunochemical analysis of myosin heavy chain during avian myogenesis in vivo and in witro. I Cell Biol 95: 763-770.

Borgers $M$ and Flameng W, $1993 \mathrm{a}$. Morphology of the acute and chronic ischemic myocardium in man. In: Piper HM and Preusse CJ (eds.) Ischemia-reperfusion in cardiac surgery. Kluwer Academic Publishers, 353-375.

Borgers M, Thoné F, Wouters L, Ausma J, Shivalkar B, Flameng W, 1993b. Structural correlates of regional myocardial dysfunction in patients with critically coronary artery stenosis: chronic hibemation? Cardiovasc Pathol 2:237-245.

Borisov AB, 1991. Myofibrillogenesis and reversible disassembly of myofibrils as adaptive reactions of cardiac muscle cells. Acta Physiol Scand 5599: 71-80.

Debus $\mathrm{E}$, Weber K, Osborn M, 1983. Monoclonal antibodies to desmin, the muscle specific intermediate filament. EMBO J 2: 2305-2312.

Flameng W, Wouters L, Sergeant $P_{*}$ Lewi P, Borgers M, Thoné F, Suy R, 1984. Multivariate analysis of angiographic histologic and electrocardiographic data in patients with coronary heart disease. Circulation 70:7-17.

Fürst DO, Osborn M, Nave R, Weber K, 1988. The organisation of titin filaments in the half-sarcomere revealed by monoclonal antibodies in immunoelectron microscopy: a map of ten non-repetitive epitopes starting at the Z line extends close to the $M$ line. I Cell Biol 106: $1563-1572$.

Fürst DO, Nave R, Osborn M, Weber K, 1989a. Repetitive litin epitopes willh a $42 \mathrm{~nm}$ spacing coincide in relative position with known $A$ band striations also identified by major myosin-associated proteins. An immunoelectron-microscopical study on myofibrils. J Cell Sci 94: 119- 125 .

Fürst DO, Osborn M, Weber K, 1989b. Myogenesis in the mouse embryo: Differential onset of expression of myogenic proteins and the involvement of titin in myofibril assembly. J Cell Biol 109: 517-527.

Fürst DO, Vinkemeier U, Weber K, 1992. Mammalian skeletal muscle C-protein: purification from bovine muscle, binding to titin and the characterization of a full-length human cDNA. J Cell Sci 102: 769-778. 
Gassner D, 1986. Myofibrillar interaction of blot immunoaffinity-purified antibodies against native titin as studied by direct immunofuorescence and immunogold staining. Eur J Cell Biol 40: 176-184.

Greaser ML, Handel SE, Wang SM, Schultz E, Bulinski JC, Lessard JL, 1989. Assembly of titin, myosin, actin and tropomyosin into myofibrils in cultured chick cardiomyocytes: In Stockdale F, Kedes $L$ (eds) Cellular and molecular biology of muscle development. UCLA Symposium on molecular and cellular biology. New Series, Liss New York Vol 93: $246-257$.

Handel SE, Wang SM, Greaser ML, Schultz E, Bulinski JC, Lessard JL, 1989. Skeletal muscle myofibrillogenesis as revealed with monoclonal antibody to titin in combination with detection of alpha and gamma isoforms of actin. Dev Biol 132: 35-44.

Harary 1, 1979. Biochemistry of cardiac development: in vivo and in vitro studies. In: Berne RM et al.(eds.). Handbook of Physiology, section 2: The cardiovascular system, American Physiological Society, Baltimore, Vol I: 34-60.

Higuchi H, Suzuki T, Kimura S, Yoshioka T, Maruyama K, Umazume Y, 1992. Localization and elasticity of connectin (titin) flaments in skmed frog muscle fibres subjected to partial depolymerization of thick filaments. J Muscle Res Cell Motil 13: $285-294$.

Koretz JF, Irving TC, Wang K, 1993. Filamentous aggregates of native titin and binding of C-protein and AMP-deaminase. Arch Biochem Biophys 304: 305-309.

Labeit S, Gautel M, Lakey A, Trinick J, 1992. Towards a molecular understanding of titin. EMBO J 11: $1711-1716$.

Maes A, Flameng W, Nuyts J, Borgers M, Shivalkar B, Ausma J, Bormans G, Schiepers C, De Roo M, Mortelmans L, 1994. Histological alterations in chronically hypoperfused myocardium. Correlation with PET findings. Circulation 90, 735-745.

Manasek FJ, 1986. Mitosis in developing cardiac muscle. J Cell Biol 37: 191-196.

Osborn M, Weber K, 1982. Immunofluorescence and immuncytochemical procedure with affinity purified antibodies: tubulin-containing structures. Methods Cell Biol 24: 97 132.

Raats FR, Henderik JB, Verdijk M, van Oort FLG, Gerards WLM, Ramaekers FCS, Bloemendal H, 1991. Assembly of the carboxy-terminally deleted desmin in vimentin free cells. Eur J Cell Biol 56: 84-103.

Rahimtoola SH, 1985. A perspective on the three large multicenter randomized clinical triats of coronary bypass surgery for chronic stable angina. Circulation $72(\operatorname{suppl} V)$ : $123-135$.

Rahimtoola $\mathrm{SH}_{*}$ 1989. The hibemating myocardium. Am Heart J 117: $211-221$.

Ross J, 1991. Myocardial perfusion-contraction matching. Implications for coronary heart disease and hibernation. Circulation $83: 1076-1083$.

Schaart G, Viebahn C. Langmann W, Ramaekers FCS, 1989. Desmin and titin expression in arly postimplantation mouse embryos. Dewelopment 107: 585-596.

Schaart G, Pieper FR, Kuypers HJH, Bloemendal H, Ramaekers FCS, 1991. Baby Hamster kidney (BHK-21/C13) cells can express striated muscle type proteins. Differentiation 46: $105-115$. 
Schelbert HR, 1991. Positron emission tomography for the assessment of myocardal viability. Circulation 84(suppl D): 122-131.

Schultheiss $T$, Lin Z, Lu M-H, Murray J, Fischman DA, Weber K, Masaki T, Tmamura M, Holtzer $H, 1990$. Differential distribution of subsets of myofibriliar protens in cardiac non-striated and striated myofibrils. J Cell Biol 110: 1159-1172.

Sharp WW, Terracio L, Borg TK, Samarel AM, 1993. Contractile activity modulates actin synthesis and turnover in cultured neonatal rat heart cells. Circ Res 73: 172-183.

Skalli O, Gabbiani G, Babaï F, Seemayer TA, Pizzolato G, Schürch W, 1988. Intermediate filament proteins and actin isoforms as markers for soft tissue tumor differentiation and origin. II Rhabdomyosarcomas. Am J Path 130: 515-531.

Tokuyasu KT, Maher PA, 1987a. Immunocytochemical studies of cardiac myofibrillogenesis in early chick embryos. 1. Presence of immunofluorescent titin spots in premyofibril stages. I Cell Biol 105:2781-2793.

Tokuyasu KT, Maher PA, $1987 \mathrm{~b}$. Immunocytochemical studies of cardiac myofibrillogenesis in early chick embryos. II Generation of $\alpha$-actinin dots within titin spots at the time of the first myofibril formation. J Cell Biol 105: 2795-2801.

Van der Loop FTL, Schaart G, Langmann W, Ramaekers FCS, Viebahn Ch., 1992. Expression and organisation of muscle specific proteins during early development stages of the rabbit heart. Anat Embryol 185: $439-450$.

Van der Ven PMF, Schaart G, Jap PHK, Sengers RCA, Stadhouders AM, Ramaekers FCS, 1992. Differentiation of human skeletal muscle cells in culture: maturation as indicated by titin and desmin striation. Cell Tissue Res 270: 189-198.

Van der Ven PMF, Schaart G, Croes HJE, Jap PHK, Ginsel LA, Ramaekers FCS, 1993. Titin aggregates associated with intermediate filaments align along stress fiber-like structures during buman skeletal muscle cell differentiation. J Cell Sci 106:749-759.

Vanoverschelde JLJ, Wijns W, Depré C, Essamri B, Heyndricks S, Borgers M, Bol A, Melin J, 1993. Mechanisms of chronic regional postischemic dystunction in humans: New insights form the study on non-infarcted collateral dependent myocardium. Circulation 87: $1513-1523$.

Wang S-M, Greaser ML, 1985. Immunocytochemical studies using a monoclonal antibody to bovine cardiac titin on intact and extracted myofibrils. J Muscle Res Cell Motil 6 : 293-312.

Wang S-M, Greaser ML, Schultz E, Bulinski JC, Lin JIC, Lessard JL, 1988a. Studies on cardiac myofibrillogenesis with antibodies to titin, actin, tropomyosin and myosin. II Cell Biol 107: 1075-1083.

Wang $K$, Wright J, 1988b. Sarcomere matrix of skeletal muscle- the role of thick filaments in the segmental extensibility of elastic thin filaments. Biophys I 53: 25A. 
a

a

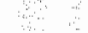




\title{
Chapter 4 \\ Nuclear lamin expression in chronic hibernating myocardium in man
}

Jannie Ausma, Guillaume J.J.M. van Eys, Jos L.V. Broers, Fred Thoné, Willem Flameng, Frans C.S. Ramaekers, Marcel Borgers

J. Mol. Cell. Cardiol. 28: 1297-1305 (1996)

\begin{abstract}
Cardiomyocytes of chronic hibernating myocardium are known to undergo structural changes, indicative of dedifferentiation. Amongst these are changes in nuclear shape and chromatin distribution. Nuclear A-type lamins are known to be expressed in a differentiation-related fashion and to contribute to nuclear integrity and chromatin organization. Lamin expression was investigated with immunocytochemical staining procedures in biopsies from patients with chronic hibernating myocardium. The expression of A-type lamins (lamin A and C) were shown to be downregulated during hibernation, while lamin B2 remained present in hibernating cardiomyocytes in a way similar to embryonic muscle cells. All heart muscle cells were shown to be negative for lamin Bl. The absence of A-type lamins in chronic hibernating cardiomyocytes could be taken as an additional argument for the dedifferentiation state of these cells. The absence of A-type lamins was accompanied by dispersion of the nuclear heterochromatin, in a way similar to nuclei of embryonic cardiomyocytes.
\end{abstract}




\section{Introduction}

In recent studies, we described the structural adaptations in cardiomyocytes from patients with chronic hibernating myocardium. The affected segments showed cardiomyocytes with loss of sarcomeres, sarcoplasmic reticulum and T-tubules, and presented abundant glycogen plaques, strands of rough endoplasmic reticulum and numerous mini-mitochondria (Vanoverschelde et al., 1993; Borgers et al., 1993; Maes et al., 1994; Ausma et al.,1995a, b). These cellular changes were not considered as degenerative but were interpreted as cellular dedifferentiation. This assumption was supported by the oceurrence of "early development" markers of the heart muscle, such as the re-expression of $\alpha$-smooth muscle actin, the staining of titin in an embryonic-like punctate pattern and the disappearance of cardiotin, a late marker of the heart muscle development (Schaart et al., 1993; Ausma et al.,1995b). The above mentioned structural alterations were accompanied by particular changes in nuclear shape and composition. The nuclei of chronic hibernating cardiomyocytes were often enlarged and their heterochromatin material was uniformly dispersed, a feature akin to nuclei of embryonic cardiomyocytes (Borgers et al., 1993). These changes led us to investigate the possible involvement of lamins in the hibernation process.

The nuclear lamina is considered to be important for nuclear envelope integrity and the organisation of interphase chromatin. It consists of a meshwork of intermediate filament type proteins. Nuclear lamins, subdivided into the A-type and B-type lamins, are members of a multigene family of proteins that are expressed in differentiation stage-dependant fashion (for reviews see Krohne and Benavente, 1986; Nigg, 1992; Moir and Goldman, 1993). Both A- and B-type lamins may have a role in the expression of genes by directly or indirectly interacting with heterochromatin (Burke and Gerace, 1986; Luderus et al., 1993). B-type lamins (lamins B1 and B2) associate with the inner nuclear membrane during both interphase and mitosis (Gerace et al., 1984). The expression of B-type lamins is found in most vertebrate cell types. In mammals, two A-type lamins have been described: lamins $A$ and $C$. These two proteins arise from the same gene by alternative splicing (Lin and Worman, 1993). The expression of A-type lamins is related to a relatively high degree of cellular differentiation. Although, numerous studies on the distribution of lamin subtypes were carried out in developing vertebrate embryos (Lehner et al., 1987; Stewart and Burke, 1987; Röber ef al., 1989) and in proliferating cells such as teratocarcinoma cells, hematopoietic cells and a diversity of normal adult tissues (Lebel et al, 1987; Stewart and Burke, 1987; Cance et at., 1993), studies on the expression of lamins in heart tissue are sparse (Lehner et al., 1987; Röber et al., 1989; Lockard and Bloom, 1993). Lamin expression in human heart has as far as we know, not been investigated. Here we report the changes in the expression of $\mathrm{A}$ - and $\mathrm{B}$-type lamins in cardiomyocytes in biopsies from patients with chronic hibernating myocardium as compared to normal heart. 


\section{Materials and Methods}

\section{Patients}

The human cardiac tissue material used in this study consisted of transmural biopsies obtained from 13 ischemic patients at the time of coronary artery bypass surgery. The biopsies used in the present study were obtained before any anastomoses were performed. All patients gave their informed consent. The study was approved by the local Ethical Committees for Research. The detailed individual patient characteristics are described previously (Maes et al, 1994). In short, all patients had severe LAD stenosis and marked anterior wall abnormalities as evaluated by angiography and $2 \mathrm{D}$ echocardiography. The viability of the myocardium was verified by Positron Emission Tomography (PET) and by the assessment of function 3 months after coronary bypass surgery. Eight patients thad, as demonstrated by PET, a flow-metabolic mismatch pattern in their hypokinetic segments. From the other five patients biopsies from normokinetic segments were used as controls.

Left ventricle biopsies derived from seven (non-ischemic) donor hearts, which were either used for orthotopic transplantation or homograft prelevation, were treated as above and served as non-ischemic controls. They have been used in a previously published study (Borgers et al., 1993)

\section{Light microscopic evaluation}

Of all patients a first biopsy was fixed for a minimum of $2 \mathrm{hr}$ in $3 \%$ glutaraldehyde buffered to $\mathrm{pH} 7.4$ with $90 \mathrm{mM} \mathrm{KH}_{2} \mathrm{PO}_{4}$, washed in the buffer supplemented with $220 \mathrm{mM}$ sucrose and postfixed for $1 \mathrm{hr}$ in $2 \% \mathrm{OsO}_{4}$ buffered with $50 \mathrm{mM}$ veronal acetate, dehydrated in a graded series of ethanol and embedded in epoxy resin (Flameng et al., 1984). Epon sections ( $2 \mu \mathrm{m}$ thick) were used for light microscopic morphometry of endo- and epicardial parts of the myocardium stained with either $0.1 \%$ toluidine blue or periodic acid-Schiff (PAS). This staining method permits independent visualization of the contractile elements and glycogen respectively and enables the unambiguous determination of the degree of myolysis. The effect of autolytic changes, which could be responsible for degradation of glycogen, should be negligible since tissues were fixed immediately after the biopsy had been taken. In order to evaluate cellular changes in the different layers of the myocardium, at least 100 myocardial cells per segment were analysed. Only cells in which the nucleus was visible in the plane of observation were included in the analysis. Cells were planimetrically scored for the degree of myolysis (sarcomere loss). Since space, formerly occupied by sarcomeres, was mainly filled up by glycogen and mitochondria, quantitation of the changes was done on PAS stained sections. The percentage of glycogen content was planimetrically evaluated for each individual cell. If the sarcomere replacement accounted for more than $10 \%$, cells were classified as affected.

The morphometric analysis of the amount of connective tissue in the myocardium 
was assessed using a grid with vertical and horizontal lines as previously describer (Flameng et al., 1984). This method allows a quantitative analysis of the volume of structures under investigation by counting the number of intersections overlying a certain structure. In this study longitudinal sections at a magnification $x 250$ wert evaluated. Blood vessels and perivascular interstitial cells were considered not tc belong to the connective tissue.

\section{Indirect immunofluorescence assays}

A second biopsy of the hibernating myocardium was quickly frozen in isopentane pre-cooled with liquid nitrogen. Five $\mu \mathrm{m}$ thick sections were air-dried, fixed in methanol $\left(-20^{\circ} \mathrm{C}\right.$ for $\left.1 \mathrm{~min}\right)$, followed by aceton $\left(4^{\circ} \mathrm{C}\right.$ for three times $5 \mathrm{~s}$ ), air dried again. The sections were incubated with the primary antibodies for $45 \mathrm{~min}$ at room temperature and washed with PBS (three steps of $10 \mathrm{~min}$ each). They were subsequently incubated with the secondary, fluorescein isothiocyanate (FITC)conjugated or goat-anti-mouse Ig-subclass specific antibody (Southern Biotechnology Associates (SBA) Inc., Birmingham, AL, USA), Rabbit-anti-mouse antibody (DAKO A/S, Glostrup, Denmark) or goat-anti-rabbit antibody (SBA) for $45 \mathrm{~min}$ and then washed in PBS (three steps of $10 \mathrm{~min}$ each).

In the double-labeling procedure the immunostaining steps were repeated with a second primary antibody of another Ig-subclass, the sections were washed in PBS and then incubated for $45 \mathrm{~min}$ with the secondary, Texas Red-conjugated Igsubclass specific antibody (SBA, Birmingham, AL, USA).

After these immunohistochemical procedures the sections were placed in distilled water for $5 \mathrm{~min}$, followed by post-fixation in methanol for $5 \mathrm{~min}$. The sections were air-dried and mounted in Mowiol (Hoechst, Frankfurt a.M., Germany) (Osborn and Weber, 1982). Nuclei were routinely stained with 4'-6-diamidine 2-o-phenylindole (DAPI: Sigma Chemicals, St. Louis, MO, USA) in a dilution of 1:10000 with PBS. As a control, application of the first antibody was omitted.

For biotin-labelled lectin the same procedure was followed; in this case fluorescein isothiocyanate (FITC)-labelled avidin (Vector Laboratories, Burlingame, CA, USA) was used as conjugate.

All slides were examined with a Zeiss Axiophot microscope. Photographs of the immunofluorescence studies were taken with a Kodak Tri-X-pan film with a 400 ISO setting.

The percentage of A-type lamin positive cardiomyocyte nuclei were counted in sections stained with anti-A-type lamin antibodies and anti-desmin antibodies (to visualize the sarcomeres), according to the protocols described above.

\section{Confocal scanning laser microscopy}

Double label immunostained myocardium sections were observed with a Bio-Rad MRC-600 confocal scanning laser microscope (Bio-Rad Laboratories, Richmond, 
CA, USA) equipped with a Krypton/Argon mixed gas laser (Ion Laser Technology, Salt Like City, UT, USA) with two separate wavelengths for the excitation of fluorescein isothiocyanate $(488 \mathrm{~nm})$ and Texas Red $(568 \mathrm{~nm})$ and mounted on a Zeiss Axiophot microscope (Carl Zeiss, Oberkochen, Germany).

The following monoclonal antibodies were used in this study: 1) LN43 directed against lamin B2 and not cross-reacting with lamin B1 (Bridger et al.,1993) which was a gift from Dr E.B. Lane (Dundee, UK). 2) 119D5F1 directed against lamin B1 and not cross reacting with lamin B2 (Machiels unpublished), kindly provided by Dr Y. Raymond (Montréal, Quebec, Canada). 3) 4.1CC4, directed against the rod domain of A-type lamins A and C, kindly provided by Dr G. Warren (Heidelberg, Germany). $41 \mathrm{CC} 4$ is known to react more strongly with lamin $\mathrm{C}$ isoforms than with lamin A isoforms (Hozák et al., 1995; Machiels et al., 1995). 4) R27, directed against the rod domain of A-type lamins A and C (Zatloukal et al., 1992), kindly provided by Dr G. Krohne (Heidelberg, Germany). R27 is known to give a stronger reaction with lamin $\mathrm{C}$ isoforms than with lamin $\mathrm{A}$ isoforms (Hozák et al., 1995; Machiels et al., 1995). 5) 133A2, raised against the carboxy terminus of 98 amino acids exclusively present in lamin A and kindly provided by Dr. Y. Raymond. This antibody recognizes lamin A but not lamin C. Epitope mapping using several deletion mutants of lamin A showed that the amino acids 598-611 form the epitope recognized by 133A2 (Hozák et al, 1995).

In addition, rabbit polyclonal antibody against vimentin, pVim (Ramaekers et al., 1983) and biotin-labeled lectin from Psophocarpus tetragonolous (Sigma Chemicals, St.Louis, USA), which binds specifically to endothelial cells of the human myocardium (Laitinen et al, 1990), were used.

\section{Results}

\section{Structural changes in chronic hibernating myocardium}

The histological and ultrastructural changes in chronic hibernating myocardium have been described in detail previously (Borgers et al, 1993; Vanoverschelde et al.,1993; Maes et al.,1994). Briefly, these cardiomyocytes were characterized by depletion of sarcomeres and accumulation of glycogen. The degree of myolysis varied amongst the patients: the replacement of contractile material by glycogen was limited to the vicinity of the nucleus in many cells, but in others glycogen comprised the bulk of cytoplasm, leaving onlly a few or no sarcomeres at the cell periphery. Cells were considered affected when more than $10 \%$ of the cell volume consisted of glycogen. The average percentage of affected cells was $23 \pm 10$ for the group of 8 patients examined in the present study, with a PET mismatch pattern. A very characteristic alteration during chronic hibernation concerned shape changes of the nuclei. These were often enlarged and showed a uniform dispersion of their heterochromatin material throughout the nucleoplasm (Fig. 1a), thereby resembling nuclei of cardiomyocytes during late developmental stages. However, a number of nuclei retained an apparently normal distribution pattern of heterochromatin in 

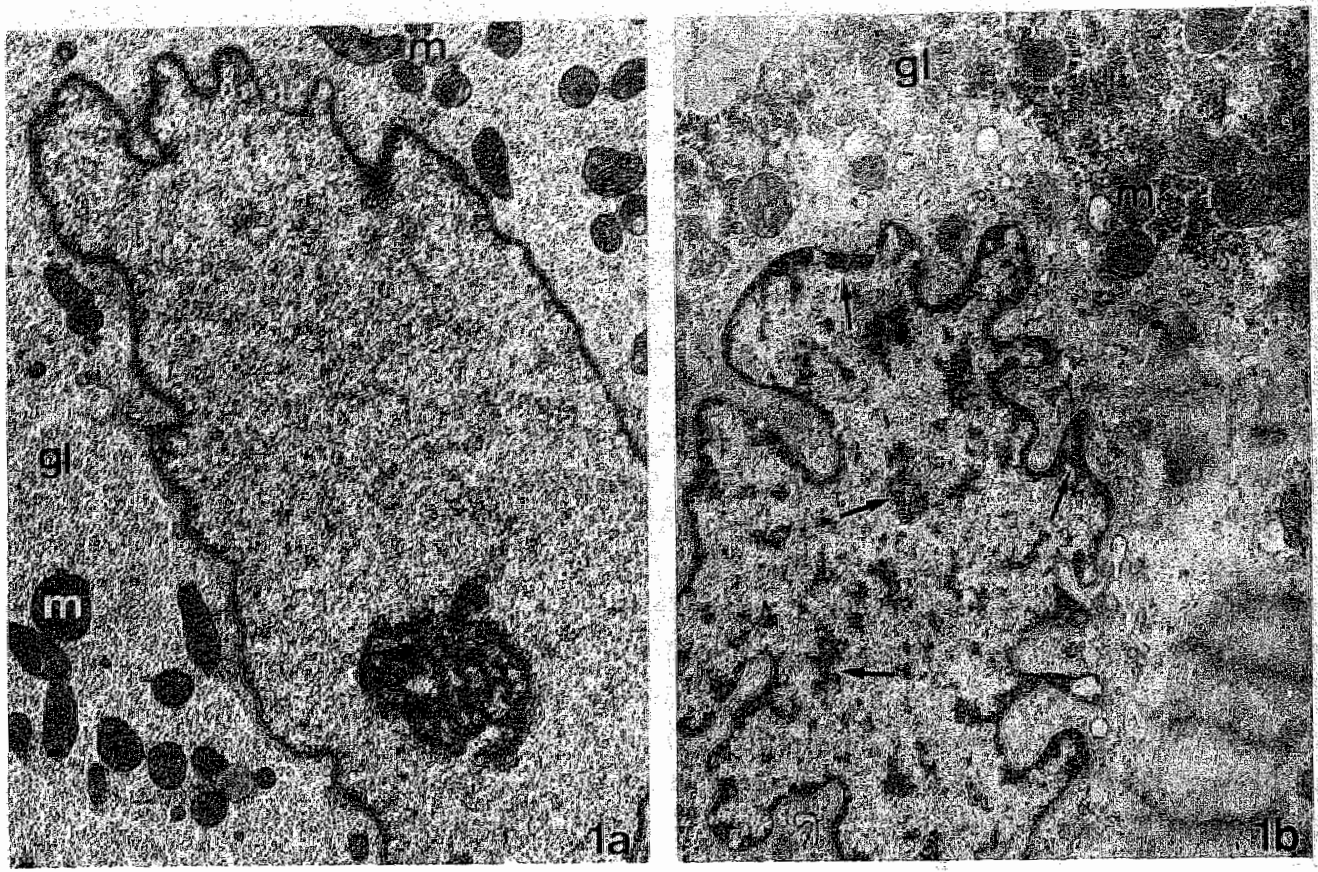

Figure 1. Electron microscopy of nuctei of hibernating cardionyocytes. (a) Detail of a hibernating cell with severe myolysis. The nucleus is surrounded by glycogen $(g)$ and small mitochondria $(m)$. The nuclear heterochomatin is unifomly dispersed over the nucleoplasm (x: 11500). (b) Detail of another hibernating cardiomyocyle showing patchy distribution of heterochromatin (arrows) (x:9500).

Table 1. Summaty of immunohistochemical results for the lamin-subtypes in nomokinetic, chonic hibernating and embryonic muscle cells.

\begin{tabular}{llccc}
\hline $\begin{array}{l}\text { Lamin } \\
\text { subtype }\end{array}$ & Antibody & Nomokinetic & $\begin{array}{c}\text { Chronic } \\
\text { Hibernating }\end{array}$ & Embryonic * \\
\hline A & $133 \mathrm{A2}$ & + & +1 or & - \\
$\mathrm{A} / \mathrm{C}$ & $41 \mathrm{CC} 4$ and R27 & + & +1 or & - \\
$\mathrm{B} 1$ & $11905-\mathrm{F} 1$ & - & - & - \\
$\mathrm{B} 2$ & LN43 & + & + & + \\
\hline
\end{tabular}

literature data (refs Lehnety al., 1987; Röberet ab, 1989; Lourim and Lin, 1989), concerning results from other speciesi.e. chicken, mice andenopus

+ pasitive

t- partly or weaklly positive

- negative 

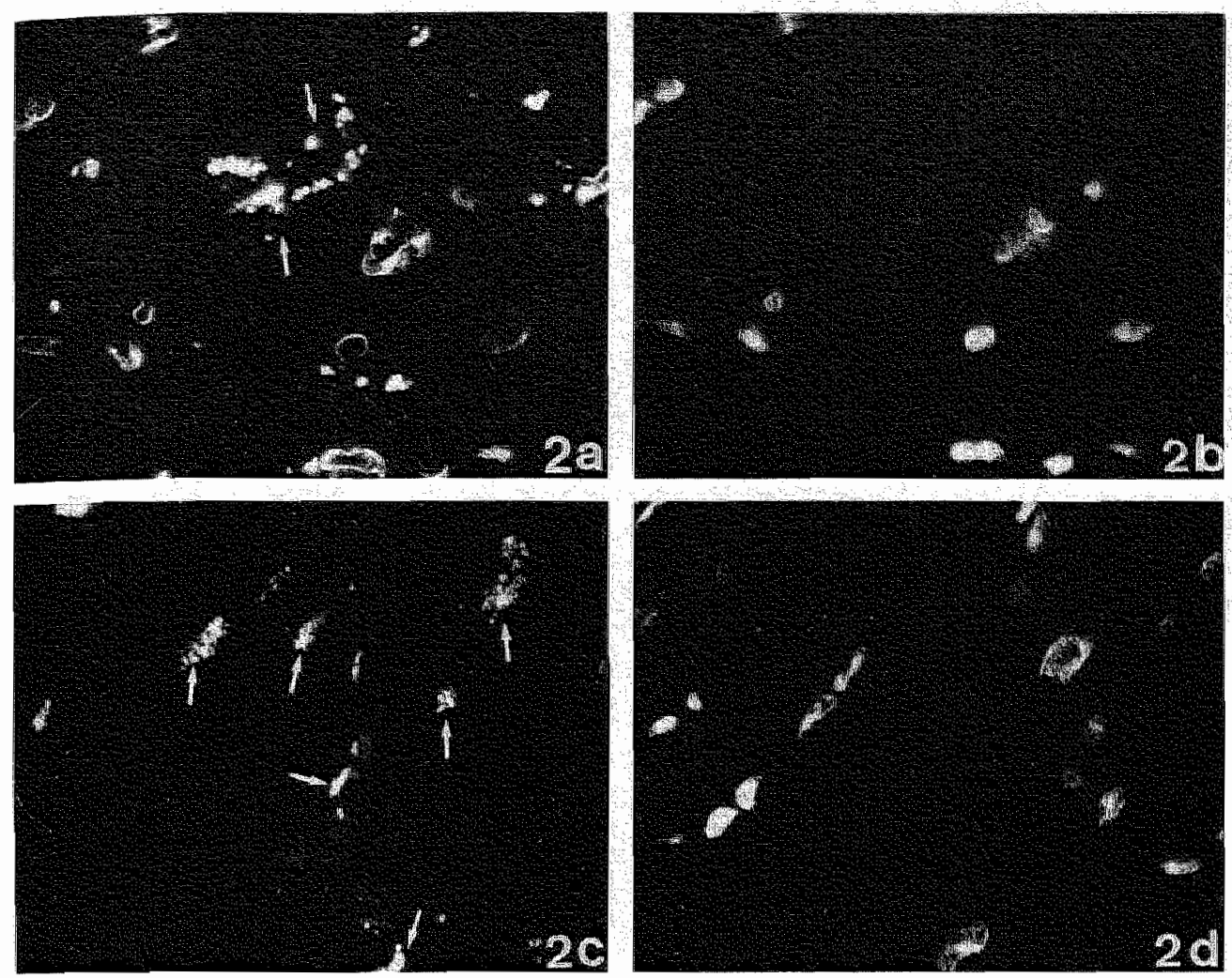

Figure 2. Immunofiuorescence nicrographs of lamin $B$ subtypes of different sections of human heart. Nuclear lamina were shown to lamin B2 positive (a) and nuclen were stained with DAPI (b) (x 500). (c) Nuclear lamina showed no staining with lamin BI (c), nuclei are wisible by DAPI staining $(d)(x 440)$. Arrows indicate autofluorescence of lipofuchsin.

otherwise severely affected cells (Fig 1b). Since the data on glycogen and contractile elements have been obtained at the jight microscopic level and those of the shape of the nuclei at the electrontion microscopic level these results have to be interpreted with caution and only indirect correlations can be suggested.

\section{Lamin expression in human myocardium}

An overview of the reactivity patterns of normokinetic and hibernating heart segments with different lamin monoclonal antibodies is given in Table 1 and depicted in figures $2-4$.

B-type lamin expression in normokinetic and hibernating heart secrions.

The normokinetic and hibernating heart sections showed identical staining patterns for B-type lamins. Lamin B2 staining was present in all nuclei throughout the 

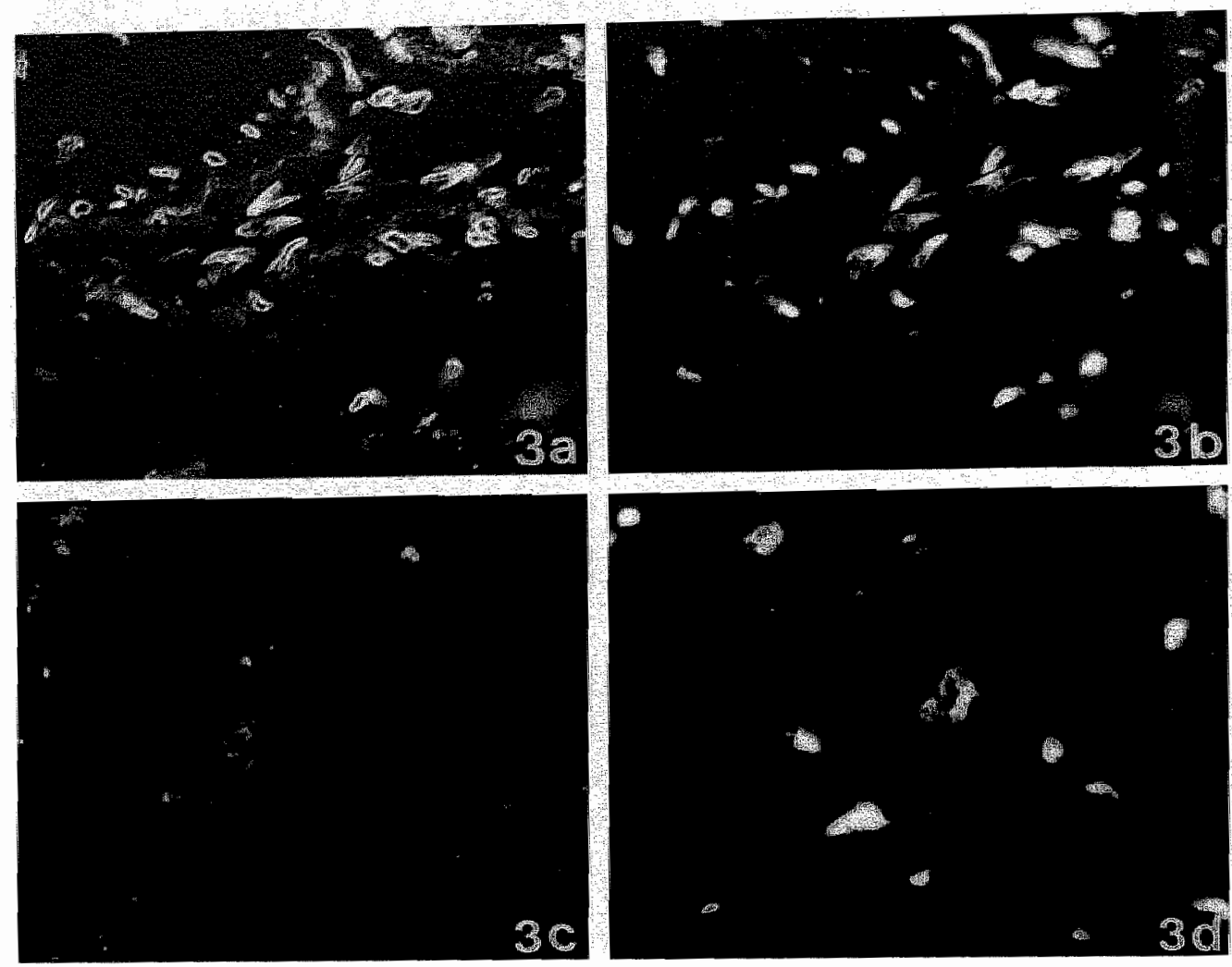

Figure 3. Immunofluorescence micrograph of A-type lamin expression in heart muscle. (a,b) Staining of a bloodvessel with A-type lamins (4ICC4) (a) and DAPI nuclear staining (b) $(x$ 400). (c,d) Staining of A-type lamins (4ICC4) (c) and DAPI nuclear staining (d) in a section from chronic hibernating myocardium. Nuclei form hibernating cardiomyocytes were shown to be negative for A-type lamins. Dot-like staining is autofluorscence of lipofuch $\sin (x 450)$.

sections (Fig. 2a and b). Identical staining intensities were seen in the nuclei of the different myocardial cell types. However, the other lamin B subtype, i.e. lamin B 1 was absent from virtually all cell types present in the heart. Cardiomyocytes were never observed positive for lamin B 1 (Fig. $2 \mathrm{c}$ and $2 \mathrm{~d}$ ) nor were chronic hibernating segments that displayed myolysis. The few lamin B1 positive cells were identified as mesenchymal cells on basis of their positive staining for vimentin. Double labeling studies with lectin and vimentin showed that some but not all of the endothelial and fibroblastic cells were positive for lamin B1. 
A-type lamin expression in normokinetic heart sections.

All cardiomyocytes in normokinetic hearts sections showed A-type lamin expression, with only the nuclear periphery stained with all three A-type monocional antibodies. Vascular smooth muscle cells (Fig. $3 \mathrm{a}$ and $3 \mathrm{~b}$ ) and interstitial cells were also observed to be positive for A-type lamins, although the reactivity was variable and occasionally absent. No differences were observed in staining intensity with the different monoclonal antibodies against A-type lamins.

A-type lamin expression in hibernating heart sections.

Nuclei of cardiomyocytes of chronic hibernating heart segments showed a decrease in staining intensity with the monoclonal antibodies against the different lamin Asubtypes. A considerable number of cardiomyocyte nuclei were found to be negative for A-type lamins (Fig. 3c and 3d). In average about 80 percent of nuclei in myolytic (hibernating) cardiomyocytes lack A-type lamin staining. With double labeling studies subtile differences in the staining intensity were sometimes seen with the different monoclonal antibodies against A-type lamins. The monoclonal antibody 133A2 (specific for lamin A) showed a more positive staining than R27 and $41 \mathrm{CC} 4$ (recognizing both lamins $\mathrm{A}$ and $\mathrm{C}$ ) in nuclei of chronic hibernating cardiomyocytes. The DAPI staining which was routinely included in the analyses did not show any signs characteristic for apoptosis.
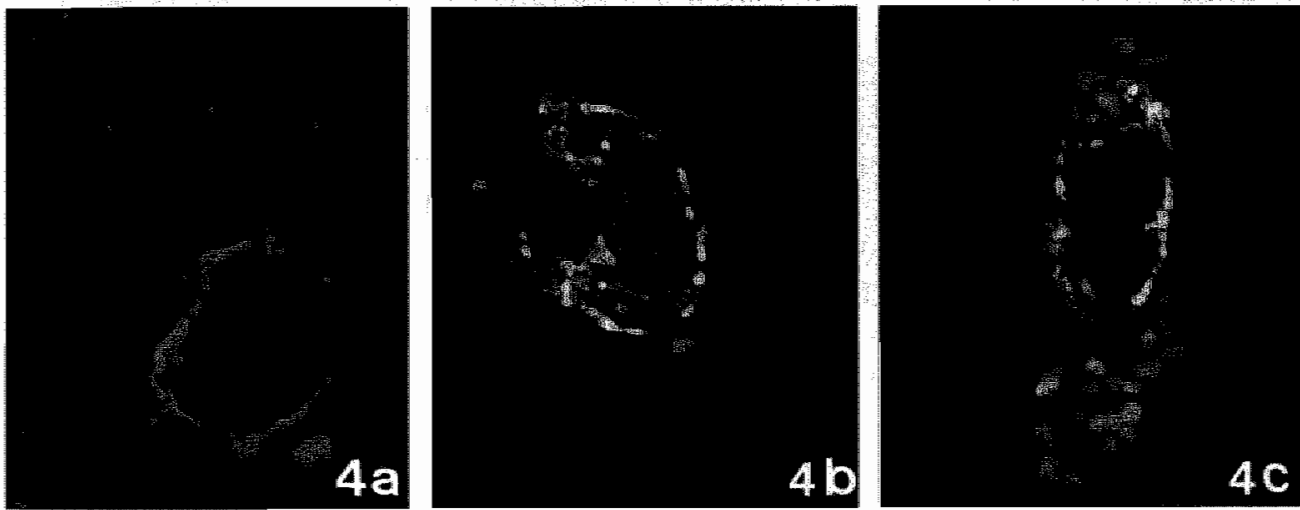

Figure 4. Confocal laser scanning microscopy of nuclei seen in chronic hibernating segments. Double labelling studies of A-type lamins (green) with lamin B2 (red). (a) Absence of A-type lamin staining, while the contour of the nucleus is visible with lamin B2 staining. as seen in approximately $80 \%$ of the cardiomyocytes with myolysis (x1570). (b) Patchy Atype lamin staining throughout the nucleoplasm of a nucleus with an irregular contour from a myolytic cardiomyocyte. This pattern is seen in a minor fraction of the myolytic cardiomyocytes (x1575). (c) A-type lamin and lamin B2 staining at the border of a nucleus from a normal cardiomyocytes. Large red dots which are visible in the perinuclear area represent lipofuchsin autofluorescence ( $x$ 1750). 


\section{Internuclear distribution of lanins}

In order to investigate the organisation of A-type lamins in nuclei of chronic hibernating cardiomyocytes immunofluorescently stained sections were analyzed by confocal laser scanning microscopy. Although, most myolytic cardiomyocytes were negative for A-type lamins ( $80 \%$ ) (Fig. 4a), some displayed these lamins $(20 \%)$. In several of these cells A-type lamin staining was seen as patches over the whole nucleoplasm instead of being concentrated at the border of the nucleus (Fig. 4b). In contrast, normal cardiomyocytes displayed A-type and B-type lamin staining at the border of the nuclei (Fig. 4c).

\section{Discussion}

Cardiomyocytes from chronic hibernating myocardium display typical subcellular alterations such as loss of myofibrils, accumulation of glycogen, fragmentation of sarcoplasmic reticulum, the presence of strands of rough endoplasmic reticulum, loss of T-tubular structures and shape changes in their mitochondria (Borgers et al, 1993). Some of these changes are cellular features of dedifferentiation. In addition, the expression pattern of contractile and cytoskeletal proteins such as titin, cardiotin and $\alpha$-smooth muscle actin resembles that of embryonic cardiomyocytes (Ausma et al., 1995a,b). Nuclei of chronically hibernating cardiomyocytes are often enlarged and many of them demonstrate a uniform dispersion of their heterochromatin in a way similar to that observed during embryonic development. Nuclear A-type lamins are known to be expressed in a differentiation related fashion and contribute to nuclear integrity and chromatin organization. A-type lamin expression is absent in undifferentiated cells or cells at early stages of differentiation (Stick and Hansen, 1985; Stewart and Burke, 1987; Lehner et al., 1987; Paulin-Levasseur et al., 1988; Röber et al., 1989; Guilly et al., 1990). In the present study, we therefore investigated the expression patterns of different nuclear lamin subtypes in connection with the hypothesis that chronic hibernating myocardium exhibits dedifferentiation characteristics.

\section{The expression of A-type lamins in normal and chronic hibernating myocardium}

Our results obtained with monoclonal antibodies directed against $\mathrm{A}$-lype lamins indicate the loss of lamins $A$ and $C$ in $80 \%$ of the cardiomyocytes displaying myolysis. Since we have used A-type lamin antibodies recognizing different epitopes on both molecules, it can be excluded that these findings result from epitope masking or partial breakdown of the lamins. Our results thus indicate that the expression of both A-type lamins is absent as a result of their hibernating state, providing additional proof for their dedifferentiated phenotype. In particular the fact that lamin B2 remains present in cells that lack A-type lamins supports the idea 
that the myolytic cells are not subjected to degeneration. In such processes both Aand B-type lamins disappear simultaneously (Oberhammer et al., 1994; Tinnemans et al., 1995).

We realize that caution must be taken in correlating lamin expression in cardiomyocytes during chronic hibernation in man with that during cardiac differentiation, since expression of different lamin subtypes during development of human cardiac muscle has not yet been documented. A-type lamin expression did not occur during myofibrillogenesis in chicken and mouse before the cells have committed to the myogenic differentiation pathway, as indicated by the expression of several specific muscle cell markers. A-type lamin expression preceded, however the induction of late muscle specific proteins e.g. tropomyosin and myosin heavy chain (Lourim and Lin, 1989; Röber et al., 1989). The absence A-type lamin staining observed in a considerable number of the myolytic cells correlated to the "embryonic" like uniform distribution of nuclear chromatin. Electron microscopic views indicated that several of these nuclei were enlarged, projected numerous extensions into the cytosol and their heterochromatin became uniformly dispersed over the whole nucleoplasm. In other nuclei, a more patchy heterochromatin distribution was seen. These nuclei may possibly correspond to those showing a pathy A-type lamin distribution. Alterations in the composition of the nuclear lamina may be important in establishing cell- or tissue-specific differences in nuclear architecture. A-type lamins are assumed to exert their effect on gene expression via regulation of chromatin topology. The role of lamin $\mathrm{A}$ was established by transfection of chick embryonic myogenic cells with lamin $\mathrm{A}$, or lamin A lacking the nuclear localization signal. Transfections with either one of these constructs resulted in an increase of the muscle specific proteins tropomyosin (Lourim and Lin, 1992).

\section{The expression of B-type lamins in normal and chronic hibernating myocardium}

Studies on lamin expression in heart muscle published so far did not distinguish between the two lamin $B$ subtypes and in all cardiac cell types a ubiquitous expression of lamin B1 and لamin B2 is assumed (Röber et al., 1989; Lockard and Bloom, 1993).

Our study shows that all cardiac muscle cells, including the hibernating ones, were lamin type BI negative. Although all nuclei of cardiac cell types were shown to be positive for lamin $\mathrm{B} 2$, only a small percentage of the interstitial cells (fibroblasts, pericytes and endothelial cells) were shown to be lamin B 1 positive.

So far, the expression of B-type lamins has been thought not to be developmentally regulated or to be associated with the state of differentiation (Stick and Hansen, 1985; Paulin-Levasseur et al., 1988; Röber et al., 1989; Guilly et al., 1990). The only report showing a differential expression of both B-type lamins concerns human liver, where lamin B2 is a minor component over B1 (Zatloukal et al., 1992). However, our preliminary studies on the presence of lamins B1 and B2 in 
several human tissues indicate that a differential expression of these two B-type lamins, especially the absence of lamin B1, occurs more often than previously assumed (Broers et al., unpublished). The biological implication of the absence of lamin B 1 remains to be established, but it should be kept in mind that B-type lamins have been shown to be involved in interactions between chromatin and the inner nuclear membrane (Moir et al, 1994; Ludérus et al., 1992). In this sense, it can be speculated that the differential expression of lamin B1 may be involved in directing cells towards specific differentiation pathways. Apparently, the presence of lamin B2 seems to be sufficient to form a proper nuclear lamina in cardiac muscle cells.

We can conclude that the redistribution of nuclear heterochromatin in hibernating cardiomyocytes is accompanied by the loss of A-type lamins. These phenomena may exert an effect on gene expression in these cells resulting in an embryonic phenotype.

\section{Acknowledgements}

We are grateful to Dr Y. Raymond (Quebec, Canada), Dr I.G. Warren (London, UK), Dr. E.B. Lane (Dundee, UK) and Dr. G. Krohne (Würzburg, Germany), who provided the antilamin monoclonal antibodies.

\section{References}

Ausma J, Schaart G, Thoné F, Shivalkar B, Flameng W, Depré C, Vanoverschelde J-L, Ramaekers F, Borgers M, 1995a. Chronic ischemic viable myocardium in man: aspects of dedifferentiation. Cardiovasc Pathol 4:29-37.

Ausma J, Fürst D, Thoné F, Shivalkar B, Flameng W, Weber K, Ramaekers F, Borgers M, 1995b. Molecular changes of titin in left ventricular dysfunction as a result of chronic hibernation. J Mol Cell Cardiol 27:1203-1212.

Borgers M, Thoné F, Wouters L, Ausma J, Shivalkar B, Flameng W. 1993. Structural correlates of regional myocardial dysfunction in patients with critically coronary artery stenosis: chronic hibernation? Cardiovasc Pathol 2:237-245.

Burke and Gerace L, 1986. A Cell free system to study reassembly of the nuclear envelope at the end of mitosis. Cell 44: 639-652.

Bridger JM, Kill I, O'Farrell M, Hutchison CJ, 1993. Internal lamin substructure within G1 nuclei of human dermal fibroblasts. J Cell Sci 104: 297-306.

Cance WG, Chaudhary N, Worman HJ, Blodel G, Cordon-Cardo C, 1992. Expression of the nuclear lamins in normal and neoplastic human tissues. J Exp Clin Cancer Res 11:

Flarneng W, Wouters L, Sergeant P, Lewi P, Borgers M, Thoné F, Suy R, 1984. Multivariate analysis of angiographic histologic and electrocardiographic data in patients with coronary heart disease. Circulation 70: 7-17. 
Gerace L, Comeau C, Benson M, 1984. Organisation and modulation of nuclear lamina structure. J Cell Si (Suppl I) 137-160.

Guilly M-N, Kolb J-P, Gosti F, Godeau F, Courvalin J-C, 1990. Lamins A and C are not expressed at early stages of human lymphocyte differentiation. Exp Cell Res 189: 145148.

Hozák P, Sasseville M-J, Raymond X, Cook PR, 1995. Lamin proteins form an internal nucleoskeleton as well as a peripheral lamina in human cells. $J$ Cell Sci 108 : In press.

Krohne $G$, Benavente $R, 1986$. The nuclear lamins. A multigene family of proteins in evolution and differentiation. Exp Cell Res. 162: 1-10.

Laitinen L, Hormia M, Virtanen I, 1990. Psophocarpus tetragonolobus agglutinin reveals $\mathrm{N}$-acetyl galactosaminyl residues confined to endothelial cells and some epithelial cells in human tissues. $J$ Histochem Cytochem 38: 875-884.

Lebel $\mathrm{S}$, Lampron $\mathrm{C}$, Royal $\mathrm{A}$, Raymond $\mathrm{Y}, 1987$. Lamins $\mathrm{A}$ and $\mathrm{C}$ appear during retinoic acid-induced differentiation of mouse embryonal carcinoma cells. I Cell Biol 105: $1099-\mathbb{1 1 0 4 .}$

Lehner CF, Stick R, Eppenberger M, Nigg EA, 1987. Differential expression of nuclear matrix proteins during chicken development. I Cell Biol 105: 577-587.

Lin $\mathrm{F}$, Worman $\mathbb{H J}, 1993$. Structural organization of the thuman gene encoding nuclear lamin $A$ and nuclear lamin C. J Biol Chem 268: 577-587.

Lockard VG, Bloom S, 1993. Trans-cellular desmin-lamin B intermediate filament network in cardiac myocytes. $J$ Mol Cell Cardiol 25: 303-309.

Lourim D, Lin JJ-C, 1989. Expression of nuclear lamin A and muscle-specific proteins in differentiating muscle cells in ovo and in vitro. J Cell Biol 109: 495-504.

Lourim D, Lin JJ-C, 1992. Expression of wild-type and nuclear localization-deficient human lamin A in chick myogenic cells. J Cell Sci 103: 863-874.

Ludérus MEE, de Graaf A, Mattia E, den Blaauwen JL, Grąnde MA, de Jong L, van Driel R, 1992. Binding of matrix attachment regions to lamin B1. Cell 70: 949-959.

Machiells BM, Broers JLV, Raymond Y, De Ley, Kuijpers HJH, Caberg NEH, Ramaekers FCS, 1995. Abnormal A-type lamin organization in human lung carcinoma cell lines. Eur J Cell Biol 67: 328-335.

Maes A, Flameng W, Nuyts J, Borgers M, Shivalkar B, Ausma J, Bormans G, Schiepers C, De Roo M, Mortelmans L, 1994. Histological alterations in chronically hypoperfused myocardium. Correlation with PET findings. Circulation 90: 735-745.

Moir RD, Goldman RD, 1993. Lamin dynamics. Curr Opinion Cell Biol 5; 408-411.

Moir RD, Montag Lowy M, Goldman RD, 1994. Dynamic properties of nuclear lamins:

Lamin B is associated with sites of DNA replication. I Cell Biol 125: 1201-1212.

Nigg EA, 1992. Assembly and cell cycle dynamics of the nuclear lamina. Seminars in Cell Biology. 3: 245-253.

Oberhammer FA, Hochegger K, Froschl G, 1994. Chromatin condensation during apoptosis is accompanied by degradation of lamin $A+B$, without enhanced activation of cde2 kinase. of Cell Biol 126: 827-837. 
Osbom M, Weber K, 1982. Immunofluorescence and immuncytochemical procedure with affinity purified antibodies: tubuhn-containing structures. Methods Cell Biol 24: 97-132.

Paulin-Levasseur $M$, Scherbath $A$, Traub $U$, Traub P, 1988. Lack of lamins $A$ and $C$ in mammalian hemopoietic cell lines devoid of intermediate filament proteins. Eur $J$ Cell Biol 47: 121-131.

Ramaekers FCS, Puts JVG, Moesker O, Kant A, Huijsmans A, Haag D, Jap PHK. Herman CJ, Vooljs $\mathrm{GP}, 1983$. Antibodies to intermediate filament proteins in the immunohistochemical identification of human tumors: an overview. Histochemical J $\mathbf{1 5}$, $691-713$.

Röber R-A, Weber K, Osborn M, 1989. Differential timing of nuclear lamin A/C expression in the various organs of the mouse embryo and the young animal: a developmental study. Development 105: 365-378.

Schaart G, Van der Ven PMF, Ramaekers FCS, 1993. Characterization of cardiotin, at structural component in the myocard. Eu* $J$ Cell Biol 62: 34-48.

Stewart C. and Burke B, 1987. Teratocarcinoma stem cells and early mouse embryos contain only a single major lamin polypeptide closely resembling lamin B. Cell 51: 383 392.

Stick R, Hansen $P_{*}$ 1985. Changes in the nuclear lamina compositon during early developent of Xenopus laevis. Cell 41: 191-200.

Tinnemans MMJF, Lenders M-HJH, ten Velde GPM, Ramaekers FCS, Schutte B, 1995. Alterations in cytoskeletal and nuclear matrix associated proteins during apoptosis. Eur J Cell Biol 68: 35-46.

Vanoverschelde JLJ, Wijns W, Depré C, Essamri B, Heyndricks S, Borgers M, Bol A, Malin J, 1993. Mechanisms of chronic regional postischemic dysfunction in humans: New insights form the study on non-infarcted collateral dependent myocardium. Circulation 87: 1513-1523.

Zatlonkal K, Denk H, Spurej G, Hutter H, 1992. Modulation of protein composition of nuclear lamina-reduction of lamins-B1 and lamins-B2 in livers of griseofulvin-treated mice. Lab Invest 66: 589-597. 


\title{
Chapter 5 \\ Chronic hibernating myocardium: interstitial changes
}

Jannie Ausma, Jack Cleutjens, Fred Thone, Willem Flameng, Frans Ramaekers, Marcel Borgers

Mol. Cell. Biochem. 147; 35-42, 1995

\begin{abstract}
Chronic left ventricular dysfunctional but viable myocardium of patients with chronic hibernation is characterized by structural changes, which consist of depletion of contractile elements, accumulation of glycogen, nuclear chromatin dispersion, depletion of sarcoplasmic reticulum and mitochondrial shape changes. These alterations are not reminiscent of degeneration but are interpreted as dedifferentiation of the cardiomyocytes. The above mentioned changes are accompanied by a marked increase in the interstitial space. The present study describes qualitative and quantitative changes in the cellular and non-cellular compartments of the interstitial space. In chronic hibernating myocardial segments the increased extracellular matrix is filled with large amounts of type I collagen, type III collagen and fibronectin. An increase in the number of vimentin-positive cells (endothelial cells and fibroblasts) compared with normal myocardium is seen throughout the extracellular matrix.

The increase in interstitial tissue is considered as one of the main determinants responsible for the lack of immediate recovery of contractile function after restoration of the blood flow to the affected myocardial segments of patients with chronic left ventricular dysfunction.
\end{abstract}




\section{Introduction}

The myocardium consists of muscle fibers and blood vessels connected and interspersed by a network of connective tissue. The scaffolding of the collagen matrix, the structural component of the connective tissue, plays an important role in maintaining the functional integrity of the myocardium $[1,2]$. It has been indicated that the composition and distribution of interstitial collagen determines the stiffness of the cardiac muscle [3-7]. An increase in interstitial collagen in experimentally induced pressure overloaded cardiac hypertrophy has been described [5,8,9]. Also changes in the amount of interstitial collagen have been reported in non-infarcted parts of human myocardium after myocardial infarction [10]. However, as far as we are aware, nothing is known about the composition of interstitial tissue in left ventricular dysfunctional myocardium of patients with chronic hibernation. In recent studies we described the structural adaptation in cardiomyocytes from patients with chronic hibernating myocardium. The affected cardiomyocytes showed loss of sarcomeres, sarcoplasmic reticulum and T-tubules, and presented abundant plaques of glycogen, strands of rough endoplasmic reticulum, numerous mini-mitochondria, and nuclei with uniformly dispersed chromatin [11-14]. These cellular changes were not considered degenerative but were interpreted as dedifferentiation of the cells. The latter assumption was supported by 'early development' markers of the heart muscle, namely 1) the re-expression of $\alpha$ smooth muscle actin; 2) the staining of titin in an embryonic-like (punctated) pattern; and 3) the disappearance of cardiotin, a late marker of the heart development $[15,16]$. The above mentioned changes were accompanied by a marked increase in the interstitial space, which correlated with the degree of myocardial cell change [12-14]. The interest in studying in detail extracellular matrix changes in the dysfunctioning parts of the chronic hibernating left ventricle is obviously related to the important contributary role in the degree and speed of functional recovery after revascularization.

The aim of the present study is to describe the structural changes in the interstitium of chronic hibernating myocardium. Next to the assessment of quantitative cellular and non-cellular changes in the interstitial tissue, we studied the distribution of the major extracellular matrix components collagens I, III and IV, laminin and fibronectin.

\section{Materials and Methods}

\section{Patients}

The human cardiac tissue material used in this study consisted of transmural biopsies from 20 patients with severe left ventricular dysfunction. Viability of the myocardium was assessed by Positron Emission Tomography (PET). The detailed description of the patient data regarding anterior wall motion abnormalities, degree of LAD stenosis, flow-metabolic match or mismatch, and functional recovery after coronary bypass surgery has already been presented (14). During coronary artery 
surgery, two transmural biopsies were taken from the anterior free wall of the left ventricle, at approximately $4 \mathrm{~cm}$ from the apex, between the distal LAD and the last diagonal branch. All patients gave their informed consent. The study was approved by the local Ethical Committee for Research. A first biopsy from each patient was fixed for a minimum of $2 \mathrm{hr}$ in $3 \%$ glutaraldehyde buffered to $\mathrm{pH} 7.4$ with $90 \mathrm{mM}$ $\mathrm{KH}_{2} \mathrm{PO}_{4}$, washed in the buffer and postfixed for $\mathrm{hr}$ in $2 \% \mathrm{OsO}_{4}$ buffered with $50 \mathrm{mM}$ veronal acetate, dehydrated in a graded series of ethanol and embedded in epoxy resin (Epon) [17]. A second biopsy was used for studies on the immunocytochemical detection of various extracellular matrix proteins. These biopsies were directly frozen in isopentane precooled with liquid nitrogen.

Left ventricle biopsies derived from 7 donor hearts, which were either used for orthotopic transplantation or homograft prelevation, were microscopically examined and served as nonischemic controls.

\section{Light microscopic evaluation}

Morphometry of morphologic changes was performed on $2 \mu \mathrm{m}$ thick sections of Epon-embedded biopsies, which were stained with periodic acid Schiff (PAS) and toluidine blue to quantify the loss of myofibrils and the glycogen content. The degree of cellular change was evaluated only in cells in which the nucleus was present in the plane of the section. Cells were planimetrically scored for the glycogen content [11]. To assess the area of the extracellular matrix, morphometry was carried out with a special grid with vertical and horizontal lines providing 117 intersections [17]. According to the basic principles of morphometry, counting of the number of intersections overlying a certain structure results in quantitative determination of the surface of the structure under investigation in relation to the surface of the entire tissue under the square grid. The totall number of intersections was regarded as $100 \%$, and the intersections counted in the connective tissue were expressed as the percentage of the entire tissue within the limits of the grid. Blood vessels and perivascular tissue were excluded from the analysis.

\section{Sirius Red Staining}

Frozen sections of $5 \mu \mathrm{m}$ thickness were stained with the collagen-specific dye Sirius Red (Polysciences, Warrington, PA, USA) according to the method of Junqueira et al. [18]. Sections were fixed overnight with $3.7 \%$ formaldehyde buffered with $0.037 \mathrm{M}$ phosphate buffer $(\mathrm{pH} 7.4)$. After being washed for 10 min with tap water and then with distilled water $(2 \times 2 \mathrm{~min})$, the slides were treated with $0.2 \%$ phosphomolybdic acid $(5 \mathrm{~min})$. Subsequently, $0.1 \%$ Sirius Red, dissolved in a saturated picric acid solution was applied for $90 \mathrm{~min}$. The slides were then treated with $0.01 \mathrm{~N} \mathrm{HCl}(2 \mathrm{~min})$, dehydrated in a graded series of ethanol, placed in xylol for 2 min and mounted in Entellan (Merck, Darmstadt. Germany). The collagen volume fraction was determined as the area stained with Sirius Red as a percentage of the total tissue area, by use of a Quantimet 570 morphometer (Leica, Cambridge, 
UK). The area occupied by blood vessels was subtracted from the total area of the interstitial tissue.

\section{Immunohistochemical studies}

The following antibodies were used in this study:

1) A rabbit polyclonal antibody against human type I collagen, AB745 (Chemicon, Tenecula, CA, USA) [19].

2) A polyclonal antibody against human type III collagen, AB747 (Chemicon, Tenecula, CA, USA) [19].

3) A mouse monoclonal antibody against human type IV collagen, 1042 [20].

4) A rabbit polyclonal antibody against human total fibronectin, A245 (DAKO A/S, Glostrup, Denmark) [21].

5) A mouse monoclonal antibody against human laminin, 4E10, which was a gift form UW Wewer [22].

6) A mouse monoclonal antibody RV202 against vimentin, which labels mesenchymal cells [23].

7) A rabbit polyclonal antibody against vimentin, pVim [24].

8) A mouse monoclonal antibody, sm-1 reacting specifically with the $\alpha$-smooth muscle isoform of actin $[25,26]$ (Sigma, St. Louis, USA).

9) A mouse monoclonal antibody against desmin, RD301 [27,28].

In addition, biotin-labelled lectin from psophocarpus tetragonolobus (Sigma Chemicals, St. Louis, USA), which binds specifically to endothelial cells of the human myocardium [29], was used.

Indirect immunofluorescence studies were performed on frozen sections $5 \mu \mathrm{m}$ thick. They were air-dried before use, and dipped in methanol $(5 \mathrm{sec})$ and in acetone $(3 \times 5 \mathrm{sec})$, both at $-20^{\circ} \mathrm{C}$, air-dried, and then incubated with primary antibodies for $45 \mathrm{~min}$ at room temperature and washed with PBS ( $3 \times 1.0 \mathrm{~min})$. The sections were then incubated for $45 \mathrm{~min}$ at room temperature with the secondary, fluorescein isothiocyanate (FITC)-conjugated goat-anti-mouse Ig or goat-antirabbit Ig (Southern Biotechnology Associates (SBA) Inc., Birmingham, AL/USA). Finally, the sections were washed in PBS ( $3 \times 10 \mathrm{~min})$ and mounted.

In the double labelling procedure, the immunostaining steps were repeated with a second primary antibody of another Ig-subclass, the sections were washed and then incubated for $45 \mathrm{~min}$ with the secondary, Texas Red conjugated Ig-subclass specific antibody (SBA, Birmingham, AL, USA).

After these immunohistochemical procedures the sections were placed in distilled water for $5 \mathrm{~min}$, followed by postfixation in methanol for $5 \mathrm{~min}$. The sections were air-dried and mounted in Mowiol (Hoechtst, Frankfurt a.M., Germany). Nuclei were routinely stained with 1:10000 diluted 4'-6-diamidine 2-o-phenylindole (DAPI: Sigma Chemicals, St. Louis, USA).

As a control, application of the primary antibody was replaced by PBS. 
For the biotin-labelled lectin the same procedure was followed; in this case fluorescein isothiocyanate (FITC)-labelled avidin (Vector Laboratories, Burlingame, USA) was used as conjugate.

\section{Results}

Morphological changes

Cardiomyocytes from chronic hibernating myocardium characteristically showed depletion of sarcomeres and accumulation of glycogen. The replacement of contractile material by glycogen was limited to the vicinity of the nucleus in many cells but in others glycogen comprised the bulk of cytoplasm, leaving only a few or no sarcomeres at the periphery of the cell. Cells were considered as affected when more than $10 \%$ of the cell volume was occupied by glycogen (Table I). The mean percentage of affected cells was $18 \%$ for this group of 20 patients. In cardiomyocytes bordering an infarcted region, a loss of contractile material was seen similar to that in non-infarcted regions.

Myocardial segments in which these cellular changes predominate, also show a marked increase in connective tissue (Fig. 1). Four of the 20 biopsies examined showed the presence of scar tissue. In the 16 non-infarcted patients the total area of connective tissue was $8 \%$, whereas for the 4 patients with infarction it amounted to $49 \%$. In control hearts the connective tissue area comprised approximately $2 \%$.

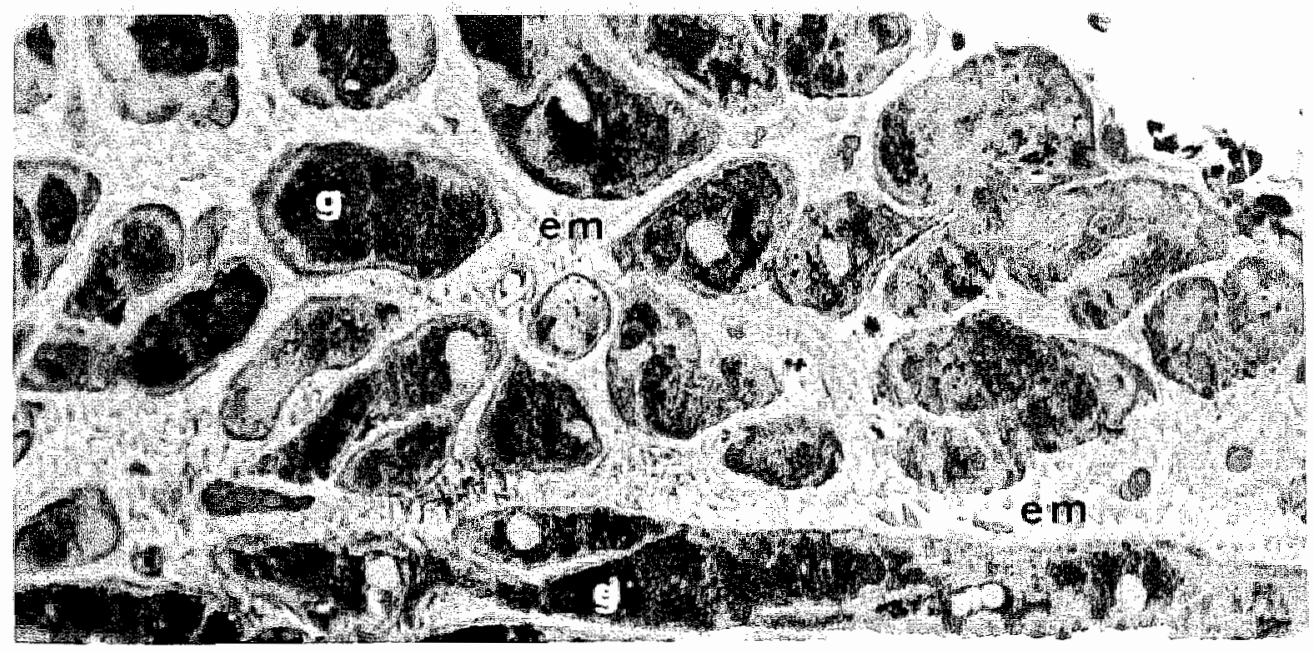

Figure 1. Light microscopy of morphological changes in chronic hibernating myocardiam. Section $(2$ un thick) of an affected area. stained with PAS/toludine blue showing that the centers of mast cells are myolytic. The myotyc areas are filled with dakly stained material (glycogen. g). The extracellular matrix (em) surrounding the chronic hibernating myocardial cells is increased. Magnification: X 360. 
Table 1: Changes in interstial trsue and cardiomyocyte composition in chronic hibernang myocardiam

\begin{tabular}{|c|c|c|c|}
\hline Patients & $\begin{array}{c}\text { collagen volume fraction } \\
(\%)\end{array}$ & $\begin{array}{c}\text { total area of connective tissue } \\
\qquad(\%)\end{array}$ & $\begin{array}{c}\text { affected cells } \\
(\%)\end{array}$ \\
\hline $\begin{array}{r}\text { no infarct } \\
1 \\
2 \\
3 \\
4 \\
5 \\
6 \\
7 \\
8 \\
9 \\
10 \\
11 \\
12 \\
13 \\
14 \\
15 \\
16\end{array}$ & $\begin{array}{c}1.4 \\
3.5 \\
7.2 \\
3.4 \\
2.1 \\
12.4 \\
6.5 \\
3.8 \\
2.5 \\
2.9 \\
6.6 \\
5.0 \\
5.2 \\
8.6 \\
6.3 \\
0.9\end{array}$ & $\begin{array}{c}4 \\
10 \\
8 \\
18 \\
14 \\
18 \\
9 \\
9 \\
4 \\
4 \\
9 \\
4 \\
4 \\
7 \\
10 \\
5\end{array}$ & $\begin{array}{c}22 \\
16 \\
16 \\
24 \\
17 \\
75 \\
7 \\
15 \\
3 \\
9 \\
21 \\
8 \\
16 \\
18 \\
8 \\
16\end{array}$ \\
\hline mean $(n=16)$ & 5 & 8 & 18 \\
\hline $\begin{array}{l}17 \\
18 \\
19 \\
20\end{array}$ & $\begin{array}{l}14.7 \\
31.0 \\
18.5 \\
14.2\end{array}$ & $\begin{array}{l}23 \\
88 \\
28 \\
56\end{array}$ & $\begin{array}{c}24 \\
7 \\
21 \\
12\end{array}$ \\
\hline mean $(n=4)$ & 20 & 49 & 16 \\
\hline $\begin{array}{l}\text { Controls } \\
\text { mean }(n=7)\end{array}$ & notdone & 2 (range $1-5$ ) & $\frac{P}{O(\text { range } 0-0)}$ \\
\hline
\end{tabular}

\section{Quanification of the collagen content}

The collagen volume fraction as revealed with Sirius Red, is shown in Table I for the 20 patients. In chronic hibernating myocardium Sirius Red staining was visible around myocardial cells and was displayed as large bundles in the broadened interstitial spaces of the severely affected areas (Fig. 2a). In non- or less-affected zones such bundles were sparsely seen (Fig. 2b). The mean collagen volume fraction for non-infarcted chronic hibernating myocardium was about $5 \%$, and for patients with an infarction approximately $20 \%$. The collagen content in control myocardium was not assessed in the present samples but has been evaluated recently (10) and amounted to $2.7 \pm 0.5 \%$ in a control group of 18 patients without cardiovascular disease. In some of our patients the percentage of collagen, as determined by Sirius Red morphometry, was apparently higher than the percentage 

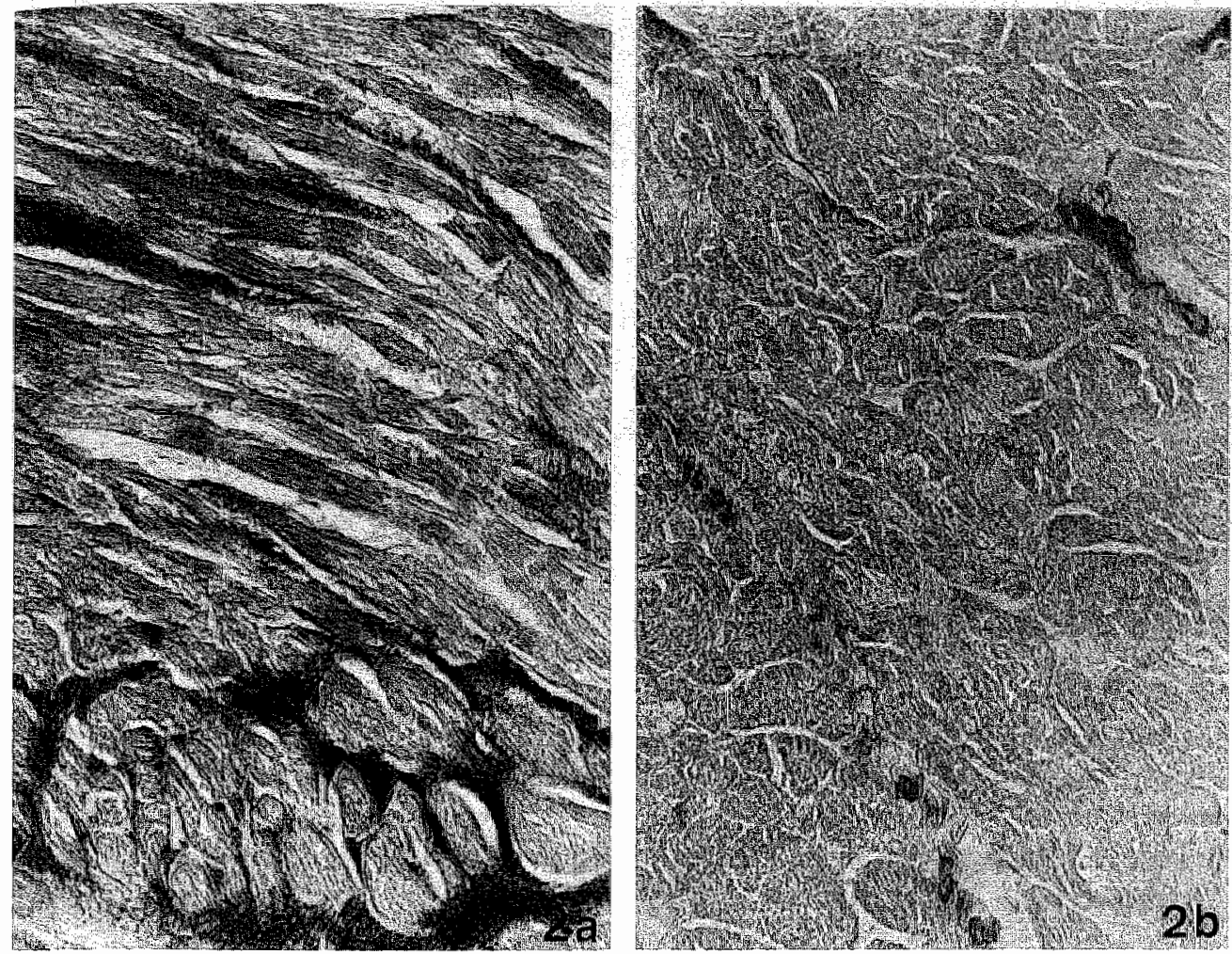

Figure 2. Sirius Red staining on frozen sections of the left ventricle. (a) Chronic hibernating myocardium surounded by extensive collagen deposits (armows). (b) Chronic hibernating myocardium with a low amount of Sirius Red-positive staining (arrows) and correspondingly a small increment of the extracellular matrix. Magnification X350.

of fibrosis as determined by intersection measurements. This difference may result from the fact that the two measurements were performed on different biopsies from the same patient and small differences in fibrosis do occur in adjacent areas of chronic hibernating myocardium.

\section{Immunofluorescence studies}

Collagen types I and III

As studied with polyclonal antibodies, type I and III collagens were present throughout the extracellular matrix of the myocardium, having a fibrillat appearance. In normal myocardium, bundles of interstitial collagen were concentrated mainly around blood vessels, while cardiomyocytes were found interspersed by small amounts of fine fibers of type I and III collagen (Fig. 3a). In 

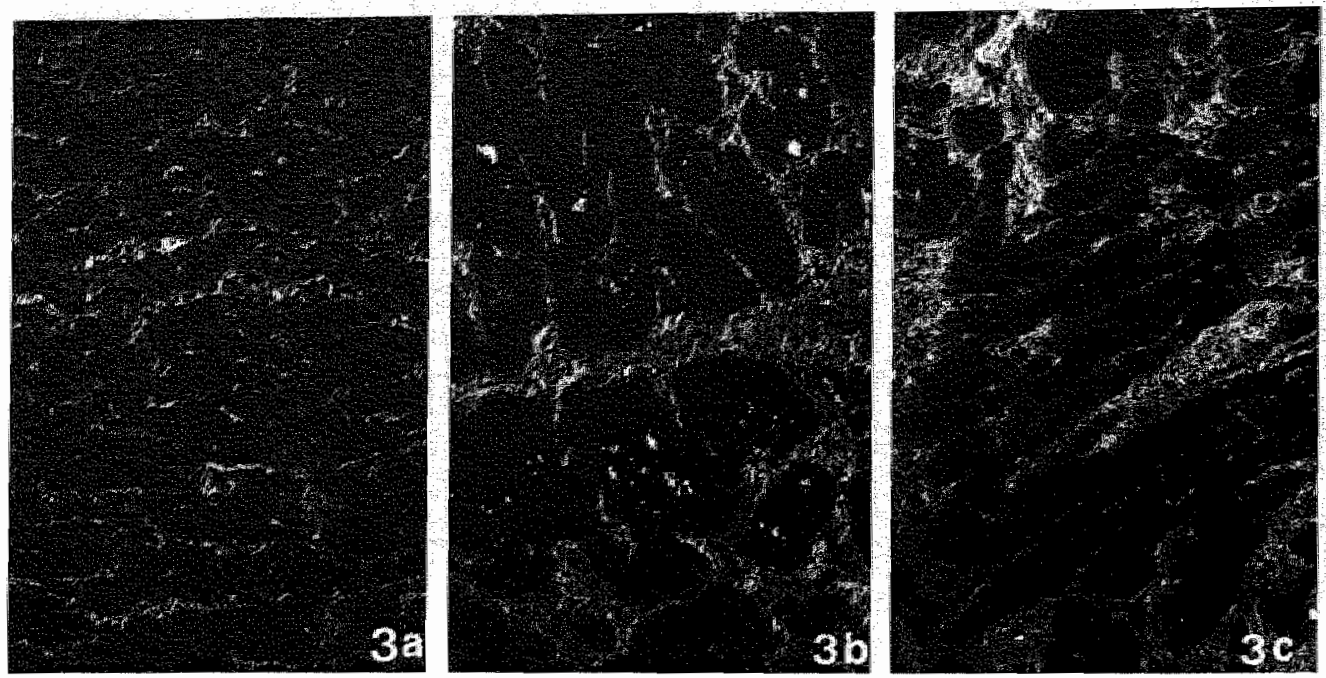

Figure 3. Immunofluorescence micrographs of frozen sections of myocardium incubated with anti-collagen type I. (a) Staining in control myocardium. Collagen $I$ is sparsely distributed throughowt the extracellular matrix. (b) Staining in chronic hibernating myocardium. Marked increase in the amount of collagen is seen in the enlarged interstitial space (arrows). (c) The border of an infarct (upper part) shows extensive staining of the markedly enlarged connective tissue compartment. Magnification: X235
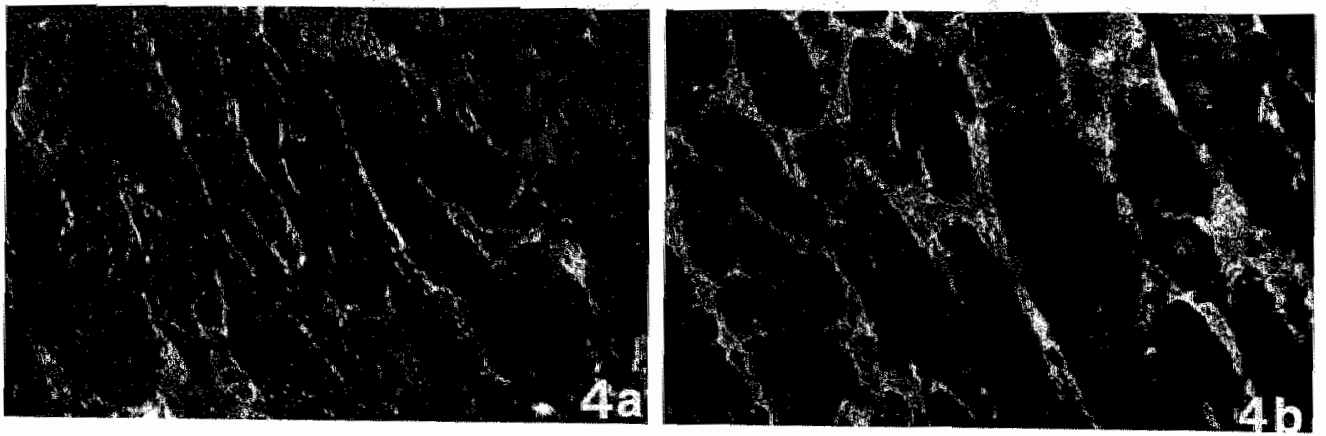

Figure 4. Immunofinorescence mictographs of frozen biopsies from chronic hibernating myocardiam. showing staining of fibronectin in an area with a nearly nomal interstitial space (a), and in a zone wish a markedly increased interstitial space (b) Note the increment in the amount of fibronectin in the latter (arrows). Magnification $X 270$. 
chronic hibernating myocardial segments increased amounts of type I and III collagen were seen throughout the enlarged interstitial space (Fig. 3b). The cardiomyocytes at the border of an infarcted zone were surrounded by these two collagen subtypes (Fig. 3c).

\section{Fibronectin}

In normal myocardium the immunoreactivity to fibronectin was present in the interstitial space between the cardiomyocytes and at the sarcolemma of myocardial cells (Fig. 4a). In chronic hibernating myocardial cells fibronectin was found in high amounts throughout the increased interstitial space, with a distribution pattern similar to that of collagens I and III (Fig. 4b). The chronic hibernating myocardial cells were never positive for fibronectin in their cytoplasm. As for type I and III collagens, the cardiomyocytes bordering an infarcted zone were surrounded by large amounts of fibronectin.

\section{Collagen IV and laminin}

Like fibronectin, type IV collagen and laminin are components of the basement membrane of the cardiomyocytes. In normal myocardium, type IV collagen and laminin were co-localized at the sarcolemma of cardiomyocytes. In chronic hibernating myocardium the basal lamina of cardiomyocytes stained in a normal way for type IV collagen and laminin (Fig. 5). In the interstial space, type IV collagen and laminin were both seen surrounding the endothelial cells of capiliaries and small interstitial cells.

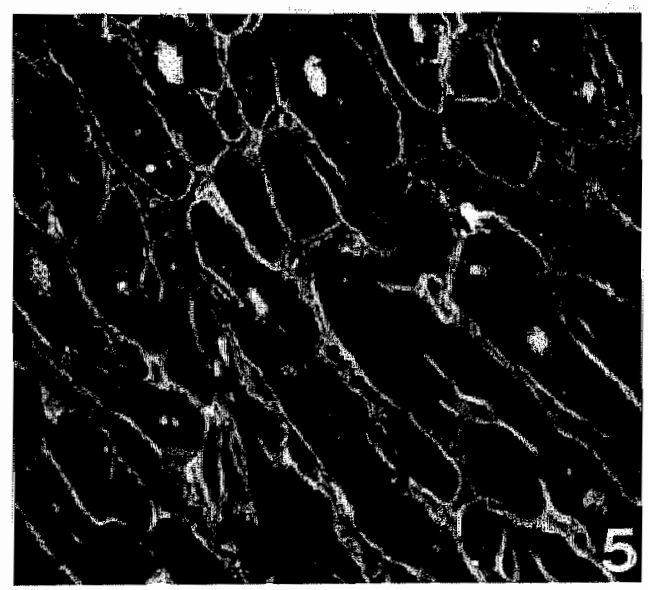

Figure 5. Immunofluorescence micrograph of a section from chronic hibernating myocardium showing immunohistochemical staining of the basement membrane with anti-collagen $N$. There are no abnormalities in the staining pattern compared with control myocardium. The extended extracellular spaces are indicated by asterisks. Magnification: X300. 


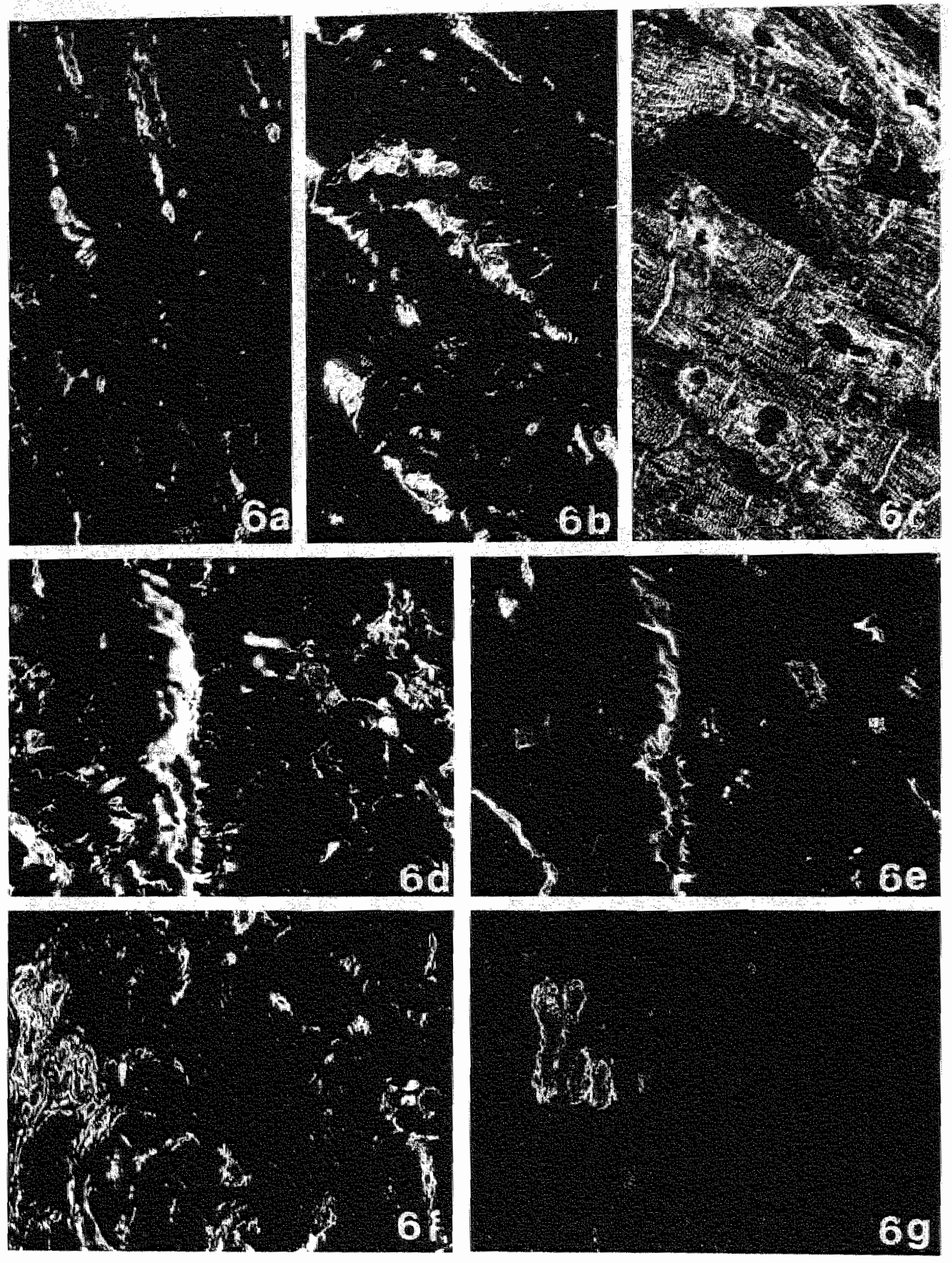


Figure 6. Immanofluorescence micrographs of control (a) and chronic hibernating myocardium $(b-g)$ incubated with antibodies to vimentin $(a, b, d, f)$, desmin (c) $\alpha$-smooth muscle actin $(g)$, or the endothetiat marker lectin (e). Figures $b$ and $c, d$ and $e, f$ and $g$ are double-label pictures of exactly the same area. For deraled explanation see text. Magnification:X300.

\section{Vimentin}

Vimentin normally stains mesenchymal cells. In normal myocardium vimentinpositive staining was detected within fibroblasts, endothelial cells and smooth muscle cells (Fig. 6a). In chronic hibernating myocardium the whole interstitial space was filled with numerous vimentin-positive cells (Fig. 6b). Most of the vimentin-positive cells were recognized as endothelial cells or fibroblast-like cells. This is also clearly evidenced by the large number of small DAPI-positive nuclei (Fig. 6b). The very intense staining for vimentin in the broadened interstitial spaces was due to the presence of a higher number of vimentin-containing cells. To make a clear distinction between cells of endothelial, fibroblast, myofibroblast and smooth muscle origin, specific markers for these cell types, respectively lectin, desmin and $\alpha$-smooth muscle actin were used. The vimentin-pasitive cells were not reactive for desmin (compare Fig $6 \mathrm{~b}$ and $\mathrm{c}$ ). Some of the vimentin-positive cells were identified as endothelial cells by their lectin-binding capacity (compare Fig $6 \mathrm{~d}$ and e). The reactivity to $\alpha$-smooth muscle actin was restricted to smooth muscle cells of blood vessels (compare Fig 6f and g).

\section{Discussion}

Cardiomyocytes of chronic hibernating myocardium undergo typical ultrastructural changes of which the replacement of sarcomeres by glycogen is the hallmark [1114]. Events of a purely degenerative nature, such as acute necrosis of myocytes, abnormal storage of lipids or multilamellar bodies, gross intracellular edema, or the presence of inflammatory cells, are only rarely seen. Cells with this hibernating. phenotype are found in severely stenosed myocardial segements derived from patients with or without previous infarction. In the former case, such cells frequently border the infarcted zone. The changes in the cardiomyocytes are accompanied by a marked increase in the amount of connective tissue material [11]. This increase is most pronounced in areas where the structurally affected cardiomyocytes prevail $[12,14]$.

\section{Quantification of the increase of extracellular matrix}

Quantification of the collagen content in chronic hibernating myocardium by Sirius Red morphometry emphasizes an increased volume fraction of collagen throughout the extracellular matrix. The average collagen concentration in chronic hibernating myocardium is about two times higher than in normal hearts [10]. Increases in the concentration of collagen similar to that of chronic hibernating myocardial 
segments were also found in non-infarcted segments of the rat myocardium after infarction [30].

In the present study a markedly increased immunofluorescence of types I and III collagen and fibronectin could be demonstrated in the extracellular matrix of chronic hibernating myocardium. Fibronectin was never seen in the cytoplasm of cardiomyocytes, as previously described for necrotic cardiomyocytes after myocardial infarction [31]. Necrosis of cardiomyocytes was seldom observed in our cases. In pressure-overload hypertrophy, the accumulation of collagen (called reactive fibrosis) occurred in the absence of cardiomyocyte necrosis [5,32]. This process also occurs in chronic hibernating myocardium.

\section{The basement membrane}

In addition to its presence in the extracellular matrix, fibronectin is also part of the basement membrane of cardiomyocytes. There is no difference in its location between normal and chronic hibernating cardiomyocytes. Other basement membrane components, such as type IV collagen and laminin, also show an identical distribution pattern between affected and non-affected tissues, suggesting that the basement membrane of chronic hibernating myocardial cells is intact. This is in strong contrast to what has been observed in necrotic cardiomyocytes during an acute infarction [33] or in dilated cardiomyopathy [34], where an irregular staining pattern for these constituents is displayed.

\section{The nature of the interstitial cells}

The question arises whether the increase in extracellular matrix is caused by an increased production of extracellular matrix components by existing interstitial cells or by an increase in the total number of interstitial cells. By use of the combination of DAPI staining of nuclei and an immunohistochemical approach for the determination of the phenotype of interstitial cells, it was demonstrated that in hibernating myocardium the number of cells of endothelial and fibroblast origin throughout the interstitial space is dramatically increased. Since these interstitial cells clo not contain desmin or $\alpha$-smooth muscle actin, they can be clearly differentiated from myofibroblasts. This suggests that no transformation of fibroblasts into myofibroblasts has occurred in these chronic hibernating segments, as is for instance the case in healing wounds [35-37] or in scar tissue of the heart during pressure-overload of the right ventricle [38]. It is therefore likely that the increased amounts of types I and III collagens and fibronectin in chronic hibernating myocardium are a result of increased fibroblast proliferation.

\section{Effect of the increased extracellular matrix}

The presence of an increased collagen content in the extracellular matrix may contribute to increased stiffness of the left ventricle, especially because the rigidity of type I collagen. This has been observed in patients with coronary artery disease 
and dilated cardiomyopathy [39]. Increased collagen concentrations leading to greater stiffness of the myocardium have also been described in conditions of pressure-overload hypertrophy $[5-7,9,32,38,40,41]$. In the rat hypertrophy model, fibroblast proliferation and collagen synthesis increased within several days after abdominal aorta constriction and resulted in an abnormal stiffness of the myocardium [5]. Furthermore, the excess collagen may impair contractile function of the cardiomyocytes, as a consequence of the disruption of force transmission between the contracting cells [41].

After restoration of the blood flow by coronary artery bypasss surgery, recovery of contractile function is often delayed in cases of chronic hibernating myocardium $[12,43]$. Although such a recovery to normal function is, at least in part, dependent on the building of a normal amount of sarcomeres, the presence of an extensive extracellular matrix compartment may certainly be one of the major causes of the delay in recovery. Full recovery conceivably might only occur when the interstitial tissue is recluced to normal proportions.

\section{References}

1. Eghbali M, Eghballi M, Robinson TF, Seifter S, Blumenfeld OO: Collagen accumulation in heart ventricles as a function of growth and aging. Cardiovase Res 23 : 723-729, 1989.

2. Caufield JB and Borg TK: The collagen network of the heart. Lab Invest 40, 364-372, 1979.

3. Weber KT, Janicki JS, Shroff SG, Pick R, Chen RM, Baskey KI: Collagen remodelling of the pressure overloaded, hypertrophied non-human primate myocardium. Circ Res 62: 757-765, 1988 .

4. Weber KT: Cardiac interstitium in health and disease: the fibrillar collagen network. J Am Coll Cardiol 13: 1637-1652, 1989.

5. Doering CW, Jalil JE, Janicki JS, Pick R, Aghili S, Abrahams C, Weber KT: Collagen network remodelling and diastolic stiffness of rat left ventricle with pressure overload hypertrophy. Cardiovasc Res 22: 686-695, 1988.

6. Jalil JE, Doering W, Janicki JS, Pick R, Clark WA, Abrahams C, Weber KT: Structural vs. contractile protein remodelling and myocardial stiffness in hypertropied rat left ventricle. J Mol Cell Cardiol 20: 1179-1.187, 1988.

7. Jali] JE, Doering W, Janicki JS, Pick R, Shroff SG, Weber KT: Fibrillar collagen and myocardial stiffness in intact hypertropied rat left ventricle. Circ Res 64: 1041-1050, 1989.

8. Pick R, Janicki JS, Weber KT: Myocardial fibrosis in nonhuman primate with pressure overload hypertrophy. Am J Pathol 135: 771-781, 1989.

9. Contard F, Koteliansky V, Marotte F, Dubus I, Rappaport I, Samual JL: Specific alterations in the distribution of extracellular matrix components within rat myocardium during the development of pressure overload. Lab lnvest 64: 65-75, 1991. 
10. Volders PGA, Willem IEMG, Cleutjens JPM, Arends J-W, Havenith MG, Daemen MAP: Interstitial collagen is increased in the non-infarcted human myocardium after myocardial infarction. $\mathbb{~ M o l ~ C e l l ~ C a r d i o l ~ 2 5 : ~ 1 3 1 7 - 1 3 2 3 , 1 9 9 3 . ~}$

11. Borgers M, Thone F, Wouters L, Ausma J, Shivalkar B, Flameng W: Structural correlates of regional myocardial dysfunction in patients with critically coronary artery stenosis: chronic hibenation? Cardiovasc Pathol 2: 237-245, 1993.

12. Vanoverscheldej-L, Wijns W, Depré C, Essamri B, Heyndricks GR, Borgers M, Bol $A$, Melin J: Mechanisms of chronic regional postischemic dysfunction in humans: new insights from the study of non-infarcted collateral dependent myocardium. Circulation 87 : $1513-1523,1993$.

13. Ausna $J$, Ramaekers $F$, Flameng $W$, Borgers $M$ : Cellular adaptation in hibernatingmyocardium in man. In: Hori $M$, Maruyama $Y$, Reneman RS (eds.) Cardiac adaptation and failure. Springer-Verlag, Tokyo, 85-99, 1994.

14. Maes A, Shivalkar B, Flameng W, Nuyts J, Borgers M, Ausma J, Bormans G, Schiepers C, De Roo M, Mortelmans L: Histological alterations in chronically hypoperfused myocardium: correlation with PET findings. Circulation 90: 735-745, 1994.

15. Schaart G, Vander Ven PMF, Ramaekers. FCS: Characterization of cardiotin, a structural component in the myocard. Eur J Cell Biol 62: 34-48, 1993.

16. Ausma J, Schaant G, Ramaekers F, Flameng W, Borgers M: Molecular changes in chronic hibernating myocardium. J Muscle Res Cell Motil 15: 211, 1994.

17. Flameng W, Wouters L, Sergeant P, Lewi P, Borgers M, Thoné F, Suy R: Multivariate analysis of angiographic histologic and electrocardiographic data in patients with coronary heart disease. Circulation 70: 7-17, 1984.

18. Junqueira LCU, Bignolas G, Bretani RR: Picrosirius staining plus polarization microscopy: a specific method for collagen detection in tissue sections. Histochem $J$ $11,447-455,1979$.

19. Bedossa P, Bacci J, Lemaigre $G$, Martin $E$ : Effects of fixation and procession on the immunohistochemical visualisation of type-I, -IIJ and IV collagen in paraffinembedded liver tissue. Histochemistry 88: 85-89, 1987.

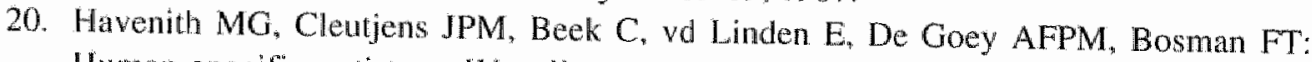
Human specific anti-type IV collagen monoclonal antibodies, characterization and immunochemical application. Histochemistry 87:123-128, 1987.

21. Van Helden WCH, Kok-Verspuy A, Harff GA, van Kamp GJ: Rate-nephelometric determination of frbronectin in plasma. Clin Chem 31: 1.182-1184, 1985.

22. Wewer U, Albrechtsen R, Manthorpe M, Varon S, Engvall E. Ruoslathi E: Human laminin isolated in a nearly intact biologically active form from placenta by limited proteolysis. J Biol Chem 20: 12654-12660, 1983.

23. Ramaekers FCS, Huijsmans A, Schart G, Moesker O, Vooijs GP: Tissue distribution of keratin 7 as monitored by a monoclonal antibody. Expl Cell Res 170: 235249,1987. 
24. Ramaekers FCS, Puts IJG, Moesker O, Kant A, Huysmans A, Haag D, Jap PHK. Herman CJ, Vooijs GP: Antibodies to intermediate filament proteins in immunohistochemical identification of human tumors: an overview. Histochen $\mathrm{J}: 15$, $691-713,1983$.

25. Woodoock-Mitchell J, Mitchell JJ, Low RB, Kieny M, Sengel P, Rubbia Li, Skalli O, Jackson $\mathrm{B}$, Gabbiani $\mathrm{G}$ : $\alpha$-Smooth muscle actin is transiently expressed in embryonic rat cardiac and skeletal muscles. Differentiation 39: 161-166, 1988.

26. Skalli O, Ropraz P, Trzeciak A, Benzonana G, Gillesen D, Gabbiani G: A monoclonal antibody against $\alpha$ smooth muscle actin: a new probe for smooth muscle differentiation. J Cell Biol 103: 2787-2796, 1986.

27. Raats FR, Henderik IB, Verdijk M, van Oort FLG, Gerards WLM, Ramaekers FCS, Bloemendall $\mathrm{H}$ : Assembly of the carboxy-terminally deleted desmin in vimentin free cells. Eur J Cell Biol 56: 84-103, 1991.

28. Schaart G, Viebahn C, Langmann W, Ramaekers FCS: Desmin and titin expression in early postimplantation mouse embryos. Development 107: 585 596, 1989.

29. Laitinen L, Hormia M, Virtanen I: Psophocarpus tetragonolobus agglutinin reveals Nacetyl galactosaminyl residues confined to endothelial cells and some epithelial cells in human tissues. I Histochem Cytochem 38: 875-884, 1990.

30. van Krimpen C, Smits JFM, Cleutjens JPM, Debels JJ, Schoenmaker RG, StruykerBoudier HAJ, Bosma FT, Daemen MJAP: DNA synthesis in the non-infarcted cardiac

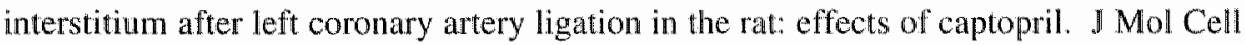
Cardiol 23: 1245-1253, 1991.

31. Cassells W, Kimura H, Sanchez JA, Yu Z-X, Ferrans VJ: Immunohistochemical study of fibronectin in experimental myocardial infarction. Am J Pathol 137:801 -810, 1990 .

32. Weber KT, Jalil JE, Janicki JS, Pick R: Myocardial collagen remodelling in pressure overload hypertrophy. A case for interstitial heart disease. Am Heart J 2: 931-940, 1989.

33. Vracko R, Cunninghasm D, Frederickson G, Thorning D: Basal lamina of rat myocardium. Its fate after death of cardiac myocytes. Lab Invest 58: 77-87, 1988.

34. Wolff PG, Kühl U, Schultheiss H-P: Laminin distribution and autoantbodies to laminin in dilated cardiomyopathy and myocanditis. Am Heart II 117: 1303-1309, 1989.

35. Gabbiani $G$, Le Lous $M$, Bailey AJ, Bazin $S$, Delaunary A: Collagen and myofibroblasts of granulation tissue. Virchows Arch B Cell Path 21: 133-145, 1976.

36. Darby I, Skalli I, Gabbiani G: $\alpha$-Smooth muscle actin is transiently expressed by myofibroblasts during experimental wound healing. Lab Invest 63: 21-29, 1990.

37. Skalli O, Schiirch, Seemayer T, Lagacé R, Montandon D. Pittet B, Gabbiani G: Myofibroblasts from diverse pathologic settings are heterogeneous in their content of actin isoforms and intermediate filament proteins. Lab Invest 60, 275-285, 1989.

38. Lesie KD, Taatjes DJ, Schwarz J, won Tunkovich M, Low RB: Cardiac myofibroblasts express alpha smooth muscle actin during right ventricular pressure overload in rabbit. Am J Pathol 139: 207-216, 1991. 
39. Bishop JE, Greenbaum R, Gibson DG, Yacoub M, Laurent GI: Enhanced deposition of predominantly type I collagen in myocardial disease. I Mol Cell Cardiol 22: 1157 $1165,1990$.

40. Weber KT, Brilla CG: Pathological hypertrophy and cardiac interstitium. Circulation 83: $1849-1865,1991$.

41. Villarreal FJ, Dillmam WH. Cardiac hypertrophy changes in mRNA levels for TGFB1, fibronectin and collagen. Am J Physiol 262. H1861-H1866, 1992.

42. Weber KT, Brilla CG, Janicki JS. Myocardial fibrosis : functional significance and regulatory factors. Cardiovascular Research 27: 341-348, 1993.

43. Tubau JF, Rahimtoola SH: Hibernating myocardium : a historical perspective. Cardiovase Drugs Ther 6: 267-271, 1992. 


\title{
Chapter 6 \\ Structural changes of atrial myocardium due to sustained atrial fibrillation in the goat
}

\author{
Jannie Ausma MSc, Maurits Wijffels MD PhD, Fred Thoné, Luc Wouters MSc, \\ Maurits Allessie MD PhD, Marcel Borgers PhD \\ submitted for publication
}

\begin{abstract}
Background

After cardioversion of sustained atrial fibrillation, the electrical and contractile functions of the atria are impaired and recurrences of atrial fibrillation frequently occur. Whether remodelling of the structure of atrial myocardium is the basis for this problem is not known.

Methods and Results

Sustained atrial fibrillation was induced by electrical pacing in 13 chronically instrumented goats. After 9 to 23 weeks the goats, were sacrificed and the atrial myocardium was examined by light and electron microscopy. A substantial proportion of the atrial myocytes (up to $92 \%$ ) revealed marked changes in their cellular substructures, such as loss of myofibrils, accumulation of glycogen, changes in mitochondial shape and size, fragmentation of sarcoplasmic reticulum, and dispersion of nuclear chromatin. These changes were accompanied by an increase in size of the myocytes (up to $195 \%$ ). There were no signs of cellular degeneration and the interstitial space remained unaltered.

Conclusion

Sustained atrial fibrillation in goats leads to structural changes in the atrial myocytes similar to those seen in ventricular myocytes from chronic hibernating myocardium.
\end{abstract}

\section{Condensed abstract}

Goats with sustained atrial fibrillation showed marked changes in structure of the atrial myocytes. Replacement of sarcomeres by glycogen was the most characteristic change, accompanied by changes in mitochondrial shape and size, fragmentation of sarcoplasmic reticulum and dispersion of nuclear chromatin. Cellular degeneration was absent, but a marked increase in cell volume was observed. These structural changes, which closely resemble the changes in hibernating ventricular myocytes, may explain the depressed contractile function of the atrial myocardium after cardioversion of atrial fibrillation. 


\section{Introduction}

Restoration of sinus rhythm after atrial fibrillation (AF) either by pharmacological or electrical cardioversion is often associated with a delayed recovery of atrial contractile function. The time needed for recovery appears to be related to the duration of atrial fibrillation prior to cardioversion. Immediately after cardioversion, the atrial contraction is uswally weak, but its strength increases progressively during the initial weeks of sinus rhythm. ${ }^{1-3}$ It is not clear whether this problem is based on functional or on structural changes. Alterations in myocardial structure in patients with atrial arrhythmias have been described previously by Mary-Rabine et al. ${ }^{4}$ In a group of patients with atrial arrhythmias of various aetiologies, these authors observed a variefy of structural changes in the atrial myocardium. In addition to degenerative changes, part of the myocytes showed changes in cellular substructures, such as loss of myofibrils, presence of glycogen granules, accumulation of sarcoplasmic reticulum-like material, and an abundance of mitochondria. While it was the patients with chronic atrial fibrillation who showed the most pronounced structural alterations, it was not clear however whether these structural abnormalities were caused by atrial fibrillation itself or by the concomitant underlying heart disease.

To study the structural changes in the atria resulting from chronic atrial fibrillation, we maintained atrial fibrillation in normal goats for a prolonged period of time. After 9 to 23 weeks of sustained AF, several areas of the right and left atria were examined by light and electron microscopy to investigate the structural alterations. due to atrial fibrillation and to compare the degree of change at different atrial sites.

\section{Material and Methods}

Twenty female goats, weighing between 41 and $82 \mathrm{~kg}$ were used for this study. Thirteen goats were subjected to sustained AF, and 7 in sinus rhythm served as controls. Animal handling was carried out in accordance with the guidelines of the American Society of Physiology and approved by the Animal Investigation Committee of Maastricht University.

\section{Chronic atrial fibrillation model}

The goat model of sustained atrial fibrillation (AF) has been described in detail by Wijftels et al.5 Briefly, the goats were chronically instrumented with multiple unipolar electrodes sutured to the epicardial surface of the free wall of the right and left atria and on the bundle of Bachmann. After a period of 2 to 3 weeks the animals were connected to a fibrillation pacemaker, which continously reinduced atrial fibrillation by automatic delivery of a I-second burst of stimuli $(50 \mathrm{~Hz})$ as soon as sinus rhythm resumed. Initially, the episodes of electrically induced AF were short-lasting and self-terminated after $6 \pm 3$ seconds. However, as a result of the artificial maintenance of $\mathrm{AF}$, the duration of AF progressively increased to become sustained ( $>24$ hours) after an average of $7.1 \pm 4.8$ days. The total duration 
of artificially maintained atrial fibrillation in the 13 goats ranged between 9 and 23 weeks (median $15 \pm 5$ weeks).

\section{Morphological assessments}

At the end of the period of sustained AF, the goats were anaesthetized with thiopental $(10-15 \mathrm{mg} / \mathrm{kg})$ and ventilated by halothane (1-2\%) and a 1:2 mixture of $\mathrm{O}_{2}$ and $\mathrm{N}_{2} \mathrm{O}$. The heart was quickly removed and parts of the left and right atrial wall, appendages, trabecular muscles, the inter-atrial septum and the bundle of Bachmann were cut into small blocks $\left(4 \mathrm{~mm}^{3}\right)$, fixed in $3 \%$ glutaraldehyde in $90 \mathrm{mM}$ potassium phosphate, buffered to a $\mathrm{pH}$ of 7.4 , and kept for at least $24 \mathrm{~h}$ at room temperature. After washing in the same buffer for another $24 \mathrm{~h}$, the tissue blocks were postfixed for $1 \mathrm{~h}$ in $1 \%$ osmium tetroxide, buffered with $50 \mathrm{mM}$ veronal acetate, rapidly dehydrated through a graded ethanol series and routinely embedded in Epon. ${ }^{6}$ The atria of the 7 goats in sinus rhythm were prepared in the same way.

For electron microscopy, ultrathin sections were cut from each sample, counterstained with uranium acetate and lead citrate, and examined in a Philips CM100 electron microscope.

\section{Quantification of atrial remodelling}

Sections $2 \mu \mathrm{m}$ thick, derived from various sites of the atria, were examined by light microscopy. To quantify the degree of myolysis and to identify cells with accumulation of glycogen, sections were stained with periodic acid Schiff (PAS) and counterstained with toluidine blue. ${ }^{7}$ In order to quantify the extent of myolysis in the cardiomyocytes, at least 2 sections per atrial site were examined and at least 200 cells per section were analyzed. The extent of cell change was evaluated only in cells in which the nucleus was present in the plane of the section. Cells were scored by morphometry as mildly myolytic if myolysis involved $10-25 \%$ of the cytosol and as severily myolytic if more than $25 \%$ of the sarcomeres were absent.

To assess the amount of connective tissue in the myocardium, morphometry was carried out with the aid of a grid of vertical and horizontal lines providing 121 intersections (points). This technique has been applied in a previous study. ${ }^{7}$ In accordance with the principles of morphometry, counting of the number of points overlying a certain structure results in quantitative determination of the volume of the structure under investigation in relation to the volume of the entire tissue under the square grid. The total number of points was defined as $100 \%$, and the points counted in the connective tissue were expressed as a percentage of the entire tissue within the limits of the grid. The same procedure was repeated on different areas of the same section. Blood vessels and perivascular interstitial cells were excluded from the connective tissue quantification.

To assess whether sustained atrial fibrillation induced changes in the size of cardiomyocytes, the surface area of the cardiomyocytes was measured with a 
digital imaging system (Metasystems equipment with ISIS software). Area measurements were performed for three categories of cells 1) normal cardiomyocytes (without myolysis), 2) moderately affected cells (between 10 and $25 \%$ inyolysio) and 3 ) severely affected cells ( $>25 \%$ myolysis). The measurements were performed in left atria, right atria and inter-atrial septa from 6 goats with sustained AF. The number of cells that were evaluated for each tissue sample varied between 262 and 388 .

\section{Statistical analysis}

Data on myolytic cell changes and connective tissue changes were tested for statistical significance by means of the Wilcoxon-Mann-Whitney rank test. Correlation between variables was evaluated using Spearman rank correlation. Exact two-tailed p-values were obtained with the StatXact program. ${ }^{8}$ P-values less than or equal to 0.05 were considered to indicate statistical significance.

Data on myocardial cell-size measurements were transformed to logarithms, since the original measurements showed to be log-normally distributed. Subsequently, a mixed effects analysis of variance ${ }^{9}$ with restricted maximum likelihood variance estimation, was carried out using the SAS system for statistical analysis. In this analysis, the classification of the myocytes (site, severity of alteration) served as fixed effect, while the animal for which the measurements were obtained was considered as a random effect. Mean values, adjusted for the number of measurements and overall level of each animal, and the corresponding $95 \%$ confidence intervals for the mean were obtained by back-transformation of the least squares estimates.

\section{Results}

\section{Structural changes after sustained atrial fibrillation}

\section{Light microscopy}

Atrial myocytes from goats in sinus rhythm showed compact sarcomeres occupying the entire cytoplasm (Fig 1a). In contrast, atrial myocytes of goats in sustained atrial fibrillation were often depleted of contractile material and showed accumulation of glycogen (Fig lb). In these cells, myolysis started in the perinuclear area and often extended towards the plasma membrane. This loss of sarcomeres did not result in atrophic degeneration of the cardiomyocytes. On the contrary, the myocytes were moderately enlarged (see quantitative assessments below). The myolysis and glycogen accumulation was seen at all different atrial sites.

No obvious changes were seen in the content or distribution of the connective tissue in the atrial myocardium. The numbers of fibroblasts, endothelial cells, pericytes and interstitial mesenchymal cells were normal. Inflammatory cell infiltrates were virtually absent. 

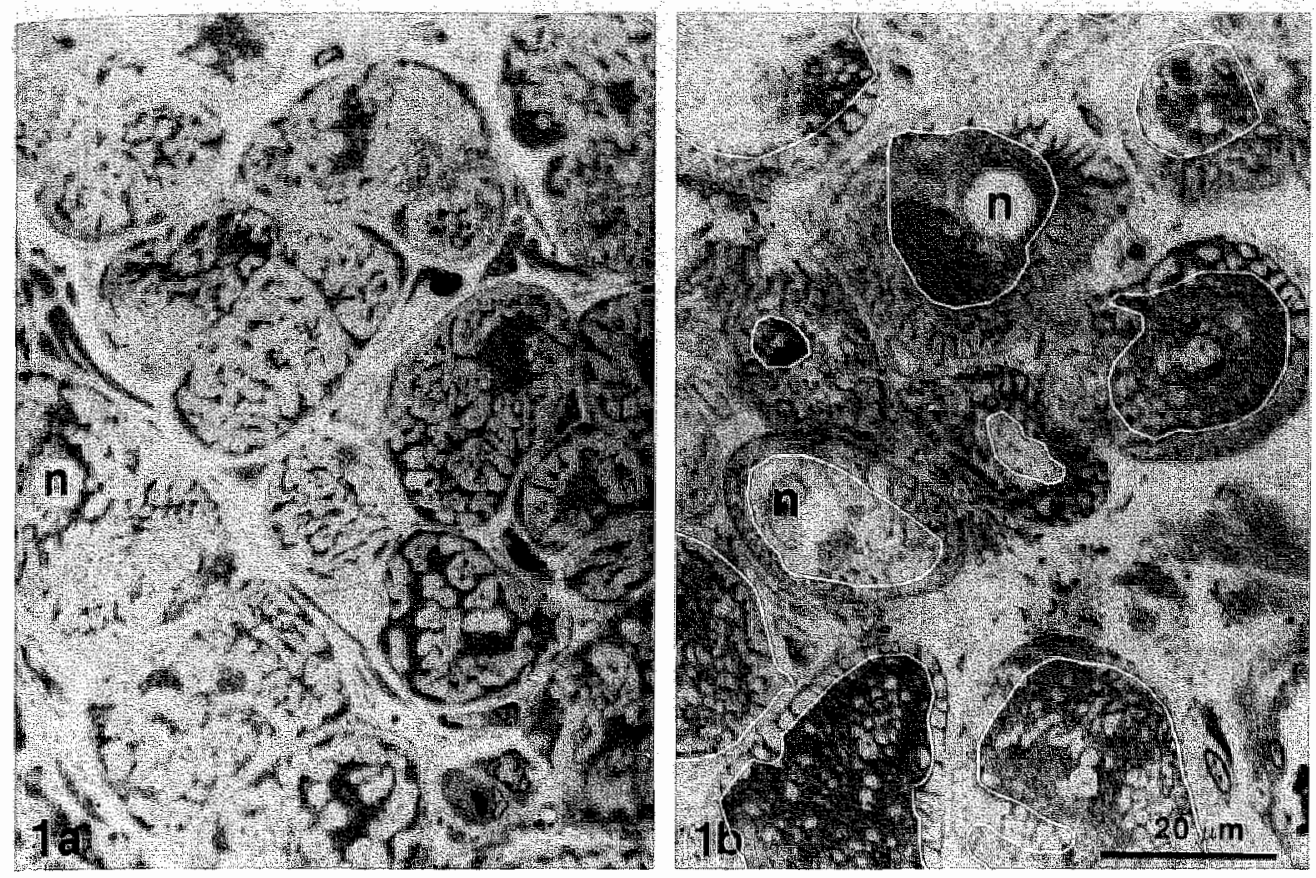

Figure 1: Light microscopy of 2 um thick sections fiom goat atrial myocondium.

a) Atrial myocardium from a goat in sinus rhythm with normally structured cardiomy. ocytes. PAS staining (gray areas) is almost absent within these cardiomyocyles. The sarcomeres, stained with toluidine blue, are present throughout the cytoplasm of the cardiomyacytes. $n=$ nucleus $(X: 830)$.

b) Section from a goat in chronic atrial fibrillation showing severe myolysis. The central past of the myocytes is free of sarcomeres (circled areas). Most cells contain abundant glycogen (PAS positive staining); $n=$ nucleus. $(X: 830)$.

\section{Electron microscopy}

At the ultrastructural level, atrial myocytes from goats in sinus rhythm showed a highly organized sarcomeric structure with rows of uniformly sized mitochondria in between (Fig $2 \mathrm{a}, 3 \mathrm{a}$ ). Atrial granules were mainly confined to the perinuclear area. A typical distribution of heterochromatin in the form of clusters at the nuclear membrane was present in all cardiomyocyte nuclei (Fig 3a).

The atrial myocytes from goats in sustained atrial fibrillation had undergone typical alterations of a non degenerative nature. The following characteristic changes were observed: 1) Depletion of contractile material (myolysis). The disappearance of sarcomeres was often limited to the vicinity of the nucleus, but also frequently involved the entire cytosol in which then only fragments of sarcomeres were present (Fig 2b, 3b). In cells showing a moderate degree of myolysis, the 

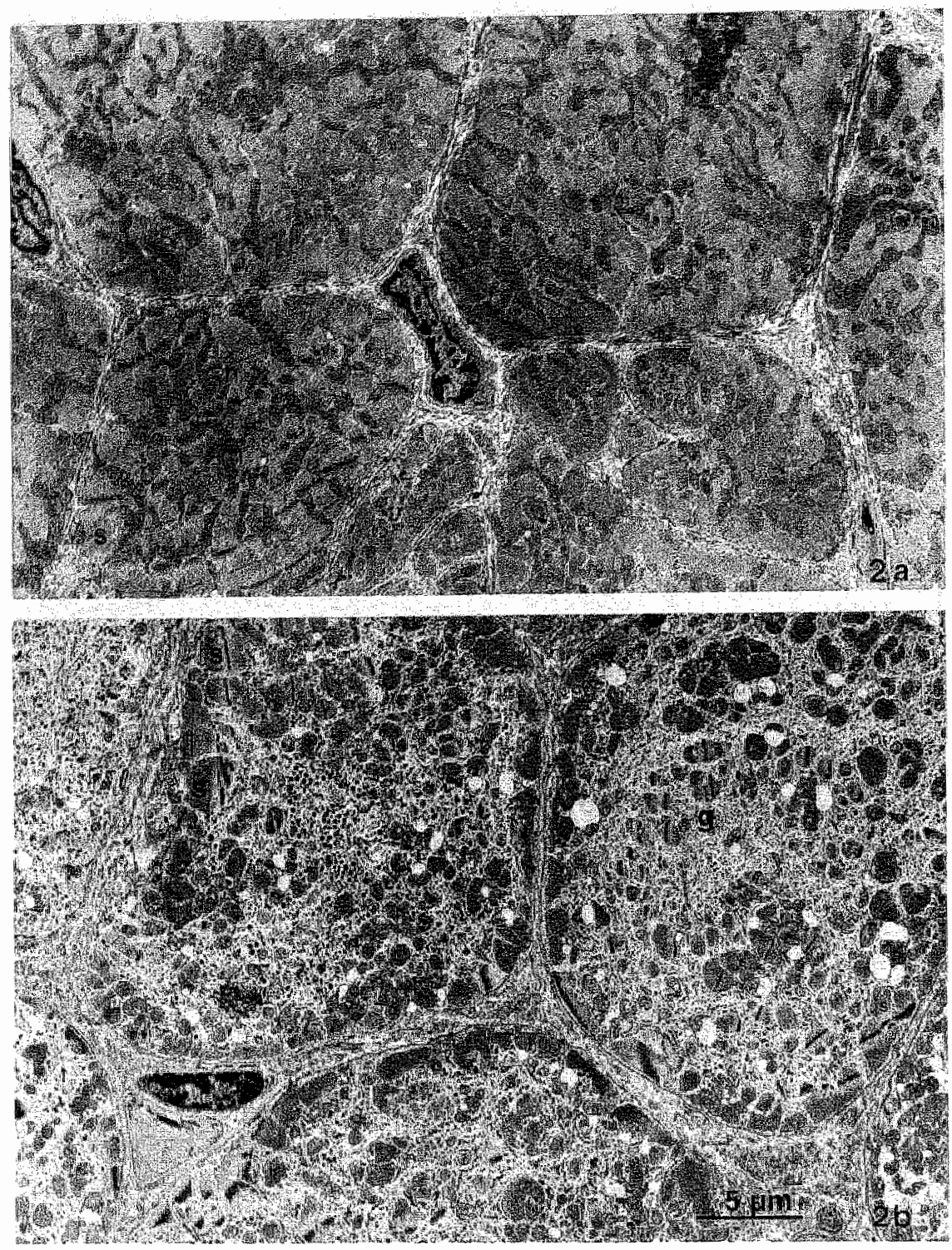

Figure 2. Electron microscopy of goat atmal myocardiam.

a) Arial myocardium from a gaat in sinus rhytm. Nate the presence of sarcomeres $(s)$ thrughou the entre cyosol and the presence of nomal mitochondra $(m)$ berween the sarcomeres. $(X: 3000)$.

b) Sevely affected atrial mocardium from a goat in chromic atrial fibrillation. Normal sacomeses (s) are only present at the periphery of the cells, with residual parts of sarcomeres also present more centrally. Glycogen (gl) has accumulated in the sarcomene-depleted areas, $(X .3000)$. 

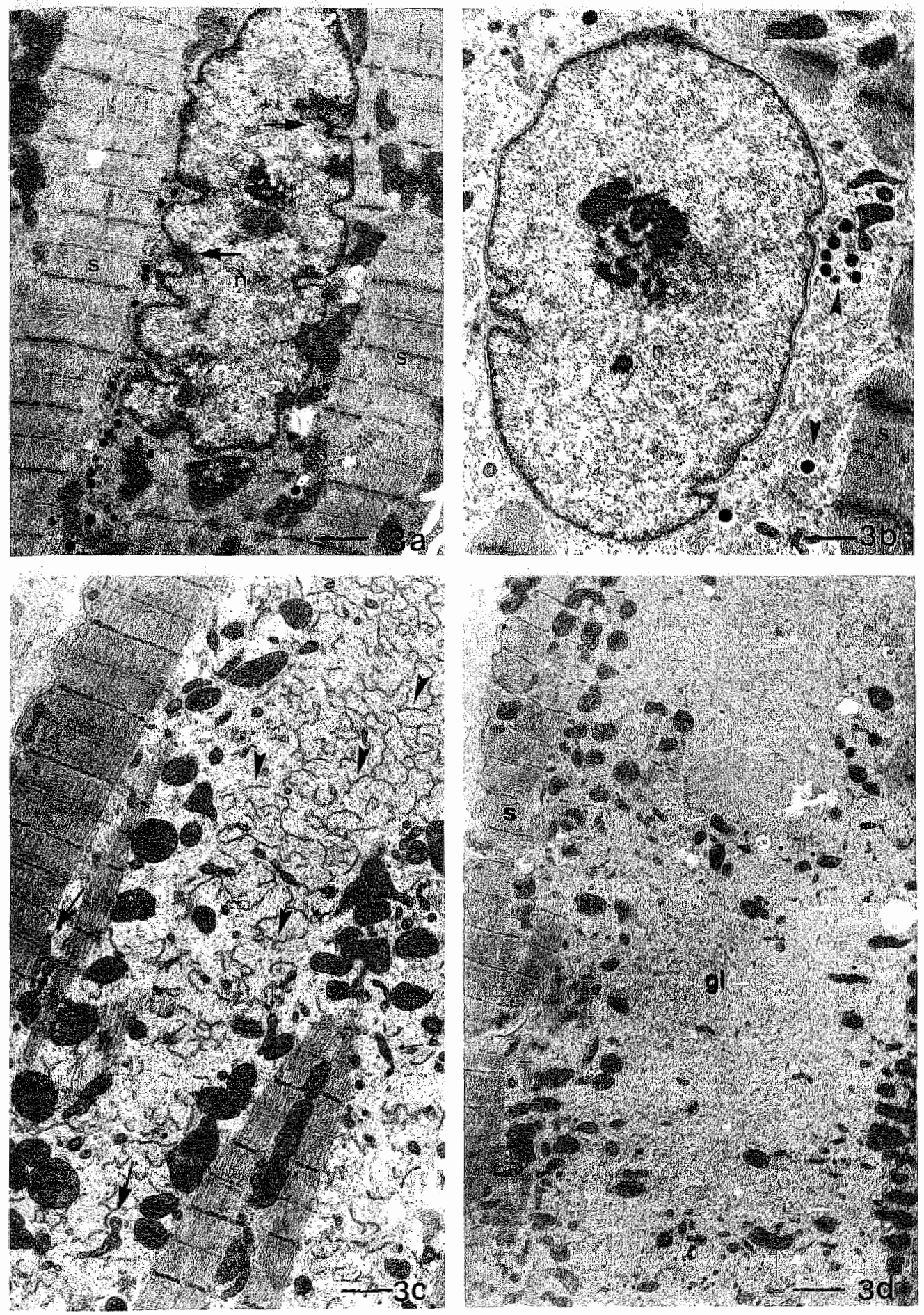
Figure 3. Electron microscopic pictures showing details of the subcellular organisation of the atrial myocardium from goats in simus thythm (a) and after prolonged atrial fibrillation $(b, c, d)$.

a) Detal of a nonal atrial cardionyocyte from a control animal showing regularly strucwed sarcomeres ( $s$ ) surpounding the nuclews (n) in which the heterochromatin (arrows) is clustered near the wuclear membrame (X:5670).

b) Detail of the nuclear area from chrowically fibrillating myocardium showing the dispersion of heterochromatim throughout the nucleus $(n)$. In the vicinity of the nucleus the sarcomeres are dissolved and glycogen is present. Some remnants of sarconteres (s) can still be seen. Atrial granules (arrowheads) are found in the vicinity of the nucleus (X:5670).

c) Longindinal section of part of an atrial cardiomyocyte from chronically fibrillating atrial myocardium showing remants of sarcoplasmic reticulum membranes (arrowheads) and abnowally shaped mitochondria (arrows) ( $x: 7500)$.

d) Severely affected myolytic atrial cardiomyocyte with huge amounts of glycogen (gl) prew sent in the myolytic area. Only a rim of sarcomeres (s) is still present at the border of the cell $(X: 4400)$.

peripherally located sarcomeres maintained their structural integrity (Fig 3c). 2) Huge amounts of glycogen filled the myolytic space in almost all cells that underwent myolysis (Fig 3d). 3) A network of disorganized membranes, most probably remnants of sarcoplasmic reticulum, were present in myolytic areas (Fig 3c). 4) Another typical change was observed in the mitochondria residing in the areas depleted of sarcomeres: many mitochondria were smaller, and had become elongated, with their cristae orientated in a longitudinal fashion (Fig. 3c). In crosssections, such mitochondria had a doughnut-like shape (Fig 3c). 5) A final characteristic alteration was seen in the nuclei: whereas in normal myocytes the heterochromatin is clustered in condensed aggregates near the nuclear membrane, the heterochromatin was now dispersed uniformly throughout the nucleoplasm (Fig. 3b). These nuclei resembled the interphase nuclei of myocytes during embryonic/fetal development. There were no clear signs of subcellular degeneration, such as cytolysis, the formation of an extensive lysosomal apparatus, the presence of autophagic vacuoles, mitochondrial swelling or loss of the integrity of the sarcolemma. 


\section{Quantification of the structural changes}

Morphometric assessment of the number of myocytes with myolysis or glycogen accumulation, the extent of myolysis in each cardiomyocyte and the amount of connective tissue (interstitial space) was performed in 13 goats with sustained atrial fibrillation and in 7 goats in sinus rhythm. Changes in the size of the atrial myocytes was correlated with the extent of myolysis in 6 goats with chronic atrial fibrillation. In all goats with sustained atrial fibrillation, a considerable but variable proportion of the atrial myocytes (up to $92 \%$ ) was affected by myolysis. Cells were considered to be mildly affected when 10 to $25 \%$ of the sarcomeres had disappeared. Cells with $>25 \%$ myolysis were considered to be severely affected. The results of the morphometric analysis are presented in table 1, together with the statistical analysis ( $p$-values). The percentage of myolytic myocytes was significantly higher in all parts of fibrillating atria examined. While during sinus rhythm $7.4 \%$ of the myocytes from the left atria showed some degree of myolysis, $51.8 \%$ of the cardiomyocytes in atria from goats with chronic atrial fibrillation showed mild or severe myolysis. For the right atrium these percentages were $8.2 \%$ and $58.9 \%$ respectively ( $<<0.01$ ). In goats in sinus rhythm, $12.8 \%$ of the cells in the inter-atrial septum were myolytic, compared to $47.8 \%$ after sustained atrial fibrillation $(p<0.01)$. In the left atrial appendage $22.2 \%$ of the myocytes from goats in sinus rhythm were myolytic compared with $33.3 \%$ in goats with chronic atrial fibrillation $(\mathrm{p}<0.05)$. In the right atrial appendage, similar differences were observed, $10.3 \%$ vs. $45.5 \%(p<0.05)$. For trabeculae in the left atrium the percentages were $13.7 \%$ vs. $32.7 \%(\mathrm{p}<0.05)$ and in the right atrium $7.4 \%$ vs. 46.2 $\%(\mathrm{p}<0.05)$. In goats with prolonged $\mathrm{AF}$, the number of myolytic cells in the bundle of Bachmann was not different from other areas in the atria.

If only the severely affected myocytes ( $>25 \%$ myolysis) are considered, a statisically significant difference between myocytes from goats in sinus rhythm and those in sustained AF was found at all sites with the exception of the right atrial appendage and the inter-atrial septum (Table 1 ).

The myolytic changes were accompanied by an increase in size of the myocytes. In table 2, the mean sizes of the atrial myocytes, together with the $95 \%$ confidential intervals, are given for myocytes without myolysis, and those with mild and with severe myolysis. The cell size was significantly different in the three groups $(\mathrm{p}<0.01)$. The adjusted means of the right atrial cell size, obtained by the mixed models analysis of variance was $158 \mu \mathrm{m}^{2}$ in cells without myolysis, $226 \mu \mathrm{m}^{2}$ in cells with mild myolysis, and $295 \mu \mathrm{m}^{2}$ in cells with severe myolysis. The adjusted means in the left atria were $170 \mu \mathrm{m}^{2}, 240 \mu \mathrm{m}^{2}$ and $335 \mu \mathrm{m}^{2}$ respectively. For the inter-atrial septum these values were $187 \mu \mathrm{m}^{2}, 253 \mu \mathrm{m}^{2}$ and $334 \mu \mathrm{m}^{2}$. The degree of myolysis was thus clearly correlated with an increase in size of the myocyte $(p<0.01)$. 


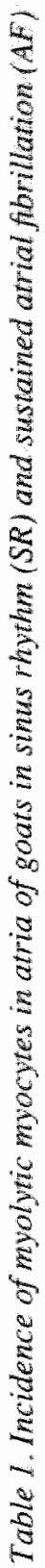

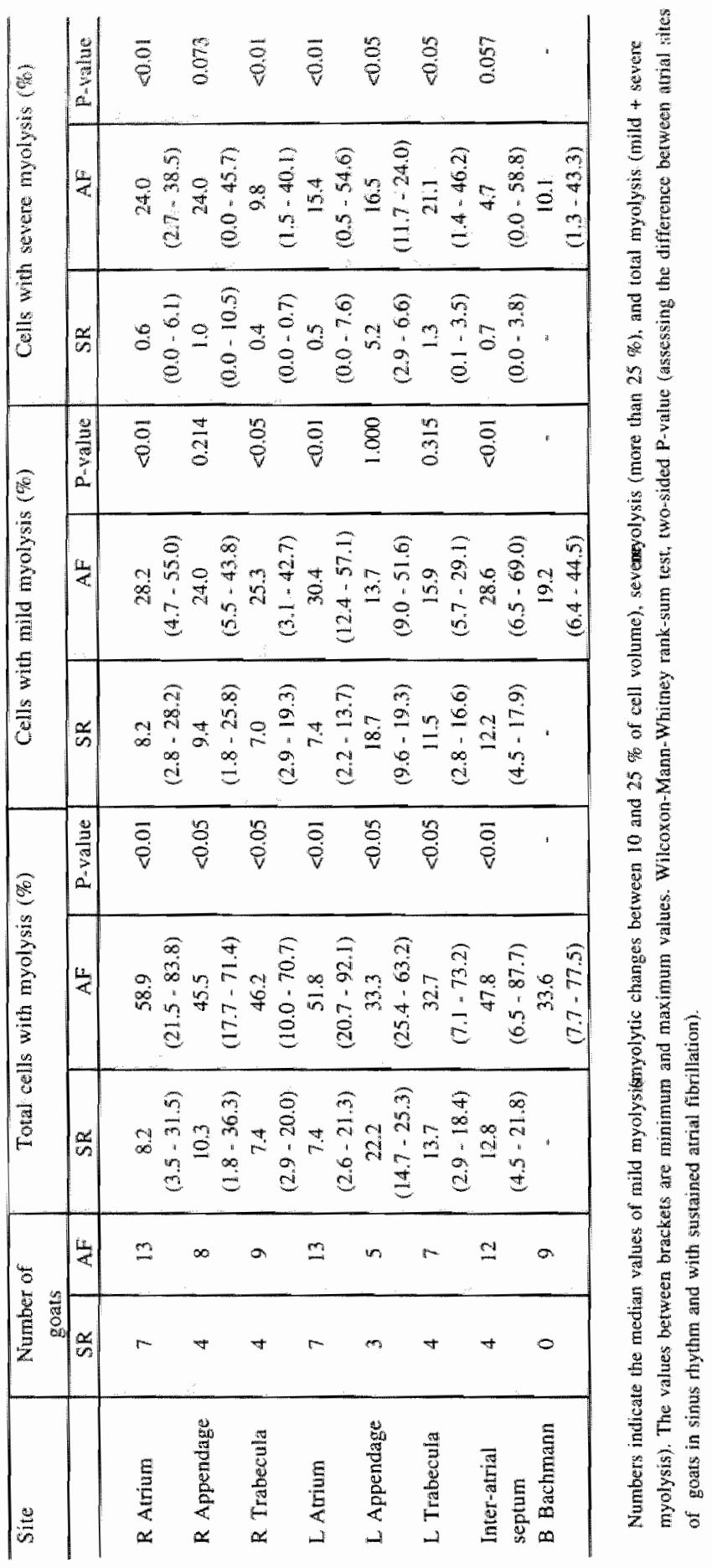


Table 2. Size of atrial myocytes (am2) whout and with mild and severe myolysis in goats with chronic atrial fibrillation.

\begin{tabular}{|c|c|c|c|}
\hline Site & Normal cells (4m) & Nild myolysis $\left(\mathrm{mm}^{2}\right)$ & Severe myolysis $\left(\mathrm{mm}^{2}\right)$ \\
\hline Right atrial free wail & $\begin{array}{c}158 \\
(n=354: 133-188)\end{array}$ & $\begin{array}{c}226+ \\
(\mathrm{n}=368 ; 191-269)\end{array}$ & $\begin{array}{c}2951 \\
(\mathrm{n}=292 ; 269-351)\end{array}$ \\
\hline Left atriall free wall & $\begin{array}{c}170^{*} \\
(\mathrm{n}=357 ; 143-202)\end{array}$ & $\begin{array}{c}240 t \\
(n=359202-286)\end{array}$ & $\begin{array}{c}3351 \\
(n=263 ; 282-399)\end{array}$ \\
\hline Inter-atrial septum & $\begin{array}{c}187^{*} \\
(\mathbf{n}=281: 157 \cdot 222)\end{array}$ & $\begin{array}{c}253 \frac{1}{1} \\
(n=300,213-301)\end{array}$ & $\begin{array}{c}3341 \\
(n=262 ; 281 \cdot 398)\end{array}$ \\
\hline
\end{tabular}

Walues represent adjusted means according to a mixed models analysis of wariance, mumber of cells, and 95 of confidence the mean.

* No signifant difference compared with either of the two other atrial sites

Statistical differences between the cell types with different degrees of myolysis $(*+1$, 1) for the three sites examined.

The changes in size were not different between left and right atrium and the interatrial septum. The connective tissue did not undergo any quantitative modification by prolonged atrial fibrillation: no significant differences in the percentage of connective tissue were found in the atria of goats in sinus thythm and sustained atrial fibrillation. The descriptive statistics together with the p-values (median, minimummaximum) of the morphometric analysis are given in table 3 . The percentage of interstitial tissue did not different between the different atrial sites.

The difference in duration of atrial fibrillation, varying between 9 and 23 weeks, did not lead to statistically significant differences in degree of the structural change in atrial myocytes (mild, severe and total myolysis) and connective tissue content.

Table 3. Relative quantity of connective tissue in atrial myocardium of goats in sinus rhythm (SR) and sustained atrial fibrillation (AF)

\begin{tabular}{lrrr}
\hline Site & \multicolumn{3}{c}{ Percentage of connective tissue } \\
\hline & \multicolumn{1}{c}{ SR } & AF & P-value \\
\hline R Atrium & $9.4(1.3-16.7)$ & $16.1(3.7-23.11$ & $0.10 \|$ \\
R Appendage & $15.0(4.5-21.7)$ & $10.3(3.6-17.8)$ & 0.283 \\
R Trabecula & $11.0(3.2-14.5)$ & $10.5(2.5-19.0)$ & 0.940 \\
L Atrum & $8.0(1.5-13.5)$ & $8.7(2.5-19.9)$ & 0.234 \\
L Appendage & $10.4(9.7-12.8)$ & $11.9(8.6-16.6)$ & 1.000 \\
L Trabecula & $12.0(2.7-15.2)$ & $10.7(3.0-19.3)$ & 1.000 \\
Septum & $13.2(1.4-19.4)$ & $12.9(2.3-26.0)$ & 0.521 \\
B Bachmann & & $20.7(3.8-26.7)$ & \\
\hline
\end{tabular}

Numbers indicate the median walues the percentage of connective tisstue.

The values between brackels are minimum and naximum values

Wilcoxon-Mann-Whitney rank-sum tesa, lwo-sided $P_{\text {-value }}$ (assessing the difference between atrual sites of goats in sinus thyhm and witli sustained atriabl fibrillation) 


\section{Discussion}

The present ultrastructural study and morphometric assessment in atrial tissue from goats in sustained atrial fibrillation elucidated profound structural changes in the atrial myocytes. Depletion of contractile material and accumulation of glycogen were found in a substantial proportion of the myocytes derived from a variefy of atrial sites. Two remarkable features accompanied these myolytic changes. First of all, the cells did not show atrophy, but, on the contrary, were enlarged in size. The increase in cell size appeared to correlate with the degree of myolysis. The myocytes from the fibrillating atria did not show any degenerative changes. Secondly, quantitative assessment failed to demonstrate any alterations in the extracellular matrix.

The changes in atrial myocytes described above should be compared with the alterations reported for a variety of other pathophysiological conditions of the atrial myocardium, both in humans and in animals.10-12 In patients with atrial arrhythmias, Mary-Rabine and co-workers showed that myolysis and glycogen storage were only observed in a small number of cells and that these changes were frequently accompanied by "lysosomal degeneration". These structural abnormalities appeared to be more pronounced when the underlying pathology was aggravated by sustained atrial fibrillation. ${ }^{4}$

Patients with an atrial septum defect and atrial dilatation have been reported to show focal degenerative changes. ${ }^{10}$ Some of the cells were myolytic and showed similar alterations in the myofilaments, sarcoplasmic reticulum, mitochondria and cytosol to those seen in our study. Similar changes have also been described in cardiomyopathic feline hearts with atrial arrhythmias, and in dogs with mitral valve stenosis and intermittent atrial arrhythmias. ${ }^{\| 1,12}$ These changes were characterized as "degenerative", although degeneration involving the lysosomal compartment was absent.

In most of the above studies, the term degeneration was used as a synonym for loss of myofilaments. In our opinion, cellular alterations that are not accompanied by lysosomal degradation, should not be interpreted as degenerative, but should be described as dedifferentiation.

During cardiac development, cardiomyocytes show some specific structural features like paucity of contractile filaments and sarcoplasmic reticulum, glycogen storage, mitochrondrial shape changes, homogeneous nuclear chromatin distribution. Since we found similar changes in myocytes from chronically fibrillating atria, these subcellular changes could be regarded as phenotypic changes, characteristic for dedifferentiation of the cells. This is futher supported by the close resemblance of these cells with P-cells in the sinus- and AV-node and the transitional cells of the atrial myocardium. These transitional cells have been referred to by others as embryonic-like cells. ${ }^{13,14}$ 
What causes the structural changes of the atrial myocardiun due to sustained atrial fibrillation?

The possible causes underlying the structural modifications during prolonged atrial fibrillation are not well understood. Sarcomere depletion might occur as a result of prolonged absence or down-regulation of contractile activity. Non- or less contractile segments of the heart become subjected to increased passive stretch, which may induce ultrastructural changes. The passive stretch of non-contracting myocardium may be particularly important for the explanation of the increase in size of the cardiomyocytes. ${ }^{15,16}$ A role of normal contractile activity for maintaining a normal sarcomere structure is further supported by mechanical unloading and reloading experiments. ${ }^{17,18}$ On the basis of these experiments, it was concluded that sustained contractile activity of cardiac muscle appears to be essential for the maintenance of the contractile filaments.

A striking observation was that in most of the myolytic cells, glycogen accumulated at sites where sarcomeres were depleted. The reason for this glycogen storage is not known, but it has been suggested that a lowered oxygen supply/demand ratio may play an important role by switching the energy metabolism from the use of fatty acids to the use of glucose. ${ }^{19}$ White and coworkers showed that immediately after induction of atrial fibrillation, oxygen consumption in the atrial tissue increases more than threefold, resulting in a marked reduction of the flow reserve during atrial fibrillation. ${ }^{20}$ Whether atrial fibrillation actually causes ischemia is at present unknown. Intracellular accumulation of glycogen may either be the result of a metabolic excess of glucose, or the consequence of impaired catabolism of glycogen, due to a deficient phosphorylase activity, for instance. ${ }^{21}$ The cell volume is maintained despite the depletion of contractile material, and, in fact, an increase in cell volume was observed. We believe that the glycogen accumulation, which correlated strongly with the degree sarcomere-depletion, is responsible for the increase in cell volume. Storage of large quantities of glycogen has also been found in fetal cardiac muscle 22 , and in a number of cardiac cells such as Purkinje fibres and atrio-ventricular node cells ${ }^{23}$, and in transitional atrial cells ${ }^{13}$ in adult hearts.

\section{Sustained atrial fibrillation as a model for chronic hibernating myocardium}

Chronic hibernating myocardium, a condition that occurs in patients as a result of low flow ischaemia caused by stenosis of one or more coronary arteries 24.25 displays structural changes in ventricular myocardium similar to the changes in atrial myocardium due to sustained atrial fibrillation. ${ }^{7.26}$ Replacement of contractile elements by glycogen, disorganisation of sarcoplasmic reticulum, the presence of numerous mini-mitochondria and changes in nuclear shape all are features also found during ischaemia-induced myocardial hibernation. The long time required for recovery of contractile function (weeks to months), as seen in some patients after restoration of blood flow to the hibernating segments, may be explained by the 
long time needed to reverse the structural alterations assigned as cellular dedifferentiation, a process presumed to need time to reverse. 27,28

To date, there are no animal models available in which the structural adaptations of the myocardium mimic those of chronic hibernating myocardium in man. The animal model presented here may be the first to lend itself to the study of the events leading to such cellular adaptations. Although we realize that this is a model with structural adaptations in atria and not in ventricular myocardium, we think it can provide valuable answers to a series of essential questions pertaining to chronic hibernating myocardium.

Possible clinical relevance

In patients with chronic atrial fibrillation, there is a correlation between the duration of atrial fibrillation and the time needed to recover atrial contractile function after cardioversion. In these patients it may take several weeks for the atrial contractile function to recover. ${ }^{\text {t-3 }}$

The changes in subcellular structure of the atrial myocytes due to prolonged episodes of atrial fibrillation as described in this paper may explain the lack of immediate recovery of contractile function in the atria after successful conversion to sinus rhythm. After regular synchronous triggering of contraction of the atria has been restored, it may take the cardiomyocytes several days to rebuild a normal amount of sarcomeres. In vitro studies have shown that myolysis can be induced in cultures of cardiomyocytes in which beating was arrested by verapamil. After the verapamil was removed, it took the cells 3 days to rebuild a normal contractile machinery and recover from the arrest. 18

The considerable loss of contractile material resulting from sustained fibrillation might explain the prolonged contractile failure after conversion to sinus rhythm in patients. ${ }^{1,2}$ One important difference between structural changes seen in our model and those reported in patients with atrial fibrillation is that only in the patients increases in connective tissue were observed 4,10 The absence of measurable changes in the interstitial space in goats with chronic atrial fibrillation may explain the relatively fast recovery of normal function, within 2 weeks (Allessie, unpublished). An extensive modulation of the interstitial space, as occurred in patients, would contribute to an increased stiffness of the myocardium, thus impairing contractile function, and would offer an explanation for the very long delay in recovery of normal function after cardioversion. ${ }^{1}$ It is conceivably that full recovery might occur only when the interstitial tissue has returned to normal proportions.

\section{Limitations}

Although this study clearly shows that atrial fibrillation leads to marked changes in the atrial myocytes, the mechanisms causing these structural alterations are not known. Our present study cannot answer the question whether quiescence of the atrial myocardium, elevated stretch on the atrial wall, and/or ischemia is the trigger 
for the structural changes observed. Another limitation is that goats were sacrified after 9-23 weeks of atrial fibrillation and therefore effects of longer duration of atrial fibrillation, up to a year remain unknown. In particular, therefore, the important question whether degeneration of the atrial myocytes and fibrosis formation as observed in human pathology is a result of long-lasting atrial fibrillation remains unanswered.

\section{References}

1. Manning W, Silverman D, Katz S, Riley M, Came P, Doherty R, Munson J, Douglas $P$. Impaired left atrial mechanical function after cardioversion: relation to the duration of atrial fibrillation. J Am Coll Cardiol. 1994; 23:135-140.

2. Manning WJ. Leeman DE. Gotch PJ., Come PC. Pulsed evaluation of atrial mechanical function after electrical cardioversion of atrial fibrillation. I Am Coll Cardiol. 1989; 13:617-623.

3. Van Gelder IC, Crijns HJGM, Blanksma PK, Landsman MLJ, Posma JL, Vanden Berg MP, Meijler FL, Lie KI. Time course of hemodynamic changes and improvement of exercise tolerance after cardioversion of chronic atrial fibrillation unassociated with cardiac valve disease. Am J Cardiol. 1993; 72: 560-566.

4. Mary-Rabine L, Albert A, Pham TD, Hordof A, Fenoglio JJ, Malm JR, Rosen MR. The relationship of human atrial cellular electrophysiology to clinical function and ultrastructure. Circ Res. 1983; 52:188-199.

5. Wijffels MCEF, Kirchhof CJMJ, Dorland R, Allessie MA. Atrial fibrillation begets atrial fibrillation. Circulation. 1995;92:1954-1968.

6. Flameng W, Wouters L, Sergeant P, Lewi P, Borgers M, Thoné F, Suy R. Multivariate analysis of angiographic, histologic, and electrocardiographic data in patients with coronary heart disease. Circulation. 1984; 70:7-17.

7. Borgers M, Thoné F, Wouters L, Ausma J, Shivalkar B, Flameng W. Structural correlates of regional myocardial dysfunction in patients with critical coronary artery stenosis: chronic hibernation? Cardiovasc Pathol 1993; 2:237-245.

8. Mehta C, Patel N. StatXact, Statistical Sofiware for Exact Nonparametric Inference. Cambridge, MA: CYTEL Corporation, 1995.

9. Littel] RC, Milliken GA, Stroup WW, Wolfinger RD. SAS@ System for mixed models. SAS intitute, CARY, NC, 1996.

10. Fenoglio J, Pham TD, Hordof A, Edie RN, Wit AL. Right atrial ultrastructure in congenital heart disease. II. Atrial septal defect: effects of volume overload. Am .l Cardiol . 1979; 43:820-827.

11. Boyden PA, Tilley LP, Pham TD, Liu S-K. Fenoglio JJ, Wit AL. Effects of left atrial enlargement on atrial transmembrane potentials and structure in dogs with mitral valve fibrosis. Am . Cardiol ..1982; 49:1896-1908.

12. Boyden PA., Tilley LP, Albala A, Liu S-K, Fenoglio JJ, Wit AL. Mechanisms for atrial arrhythmias associated with cardiomyopathy: a study of feline hearts with primary myocardial disease. Circulation 1984,69 1036-1047.

13. Berger M, Rona $G$. Functional and fine structural heterogeneity of atrial cardiocytes. In: Bajusz E, Jasmin G (eds): Methods and Achievements in Experimental Pathology, Functional Morphology of the Heart. Basel, München, Paris, London, New York, Sydney: S. Karger 1971; 540-590. 
14. Sherf $L_{-}$James TN. Fine suructure of cells and their histologic organization within internodal pathways of the heart clinical and electrocardiographic implications. Am $J$ Cardiol 1979:44:345-369.

15. Sadoshima J, Takahash $\mathrm{T}$, Jahn L, Izumo S. Role of mechano-sensitive ion channels, cytoskeleton, and contratile activity in stretch-induced immediate-early gene expression and hypertrophy of cardiac myocytes. Proc Narl Acad Sci USA .1992; 89: $9905-9909$

16. Yamazaki T, Komuro 1, Yazaki Y. Molecular mechanisms of cardiac cellular hypertrophy by mechanical stress. $\mathrm{Nol}$ Cell Cardiol. 1995; 27:133-140.

17. Thompson EW, Marino TA, Uboh CE, Kent RL, Cooper G. Atrophy reversal and cardiocyte redifferentiation in reloaded cat myocardium. Circ Res. 1984; 54:367-377.

18. Sharp WW, Terracio L, Borg TK, Samarel AM. Contractile activity modulates actin synthesis and turnover in cultured neonatal rat heart cells. Circ Res. 1993; 73:172183.

19. Harary I. Biochemistry of cardiac development: in vivo and in vitro studies. In: Berne RM, Sperelakis N, Geiger SR (eds): Handbook of Physiology: Section 2. The Cardiovascular System. Baltimore: American Physiological Society, 1979:43-60.

20. White CW, Jerver RE, Weiss HR, Marcus ML. The effects of atrial fibrillation on atrial pressure-volume and fow relationships. Circ Res. 1982; 51: 205-215.

21. Stul JT, Mayer. Biochemical mechanisms of adrenergic and cholinergic regulation of myocardial contractility. In Berne RM, Sperelakis N, Geiger SR (eds): Handbook of Physiology section 2: The cardiovascular sysrem. American Physiological Society, Bethesda, Maryland, 1979: 741-774.

22. Manasek FJ. Mitosis in developing cardiac muscle. J Cell Biol. 1968; 37:191-196.

23. Sommer JR, Johnson EA. Ultrastructure of cardiac muscle. In: Berne RM, Sperelakis N. Geiger SR (eds): Handbook of Physiology. Section 2. The Cardiovascular System. Bethesda, Maryland: American Physiological Society. 1979: 113-186.

24. Rahimtoola SH. A perspective on the three large multicenter randomized clinical trials of coronary bypass surgery for chronic stable angina. Circulation. 1985; 72(Suppl. V):123-125.

25. Rahintoola SH. From coronary artery disease to heart failure: Role of hibernating myouardium. Am J Cardiol.1995; 75:16E-22E.

26. Ausma J, Schaart G, Thoné F, Shivalkar B, Flameng W, Depré C, Vanoverschelde J$L$, Ramaekers F, Borgers $M$. Chronic ischemic viable myocardium in man: aspects of dedifferentiation. Cardiovasc Pathot. 1995; 4:29-37.

27. Vanoverschelde J-LJ, Wijns W, Depre C, Essamia B, Heyndricks GR, Borgers M, Bol A, Melin J. Mechanisms of chronic regional postischemic dysfunction in humans: new insights from the study of non-infarcted collateral dependent myocardium. Circulation.1993; 87:1513-1523.

28. Maes A, Flameng W, Nuyts J, Borgers M, Shivalkar B, Ausma J, Bormans C, De Roo M. Mortelmans L. Histological alterations in chronically hypoperfused myocardium. Correlations with PET tindindings. Circulation. 1994: 90:735-745. 


\title{
Chapter 7 \\ Dedifferentiation of atrial cardiomyocytes as a result of chronic atrial fibrillation
}

\author{
Jannie Ausma, Maurits Wijffels, Guillaume van Eys, Masafumi Koide, \\ Frans Ramaekers, Maurits Allessie, Marcell Borgers \\ submitted for publication
}

\begin{abstract}
Chronic atrial fibrillation was induced in goats by electrical pacing. After 9-23 weeks of sustained atrial fibrillation the morphology of the atrial structures was examined. The majority of the cardiomyocytes exhibited marked changes in their cellular substructures, with the replacement of sarcomeres by glycogen as the main characteristic. Using immunohistochemical staining procedures the expression and organisation of contractile and cytoskeletal proteins was assessed in these cases and compared with the expression and organisation of these proteins in normal atria. Part of the atrial cardiomyocytes acquired a dedifferentiated phenotype, as deduced from the re-expression of $\alpha$-smooth muscle actin, the disappearance of cardiotin and the staining patterns of titin, which resembled those of embryonic cardiomyocytes. From these results we conclude that chronic atrial fibrillation induces myocardial dedifferentiation. This model of chronic atrial fibrillation in goats offers the possibility to study the time course of changes in cardiac structure during sustained atrial fibrillation and after cardioversion.
\end{abstract}




\section{Introduction}

Chronic atrial fibrillation (CAF) is characterized by an inadequate contractile function with increased oxygen consumption, possibly confounded by increased wall stretch.' In chronic fibrillating atria there is a considerable delay in the recovery of contractile function after reconversion to sinus rhythm. Recently, we described a variety of ultrastructural changes in atrial cardiomyocytes after sustained atrial fibrillation, with the replacement of contractile elements by glycogen as the main feature. ${ }^{2-4}$ Furthermore, disorganisation to complete loss of sarcoplasmic reticulum is observed as well as an increase in strands of rough endoplasmic reticulum. Mitochondria underwent typical changes in size and shape and the nuclear chromatin is dispersed. The structural observations are suggestive of phenotypic adaptation rather than degeneration of the cardiomyocytes. ${ }^{3,5}$ This phenomenon does not lead to a decrease in cell volume, mainly because of glycogen accumulation at the sites of sarcomere loss. Similar alterations have been reported in dedifferentiating cardiomyocytes of chronic hibernating myocardium (CHM) ${ }^{6} \mathrm{CHM}$ is a clinical condition defined as the ability of the myocardium to adapt to chronic ischemia by down-regulating its contractile function, thereby maintaining cell viability for a prolonged period of time . 7,8

We investigated the expression, structural organization and assembly of a number of markers of cardiac development. ${ }^{9-11}$ During cardiogenesis different structural proteins are expressed sequentially at different phases of myofibril formation, and the degree of assembly of most of these muscle-specific constituents increases with differentiation. ${ }^{12-16}$ The expression and organization of muscle-specific proteins is evidently related to the extent of cardiac muscle cell development. In CHM this typical structural organisation is lost and the cells seem to acquire an embryonic phenotype. For example, $\alpha$-smooth muscle actin, a protein which is present in embryonal/fetal heart muscle cells, but absent in adult cardiomyocytes, is reexpressed in cardiomyocytes during chronic hibernation." On the other hand, cardiotin, that cannot be detected in embryonic heart and seems to be expressed only after birth ${ }^{17}$ is virtually absent in CHM ${ }^{9}$ Finally, a punctated titin staining pattern in CHM resembles its organisation in embryonic cardiomyocytes. 9.10

On the basis of the resemblance between the ultrastructural changes in CHM and CAF we hypothesized that CAF cardiomyocytes revert to an embryonic phenotype. The aim of the present study was to test this dedifferentiation hypothesis for atrial cardiomyocytes undergoing CAF. We therefore investigated the expression and (re)organisation of markers of muscle cell development and function in goat myocardium subjected to sustained AF.

The findings reported here support the hypothesis that the adaptation of the cardiomyocytes as a consequence of contractile unloading upon CAF results in dedifferentiation of the affected cardiomyocytes. 


\section{Materials and Methods}

Animals

A total of 20 female goats were used in this study: Of these, 13 goats were subjected to CAF and 7 goats with sinus rhythm were used as controls. Animal handling was carried out in accordance with the guidelines of the American Society of Physiology and approved by the Animal Investigation Committee of the Universiteit Maastricht.

\section{Chronic atrial fibrillation model}

The detailed procedure for induction of CAF in goats was described previously by Wijffels et al. ${ }^{18}$ Briefly, the goats were instrumented with unipolar electrodes sutured to the epicardial surface of the bundle of Bachmann and the free wall of the right and left atrium. Two- to three-weeks after implantation of the electrode, the animals were connected to the fibrillation pacemaker, which maintained atrial fibrillation (AF) continously by the automatic delivery of a 1-sec burst of stimuli $(50 \mathrm{~Hz})$ promptly after detection of the sinus rhythm. Initially, electrically induced $\mathrm{AF}$ was short-lasting and self-terminating after $6 \pm 3$ seconds. As a result of the artificial maintenance of $\mathrm{AF}$, the duration of $\mathrm{AF}$ increased progressively, becoming sustained ( $>24$ hours) after $7.1 \pm 4.8$ days. For the goats used in the present study the total duration of sustained atrial fibrillation was $9-23$ weeks.

\section{Morphologic evaluation}

At the end of the experimental period the goats were anaesthetized by Nesdonal $(15 \mathrm{mg} / \mathrm{kg})$ and anaesthesia was maintained by ventilation with halothane $(1-2 \%)$ and a 1:2 mixture of $\mathrm{O}_{2}$ and $\mathrm{N}_{2} \mathrm{O}$. The heart was quickly removed and parts of the left and right free atrial walls, including trabecular muscle, the atrial septum, the bundle of Bachmann and the anterior wall of the left ventricle, were divided into small blocks (c. $4 \mathrm{~mm}^{3}$ ). For morphological assessment the blocks were fixed in $3 \%$ glutaraldehyde buffered to $\mathrm{pH} 7.4$ with $90 \mathrm{mM}$ potassium phosphate for at least $24 \mathrm{~h}$ at room temperature. After a washing step in the same buffer for another $24 \mathrm{~h}$, tissue blocks were postfixed with $1 \%$ osmium tetraoxide in $50 \mathrm{~mm}$ veronal acetate buffer for $\mathrm{l}$, rapidly dehydrated through a graded ethanol series and routinely embedded in the epoxy-resin Epon. ${ }^{19}$

For immunohistochemical studies some tissue blocks (c. $\left.4 \mathrm{~mm}^{3}\right)$ were immediately frozen in isopentane precooled with liquid nitrogen and stored at $-80^{\circ} \mathrm{C}$. The expression of $\alpha$-smooth muscle actin was assessed on tissue fixed in with $3 \%$ phosphate-buffered glutaraldehyde for $30 \mathrm{~min}$ at $4^{\circ} \mathrm{C}$, and stored in the buffer solution without glutaraldehyde until use. Before frozen sections were made, the blocks were washed successively in $10 \%, 15 \%$ and $20 \%$ sucrose in phosphatebuffered saline (PBS), each for $4 \mathrm{~h}$ before they were frozen in isopentane precooled liquid nitrogen. 
Light microscopic examination of the morphologic changes was performed on 2 Hm thick sections of Epon-embedded blocks staned with periodic acid Schiff (PAS) and $0.1 \%$ toluidine blue to quantify the loss of myofibrils and glycogen content. The degree of cellular changes was evaluated only in cells in which the nucleus was present in the plane of the section. Cells were planimetrically scored for glycogen content. ${ }^{6}$

To assess the amount of connective tissue, morphometry was carried out with a special grid with vertical and horizontal lines providing 121 intersections. ${ }^{19}$ According to the basic principles of morphometry, counting of the number of intersections overlying a certain structure results in a quantitative determination of the surface of the entire structure under the square grid. The total number of intersections was regarded as $100 \%$, and the intersections counted in the connective tisste were expressed as the percentage of the entire tissue within the limits of the grid. Blood vessels and perivascular tissue were excluded from the analysis.

\section{Picrosirius red staining}

Frozen sections $5 \mu \mathrm{m}$ thick were stained with the collagen-specific dye picrosirius red (Polysciences, Warrington, PA, USA) according to the method of Junqueria et al. ${ }^{20}$ Sections were fixed overnight with $3.7 \%$ formaldehyde buffered with $0.037 \mathrm{M}$ phosphate buffer ( $\mathrm{pH} 7.4)$. After they were washed for $10 \mathrm{~min}$ with tap water and distilled water $(2 \times 2 \mathrm{~min})$ the slides were treated with $0.2 \%$ phosphomolybdic acid ( 5 min). Subsequently, $0.1 \%$ Sirius Red, dissolved in a saturated picric acid solution was applied for $90 \mathrm{~min}$. The slides were then treated with $0.01 \mathrm{~N} \mathrm{HCl}(2$ min), dehydrated in a graded series of ethanol, placed in xylol for 2 min and mounted in Entellan (Merck, Darmstadl, Germany).

The picrosirius red stained sections were studied with a polarization light microscope. Picrosirius red provides high-contrast images by enhancing the birefringence of the fibrillar collagen, while different colors indicate the different fiber sizes. ${ }^{21}$

\section{Immunohistochemical staining procedures}

The primary antibodies listed in table 1 were used in this study. Indirect immunofluorescence assays were performed on $5-\mu \mathrm{m}$ thick frozen sections. Sections were air-dried before use. For treatment with antibodies against sarcomeric-, cytoskeletal-and sarcoplasmic reticulum proteins sections were pretreated with $0.5 \%$ Triton X-100 (BDH Chemicals Ltd., Poole, UK) in PBS for 5 min at room temperature, followed by a wash in PBS ( 3 times 5 min). For treatment with antibodies against nuclear lamins and proteins of the interstitial space sections were pretreated by dipping in methanol $(5 \mathrm{sec}$ ) and in acetone ( 3 times $5 \mathrm{sec}$ ) both of $-20^{\circ} \mathrm{C}$ and air dried. The sections were incubated with the primary antibodies for $45 \mathrm{~min}$ and then washed with PBS (three 10-min steps). They were then incubated for $45 \mathrm{~min}$ with the secondary antibody, i.e. fluorescein isothiocyanate (FITC)- 
Table 1: Overwew of the antisera used in this sudy

\begin{tabular}{|c|c|c|c|}
\hline Abbreviation & Antigen/Epitope & $\begin{array}{l}\text { Subclass; } \\
\text { dilution }\end{array}$ & Refentences \\
\hline 9D10 & $\begin{array}{l}\text { Titin, 1-band, } \\
\text { at the A-I junct onal part }\end{array}$ & $\lg M: 1: 10$ & 49,50 \\
\hline $\mathrm{T} 12$ & $\begin{array}{l}\text { Titin, I-bsnd part, } \\
\text { close to the Z-disc }\end{array}$ & $\operatorname{lgCl} 1 ; 1 ; 0$ & 51 \\
\hline $\mathrm{T} 30$ & $\begin{array}{l}\text { Titin, repetitve sequences } \\
\text { of the A-bund, C-stripes }\end{array}$ & $\operatorname{lgG} 11 ; 1: 10$ & 52 \\
\hline $\mathrm{T} 31$ & $\begin{array}{l}\text { Titin, repetive seguences } \\
\text { of the } \mathrm{A} \text {-band, P-stripes }\end{array}$ & $\lg G 1 ; 1: 10$ & 52 \\
\hline $\mathrm{T} 41$ & Titin, KSP-serpence repeats region & $\lg 0: 1: 5$ & 53 \\
\hline AA241 & M-protein & $\operatorname{IgG} 1: 1: 10$ & 54 \\
\hline BB78 & Myomesin & $\lg G: 1: 10$ & 54 \\
\hline$\alpha-653$ & $\alpha$-actinin & poly; : 1:100 & Fuist of al, urpubl. \\
\hline $\mathrm{CIC} 2$ & cardiac C-protein. & rat polyclonal & 55 \\
\hline$a-5 M-1$ & $\alpha$-smooth muscle actin & $\operatorname{lgG} 2 a ; 1: 200$ & 24,56 \\
\hline IID8 & SERCA 2 & $\operatorname{lgCl} ; 1: 1000$ & 57 \\
\hline SERCA $2 a$ & SERCA 2A & poly: 1:100 & 58 \\
\hline SERCA 20 & SERCA $2 B$ & poly: $1: 100$ & 59 \\
\hline SERCA 3 & SERCA 3 & poly: $1: 100$ & 60 \\
\hline FKBP"-12 & FK506 binding protein & $\lg G 1: 11: 25$ & 61 \\
\hline VIIIDI2 & calsequestrin & $\lg 02 b ; 1: 50$ & 62 \\
\hline PL.B & phospholamban & $\operatorname{lgG1} ; 1: 50$ & 63 \\
\hline$M F-20$ & myosin heavy chain & $\lg \mathrm{G} 2 \mathrm{~b} ; 1.5$ & 64 \\
\hline TM311 & tropomyosin & $1 g \mathrm{O} 1: 1: 25$ & 42 \\
\hline DE-R-1H & desmin, rod domain & $\lg G 1: 1: 10$ & 65 \\
\hline RD301 & desmin, lail domain & $\lg \mathrm{CH}_{2} \mathrm{~b}$ und & 60 \\
\hline K5 & desmin & poly: $1: 40$ & 67 \\
\hline $\mathrm{R} 2 \mathrm{G}$ & cardiotum & IgM: and & 17 \\
\hline RV 202 & vimentin & $\lg G 1 ;$ and & 68 \\
\hline CAM 5.2 & keratin 8 & $\operatorname{lgG} 2 a ; 1: 10$ & 69 \\
\hline RCKIOG & keratin 18 & \gG : and & 68 \\
\hline A245 & plasma tibronectin & poly: 1.200 & 70 \\
\hline $\mathrm{T} 2 \mathrm{HS}$ & temescin & $\lg 0 ; 1: 50$ & 71 \\
\hline EN-3E2 & cellutan fibronectin & $\lg M: 1: 100$ & 72 \\
\hline $11-5-\mathrm{F}$ & desmoplakin I \& I] & $\lg \mathrm{OI}: 1: 10$ & 73,74 \\
\hline $\mathrm{Dg} 3.10$ & desmoglein & $\operatorname{lgG1} 1: 1: 10$ & 75 \\
\hline Conn-43 & connexint -43 & $\operatorname{lgGl} ; 1: 200$ & 76 \\
\hline $41 \mathrm{CC} 4$ & lamin, rod domain of lamins $A$ and $C$ & $\operatorname{lgM}$; und & 77,78 \\
\hline R27 & lamin, rod domain of tamins $A$ and $C$ & IgM; arnd & 79 \\
\hline $\mathrm{LN} 43$ & Iamiqu $\mathbb{B 2}$ & $\operatorname{lgCl}$; und & 80 \\
\hline $133 \mathrm{~A} 2$ & Iamin A & $\operatorname{Ig} C 3 ; 1: 1000$ & 77 \\
\hline
\end{tabular}

(4) The monoclonal antibodies 9010 and MF20 were obtaned from the Developmental Sudics Hybridoma Bank, mantained by the department of Phamacology and Molecular Sciences. Johns Hopkins Universiy School of Medicine, Baltimore, MD, USA, and the Department of Biology, University of Iowa, Iowa City, UA, USA., under entract NO1-H3D 2915 from the NICHD. 
conjugated goat-anti-mouse Ig (Southern Biotechnology Associates [SBA] Inc, Birmingham, Al., USA) or goat-anti-rabbit antibody (SBA) and washed in PBS (three 10 -min steps).

In the double-labelling procedure the immunostaining steps were repeated with a second primary antibody of another Ig-subclass, the sections were washed in PBS and then incubated for $45 \mathrm{~min}$ with a secondary Texas Red conjugated Ig-subclass specific antibody (SBA). After these immunohistochemical procedures the sections were placed in distilled water for $5 \mathrm{~min}$, followed by a post-fixation step in methanol for 5 min (except for cardiotin). Sections were air-dried and mounted in Mowiol (Hoechst, Frankfurt a.M. Germany). Nuclei were routinely stained with 4'6-diamidine 2-o-phenylindole (DAPI), diluted 1:10000 (Sigma Chemicals, St. Louis, USA).

For negative controls, application of the primary antibody was omitted.

Rhodamine-labelled phalloidin (Molecular Probes Inc. Eugene, OR, USA) was used to stain filamentous actin. In this case sections were pretreated with $0.6 \mathrm{M} \mathrm{KI}$, $1 \mathrm{M} \mathrm{KCl}, 1 \%$ Triton X-100 in PBS for $5 \mathrm{~min}$, washed with PBS in 3 times $5 \mathrm{~min}$, incubated with rhodamine-labelled phalloidin for $30 \mathrm{~min}$ (dilution 1:80 in PBS), followed by 3 washing steps of $10 \mathrm{~min}$ each, mounted and postfixed as described above.

The immunoperoxidase method was used for the detection of $\alpha$-smooth muscle actin in glutaraldehyde-fixed samples. Five micron thick sections were air-dried before use, and treated with $0.5 \%$ Triton $\mathrm{X}-100$ for $15 \mathrm{~min}$ at room temperature, followed by a 10-min wash in PBS. The sections were then treated with $1 \mathrm{mg} / \mathrm{ml}$ $\mathrm{NaBH}_{4}$ in PBS for 15 min, washed in PBS and preincubated with $5 \%$ normal goat serum in PBS containing $0.1 \%$ bovine serum albumin (BSA; Sigma, St. Louis, USA). After a wash in PBS supplemented with 0.1\% BSA, the sections were incubated overnight with the primary antibody at room temperature. The sections were then washed for $30 \mathrm{~min}$ in PBS and incubated for $1 \mathrm{~h}$ with peroxidaseconjugated rabbit-anti-mouse Ig (DAKO A/S, Glostrup, Denmark). After washing with PBS (three 10-min steps) peroxidase activity was detected with 3-amino-9. ethylcarbazole (AEC, Sigma, St. Louis, USA): $40 \mathrm{mg}$ of AEC was dissolved in 10 $\mathrm{ml} \mathrm{N}, \mathrm{N}$ dimethylformamide (Merck, Darmstadt, Germany) and added to $190 \mathrm{ml}$ of $0.05 \mathrm{M}$ sodium acetate buffer $(\mathrm{pH} 4.95)$. Hydrogen peroxide was added to a final concentration of $0.01 \%(\mathrm{v} / \mathrm{v})$. After incubation for 10 min the sections were rinsed with tap water, counterstained with haematoxylin (Sigma Diagnostics, St. Louis, USA) and mounted with Kaiser's glycerol gelatin (Merck, Darmstadt, Germany).

All slides were examined with a Zeiss Axiophot microscope. Photographs of the immunofluorescense preparations were taken with a Kodak Tri-X-pan film and the photographs of the immunoperoxidase labelled sections were taken with a Kodak EPY $64 \mathrm{~T}$ film. 


\section{Results}

\section{Morphological alterations}

Atria from goats with CAF underwent considerable subcellular structural alterations. The most obvious of these was the depletion of sarcomeres, which started in the perinuclear region and extended towards the periphery of the cardiomyocytes. This process did not give rise to loss of cell volume since the cytoplasmic space resulting from myolysis became filled with glycogen (Fig $1 a_{n}$ b). In fact, a moderate increase in cell volume was noted. ${ }^{2-4}$ This changes are present in roughly $50 \%$ of the cardiomyocytes of all CAF goats. The alterations were present throughout the right- and left atria, appendages, trabeculae, interatrial septum and bundle of Bachmann. Quantification of the extracellular matrix volume fraction indicated a slight but not significant increase in the amount of connective tissue from $9 \%$ in control atria to $12 \%$ in CAF atria. The collagen fiber thickness, as assessed by polarization light microscopy on picrosirius red stained sections, was identical in the myocardium from goats in sinus rhythm and goats with CAF, indicating that no change in collagen composition takes place during CAF.

\section{Immunocytochemistry of structural proteins in cardiomyocytes}

Contractile and cytoskeletal proteins: Cardiomyocytes affected by CAF, displaying myolysis in the perinuclear area, showed no remnants of contractile proteins in the sarcomere-free zones when assayed with the various mono- and polyclonal antibodies directed against these proteins. At the periphery of the cell, where sarcomeres persisted, myosin, actin, tropomyosin and $\alpha$-actinin were still present in their normal cross-striated patterns (Fig 2a). The expression levels of these proteins appeared to be unaltered in the remaining sarcomeres. In the cytosol of CAF cardiomyocytes a disorganisation of the intermediate filament-type protein desmin was observed and in the sarcomeres at the periphery of the characteristic myolytic cardiomyocytes, elevated desmin levels were detected by immunohistochemical staining with three different anti-desmin antibodies (Fig 2b). Sometimes, normal desmin cross-striations were lost in these affected cardiomyocytes or the desmin organization was irregular while other sarcomeric proteins, such as actin, were still present in a normal cross-striated pattern (Fig 2a,b). In addition, part of the cardiomyocytes showed residual, disorganised desmin staining in areas that lacked contractile proteins as shown by double-labelling immunofluorescence studies (compare Fig 2a and 2b). In these cells desmin plaques were located in the myolytic areas aligning the residual sarcomeres. Desmin was frequently lacking at the site of the intercalated disc (see below).

$\alpha$-Smooth muscle actin, which was not detected in atrial cardiomyocytes from goats in sinus rhythm (Fig 3a) was re-expressed in a substantial portion of the atrial cardiomyocytes from CAF goats as detected with the antibody sm-1 (Fig 3b). As expected, smooth muscle cells from blood vessels reacted strongly with the sm-1 

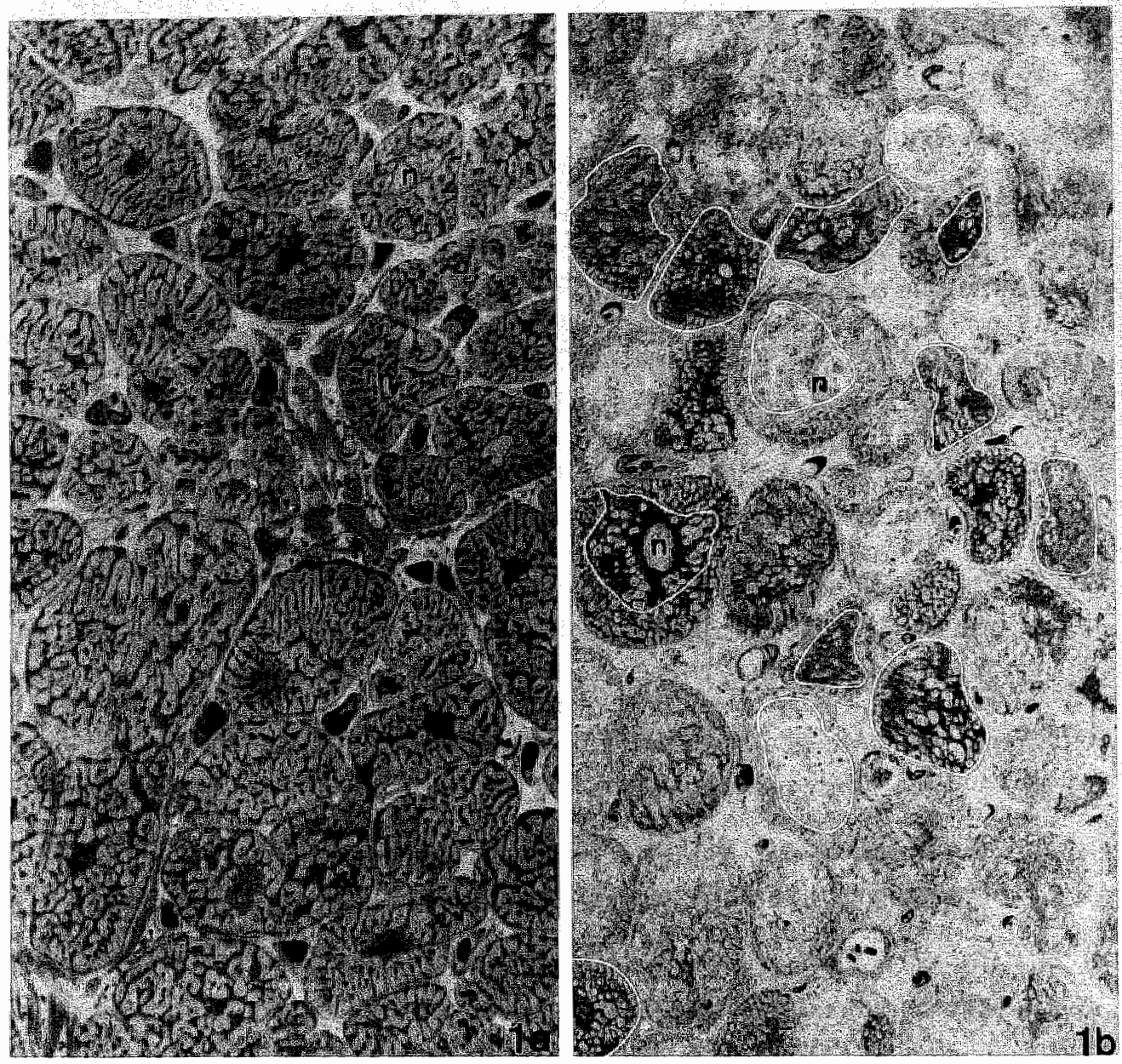

Figure I $(a, b)$. Light microscopy of atrial myocardium in $2 \mu$ m thick sections stained with PAS and toludine blue. (a) Arral cardiomyocytes of a goat in sinus rhythm virtually lacking glycogen (PAS positive staining). ( $x 470$ ) (b) Atrial cardionyocytes of a CAF goat showing myolytic cells (circled areas) most of them staining for glycogen (PAS positive). $(n=$ nucless, $g=$ glycogen $) .(x 330)$.

antibody. In areas where cardiomyocytes with severe myolysis prevailed the $\alpha$ smooth muscle actin was located at the periphery of the cells rather than extending throughout the cytoplasm. Re-expression of other embryonically expressed cytoskeletal proteins, such as the intermediate filament-type proteins vimentin and keratins 8 and 18 , could not be detected in the atrial cardiomyocytes from CAF goats. 

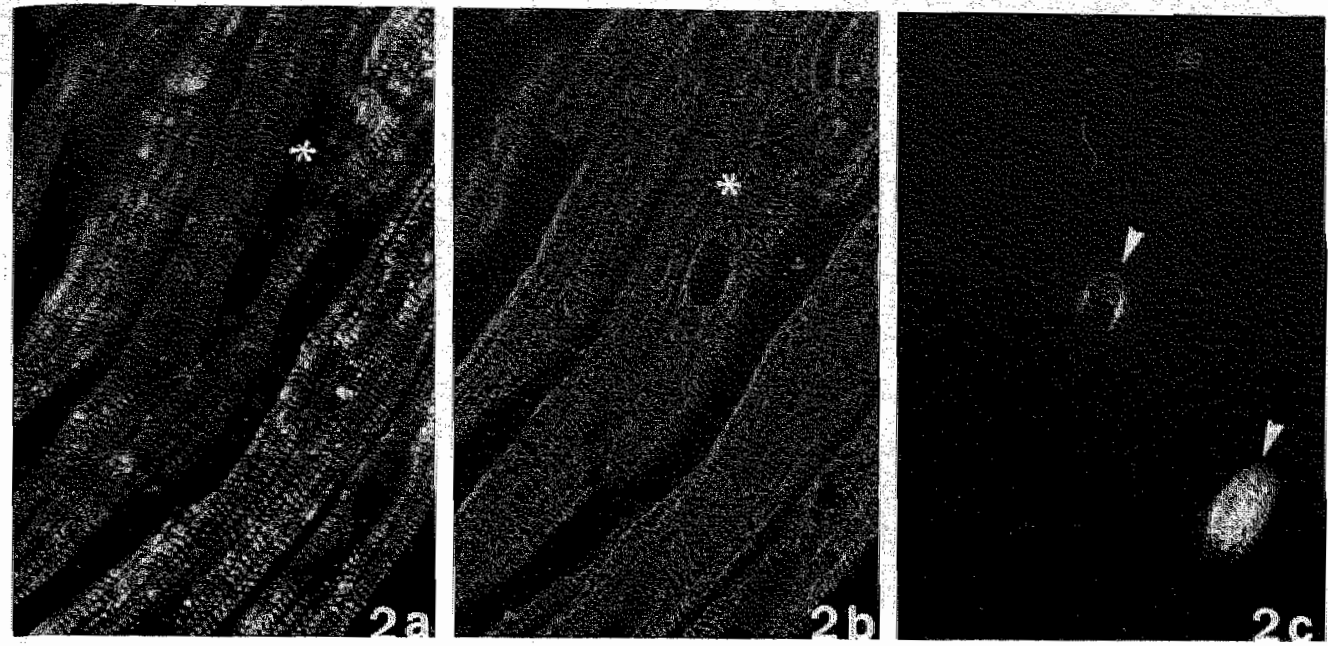

Figure $2(a, b, c)$ Immunofuorescence micrographs showing the expression of sarcomeric proteins in atrial myocardium from goats with myolysis. Actin, desmin double-labelling immunofuorescence with DAPI-nuclear staining. (a) Actin cross-striations are still infact in segments with myolysis. Cross-striations remained at the periphery of the cells. (x400). (b) Disorganized desmin staining. Note the desmin staining in the myolytic areas without actin cross-striated staining (asterisk). (c) DAPI staining of nuclei from cardionyocyles and interstitial cells. Nuclei in the middle of the myolytic areas are indicated by an arrowhead (x395).

Titin and its associated proteins: In normal atrial cardiomyocytes monoclonal antibodies directed against the different epitopes of titin, as well as those directed to the titin-associated proteins myomesin, M-protein and C-protein, showed typical cross-striated staining patterns. Fig. 4 presents an overview of the subsarcomeric location of the titin epitopes for the different antibodies. An example of titin staining in normal myocardium with the 9D 10 and T30 antibody are shown in Fig $5 \mathrm{a}$ and $5 \mathrm{~b}$. Atrial cardiomyocytes from CAF goats with perinuclear myolysis showed similarly cross-striated patterns in the sarcomeres located at the periphery with part of the anti-titin antibodies. Loss of cross-striations was observed with the antibodies directed against the A-I junctional part of titin (9D10 and T30) and for C-protein $(\mathrm{ClC} 2)$ in CAF myocardium. Double labelling immunofluorescence studies indicated the disappearance of the cross-striated staining patterns of these three epitopes (Fig 5c,d) and indicated that this was a stepwise process. The cells with less extensive myolysis showed a loss of double-banded cross-striations and the occurrence of titin staining as single bands. In addition, the staining intensity was lower than in normal cells. In more severely affected cells the titin epitope recognized by the $9 \mathrm{D} 10$ was detected in a punctate fashion. 

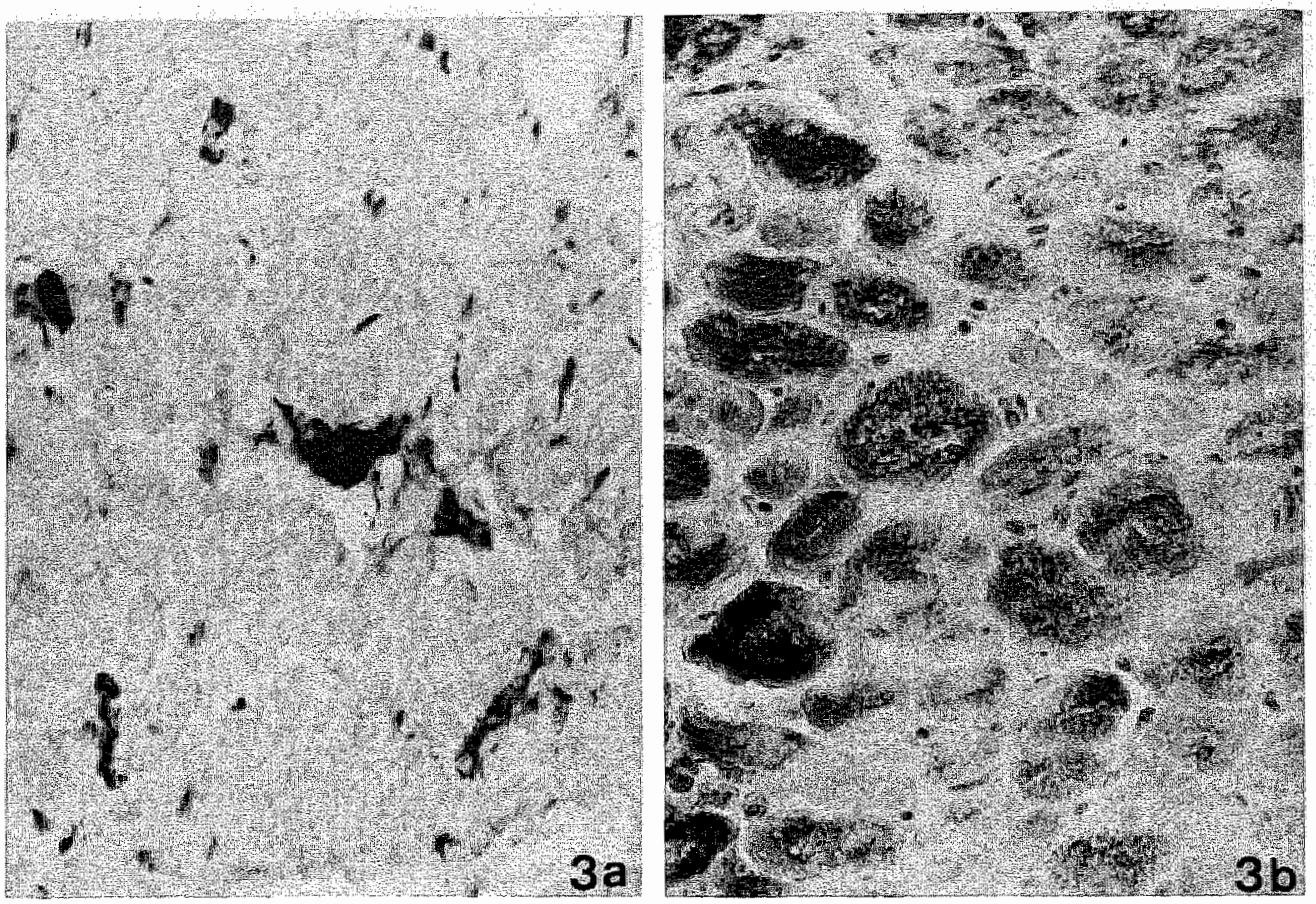

Figure 3. Immunoperoxidase labelling of $\alpha$-smooth muscle acrin. (a) $\alpha$-smooth muscle actin in atrial myocardium of goats in simus rhythm is present in vascular smooth muscle but absent from the cardiomyocytes. (b) In a chronic fibrillating atrial segment a portion of the cardiomyocytes display $\alpha-$-smooth muscle actin expression $(x 300)$.

In contrast, the staining patterns of titin antibodies (T12, T31, T41), the M-protein antibody (AA241) and myomesin (BB78), which recognize epitopes located closer to the $\mathrm{Z}$-line and $\mathrm{M}$-line, were unaltered in the remaining sarcomeres throughout the various stages of dedifferentiation (fig $5 \mathrm{e}, \mathrm{f}$ ), exhibiting a location similar to that of other sarcomeric proteins, such as actin for example (fig $5 g, h$ ). With these antibodies clear cross-striations were visible at regular distances in the sarcomeres of the CAF cardiomyocytes. Double-labelling immunofluorescence studies showed that the organization of titin and its associated proteins located near the Z-line and close to the centre of the A-band were still organized normally, while in the same cells the cross-striated pattern of the titin-epitopes located at the A-I junction and the first part of the A-band were lost (fig $5 e, f$ ).

Sarcoplasmic reticulum proteins: In normal atrial myocardium of goats in sinus rhythm, monoclonal antibody $\mathrm{R} 2 \mathrm{G}$ reveals cardiotin in the longitudinal sarcoplasmic reticulum (SR). Double labelling immunofluorescence studies indicate that cardiotin staining partly co-localizes with the sarco(endo)plasmic reticulum Ca-ATPase protein SERCA 2a (Fig 


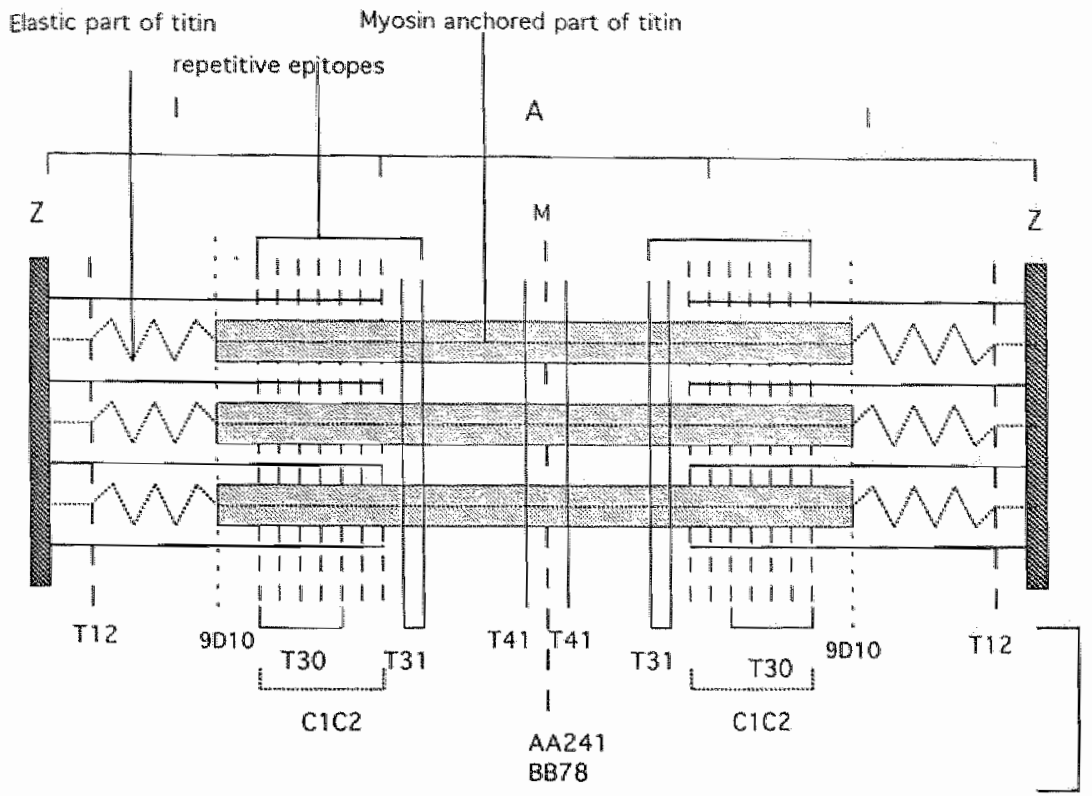

Epitopes

Figure 4. Schematic representation of the ropography of the epitopes recognized by the different anti-titin and anti-fith-associated proteins antibodies. Z: Z-line, M: centre of the M-band, A and I mark the anisorropic and isotropic bands respectively.

$6 a, b)$, although no overlap with SERCA $2 a$ was noted in the junctional SR. The cardiotin distribution was altered in most of the atrial cardiomyocytes from CAF goats. In the least affected areas the cardiotin arrays became shorter, whereas in areas that displayed more extensive myolysis these structures became sparse, ultimately disappearing entirely. In contrast to the disappearance of cardiotin, the organisation of the SERCA $2 a$ remained intact in the remaining sarcomeres (Fig $6 \mathrm{c}$, d). In areas where sarcomeres persisted, the staining intensity of SERCA 2a was comparable to that in sarcomeres of normal cardiomyocytes. Myolytic areas, although containing remnants of $\mathrm{SR}$, did not show SERCA 2a staining. Both normal and affected cardiomyocytes were negative when immunostained with antibodies against other SERCA isoforms, i.e. SERCA 3 and SERCA 2b. SERCA 3 staining was restricted to larger blood vessels, while SERCA $2 b$ staining was present only in interstitial cells such as fibroblasts, endothelial cells and smooth muscle cells.

The organisation and expression of other SR proteins, i.e phospholamban, calsequestrin and FK506-binding protein (FKBP-12), closely resembled SERCA 2a staining in myocardium from goats with sinus rhythm and CAF. Myolytic areas did not stain for these proteins. 

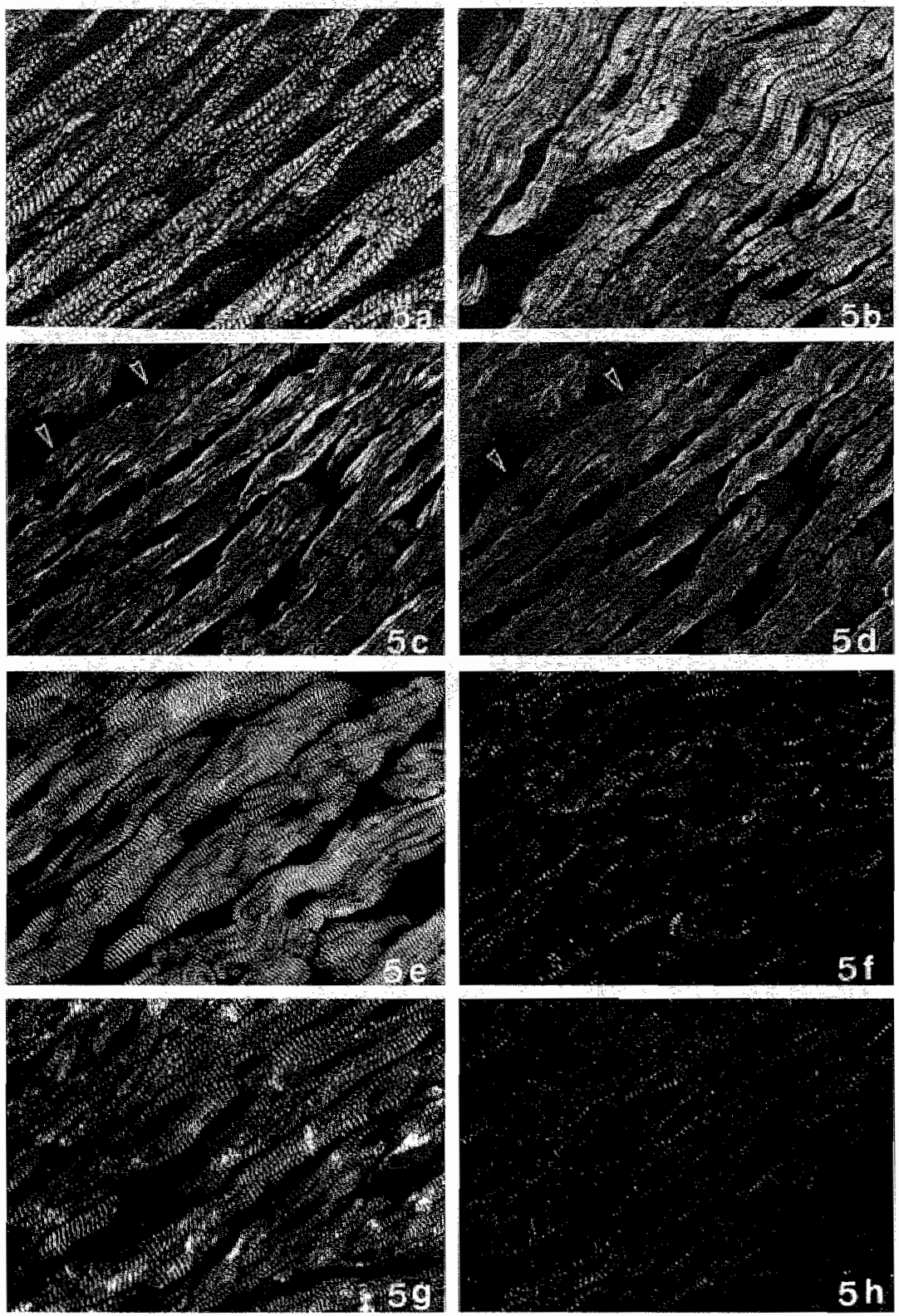

Figure 5. (a. b) mmunofhorescence micrographs of atrial myocardium from a goats in sinus rhwm. (a) stained for titin (9D10) showing a normal double-banded cross-striated pattern. (b) T30 titin staining showing normal cross-striations.

(c,d) Dowble labelling of a section of CAF myocardium with anti-C-protein (CIC2) (c) and the first part of the A-band (T30) (d).CIC2 and T30 staining are lost in the same areas of the sarcomeres (arrowheads). 
(ef) Double-labelling of a section of CAF myocardinn with two anti-tin antibodies one of which recognizes the I-band part of fitin neat the Z-line (T12), the other recognizing the A-I junctional part (9D10). T12 staining remained intact in severely affected candiomyocytes (e), while part of the 9010 staming was almost completely lost $(f)$.

$(\mathrm{g}, \mathrm{h})$ Double-labelling of a section of CAF myocardiwn with actin (phalloidin) and the A-l junctional part of titin $(9010)$. (g) Actin staining is shill intact in these cells, whereas (h) tinis is visible only as short striations. (x35).
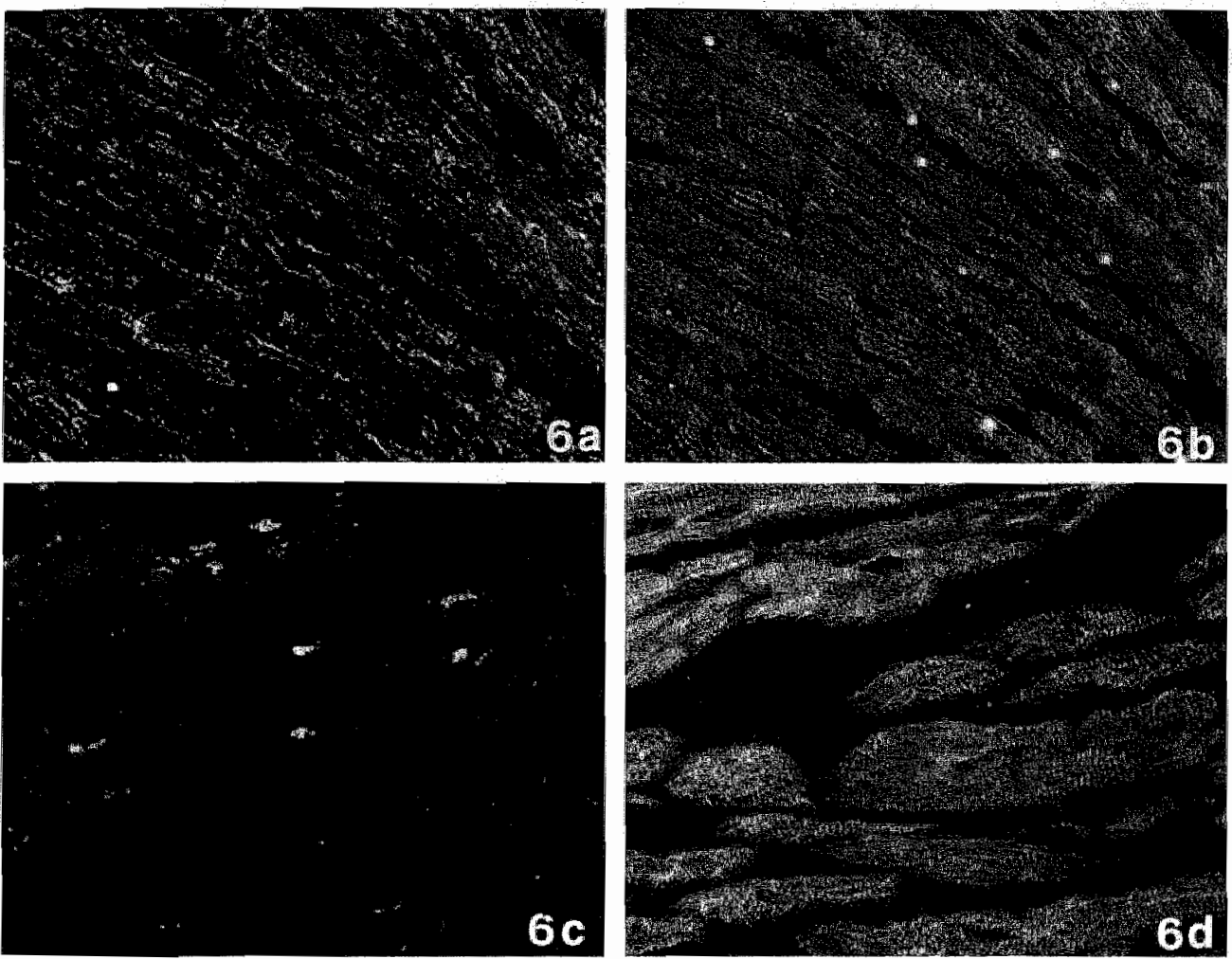

Figure 6. Immunofuorescence double-labelling of a section of arrat myocardium from goats in sinus rhythm $(a, b)$ or with CAF $(c, d)$ stained for cardiotin $(a, c)$ and SERCA $2 a$ $\left(b, d^{\prime \prime}\right)$.

(a) Cardiotin. with characteristic longivdinally oriented filaments muning parallel at regular distance between the sarcomeres. (b) SERCA 2 a, with longitudinal and crossstriated staining of the sarcoplasmic reticulum.

(c) Loss of cardiotin in CAF cardiomyocytes. (d) Narmal SERCA 2 a in arrial cardiomyocytes from goats with CAF. (x390). 

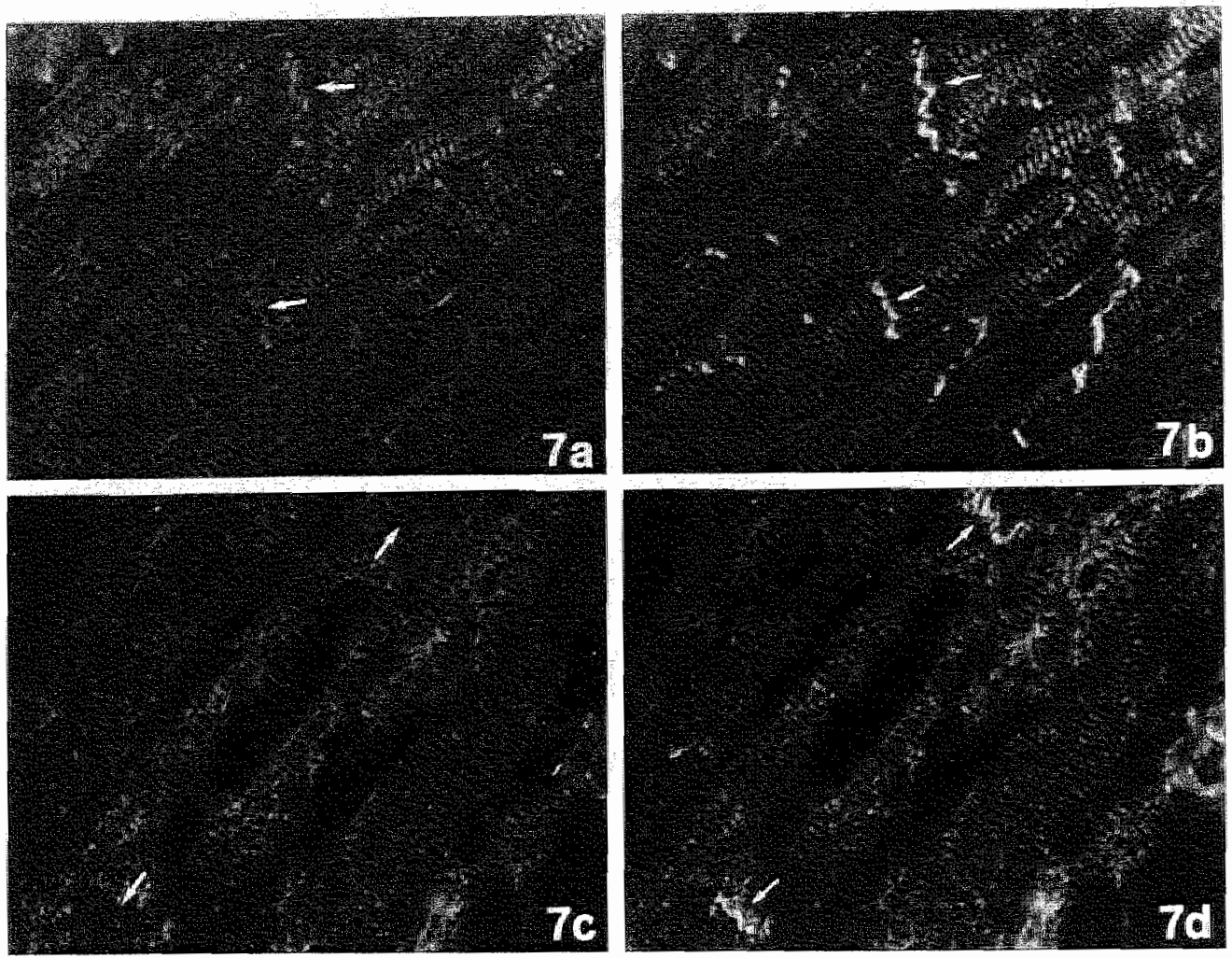

Figure 7 ( $a$, b) Immunofluorescence double-labelling of a frozen section from a normal atrium from a goat in sinus shythm with desmin and desmoplakin. (a) Desmin is visible in a clear cross-striated pattern. At the site of the desmosomal contact sites an intensified desmin staining is visible (arrows). (b) Desmosomes stained with desmoplakin together with the desmin staining. Desmoplakin staining (arrows) overlays the desmin staining at the level of the intercalated disk ( $x 485)$.

(c, d) Immunofturescence double labelling of a frozen section of CAF atrial nyocardium stained with desmin and desmoplakin. Desmin loses its normal regular organisation and at the cell-cell contact site, intensified destitin staining is virtually absent (arrows). (d)

Desmoplakin staining (arrows) is still present, but at this site intensified desmin staining is lacking. (x485).

Nuclear lamins: Nuclei of cardiomyocytes of CAF segments showed a nuclear lamin expression similar to that of the nuclei of cardiomyocytes in non affected myocardium, expressing both A-type lamins (lamins A and C) and lamin B2. With double-labelling immunofluorescence microscopy, no differences in organisation or staining intensities were detected with different monoclonal antibodies against Atype lamins. The DAPI staining pattern did not disclose any alterations at the DNA level, such as for example chromatin condensation indicative of apoptosis. 
Cell adhesion molecules: Desmin staining at the level of the intercalated discs, as seen in normal atrial cardionyocytes, was lost in many CAF cardiomyocytes (Fig 6). In normal cardiomyocytes an intensified desmin staining co-locates with the desmosomal proteins desmoplakin and desmoglein (Fig 7a, b). In a substantial portion of the altered cardiomyocytes affected by CAF, the latter proteins were clustered, exhibiting a dot-like appearance, without co-location with desmin (Fig. $7 \mathrm{c}, \mathrm{d})$. The gap-junction protein connexin- 43 was visible in a linear punctated arrangement in the intercalated discs of normal cardiomyocytes. In the affected cardiomyocytes the connexin- 43 staining pattern was dispersed over the area of the cell-cell contact.

Interstitial tissue: In atrial myocardium from goats in sinus rhythm and CAF, total fibronectin was detected immunohistochemically in the interstitial space between the cardiomyocytes and at the sarcolemma. Markers for extracellular matrix remodelling, such as cellular fibronectin and tenascin, were not present in goats during CAF (results not shown). Immunofluorescence staining of mesenchymal cells with vimentin showed the presence of a normal number of interstitial cells in sections from CAF goats relative to control atria. There was no evidence of transformation of fibroblasts into myofibroblasts, since the interstitial cells were negative for desmin and $\alpha$-smooth muscle actin.

\section{Discussion}

We have previously described that cardiomyocytes of CAF hearts undergo a variety of structural changes, such as depletion of contractile filaments, accumulation of glycogen, alterations in shape and size of mitochondria, nuclear morphology, disorganisation or even disappearance of sarcoplasmic reticulum, and proliferation of rough endoplasmic reticulum. ${ }^{4}$ The structurally altered cells show no degenerative changes. Manifestations of acute ischemia, such as mitochondrial swelling and loss of sarcolemmal integrity were absent. These structural adaptations, in view of their resemblance to developing heart, are interpreted as phenotypic changes akin to dedifferentiation. A major point in this respect is to establish to what extent the observed changes are compatible with life and amenable to reversal. It is therefore essential to elucidate the nature of the adaptation, i.e. to verify the dedifferentiation hypothesis and to exclude or detect confounding degenerative phenomena. The presence of cardiomyocytes with the above-described structural changes might have an effect on the recovery of a normal contractile function after cardioversion. It is known that there is a considerable delay in recovery of contractile funciion of chronically fibrillating 
atria after cardioversion to sinus rhythm. ${ }^{22,23}$ Moreover, it has been established that patients with CAF are vulnerable to relapse after cardioversion. It would therefore be interesting to find out whether this phenomenon is related to abnormalities of the underlying atrial structure. In our previous work on CHM we explored a similar working hypothesis and obtained evidence in support of a dedifferentiation process in such lesions $6,9.10$ The analysis of expression of marker proteins representative of early developmental stages of heart muscle was found instrumental in this respect and therefore included in the underlying study.

\section{Re-expression of embryonic-type heart muscle proteins}

Whereas other structural proteins remain largely unaltered as long as sarcomeric structures are retained, $\alpha$-smooth muscle actin is re-expressed during CAF. During normal embryonic development the expression of $\alpha$-smooth muscle actin is seen with the onset of myofibrillogenesis of both cardiac and skeletal muscle. Alphasmooth muscle actin is then gradually lost from striated muscle cells during further fetal development. $24,25,26$ CAF leads to the co-expression of this embryonic actin isoform next to $\alpha$-sarcomeric (skeletal and cardiac) actin. Such a co-expression of $\alpha$-smooth muscle actin and the sarcomeric forms of actin is also observed in CHM. In this respect, dedifferentiation in CAF cardiomyocytes resembles this process in the cells of CHM. This process of dedifferentiation is incomplete, as indicated by the fact that vimentin, cytokeratins 8 and 18 , which are known markers of very early developmental stages of the myocardium, are not expressed in CAF hearts. ${ }^{16}$

\section{Structural changes in the titin molecules indicative of dedifferentiation}

Alterations in the immunohistochemical detectability of the titin epitopes of the A-I junction and the first part of the A-band in affected cardiomyocytes from CAF goats also indicate that these cells undergo dedifferentiation. The loss of the titin epitope detected by the monoclonal antibody 9D10 in cardiomyocytes affected by $\mathrm{CAF}$ started with the fragmentation of titin striations, ultimately leading to a dotlike staining patern. A similar punctate pattern was seen with this antibody during cardiac and skeletal myofibrillogenesis, at the onset of the formation of myofibrils $13-15,27,30$ and during skeletal muscle cell differentiation in culture, ${ }^{28,29,31,32}$ As was the case in CHM the titin epitopes that are located near the $\mathrm{Z}$ line and at the distal part of the A-band remained detectable during CAF. Thus at the $\mathrm{N}$-terminal and $\mathrm{C}$-terminal, organisation of the titin molecule seems to remain intact. In cardiomyocytes from CAF, titin therefore seems to exist in a molecular organisation that is also found in embryos and CHM. ${ }^{9.10}$ Furthermore, the titin associated proteins, such as $\alpha$-actinin, $M$-protein and myomesin are retained in a normal supramolecular organization of the otherwise affected sarcomeres. These results strongly suggest a change in the structure of the middle part of the titin molecule or its molecular environment. At the molecular level changes may occur either in the titin molecule itself or in its molecular assembly with other sarcomeric 
proteins. Such structural changes first become apparent for the myosin-anchoring part of titin, which interacts with C-protein and includes the junction between the ellastic and rigid part of the molecule. The absence of immunostaining of the A-I junction and first part of the A-band of titin in CAF hearts may be the result of proteolytic degradation or masking of epitopes in this part of the titin molecule, the C-protein or both. Differences in staining patterns between normal and dedifferentiated cardiomyocytes in both $\mathrm{CAF}$ and $\mathrm{CHM}^{10}$ might be related to changes in the spatial structure of titin that are probably due to a change in the interaction with C-protein. Dissociation of C-protein and titin may therefore result in conformational changes of the titin molecule. The observation that immunostaining of the A-I junctional part and the first part of the A band of titin disappears simultaneously with $\mathrm{C}$-protein reactivity supports this assumption.

\section{Aiterations in SR proteins as a result of CAF}

The relatively weak and diffuse cardiotin staining reaction observed in cardiomyocytes from CAF atria resembles that from embryonic/neonatal myocardium. This reaction also argues in favour of a switch of CAF cardiomyocytes to an embryonic phenotype in a way similar to that seen in CHM. Studies on hearts from different species (human, monkey, rabbit) disclosed that the expression of cardiotin in the heart is initiated after birth. ${ }^{17}$ The disappearance of cardiotin during CAF supports the hypothesis that a reverse sequence of cardiomyocyte differentiation events takes place. However, other SR proteins (SERCA 2a, phospholamban, calsequestrin, FKBP) remained present in the sarcomeres at the periphery of atrial cardiomyocytes displaying myolysis. This observation is in line with our electron microscopic data, which showed that wellorganized SR is present only in areas where sarcomeres remained intact. This suggests a normal $\mathrm{SR}$ with $\mathrm{Ca}^{2+}$-handing in the remaining sarcomeres of these myolytic cells. CAF did not result in the anticipated switch in SERCA isoform expression. SERCA 3 mRNA, normally detected in the heart tube of rat embryos, was not found. ${ }^{33}$ This observation may be related to the fact that dedifferentiation progresses to a certain stage and is not complete. On the other hand species differences may explain the absence of SERCA 3 re-expression.

\section{Embryonic-like nuclear morphology in CAF cardiomyocytes}

The uniform distribution of nuclear chromatin, as seen by electron microscopy in CAF, indicates for nuclei an embryonic level of differentiation. In CHM a similar nuclear ultrastructure was seen. In the dedifferentiated cells of CHM a loss of Atype lamin expression was observed, while the B-type lamin expression remained intact." So far, the expression of lamin A in CAF cardiomyocyte nuclei is the only marker which is at variance with the observations in CHM cells. No decrease in the A-type lamin staining was observed in CAF nuclei. 


\section{Cellular cohesion in CAF cardiomyocytes}

In the heart, desmosome-desmin interconnections form the intercellular adhering junctions and increstse tensile strength and mechanical resistance of the whole tissue. ${ }^{34}$ Desmin plays a role in the organisation and/or stabilization of the attachment of myofibrils to the junctional membrane. ${ }^{35}$ The tissue integrity of CAF myocardium may be affected by the loss of desmin at the intercalated disc, as can be deduced from the absence of co-location of desmin with the plaque associated protein desmoplakin and transmembrane glycoprotein desmoglein. Loss of desmin at the intercalated disc and/or increased amounts in combination with disarray of desmin at the Z-line were observed in hypertrophic myocardium and in dilated cardiomyopathic myocardium. ${ }^{36-38}$ This was also reflected by the presence of plaques of desmin in the myofilament-depleted CAF cells.

During embryonic development of the heart desmin is reorganized from a filamentous to a cross-striated expression pattern before co-location with desmoplakin is observed. Therefore, detachment of desmin from the intercalated disc in CAF resembles its organisation in later stages of heart muscle development. 39

Lateral cohesion between cardiomyocytes in CAF did not seem to be alltered since quantification of the extracellular matrix volume fraction of CAF versus control atrial myocardium indicated only a slight, non-significant increase. The absence of tenascin and cellular fibronectin expression in CAF atria suggest the absence of extracellular matrix remodelling. On the basis of tenascin expression in patients with a previous myocardial infarction, Willems et al suggested that there is a remodelling of the extracel]ular matrix during hibernation. ${ }^{40}$ The birefringence pattern in the Picrosirius Red stained sections also points in this direction. With polarized light Whitacker et al. detected changes in the molecular organisation of collagen in healing myocardial infarcts. ${ }^{41}$ In areas where the healing was incomplete, thin new collagen fibers were present. The similar fiber thickness distribution in CAF and normal atria provides an additional argument for the absence of overt extracellular matrix remodelling. Phenotypical changes of the interstitial cells were not observed when various immunohistochemical markers were used.

\section{Factors influencing the structural reorganization in CAF}

The underlying cause of the structural reorganization during CAF is not known. Because of the simillarity to structural changes seen in CHM, contractile unloading might be responsible for the myolytic changes. Experiments with altered mechanical load in vitro and in wivo indicated that mechanical load is essential in maintaining contractile filaments. ${ }^{42,43}$ Another factor that may influence the ongoing reorganization is the increase of passive stretch pulling on the noncontractile cardiac walls, possibly affecting cardiomyocyte cohesion at the level of the intercalated disc during $\mathrm{CAF}$, and mediating the increase in interstitial tissue in 
CHM. 44 Recently, several publications have reported that cell-cell and cellextracellular matrix associations influence the spatial organization and differentiation state of cells. ${ }^{45,46}$ Loss of cell-cell contact; either lateral by an increment in the interstitial space (as in CHM) or through loss of intracellular cohesion at the level of the intercalated disks (as during CAF) may result from the dedifferentiation events, or cause the dedifferentiation of the cardiomyocytes.

An important question that has not been answered relates to the redifferentiation potential of the altered cells. The redifferentiate of cardiomyocytes was indirectly suggested by Borisov, who reported that cardjac muscle cells at early, intermediate and terminal stages of differentiation are capable of adaptive remodelling of their contractile system both in vivo and in vitro. ${ }^{47}$ Sharp et al. established that in verapamil-arrested cultured cardiomyocytes from neonatal rat, in which an initial steep reduction in the amount of actin was observed, the process could be entirely reversed upon omission of the drug. 48 If the structural changes of the by CAF or CHM affected cardiomyocytes are reversible is not known. It is conceivable that cells need a prolonged period of time to rebuild normal contractile machinery. This might explain, at least in part, the delay in recovery of contractile function after cardioversion of CAF and after coronary artery bypass surgery in the case of CHM. The striking resemblance of the phenotypes of cardiomyocytes from CAF and CHM indicate that sustained atrial fibrillation in goats provides a model which may also be used to study dedifferentiation phenomena occurring in patients with CHM. This provides an opportunity to obtain more insight into the cascade of events leading to cardiomyocyte dedifferentiation and to study the reversibility of the structural changes involved in this disease.

\section{Acknowlegdments}

The authors would like to thank Judith Neyssen and Ingeborg de Wolff for technical assistance. They are grateful to Dr. D. O. Fürst (Goettingen, Germany) for antibodies against the different titin epitopes and titin-associated proteins. They thank Dr. G. Schatart, (Maastricht, The Netherlands) for providing the monoclonal antibodies against cardiotin and Dr. M. Gautel (Heidelberg, Germany) for the monoclonal andibodies against cardiac-Cprotein. They are indebted to Dr. II. G. Warren (London, UK), Dr. E. B. Lane (Dundee, UK) and Dr. G. Krohne (Würzburg, Germany), who provided the anti-lamin monoclonal antibodies and Dr. F. Wuytack (Leuven, Belgium) for the anti-SERCA polyclonal antibodies. Dr. J. Cleutjens, Department of Pathology, Universiteit Maastricht (The Netherlands) helped with the polarization light microscopy. Part of this work wats supported by the Dutch organisation for Scientific Research (N.W.O.) grant 900-516-318 and the Dutch Heart Foundation grant NHS 92.316. 


\section{Refirences}

1. White CW, Kerber RE, Weiss HR, Marcus ML: The effects of atrial fibrillation on atrial pressure-volume and flow relationships. Circ Res 1982, 51, 205-215

2. Borgers $M$, Ausma J, Wijffels $M$, Allessie M: Atrial fibrillation in the goat: a model for chronic hibernating myocardium. Circ $1994,90,1-407$

3. Borgers $M$, Thone $F$, Ausma $J$, Wijfels $M$, Allessie $M$ : Structural changes of atrial myocardium after chronic atrial fibrillation in the goat. J Mol Cell Cardiol 1996, 28, A23

4. Ausma , Wijfels M, Thoné F, Wouters L, Allessie M, Borgers M: Structural changes of atrial myocardium after chronic atrial fibrillation in the goat. Manuscript in preparation

5. Ausma J, Borgers M, Wijffels M, Ramaekers $\mathbb{F}$, Allessie $M$ : Chronic atrial fibrillation induces changes in cardiomyocytes phenotype. J Mol Cell Cardiol 1996, 28, A80

6. Borgers $M$, Thoné $\mathbb{F}$, Wouters L, Ausma J, Shivalkar B, Flameng W: Structural correlates of regional myocardial dysfunction in patients with critically coronary artery stenosis: chronic hibernation? Cardiovasc Pathol 1993, 2, 237-245

7. Rahimtoola SH: A perspective on the three large multicenter randomized clinical trials of coronary by pass surgery for chronic stable angina. Circulation 1985, 72, V-123-135

8. Vanowerschelde JLJ, Wijns W, Depré C, Essamri B, Heyndricks S, Borgers M, Bol A, Melin I: Mechanisms of chronic regional postischemic dysfunction in humans: New insights form the study on non-infarcted collateral dependent myocardium. Circulation $1993,87,1513-1523$

9. Ausma J, Schaart G, Thoné F, Shivalkar B, Flameng W, Depré C, Vanoverschelde J-L, Ramaekers F, Borgers M: Chronic ischemic viable myocardium in man: aspects of dedifferentiation. Cardiovase Pathol 1995, 4, 29-37

10. Ausma J, Fürst D, Thoné F, Shivalkar B, Flameng W, Weber K, Ramaekers F, Borgers M: Molecular changes of titin in left ventricular dysfunction as a result of chronic hibernation. J Mol Cell Candiol 1995, 27, 1203-1212

11. Ausma J, Van Eys GJJM, Broers JLV, Thone F, Flameng W, Ramaekers FCS, Borgers M: Nuclear lamin expression in chronic hibernating myocardium in man. J Mol Cell Cardiol 1996, 28, 1297-1305

12. Danto BI, Fischman DA: Immunocytochemical analysis of intermediate filaments in embryonic heart cells with monoclonals to desmin. J Cell Biol 1984, 98, 2179-2191

13. Tokuyasu KT, Maher PA: Immunocytochemical studies of cardiac myofibrillogenesis in early chick embryos. I. Presence of immunofluorescent tilin spots in premyofibril stages. J Cell Biol 1987, 105, 2781-2793

14. Tokuyasu KT, Maher PA: Immunocytochemical studies of cardiac myofibrillogenesis in early chick embryos. II Generation of $\alpha$-actinin dots within titin spots at the time of the first myofibril formation. J Cell Biol 1987, 105, 2795-2801

15. Schaart G, Viebahn C, Langmann W, Ramaekers FCS: Desmin and titin expression in early postimplantation mouse embryos. Development 1989, 107, 585-596 
16. Van der Loop FTL, Schaart G, Langmann W, Ramaekers FCS, Viebahn Ch: Expression and organisation of muscle specific proteins during early development stages of the rabbit heart. Anat Embryol 1992, 185, 439-450

17. Schaart G, Van der Ven PMF, Ramaekers FCS: Characterization of eardiotin, a structural component in the myocard. Eur J Cell Biol 1993, 62, 34-48

18. Wijffels MCEF, Kirchhof CJHJ, Dorland R, Allessie MA: Atriall fibrillation begets atrial fibrillation. A study in awake chronically instrumented goats. Circulation 1995, 92, 1954-1968

19. Flameng W, Wouters L, Sergeant P, Lewi P, Borgers M, Thoné F, Suy R: Multivariate analysis of angiographic histologic and electrocardiographic data in patients with coronary heart disease. Circulation 1984, 70, 7-17

20. Junqueira LCU, Bignolas $\mathrm{G}$, Bretani RR: Picrosirius staining plus polarization microscopy: a specific method for collagen detection in tissue sections. Histochem J 1.979, 11, 447-455

21. MacKenna DA, Omens JH, McCulloch AD, Covell JW: Contribution of collagen matrix to passive left ventricular mechanisms in isolated rat hearts. Am J Physiol 1994 , 266, H1007-H1018

22. Shapiro EP, Effron MB, Lima S, Ouyang P, Siu CO, Bush D: Transient atrial dysfunction after conversion of chronic atrial fibrillation to sinus thythm. Am J Cardiol $1988,62,1202-1207$

23. Manning W, Silverman D, Katz S, Riley M, Came P, Doherty R, Munson J, Douglas P:Impaired left atrial mechanical function after cardioversion: relation to the duration of atrial fibrillation. J Am Coll Cardiol 1994, 23, 135-140

24. Woodcock-Mitchell J, Mitchell JJ, Low RB, Kieny M, Sengel P, Rubbia L, Skalli O, Jackson B, Gabbiani G: $\alpha$-Smooth muscle actin is transiently expressed in embryonic rat cardiac and skeletal muscles. Differentiation. 1988, 39, 161-166

25. Babai F, Musir-Aghdam J, Schurch W, Royal A, Gabbiani G: Coexpression of $\alpha-$ sarcomeric, $\alpha$-smooth muscle actin and desmin during myogenesis in rat and mouse embryos I. Skeletal muscle. Differentiation 1990,44, 132-142

26. Bochaton-Piallat M-L, Roprax P. Gabbiani G, Santeusanio G, Palmieri G, Schiaroli S, Spagnoli LG: Actin isoform and intermediate filament protein expression in human developing skeletal muscle. BAM 1992, 2, 83-87

27. Wang S-M, Greaser ML, Schultz E, Bulinski JC, Lin JJC, Lessard JL: Studies on cardiac myofibrillogenesis with antibodies to titin, actin, tropomyosin and myosin. J Cell Biol 1988, 107, 1075-1083

28. Van der Loop FTL, Van der Ven PMF, Fürst DO, Gautel M, Van Eys GJJM, Ramaekers FCS: Integration of titin in the sarcomeres of cultured differentiating human skeletal muscle cells. Eur J Cell Biol,1996, 69, 301-307

29. Van der Loop FTL, Van Eys GJJM, Schaart G, Ramaekers FCS: Titin epxression as an early marker of heart and skeletal muscle differentiation in vitro. Developmental reorganisation in relation to cytoskeletal constituents. I Muscle Res Cell Motil 
30. Schutheiss T, Lin Z, Lu M-H, Murray J, Fishman DA, Weber K, Masaki T, Imamura M, Holzer H: Differential distribution of subsets of myofibrillar proteins in cardiac non-striated and striated myofibrils. I Cell Biol 1990, 1 10, 1159-1172

31. Wan der Ven PMF, Schaart G, Jap PHK, Sengers RCA, Stadhouders AM, Ramaekers FCS: Differentiation of human skeletal muscle cells in culture: maturation as indicated by titin and desmin striation. Cell Tissue Res 1992, 270,189 198

32. Van der Ven PMF, Schaart G, Croes HJE, Jap PHK, Ginsel LA, Ramaekers FCS: Titin aggregates associated with intermediate filaments align along stress fiber-like structures during human skeletal muscle cell differentiation. J Cell Sci 1993, 106, 749-759

33. Anger M, Samuel J-L, Marotte $F$, Wuytak F, Rappaport L, Lompré A-M: In situ mRNA distribution of sarco(endo)plasmic reticulum $\mathrm{Ca} 2+$-ATPase isoforms during ontogeny in the rat. J Mol Cell Cardiol 1994, 26, 539-55

34. Kowalczyk AP, Stappenbeck TS, Parry DAD, Palka HL, Virata MLA, Bomslaeger EA, Nilles LA, Green KJ: Structure and function of desmosomal transmembrane core and plaque molecules. Btophysial Chemistry 1994, 50, 97-112

35. Cary RB, Klymkowsky MW: Disruption of intermediate filament organization leads to structural defects at the intersomite junction in Xenopus myotomal muscle. Development 1995, 121,104\$-1052

36. Schaper J, Froede TA, Hein St, Buck A, Hashizume H. Speiser B, Friedl A, Bleese N: Impairment of the myocardial ultrastructure and changes in the cytoskeleton in dilated cardiomyopathy. Circ 1991, 83, 504-514

37. Kawaguchi $\mathbb{N}$, Fujuani N, Schaper J, Onishi S: Pathological changes of myocardial cytoskeleton in cardiomyopathic hamster. Mol Cell Biochem 1995, 144, 75-79

38. Francalanci $P$, Gallo $P$, Bernucci $P$, Silver MD, d'Amati $G$ : The pattern of desmin flaments in myocardial disarray. Hum Pathol 1995, 26, 262-266

39. Van der Loop FTL, Schaart G, Langmann H, Ramaekers FCS, Viebahn Ch: Rearrangement of intercellular junctions and cytoskeletal proteins during rabbit myocand development. Eur J Cell Biol 1995, 68, 62-69

40. Willems IEMG, Arends JW, Daemen MJAP: Tenascin and fibronectin expression in healing human myocardial scars. J Pathol 1996, 179, 321-325

41. Whitacker P, Boughner DR, Kloner RA: Analysis of healing myocardial infarction using polarized light microscopy. Am J Pathol 1989, 134, 879-893

42. Das KM, Dasgupta A, Mandal A, Geng X: Autoimmunity of cytosketetal protein tropomyosin. A clue to the pathogenetic mechanism for ulcerative collitis. I Immunol $1993,150,2487-93$

43. Thompson EW, Marino TA, Uboh CE, Kent RL, Cooper G: Atrophy reversal and cardiomyocyte redifferentiation in reloaded cat myocardium Circ Res 1984, 367-377.

44. Ausma J, Cleutjens JPM, Thoné F, Flameng W, Ramaekers F, Borgers M: Chronic hibernating myocandium: interstitial changes. Mol Cel Biochem 1995, 147, 35-42

45. Simpson DG, Carver W, Borg TK, Terracio L: Role of mechanical stimulation in the estabilishment and maintenance of muscle cell differentiation. Int Rev Cytol 1994, 150, $69-94$ 
46. Fisher SA, Periasamy M: Collagen synthesis inhibitors disrupt embryonic cardiomyocyte myofibrillogenesis and alter the expression of cardiac specific genes in vitro. J Mol Cell Cardiol 1994, 26, 721-31

47. Borisov AB: Myobrilogenesis and reversible disassembly of myofibrils as adaptive reactions of cardiac muscle cells. Acta Physiol Scand 1991, S599,71-80

48. Sharp WW. Terracio L, Borg TK, Samarel AM: Contractile activity modulates actin synthesis and turnover in cultured neonatal rat heart cells. Circ Res $1993,73,172-183$

49. Greaser ML, Handel SE, Wang SM, Schultz E, Bulinski JC, Lessard JL: Assembly of titin, myosin, actin and tropomyosin into myofibrils in cultured chick cardionyocytes. Cellular and molecular biology of muscle development. Edited by Stockdale F, Kedes L. UCLA Symposium on molecular and cellular biology. New York New Series 1989 , 93, 246-257

50. Wang S-M, Greaser ML: Immunocytochemical studies using a monoclonal anitbody to bovine cardiac titin on intact and extracted myofibrils. J Muscle Res Cell Motil 1.985, 6, 293-312

51. Fürst DO, Osborn M, Nave R, Weber K: The organisation of titin filaments in the halfsarcomere revealed by monoclonal antibodies in immunoelectron microscopy: a map of ten nonrepetitive epitopes starting at the $Z$ line extends close to the $M$ line. J Cell Biol $1988,106,1563-1572$

52. Fürst DO, Nave $R$, Osborn M, Weber $K$ : Repetitive titin epitopes with a $42 \mathrm{~nm}$ spacing coincide in relative position with known $\mathrm{A}$ band striations also identified by major myosin-associated proteins. An immunoelectron-microscopical study on myofibrils. J Cel1 Sci $1989,94,119-125$

53. Obermann WHJ, Gautel M, Steiner F, Van der Ven PMF, Weber K. Fürst DO: The structure of the sarcomeric M-band: Localization of defined domains of myomesin, $\mathrm{M}$ protein and the $250 \mathrm{kD}$ carboxy-terminal region of titin by immunoelectron microscopy. J Cell Biol 1996, 134, 1441-1453

54. Vinkemeier U, Obermann W, Weber K, Fürst DO: The globular head domain of titin extends into the center of the sarcomeric M Band. CDNA cloning, epitope mapping and immunoelectron microscopy of two titin-asociated proteins. J Cell Sci 1993, 106, 319. 330

55. Gautel M., Zuffardi O., Freiburg A., Labeit S: Phosphorylation switches specific for the cardiac isoform of myosin binding protein-C: a modulator of cardiac contraction: EMBO J 1995, 14, 1952-1960

56. Skalli O, Ropraz. P. Trzeciak A, Benzonana G, Gillesen D, Gabbiani G: A monoclonal antibody against $\alpha$-smooth muscle: a new probe for smooth muscle diflerentiation. I Cell Biol 1986,103, 2787-2796

57. Jorgenson AO, Anold W. Pepper DR, Kahl SD, Mandel F, Campbell KP: A monoclonal antibody to the Ca2+-ATPase of cardiac sarcoplasmic reticulum crossreacts with slow type I but not with fast type II canine skeletall muscle fibers: an immunocytochemical and immunochemical study. Cell Motil Cytoskelet 1988, 9, 164174 
58. Eggermont JA, Wuytack F, Verbisi $\mathbb{J}$, Casteels $R$ : Expression of the endoplasmic reticulum $\mathrm{Ca} 2+$ pump isoforms and of phospholamban in pig smooth musc]e tissues. Biochem I 1990, 271, 649-653

59. Wuytack F, Eggermont JA, Raeymaekers L, Plessers L, Casteels R: Antibodies against to non-muscle is oforms of the endoplasmic reticulum Ca2+-transport ATPase. Biochem I 1989,264,765-9

60. Wuylack F, Papp B, Verboomen H, Raeymaekers L, Dode L, Bobe R, Enouf J, Bokkalla $S$, Authi $K$, Casteels $\mathbb{R}$ : A sarco/endoplasmic reticulum $\mathrm{Ca} 2+$-ATPase 3-type $\mathrm{Ca} 2+$ pump is expressed in platelets, in lynphoide cells, and in mast cells. J Biol Chem 1994 , $269,1410-1416$

61. Kobayashi M, Ohtsuka K, Tamura K, Ohara K, Fujihira S, Hirano Y, Kusunoki C, Hayashi M, Satoh S, Katayama M. Production of monoclonal antibody against mrecombinant human FKBP-12 and subcellular localization of FKBP-12 in human mononuclear and polymorphonuclear cells. Transplant Proc 1993, 25, 655-657.

62. Knudson CM, Chaudhari N, Sharp AH, Powell JA, Beam KG, Campbell KP: Specific absence of the alpha 1 subunit of the dihydropyridine receptor in mice with muscular dysgenesis. J Biol Chem 1989, 264, 1345-1348

63. Suzuki T, Lui P, Wang JH: Rapid purification of phospholamban by monoclonal antibody immunoaffinity chromatography. Biochem Cell Biol 1987, 65, 302-309

64. Bader D, Masaki T, Fischman DA. Immunochemical analysis of myosin heavy chain during avian myogenesis in vivo and in witro. J Cell Biol 1982, 95, 763-770.

65. Debus E, Weber $\mathrm{K}$, Osborn M: Monoclonal antibodies to desmin, the muscle specific intermediate filament. EMBO J 1983, 2, 2305-2312

66. Pieper FR, Schaart G, Krimpenfort PJ, Hendrik JB, Moshage HJ, Ramaekers FCS, Berns A, Bloemendal $H$ : Transgenic expression of the expression of the musclespecific intermediate filament protein desmin in non-muslce cells. J Cell Biol 1989, 108, 10091024

67. Ramaekers FCS, Moesker O, Huysmans A, Schaart G, Westerhof G, Wagenaar SjSc,

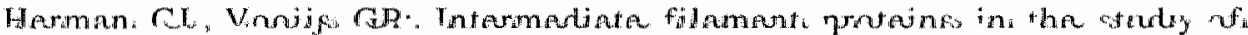
tumorheterogeneity: an in-depth study on tumors of the urinary and respiratory tracts. Ann N Y Acad Sci $1985,455,614-634$

68. Ramaekers FCS, Huysmans A, Schant G, Moesker O, Vooijs GP: Tissue distribution of keratin 7 as monitored by a monoclonal antibody. Exp. Cell Res 1987, 170, 235-249

69. Smedts F, Ramaekers F, Robben H, Pruszczynski M, Van Muijen G, Lane B, Leigh I, Vooijs P: Changing patterns of keratin expression during progression of cervical intra epithelial neoplasia. Am J Pathol 1990, 136, 657-668

70. Van Helden WCH, Kok-Verspuy A, Harff GA, van Kamp GJ: Rate-nephelometric determination of fibronectin in plasma. Clin Chem 1985, 31, 1182-1184

71. Verstraeten AA, Mackie EJ, Hageman PhC, Hilgers J, Schol. DJ, De Jongh GJ, Schalkwijk J: Tenascin expression in basal cell carcinoma. Br J Dermatol 1992, 127 , $571-574$ 
72. Garbarsch C, Mathiessen ME, OIsen BE, Moe D, Kirkeby S: Immunohistochemistry of the intracellular matrix components and the epithelio-mesenchymal junction of the human tooth germ. Histochem J 1994, 26, 110-118

73. Fleming TP, Garrod DR, Elsmore AJ: Desmosome biogenesis in the mouse preimplantation embryo. Development 1991, 112,527-539

74. Parrish EP, Steart PV, Garrod DR, Weller R: Antidesmosomal monoclonal antibody in the diagnosis of intracranial tumors $\mathbb{J}$ Pathol $1987,153,265-273$

75. Koch PJ, Walsch MJ, Schmelz M, Goldschmidt MD, Zimblemann R, Franke WW: Identification of desmoglein, a constitutive desmosomal glycoprotein as a member of the cadherin family of cell adhesion molecules. Eur J Cell Biol 1990, 53, 1-12

76. Gourdie RG, Severs NJ, Green CR, Rothery S, Germroth S, Thompson RP: The spatial distribution and relative abundance of gap junctional connexin 40 and 43 correlated to functional properties of components of cardiac atrioventricular conduction system. J Cell Sci 1993, 105, 985-991

77. Hozák P, Sasseville M-J, Raymond Y, Cook PR: Lamin proteins form an internal nucleoskeleton as well as a peripheral lamina in human cells. J Cell Sci 1995, 108, 635644

78. Machiels BM, Broers JLV, Raymond $\mathrm{Y}$, De Ley L, Kuijpers HJH, Caberg NEH, Ramaekers FCS: Abnormal A-type lamin organization in human lung carcinoma cell lines. Eur J Cell Biol 1995, 67, 328-335.

79. Zatloukal $\mathrm{K}$, Denk $\mathrm{H}$, Spurej $\mathrm{G}$, Hutter $\mathrm{H}$ : Modulation of protein composition of nuclear lamina-reduction of lamins-B1 and lamins-B2 in livers of griseofulvin-treated mice. Lab Invest 1992, 66, 589-597

80. Bridger JM, Kill I, O'Farrell M, Hutchison CJ: Internal lamin substructure within Gl nuclei of human dermal fibroblasts. J Cell Sci 1993, 104, 297-306 


\section{Chapter 8 \\ General discussion}

The original definition of hibernating myocardium as given by Rahimtoola (1985), -i.e. hibernating myocardium is a state of persistently impaired myocardial and left ventricular function at rest due to reduced coronary blood flow that can partially or completely be restored to normal either by improving blood flow or by reducing oxygen demand-has been refined and supplemented during the last decade (Rahimtoola, 1995). Today the criteria for chronic hibernating myocardium are the following: 1) abnormal wall motion (hypokinetic, akinetic, dyskinetic) of a myocardial segment supplied by a severely stenosed coronary artery. The flow reduction to the segment could be either sustained or repetitive; 2) evidence for viable myocardium by the presence of active metabolism and absence of myocardial infarction; 3) recovery of mechanical function after restoration of the blood flow. Such recovery can be either immediate or delayed (weeks to months). The contribution of our study to the further characterization of hibernating myocardium relates to the fine tuning of the definition of viable myocardium. Our results indicate that "viable" myocardium underwent marked structural remodelling during prolonged periods of hibernation. These observations are considered of great importance in explaining the fact that some patients with chronic hibernating myocardium show a delay in recovery of contractile function, which takes weeks to months after restoration of the blood flow. Studies on biopsies from patients with chronic hibernating myocardium indicate that cardiomyocytes adapt to the low-flow ischemia by downregulation of the expression of contractile proteins. The depletion of sarcomeres starts at the center of the cell and may extend towards the periphery, involving all of the cytoplasm. This change is distinct from atrophy since the space left by the dissoluted sarcomeres becomes occupied by glycogen. Another charactistic change is the presence of numerous mini-mitochondria with a healthy appearance. A third change concerns the nuclei, in which the heterochromatin is evenly distributed over the nucleoplasm. Finally, there is a considerable loss of sarcoplasmic reticulum. A nerwork of disorganized remnants of sarcoplasmic reticulum is sometimes present in the myolytic areas. In addition, the sarcolemma no longer presents protrusions (T-tubules) into the cytoplasm.

The aim of this thesis was to delineate whether these morphologic changes should be interpreted as signs of degeneration of the myocardium or rather as an adaptation of the cardiomyocytes involving a phenotypic switch from the functional (contractile) type to a non-functional (hibernating/sleeping) phenotype akin to the embryonic or neonatal state. 


\subsection{Cardiomyocyte dedifferentiation}

During embryonic development mesodermal cells develop into myoblasts, which further differentiate into cardiomyocytes. Differentiating myoblasts branch and attach to neighbouring cells in the longitudinal and lateral direction. As a result, the cardiac myofibres are interconnected in a branched network that enables the generation of well-coordinated pulsatile motions during the wave-like contraction of the heart.

Different sets of muscle specific proteins become expressed at different stages of cardiomyocyte development (Bader et al., 1982; Tokuyasu et al 1987a; 1987b; Schaart et al., 1989; Wang et al., 1989; Wessels et al., 1991; Handel et al., 1991; Van der Loop et al., 1992; 1995). In the very early developmental stages, different intermediate filament type proteins are sequentially expressed. Keratins are the first to be found in the heart anlage, while vimentin and desmin are expressed during later stages of cardiogenesis. Vimentin is found in proliferating myoblasts or in early stages of development when desmin is still undectable. In general, desmin increases during the differentiation process (Schaart et al., 1989; Van der Loop et al., 1995). The ruler protein titin, which organizes the longitudinal orientation of the myofilaments within the sarcomeres, and anchors these filaments to the Z-line, is one of the first sarcomere markers to be expressed in the developing cardiomyocyte (Tokuyasu et al., 1987a, 1987b, Wang et al., 1989; Van der Loop et al., 1992). Isoform switches of the myofilament proteins (actin and myosin) occur during different stages of cardiomyocyte development. A typical example is the switch from the smooth muscle actin isoform to the skeletal and cardiac (sarcomeric) isoforms (Woodcock-Mitchell et al., 1988; Lawrence et al., 1989; Lyons et al., 1990; 1991).

It is generally held that adult cardiomyocytes are not able to divide, but that they retain the ability to adopt an early stage of development i.e. undergo dedifferentiation. That cardiomyocytes are capable of dedifferentiation is known from in vitro studies (Eppenberger-Eberhardt et a., 1990; Donath et al., 1994; Eppenberger et al., 1995), but is less evident for the in vivo situation. It has been shown that there is structural dedifferentiation after induction of contractile unloading of cat papillary muscle (Thompson et al., 1984).

The most prominent features that we observed in patients with chronic hibernating myocardium involved the loss of myofilaments and storage of glycogen in the myolytic cytosol. The possible causes of the structural alterations in chronic hibernating myocardium are not well understood. The decrease in contractile force as a result of ischemia may give rise to loss of contractile proteins, by either a stimulation of protein breakdown or by a decrease in protein synthesis. The latter phenomon has been observed in cultured cardiomyocytes which were made quiescent by verapamil treatment (Sharp et al., 1993). Also in vivo, contractile quiescence induces depletion of myofilaments, a process that is reversible upon reinduction of contractile loading (Thompson et al., 1984). 
Titin, which is one of the earliest muscle proteins expressed during embryogenesis, changed its immunocytochemical detectability in chronic hibernating myocardium, indicating a structural change in the titin molecule or in its assembly with other sarcomeric proteins. Titin disorganisation, one of the first alterations seen in cardiomyocytes from chronic hibernating myocardium, might play a role in the onset of myolysis. This assumption is supported by the finding that titin has a crucial role in the formation of sarcomeres at early stages of development. $\alpha$ Smooth muscle actin re-expression, as found in the dedifferentiated cardiomyocytes from chronic hibernating myocardium, has been found during dedifferentiation of cardiomyocytes in vitro (Eppenberger-Eberhardt et al., 1990; Donath et al., 1994; Eppenberger et al., 1995), but more important, also during early stages of cardiomyocyte development in vivo (Woodcock-Mitchell et al., 1988; Babai et al., 1990). The absence of vimentin in hibernating cells however indicates that these cells have not returned to very early developmental stages.

Glycogen storage may be the consequence of 1) the metabolic excess of glucose as a result of impaired catabolism of glycogen (Stull and Mayer, 1979);,2) an increase in glycogen synthase activity (McNulty and Luba 1995); or 3) modifications of glucose transporter subtypes (Schwaiger et al., 1994). Histologic changes in chronic hibernating myocardium, in particular glycogen accumulation, have been found to correlate with glucose uptake as measured by positron emission tomography (Borgers et al., 1993; Vanoverschelde et al.., 1993; Maes et al., 1994; 1995; Depré et al., 1995). Because glycogen storage is seen in embryonic and foetal heart muscle cells, the glycogen accumulation in hibernating cells can be interpreted as a characteristic of less differentiated cells. An additional argument for the dedifferentiation hypothesis can be found in the similarities in glycogen accumulation between the hibernating cells and the normal conducting fibers, which are considered as less far differentiated cells (Berger and Rona, 1971a,b). Alterations in nuclear morphology, i.e. changes in nuclear heterochromatin distribution and nuclear lamina composition, are also characteristics indicative of dedifferentiation. In particular the observation that A-type lamins are lost, but lamin $B 2$ remains present during hibernation, is a strong argument in favor of the dedifferentiation hypothesis, since both A- and B-type lamins are lost during degenerative processes such as apoptosis and necrosis (Tinnemans et al., 1995, Casiano et al., 1996). This embryonic/neonatal type of nuclear organisation may exert an effect on gene expression in hibernating cells resulting in a dedifferentiated phenotype.

\subsection{Changes in extracellular matrix and cell-cell cohesion}

Although the recovery of a normal contractile function is, at least in part, dependent on the rebuilding of a normal amount of sarcomeres, the presence of an increased and/or modified interstitial tissue compartment must definitely be taken into account as a possilbe cause of the delay in recovery of function. The amount of 
interstitial tissue in patients with chronic hibernating myocardium correlated inversely with the functional outcome after coronary artery bypass surgery (Deprê et al., 1995; Maes et al., 1994; 1995; Shivalkar et al., 1996). Studies on structural changes in chronic hibernating myocardium indicated that an increase in connective tissue was consistently present in areas where dedifferentiated cardiomyocytes prevail. The collagen matrix, the major structural component of the interstitial tissue, plays an important role in maintaining the functional integrity of the myocardium (Caufield and Borg, 1979; Eghbali et al., 1989). The compostion and distribution of interstitial collagen determines the stifiness of the cardiac muscle, especially because of the rigidity of type I collagen (Doering et al., 1988; Weber 1989). Our finclings, which indicate the presence of an enlarged extracellular matrix compartment, may not only be one of the major causes that hampers the recovery of function of chronic hibernating myocardium, but might even be considered as the determining factor in determining the point of no return. The excess of intersitial tissue may impair contractile function of the cardiomyocytes because of the inadequate force transmission between contracting cells. Full recovery of function might occur only when the interstitial tissue has returned to normal proportion and composition. The interaction of extracellular matrix components, such as that of laminins with muscle cells, is modulated by its attachment to the sarcolemma at specific sites that contain cell-adhesion molecules. These molecules are known to be differentially expressed in different heart segments and during heart muscle development (Buck et al., 1993, Collo et al., 1995; Hierck et al., 1996 a,b; Terracio et al., 1991; Koch-Scheidemann ef al., 1994). It can be speculated that changes in chronic hibernating myocardium induced by either ischemia, passive stretch or other external factors, can have a cell-adhesion molecule mediated effect, which in turn might influence the dedifferentiation state of the cardiomyocyte. Our studies show that loss of cell-cell cohesion of the atrial myocytes is a prominent feature during sustained atrial fibrillation. We regard this phenomenon as a dedifferentiation characteristic of atrial myocytes. It is known from in vitro experiments that maintance of contractility, mechanical loading and the presence of cell-cell contacts are important factors in the determination of the differentiated state of the cardiomyocytes (Samarel and Engelmann 1991; Sharp et al., 1993; Simpson et al., 1993; 1994; Eppenberger et al., 1995; Van der Loop et al., 1996). Cadherins and desmoplakins have been shown to be involved in cellular rearrangements during embryonic development (Linask, 1992; Van der Loop et al., 1996). Developing tissue can modulate the expression of specific cadherins at their cell surface at different time points during development (Takeini, 1988; Linask, 1992)

\subsection{Cardiomyocyte redifferentiation}

That cardiomyocytes can redifferentiate was indirectly suggested by Borisov (1991), who reported that cardiac muscle cells at early, intermediate and terminal 
stages of differentiation are capable of adaptive remodelling of their contractile system, both in vivo and in vitro. More evidence for redifferentiation came from different studies with adult rat heart cardiomyocyte cultures (Sharp et al., 1993; Koch-Schneidemann et al., 1994; Eid et al., 1995; Lesniak et al., 1995). Sharp et al. (1993) established that in verapamil-arrested cultured cardiomyocytes, in which an initial steep reduction in the amount of actin was observed, the process could be entirely reversed upon omission of the drug. Redifferentiation of rat cardiomyocytes in culture can also be induced by attachment of the cell to extracellular matrix components and by the addition of certain growth factors (Koch-Schneidemann et al., 1994; Donath et al., 1994; Vélez et al.,1995).

Whether or not dedifferentiated cardiomyocytes from chronic hibernating myocardium can redifferentiate is not known. The redifferentiation hypothesis might explain, at least in part, the delay in recovery of contractile function in patients with coronary artery bypass surgery. To test whether redifferentiation occurs under in vivo conditions adequate animal models need to be developed. A factor that may contribute to structural redifferentiation is increased passive stretch applied to non-contracting cardiomyocytes. Passive stretch in (non-contracting) cardiomyocytes in culture results in preservation of the contractile filaments (Simpson et al., 1995). That mechanical forces influence morphogenesis of the heart is known from in vivo experiments with variable load on cardiomyocytes during different stages of development. Increased load induces the synthesis of myofibrillar proteins and hypertrophic cell growth (Simpson et al., 1994).

\subsection{Animal models for chronic hibernating myocardium}

Although it is possible to perform morphological and cell biological studies on human biopsy material, questions on the initiation and the progression of the dedifferentiation and redifferentiation processes can only be assessed with an animal model. Such a model might allow the factors to be indentified that underly the dedifferentiation and redifferentiation processes for example by affecting the expression of growth factors.

The development of suitable animal models for chronic hibernating myocardium is encumbered by several problems, mainly related to the reduction in blood flow. On the one hand it is difficult to reduce the blood flow sufficiently to induce reduction in cardiac function; on the other hand, too severe reduction will compromise the viability of the underiying myocardium and might lead to infarction. In some animal species, especially dogs, it is difficult to reduce coronary flow to a steady state, because of the natural abundance of collateral vessels. These drawbacks may influence the results of several model systems described so far. A regional cardiac dysfunction can also be attributed to the presence of mixed healthy and infarcted myocardium as was seen in pigs with chronic coronary artery stenosis (Symons et al., 1992; Mills et al., 1994; Bolukogly et al., 1992). Shen and Vatner tried to circumvent this problem by inducing chronic ischaemia through a gradual 
constriction of a coronary artery, hence avoiding compensatory mechanisms. In these experiments a steady state of chronic ischaemia was not reached.

The goat model described in this thesis is the first animal model in which the morphological adaptations strongly resemble those in chronic hibernating myocardium in man. Our hypothesis that "hibernating" cardiomyocytes adapt a "dedifferentiation" phenotype was also confirmed for atrial myocytes by the reexpression of $\alpha$-smooth muscle actin, the alterations in the detectability of certain titin epitopes and the disappearance of cardiotin. Again the process of dedifferentiation was not complete, as indicated by the absence of vimentin or cytokeratin 8 and cytokeratin 18 reexpression. Although we realize that this is a model that exhibits structural adaptations in atrial and not in ventricular myocardium, we can use it to address several questions pertaining to chronic hibernating myocardium and dedifferentiation of cardiomyocytes.

\subsection{Are hibernating cells unique to chronic hibernating myocardium?}

"Dedifferentiated" cells are not unique for chronic hibernating myocardium. Cells with similar structural alterations were found at the border of healed infarctions (Borgers, 1997). Such "dedifferentiated" cells may have been induced by regional underperfusion and low contractile activity in this area. Such cells were also prevalent in biopsies from patients with anomalous origin of the left anterior coronary artery from the pulmonary artery (ALCAPA) and cardiomyopathic patients, although in the latter pathologies hibernating cells were often intermingled with cells showing different degrees of degenerative changes (Shivalkar et al., 1994; Borgers, 1997). Atrial myocardium of patients with atrial arrhythmias and mitral valve pathologies showed, in addition to degenerative changes, a large population of the myocytes showing myolysis without accompanying degenerative changes (Fenoglio et al., 1979; Marie-Rabine et al., 1983). Many cells from cardiomyopathic hearts lacked myofilaments and had cellular characteristics of hibernating cardiomyocytes. These myolytic cardiomyocytes were intermingled with cells that had degenerative features (Schaper et al., 1991). The structural changes in chronic hibernating myocardium have been also interpreted by the same group as signs of degeneration (Elsässer and Schaper, 1995; Schwarz et al., 1996) despite the fact that improvement of left ventricular function after bypass surgery has been observed. Our view is that when the myolytic hibernating cells as seen by us in the major part of the biopsies are dedifferentiated, they will indeed degenerate if the oxygen supply is not sufficient to sustain cell viability, although they are less susceptible to ischemia (Borgers and Flameng, 1993). When hibernating cells progress to degeneration, especially when accompanied by extensive modulation of the interstitial space, full recovery of function after blood flow restoration is not very likely. However, the fact that the overwhelwing majority of altered cells is of the "healthy hibernating" type suggests that progress from the hibernating (reversible) state to the degenerative (irreversible) state is a very slowly occurring process. 


\subsection{Conclusions and outlook}

In conclusion, our morphological studies of chronic hibernating myocardium indicate that the myocardium adapts to the lowered oxygen supply. Cardionyocytes show structural characteristics of embryonic/neonatal cells. The expression pattern of some structural proteins in an embryonic-like fashion further substantiates the dedifferentiation hypothesis.

Although we have obtained some insight into the structural adaptations underlying chronic hibernating myocardium, many questions remain unanswered. The first question relates to the redifferentiation potential of the dedifferentiated cardiomyocytes after restoration of the blood flow. It is conceivable that if the structural changes in affected cardiomyocytes are reversible, it will take the cells a prolonged period of time to rebuild a normal contractile machinery.

Another question relates to remodelling of the increase in interstitial tissue. The presence of an extensive extracellular matrix compartment in hibernating myocardium may delay the further recovery of contractile function of the myocardium.

Chronic hibernating myocardium will remain a controversial issue untill a suitable animal model becomes available that fulfills to the various criteria of chronic hibernating myocardium in man. Essential questions that need to be addressed are those concerning the relative contribution of sustained/repetitive ischemia, the degree of contractile quiescence, and elevation of wall stress to the occurrence of structural changes. In addition, future work should elucidate the time course of hibernation, and discover how long such cells can survive in the dedifferentiated state and how long it generally takes the hibernating cardiomyocytes to regain the functional (contractile) phenotype.

\section{References}

Babai F, Musevi-Aghdam J, Schurch W, Royal A, Gabbiani G, 1990. Coexpression of $\alpha$ sarcomeric, $\alpha$-smooth muscle actin and desmin during myogenesis in rat and mouse embryos I. Skeletal muscle. Differentiation 44: 132-142.

Bader D, Masaki T, Fischman DA, 1982. Immunohistochemical analysis of myosin heavy chain during avain myogenesis in vivo and in vitro. J Cell Biol 95: 763-770.

Berger JM, Rona G, 1971 a. Functional and fine structural heterogeneity of atrial cardiocytes. In: Bajusz E, Jasmin G (eds): Methods and Achievements in experimental pathology. Functional morphology of the heart. Basel, Munchen, Paris, London, New York, Sydney: S. Karger, 540-590.

Berger JM, Rona G, 197lb. Fine structure of extra-nodal transitional cardiocytes in rat left atrium. J Mol Cell Cardiol 2: 181-185.

Bolukogly H, Liedtke AJ, Nellis SH, Subramanian R, 1992. Myocardial function and metabolism in pig hearts after relief from chronic partial coronary stenosis. Am $J$ Physiol 263: H20-29. 
Borgers M. Thone F, Wouters L, Ausma J, Shivalkar B, Flameng W, 1993. Structural correlates of regional myocardial dysfunction in patients with critically coronary artery stenosis: chronic hibernation? Cardiovasc Pathol 2: 237-245.

Borgers $M$, Flameng $W$, 1993. Morphology of the acute and chronic ischemic myocardium in man. In: Piper HM, Preusse Cl (eds). Ischemiareperfusion in cardiac surgery. Boston, Kluwer Academic Publishers, pp 353-375.

Borgers $M, 1997$. Pathological findings in chronic hibernating myocardium. In: Hendrickx GR, Wijns WC, Vatner SF (eds), Elsevier, Amsterdam, in press.

Borisov AB, 1991. Myobrilogenesis and reversible disassembly of myofibrils as adaptive reactions of cardiac muscle cells. Acta Physiol Scand 5599:71-80.

Buck CA, Baldwin HS, DeLisser H, Mickanin C, Shen HM, Kennedy A, Chen A, Edelmann JM, Albelda SM, 1993. Cell adhesion receptors and early mammalian heart development: an overview. C R Acad Sci Paris, Life Sci 316: 849-859.

Caufeld JB, Borg TK, 1979. The collagen network of the heart. Lab Invest 40: 364-372.

Casiano CA, Martin S , Green DR, Tan EM, 1996. Selective cleavage of nuclear autoantigens during CD95 (Fas/APO-1)-mediated T cell apoptosis. J Exp Med 184: 765770.

Collo $\mathrm{G}$, Domanico $\mathrm{SZ}$, Klier $\mathrm{G}$, Quaranta $\mathrm{V}, 1995$. Gradient of integrin $\alpha 6 \mathrm{~A}$ distribution in the myocardium during early heart development. Cell Adhes Commun 3: $101-113$.

Depré C, Vanoverschelde J-LJ, Melin JA, Borgers M, Bol A, Dion $\mathbb{R}$, Wijns W, 1995. Structural and metabolic correlates of the left ventricular ischemic dysfunction in humans. Am J Physiol 37: H1265-H1275.

Doering CW, Jalil JE, Janicki JS, Pick R, Aghili S, Abrahams C, Weber KT, 1988. Collagen network remodelling and diastolic stiffness of rat left ventricle with pressure overload bypertrophy. Cardiovasc Res 22: 686-695.

Donath MY, Zapf J, Eppenberger-Eberhardt M, Froesch R, Eppenberger HM, 1994. Insulin-like growth factor I stimulates myofibril development and decreases smooth muscle $\alpha$-actin of adult cardiomyocytes. Proc Natl Acad Sci USA 91: 1686-1690.

Eghbali M. Robinson TF; Seifter S, Blumenfeld OO, 1989. Collagen accumulation in heart ventricles as a function of growth and ageing. Cardiovasc Res 23: 723-729.

Eid H, Chen JH, Bold de AJ, 1995. Regulation of alpha-smooth muscle actin expression in adult cardiomyocytes through a tyrosine kinase signal tansduction pathway. Ann $\mathbb{N} Y$ Acad Sci 752: 192-201.

Elsisser A, Schaper J, 1995. Hibernating myocardium: adaptation or degeneration? Basic Res Cardiol 90: 47-48.

Eppenberger-Eberhardt ME, Flamme I, Kurer V. Eppenberger HM, 1990. Reexpression of a-smooth muscle actin isoform in cultured adult rat cardiomyocytes. Dev Biol 139: 269 . 278.

Eppenberger HM, Eppenberger-Eberhardt M, Hertig C, 1995. Cytoskeletal rearrangements in adult rat cardiomyocytes in culture. Ann $\mathrm{N}$ Y Acad Sci 752: 128-131. 


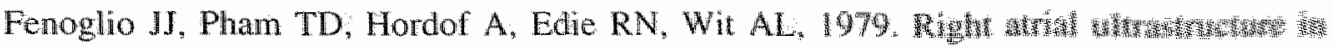

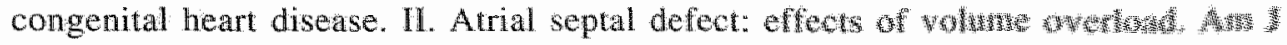
Cardiol 43: $820-827$.

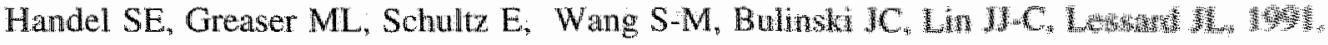

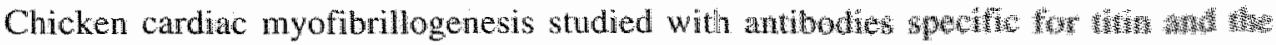

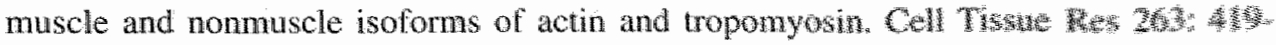
430 .

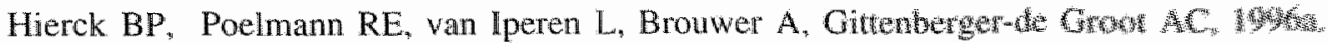

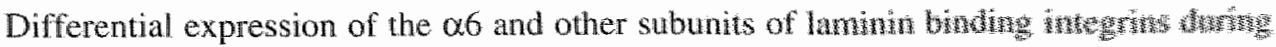
development of the murine heart. Dev Dyn 206: 100-111.

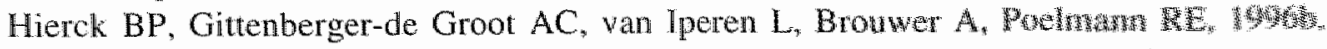

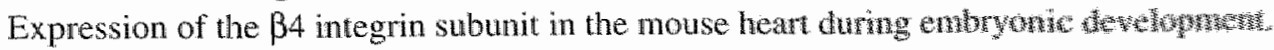
Retinoic acid advances 34 expression. Dev Dyn 207, 89-103.

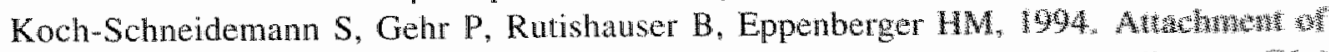

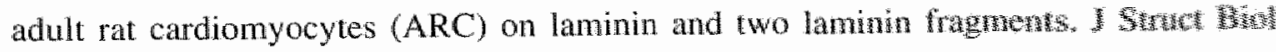
113: $107-116$

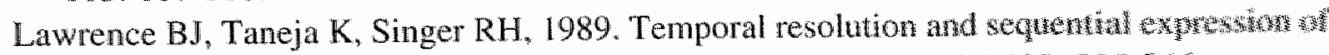
muscle-specific genes revealed by in situ hybridization. Dev Bhol $13,235-246$

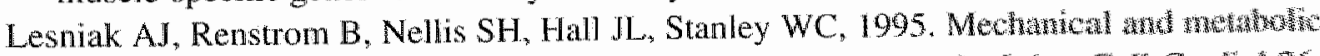
functions in pig hearts after 4 days of chronic coronary stenosis. A A Coll Cantow 2 tw 815-825.

Linask K, 1992. N-Cadherin localization in early heart development and polw expestow of $\mathrm{Na}^{+}, \mathrm{K}^{+}$-ATPase, and integrin during pericardial caelom formatound epithelialization of the differentiating myocardium. Dev Biol $151: 21,3-224$

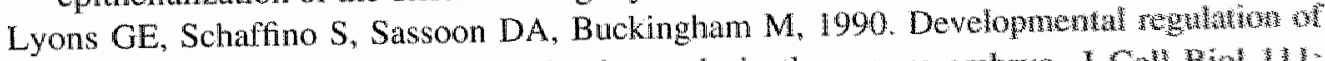
myosin genes in developing skeletal muscle in the mouse embryo. 1 Cell Bat 11 : 1465-1476.

Lyons GE, Buckingham ME, Mannherz $H G$, 1991. $\alpha$-Actin protens and gene mancwins are colocalized in embryonic mouse muscle. Development $11,451-454$.

Maes A, Flameng W, Nuyts J, Borgers M, Shivalkar B, Ausma J, Bormans G, Schiepers C, De Roo M, Mortelmans L, 1994. Histologicat alterations in chronically hypoperfused myocardium. Correlation with PET findings. Circulation 90: 735-745.

Maes A, Flameng W, Borgers M, Nuyts J, Ausma J, Bormans G, Van de Werf F, De Roo M, Mortelmans L, 1995. Regional myocardial blood flow, glucose utilization and contractile function before and after revascularization and ultrastructural findings in patients with coronary artery disease. Eur I Nucl Med 22: 1299-1305.

Mary-Rabine L, Albert A, Pham TD, Hordof A, Fenoglio JJ, Malm JR, Rosen MR, 1983. The relationship of human atrial cellular electrophysiology to clinical function and ultrastructure. Citc Res 52: 188-199.

McNulty $\mathrm{PH}$, and Luba MC. 1995. Transient ischemia induces regional myocardial glycogen symthase activation and glycogen synthesis in wiv. Am Inysiol 268: 1364 m 370 . 
Mills I, Fallon JT, Wrenn D, Sasken H, Gray W, Bier $I$, Levine D, Berman $S$, Gilson M, Gewirtz H, 1994. Adaptive responses of coronary circulation and myocardium to chronic reduction in prefusion pressure and flow. Am J Physiol 266: H447-457.

Rahimtoola $\mathrm{SH}, 1985$. A perspective on the three large multicenter randomized clinical urals of coronary bypass surgery for chronic stable angina. Circ 72: Suppl V: 123-135.

Rahimtoola $\mathrm{SH}_{1}$ 1995. From coronary artery disease to heart failure: Role of the hibernating myocardium. Am J Cardiol 75: 16E-22E.

Samarel and Engemann, 1991. Contractille activity modulates myosin heavy chain-beta expression in neonatal rat heart cells. Am J Physiol 261: H.1067-1077.

Schaart G, Viebahn C, Langmann W, Ramaekers FCS, 1989. Desmin and titin epxression in early postimplantation mouse embryos. Development 107: 585-596.

Schaper J, Froede TA, Hein St, Buck H, Hashizume H, Speiser B, Friedl A, Bleese N, 1991. Impairment of the myocardial ultrastructure and changes of the cytoskeleton in dilated cardiomyopathy. Circulation $83: 504-514$

Schwarz ER, Schaper J, vom Dahl J, Altehoefer C, Grohmann B, Schoendube F, Sheehan FH, Uebis R, Buell U, Messmer BJ, Schaper W, Hanrath P, 1996. Myocyte degeneration and cell death in hibernating human myocardium. J Am COll Cardiol 27: $1577-1585$.

Schwaiger M, Sun DQ, Deep GM Nguyen N, Haas F, Sebening F, Brosius FC, 1994. Expression of myocardial glucose transporter (GL.UT) mRNAs in patients with advanced coronary artery disease (CAD). Circulation 90: [-113.

Sharp WW, Terracio L, Borg TK, Samarel AM, 1993. Contractile activity modulates actin synthesis and turnover in cultured neonatal rat heart cells. Circ Res 73: 172-183.

Shen YT, Vatner SF, 1995. Mechanism of impaired myocardial function during progressive coronary stenosis in conscious pigs. Hibernating versus stunning. Circ Res 76: 479-488.

Shivalkar B, Borgers M, Daenen W, Gewillig M, Flameng W, 1994. ALCAPA syndrome: An example of chronic myocardial hypoperfusion? J Am Coll Cardiol 23: 772-778.

Shivalkar B, Maes A, Borgers M, Ausma J, Scheys I, Nuyts J, Mortelmans L, Flameng W, 1996. Only hibernating myocardium invariably shows early recovery after coronary revascularization. Circ 94, 308-315.

Simpson DG, Terracio L, Terracio M, Price RL, Turner DC, Borg TK, 1993. Modulation of cardiac myocyte phenotype in vitro by the composition and orientation of the extracellular matrix. J Cell Physiol 161: 89-105.

Simpson DG, Carver W, Borg TK, Terracio L, 1994. Role of mechanical stimulation in the establishment and maintenance of muscle cell differentiation. Int Rev Cytol 150: 69-94.

Simpson DG, Sharp WW, Borg TK, Price RL, Samarel AM, Terracio L, 1995. Mechanical regulation of cardiac myofibrillar structure. Ann N Y Acad Sci 752: 131-140.

Stull JT, Mayer SE, 1979. Biochemical mechanisms of adrenegic and cholinergic regulation of myocardial contractily. In. Beme RM et al (eds) Handbook of Physiology section 2: The cardiovascular system. American Physiological Society, Bethesda, Maryland, Vol I, $741-774$. 
Symons JD, Pitsillids KF, Longhurst JC, 1992. Chronic reduction of myocardial ischemia does not attenuate coronary collatoral development in miniswine. Circulation 86: 660671.

Takeini M, 1988. The cadherins: Cell-cell adhesion molecules controlling animal morphogenesis. Development 102: 639-655.

Terracio L, Rubin K, Gullberg D, Balog E, Carver W, Jyring R, Borg TK, 1991. Expression of collagen binding integrins during cardiac development and hypertrophy. Circ Res 68: 734-744.

Thompson EW, Marino TA, Uboh, Kent RL, Cooper G IVth, 1984. Atrophy reversal and cardiocyte redifferentiation in reloaded cat myocardium. Circ Res 54: 367-377.

Tinnemans MMFJ, Lenders M-HJH, ten Velde GPM, Ramaekers FCS, Schutte B, 1995. Alterations in cytoskeletal and nuclear matrix associated proteins during apoptosis. Eur J Cell Biol 68: 35-46.

Tokuyasa KT, Mayer PA, 1987a. Immunocytochernical studies of cardiac myofibrillogenesis in early chick embryos. I. Presence of immunofluorescent titin spots in premyofibril stages. J Cell Biol 105: 2781-2793.

Tokuyasa KT, Mayer PA, 1987b. Immunocytochemical studies of cardiac myofibrillogenesis in early chick embryos. II. Generation of $\alpha$-actinin dots within titin spots at the time of the first myofibril formation. I Cell Biol 105: 2795-2801.

Van der Loop FTL, Schaart G, Langman W, Ramaekers FCS, Viebahn C, 1992. Expression and organization of muscle specific proteins during the early developmental stages of the rabbit heart. Anat Embryol 185: 439-450.

Van der Loop FTL, Schaart G, Langman W, Ramaekers FCS, Viebahn C, 1995. Rearrangement of intercellular junctions and cytoskeletal proteins during rabbit myocard development. Eur J Cell Biol 68: 62-69.

Van der Loop FTL, Van Eys GJJM, Schaart G, Ramaekers FCS, 1996. Titin expression as an early indication of heart and skeletal muscle differentiation in vitro. Developmental re-organizaton in relation to cytoskeletal constituents. J Muscle Res Cell Motil 17: 2336.

Vanoverschelde JLJ, Wijns W, Depré C, Essamri B, Heyndricks S, Borgers M, Bol A, Melin J, 1993. Mechanisms of chronic regional postischemic dysfunction in humans: New insights form the study on non-infarcted collateral dependent myocardium. Circulation 87: 1513-1523.

Vélez C, Aránega E, Prados JC, Melguizo C, Alvarez L, Aranega A, 1995. Basic fibroblasi and platelet-derived growth factors as modtulators of actin and $\alpha$-actinin in chick myocardiocytes during development. Proc.Soc.Exp.Biol.Med. 210: 57-63.

Wang SM, Greaser ML, Schultz E, Bulinski JC, Lin JJC, Lessard J-L, 1989. Studies on cardiac myofibrillogenesis with antibodies to titin, actin, tropomyosin, and myosin. J Cell Biol 107: 1075-1083.

Weber KT, 1989 Cardiac interstitium in health and disease: the fibrillar collagen network. I Am Coll Cardiol 13: 1637-1652. 
Wessels A, Vermenlen JLM, Viragh Sz, Kalman F, Lamers WH, Moorman AFM, 1991. Spatial distribution of "tissue-specific" antigens in the developing human heart and skeletal muscle. II. An immunohistochemical analysis of myosin heavy chain expression patterns in the embryonic heart. Anat Rec 229: 355-368.

Woodcock-Mitchell J, Mitchell JJ, Low RB, Kieny M, Sengel P, Rubbia L, Skalli O, Jackson B, Gabbiani $\mathrm{G}, 1988$. $\alpha_{w}$-Smooth muscle actin is transiently expressed in embryonic rat cardiac and skeletal muscles. Differentiation 39: 161-166. 


\section{Summary}

Hibernating myocardium is a state of persistently impaired myocardial dysfunction at rest, due to reduced coronary blood flow that can be partially or completely restored to normal either by having the blood flow improved or the oxygen demand reduced. In Chapter 1 we document the morphologic changes underlying this chronic ischemic state of the myocardium. Studies on the ultrastructure of chronic hibernating myocardium have shown that cardiomyocytes undergo the following typical structural alterations: 1) Loss of contractile material (sarcomeres). The depletion of sarcomeres is seen initially in the perinuclear region and often extends towards the periphery of the cell; 2) Accumulation of glycogen in the myolytic cytosol; 3) Presence of numerous small doughnut-like mitochondria in the areas adjacent to the glycogen-rich perinuclear zones; 4) Redistribution of heterochromatin in nuclei of hibernating cells; 5) Depletion of organized sarcoplasmic reticulum. 6) Fragments of rough endoplasmic reticulum are frequently found; 7) Virtual absence of T-tubules. These morphological aspects are reminiscent of embryonic/fetal cells. Typical degenerative changes, such as cytoplasmic vacuolization, cytosolic edema, mitochondrial swelling, membrane disruption, accumulation of secondary lysosomes, membrane whorls, and lipid droplets are virtually absent. To find support for the hypothesis that cardiomyocytes dedifferentiate in chronic hibernating myocardium, we studied the expression and organization patterns of some markers of cardiomyocyte differentiation. The staining of titin in an embryonic-like punctated pattern, the disappearance of cardiotin, a late marker of heart muscle development, and the re-expresson of $\alpha$-smooth muscle actin all supported the view that cardiomyocytes in chronic hibernating myocardium have acquired aspects of dedifferentiation (Chapter 2). The changes in the molecular organization of titin were determined by monoclonal antibodies recognizing epitopes over the whole length of the titin molecule. The epitopes close to the Z-disc and those in the center of the A-band remained detectable at all stages of hibernation, while epitopes in the A-I junctional part and the first part of the A-band are lost. These changes resemble, at least in part, the changes occurring during muscle cell differentiation, although in reverse order (Chapter 3). Also molecular changes at the nuclear level support the dedifferentiation hypothesis. The disappearance of A-type lamins (lamin A and C), while lamin B2 remained present in the affected cardiomyocytes, shows the resemblance with cardiomyocytes during embryonic development (Chapter 4). 
Apart from changes to cardiomyocytes, an increase in extracellular matrix components such as collagen types I and III and fibronectin is often seen in hibernating segments. An increase in the number of vimentin-positive cells (endothelial cells and fibroblasts) is seen throughout the extended extracellular matrix of chronic hibernating myocardium. It is proposed that a close relationship exists between the ability of the myocardium to recover function and the amount of connective tissue (Chapter 5).

The question of reversibility of the changes will remain unanswered until an animal model becomes available in which these structural changes can be reproduced. Interestingly, the structural changes in atrial cardiomyocytes after chronic atrial fibrillation in the goat correspond to changes seen in chronic hibernating myocardium in man. The cardiomyocytes displayed loss of myofibrils, accumulation of glycogen, changes in mitochondrial shape and size, fragmentation of sarcoplasmic reticulum and dispersion of nuclear chromatin. These changes are accompanied by an increase in the size of the cardiomyocytes. Cellular degeneration is absent and, in contrast to hibernating myocardium, the interstitial space apparently remains unaltered (Chapter 6). These morphological changes in the atrial myocytes were verified as to their "dedifferentiation" characteristics. Studies on the expression and organisation of contractile and cytoskeletal proteins were performed as previously described for human samples (Chapter 7). The striking resemblance of the phenotype of these affected cardiomyocytes from goat and man indicate that sustained atrial fibrillation in goats provides a model which may also be used to study dedifferentiation phenomena occurring in patients with chronic hibernating myocardium. This model provides an opportunity to obtain a better insight into the cascade of events leading to cardiomyocyte dedifferentiation and to study the reversibility of the structural changes. The possible effects of the structural remodelling on myocardial function described above are discussed in Chapter 8. The observed morphological changes indicate that the chronic hibernating myocardium is the result of dedifferentiation rather than degeneration. Segments in which the dedifferentiated cardiomyocytes predominate, will show a delayed recovery of function, since structural remodelling to rebuild a normal amount of contractile material requires time. It may be obvious that the degree of dedifferentiation and accompanying extracellular matrix remodelling contribute to the abnormal contractile functioning and determine the ability and speed of functional recovery after revasculatization. 


\section{Samenvatting}

Hibernatie van het myocard is een toestand van een dysfunctioneel linkerventricle, ats reactie op een sterk verminderde hartspierdoorbloeding. De dysfuntie kont neer op een verminderde tot afwezige contractie in het slecht doorbloede deel van de hartspier. De onderliggende structuur van het hibernerend myocard was tot op heden niet of nauwelijks gekend. In hoofdstuk 1 zijn de morfologische veranderingen die ten grondslag liggen aan de chronische hibernatie beschreven. De myocardcellen tonen een sterk veranderde structuur, gekenmerkt door: 1) Het verlies van contractiele elementen (sarcomeren); 2) De stapeling van glycogeen in het myolytische cytosol; 3) De aanwezigheid van vele kleine, ronde mitochondria aan de rand van de glycogeen-rijke zones; 4) De herverdeling van heterochromatine in de kern; 5) De vermindering van de hoeveelheid georganiseerd sarcoplasmatisch reticulum; 6) Het frequent voorkomen van fragmenten van ruw endoplasmatisch reticulum; 7) Vrijwel volledige afwezigheid van T-tubulaire instulpingen. Dit zijn tevens morfologische kenmerken van embryonale/foetale cellen. Typische degeneratieve veranderingen, zoals de vorming van cytoplasmatische vacuoles, het zwellen van de mitochondria, de aanwezigheid van membraanschade, ophoping van secundaire lysosomen, de aanwezigheid van membraanresten en lipidedruppels, worden zelden of nooit aangetroffen in het hibernerend myocard. Op basis van het bovenstaande wordt in dit proefschrift de hypothese gesteld dat cardiomyocyten in het chronisch hibernerende hart een gededifferentieerd phenotype tonen in plaats van te degenereren. Om deze theorie te ondersteunen zijn de expressie- en organisatie-patronen van enkele differentiatiemarkers bestudeerd, zoals de typische embryonale aankleuring van titine, het verdwijnen van cardiotine, het opnieuw tot expressie komen van $\alpha$-glad spiercel actine. Deze moleculaire marker studies ondersteunen de vooropgestelde hypothese dat cardiomyocyten in het chronisch hibernerend hart dedifferentiatie karakteristieken aannemen (hoofdstuk 2). De veranderingen in de moleculaire organisatie van titine werden vastgesteld met monoklonale antilichamen tegen epitopen gelegen over de gehele lengte van het titine molecuul. De epitopen dicht bij de Z-lijn en dicht bij het centrum van de A-band gekregen bleven aantoonbaar tijdens de verschillende stadia van hibernatie, terwijl epitopen in het A-I overgangsgebied en het eerste deel van de A-band verloren gingen. Deze veranderingen vertonen tenminste gedeeltelijk overeenkomsten met de veranderingen die optreden tijdens normale embryonale spierceldifferentiatie, zij het in omgekeerde volgorde (hoofdstuk 3). Ook de moleculaire veranderingen die waar te nemen zijn in de celkern ondersteunen de dedifferentiatie hypothese. Het verdwijnen van de A-type lamines (lamine $\mathrm{A}$ en $\mathrm{C}$ ) tijdens hibernatie, terwijl lamine B2 aanwezig blijft in de aangedane cardiomyocyten, toont de overeenkomt met bepaalde stadia van de embryonale hart ontwikkeling (hoofdstuk 4).

Naast de veranderingen in de cardiomyocyten, wordt vaak een toename van de extracellulaire matrix-componenten, zoals collageen (type J en III) en fibronectine, 
gezien in de hibernerende hart segmenten. Tevens wordt een toename van het aantal vimentine-postieve cellen (endotheel cellen en fibroblasten) gezien in de toegenomen extracellulaire matrix van het hibernerende hart. Een belangrijke vraag die uit deze studie naar voren komt is of er een directe relatie bestat tussen het vermogen om de functie te herstellen en de hoeveelheid bindweefsel (hoofdstuk 5). De vraag omtrent de reversibiliteit van de structurele veranderingen zal slechts beantwoord kunnen worden door middel van een diemodel, waarin de morfologische veranderingen gereproduceerd kunnen worden. In hoofdstuk 6 wordt aangetoond dat de veranderingen in cardiomyocyten van het atrium van geiten met chronisch boezemfibrilleren overeenkomen met de veranderingen gezien in het chronische hibernerende hart van de mens. De cardiomyocyten tonen verlies van myofibrillen, ophoping van glycogeen, veranderingen in de vorm en grootte van de mitochondria, disruptie van het sarcoplasmatisch reticulum en de egale verspreiding van chromatine over de celkern. Deze veranderingen gaan gepaard met een toename van de grootte van de cardiomyocyten, terwijl cellulaire degeneratie niet wordt waargenomen. In tegenstelling tot het hibernerende hart is de interstitiële ruimte niet veranderd. De cellulaire veranderingen in atrialle cardiomyocyten worden gezien als kenmerken van"dedifferentiatie". Sudies naar de expressie en organisatie van contractiele en cytoskeletaire eiwitten, op vergelijkbare wijze uitgevoerd als tijdens de eerdere studies met de humane biopten (hoofdstuk 7), tonen grote overeenkomsten. Chronisch boezemfibrilleren in geiten verschaft een model om dedifferentiatie fenomenen te bestuderen die optreden in patienten met een chronisch hibernerend hart. Dit model biedt de mogelijkheid om een beter inzicht te verkrijgen in de reeks gebeurtenissen die leiden tot cardiomyocyte-dedifferentiatie. Het geeft bovendien de mogelijkheid om het herstel van de structurele veranderingen na cardioversie te bestuderen. De mogelijke effecten van de als boven omschreven structurele aanpassing op de hartspier functie worden bediscussieerd in hoofdstuk 8. De waargenomen morfologische en immunophenotypische veranderingen ondersteunen een hypothese voor dedifferentiatie in plaats van een degeneratie. Concluderend mogen we stellen dat dedifferentiatie en de veranderingen in de extracellulaire matrix bijdragen tot de abnormale contractiele functie in de alangedane segmenten. Deze structurele veranderingen bepalen in belangrijke mate het vermogen en snelheid van functioneel herstel na revascularisatie. 


\section{Dankwoord}

Promoveren doe je nooit alleen! ledereen die op welke wijze dan ook heeft bijgedragen aan de totstandkoming van dit boekje wil ik dan ook graag bedanken.

Een aantal mensen wil ik in het bijzonder bedanken.

Allereerst natuurlijk Prof.dr. M. Borgers, mijn promotor. Beste Marcel, u haalde me naar Maastricht, leerde me de morfologie van het hibernerend hart kennen en leverde vele ideeën. UW grenzeloos enthousiasme heeft op minn werk een sterk posirieve invloed gehad. We mogen u wel de "peetvader" van de hibernerende cel noemen en een AlO kan zich in ieder geval geen betere wensen.

Prof.dr. F.C.S. Ramaekers, mijn tweede promotor. Beste Frans, je sturende kracht bij het hibernatie gebeuren in Maastricht heeft ervoor gezorgd dat manuscripten werden afgerond en er geen tien dingen gelijktijdig werden gedaan. Bedankt woor de begeleiding en belangstelling.

Guillaume van Eys, in de aflopen jaren ben je een steeds belangrijkere rol gaan vervullen in het hibernatie-werk. De prettige samenwerking, je vele ideeën en suggesties, heb ik altijd zeer kunnen waarderen. Jeanette en de kids, 't is altijd zeer gezellig bij jullie op de Berg.

Gert Schaart, jouw morfologische kennis en je hulp bij het opzetten van het immunohistochemische werk waren voor mij een grore steun.

Prof.dr: W. Flameng. Dr: Bharati Shivalka: Dr: Alex Maes (Cardiale Helkunde en Nucleaire Geneeskunde. Katholieke Universiteit Leuven) and Prof.dr. J.A. Melin. Dr. Jean-Louis Vanoverschelde, Dr. Christophe Depre (Cardiologie, Universite Catholique de Lowam. Brussel), thanks for providing the human biopsy ramples. Your contributions were essential!

Fred Thone, van de Janssen Research Fow hathon, vete schitterende EM-foto's kwamen van wat hand an niat te vergeten de PAS-toluidine blaw coupes. Fred ww hulp was een onmishare! Andere medewerkers wan Janssen Research Foundation zoals Luc Wouter, Lambort Leijssen, Bob Joossen-Meyvis, Ingid Gevers, Greet De 
Kort. Wie ben ik nog vergelen? Waarschijnlijk velen, maar allemaal bedankt voor de hulp.

Prof.dr. M.A. Allessie en zijn medewerkers, in het bijzonder Maurits Wiffels. Juist toen de nood woor een adequat proefdiermodel hoog was waren jullie geiten nabij. Het was me een genoegen met jullie samen te werken.

Jack Cleutjens en andere medewerkers van de vakgroep pathologie jullie adviezen rondom het extracellulaire matrix gebeuren waren essenticel.

Dr. Koide of the National Chubu Hospital, thank you very much for the opportunity to visit your lab. Doomo arigatoo gozaimas.

Een aantal studenten hebben bij mij onderzoek gedaan of misschien wel "ondergaan". Odeed"Ingeborg, Judith, Gerrit en Nicolle, harstikke bedankt voor de hulp.

De AlO's van de afdeling Moleculaire Celbiologie \& Genetica, de AlO-overleg erentjes waren gezellig. Allemaal veel succes en op naar jullie promoties! Luc, ik vind het ontzettend leuk dat jij één van mijn paranimfen wilt zijn. De overige medewerkers van de vakgroep Moleculaire Celbiologie en Genetica, jullie hulp en suggesties waren onmisbaar.

De leden van de beoordelingscommissie, Prof.dr. R.S. Reneman; Prof.dr. H.J.J. Wellens, Dr. M.J.A.P. Daemen, Prof.dr. H. Jongsma en Prof. dr. J. Schaper, bedankt voor het kritisch lezen van het manuscript.

Mijn vrienden, jullie leverden de broodnodige ontspanning. In het bijzonder Christien en Ellen, de gezelligheid tijdens het "sjokken" en vooral après het rennen waren onmisbaar. Sigrid, de gezelligheid tijdens de studententijd, het gekeuvel over de wetenschap, onze wandel- en fietstochten zijn onvergetelijk. Ik vind het fijn dat je als één van mijn beste vrienden als paranimf aan mijn zijde staat.

Tot slor mijn ouders, lieve pap en mam, bedankt dat jullie me wrij lieten om mijn eigen weg te bewandelen. Het was altijd weer een goed thuiskomen in "t noorden. 


\section{Curriculum vitae}

Jannie Ausma werd geboren op 2 maart 1969 te Groningen.

$\mathrm{Na}$ het behalen van het HAVO-diploma aan het Nienoord College te Leek in 1986 is zij begonnen met het Hoger Laboratoriumonderwijs (H.L.O.) te Groningen.

In het laatste jaar van deze opleiding heeft zij haar praktijkstage gedaan bij de afdeling Comparative Biochemie van Janssen Pharmaceutica onder leiding van Dr. J.J.G.H. Geysen.

In 1990 werd het H.L.O. diploma met als afstudeerrichting Biotechnologie behaald. In datzelfde jaar vervolgde zij haar studie aan de Rijksuniversiteit Groningen.

In 1992 behaalde $z \mathrm{ij}$ haar Doctoraal Biochemie, met als afsluiting een onderzoeksstage bij Prof.dr. P.J.M. van Haastert en Dr. A.L. Drayer.

In 1992 werd zij Assistent in Opleiding bij de vakgroep Moleculaire Celbiologie \& Genetica (Prof.dr. M. Borgers en Prof.dr. F.C.S. Ramaekers) van de Universiteit Maastricht, op een door Janssen Pharmaceutica gefinancierd project.

Tijdens deze periode werd een werkbezoek van 3 maanden gebracht aan de afdeling Cardiologie van het National Chubu Hospital in Obu, Japan (Dr. M. Koide).

Sinds 1 januari 1997 is zij werkzaam op een door de Nederlandse Hartstichting gesubsidieerd onderzoeksproject. 


\section{List of publications}

Geysen J, Ausma J and Vanden Bossche H. Simultaneous purification of Emeria Tenella merozoites en schizonts by Percoll fotation, cell viability, conditions for storage. I. Parasitol. $77989-993(1991)$.

Borgers M, Thoné $F$, Wouters L, Ausrna J, Shivalkar B, Flameng W. Structural correlates of regional myocardial dysfunction in patients with critically coronary artery stenosis: Chronic hibemation? Cardiovase. Pathol 2 237-245(1993).

Ausma J, Ramaekers F, Shivalkar B, Thoné F, Flameng W, Borgers M. Cellular adaptation in hibernating myocardium in the human. In Hori M., Maruyama, Y, Reneman R.S.(eds.) Cardiac adlaptation and failure. Springer Tokyo pp85-99 (1994).

Maes A. Flameng W, Nuyts J, Borgers M, Shivalkar B, Ausma J, Bormans G, Schiepers C, De Roo $\mathrm{M}_{\text {s }}$ Mortelmans $\mathrm{L}$. Histological alterations in chronically hypoperfused myocardium. Correlations with PET findings. Circulation $90735 \times 745$ (1994).

Ausma J, Schaart G, Thoné F, Shivalkar B, Flameng W, Depré C, Vanoverschelde J, Ramaekers $F$, Borgers $M$. Chronic ischemic viable myocardium in man: aspects of dedifferentiation. Cardiovasc. Pathol.429-37 (1995).

Maes A, Flameng W, Borgers M, Nuyts J, Ausma J, Bormans G, Van de Werf F, De Roo M, Mortelmans $\mathbb{L}$. Regional myocardial blood flow, glucose utilization and contratile function before and after revascularization and ultrastuctural findings in patients with chronic coronary artery disease. Eur. J. Nucl. Med. 22 1299-1305 (1995).

Depré C, Vanoverschelde J-LJ, Melin JA, Borgers M, Bol A, Ausma J, Dion R, Wijns W. Structural and metabolic correlates of the reversibility of chronic left ventricular ischemic dysfunction in humans. Am. J. Physiol. 37 H1265-H1275 (1995).

Borgers M, Ausma J. Structural aspects of chronic hibernating myocardium in man. Basic Res. Candiol. 90 44-46 (1995).

Ausma J, Cleutjens J, Thoné F, Flameng W, Ramaekers F, Borgers M. Chronic hibernating myocardiun: interstital changes. Mol. Cell. Biochem. $14735-42$ (1995).

Ausma J, Fuirst D, Thone F, Flameng W, Weber K, Ramaekers F, Borgers M. Molecular changes of titin in chronic hibernating myocardium. J. Mol. Cell. Cardiol. 27 1203-1212 (1995).

Ausma J, van Eys GJJM, Broers JLV, Thoné F, Flameng W, Ramaekers FCS, Borgers M. Nuclear lamin expression in chronic hibernating myocardiun in man. J. Mol. Cell. Cardiol. 28 1297-1305 (1996).

Shivalkar B, Maes A, Borgers M, Ausma I, Scheys I, Nuyts I, Mortelmans L, Flameng W. Only hibernating myocardium invariably shows early recovery after coronary revascularization. Circulation 94 308-315(1996) 
Maes AF, Borgers M, Flameng W, Nuyts JL, Van de Werf, F, Ausma J, Sergeant P, Mortelmans LA. Assessment of myocardial viability in chronic coronary artery disease using technetium $99 \mathrm{~m}$-sestamibi SPECT. Correlation with histology, positron emission tomography and functional follow-up. J. Am. Coll. Cardiol. in press

Ausma J, Wijffels M, Thoné F, Wouters L. Allessie M, Borgers M. Structural changes of atrial myocardium after chronic atrial fibrillation in the goat. Submitted for publication.

Ausma J, Wijffels M, van Eys GJJM, Koide M, Ramaekers F, Allessie M. Borgers M. Dedifferentiation of atrial cardiomyocytes as a result of chronic atrial fibrillation. Submitted for publication. 